\section{Pacific Northwest}

National Laboratory

Operated by Battelle for the

U.S. Department of Energy

\title{
Laboratory-Scale Bismuth Phosphate Extraction Process Simulation to Track Fate of Fission Products
}

\author{
R. J. Serne \\ M. J. Lindberg \\ T. E. Jones \\ H. T Schaef \\ K. M. Krupka
}

February 2007

Prepared for CH2M HILL Hanford Group, Inc., and the U.S. Department of Energy under Contract DE-AC05-76RL01830

Pacific Northwest National Laboratory

Richland, Washington 99352 


\title{
DISCLAIMER
}

This report was prepared as an account of work sponsored by an agency of the United States Government. Neither the United States Government nor any agency thereof, nor Battelle Memorial Institute, nor any of their employees, makes any warranty, express or implied, or assumes any legal liability or responsibility for the accuracy, completeness, or usefulness of any information, apparatus, product, or process disclosed, or represents that its use would not infringe privately owned rights. Reference herein to any specific commercial product, process, or service by trade name, trademark, manufacturer, or otherwise does not necessarily constitute or imply its endorsement, recommendation, or favoring by the United States Government or any agency thereof, or Battelle Memorial Institute. The views and opinions of authors expressed herein do not necessarily state or reflect those of the United States Government or any agency thereof.

\author{
PACIFIC NORTHWEST NATIONAL LABORATORY \\ operated by \\ BATTELLE \\ for the \\ UNITED STATES DEPARTMENT OF ENERGY \\ under Contract DE-AC05-76RL01830 \\ Printed in the United States of America
Available to DOE and DOE contractors from the Office of Scientific and Technical Information,
P.O. Box 62, Oak Ridge, TN 37831-0062;
ph: (865) 576-8401
fax: (865) 576-5728 \\ email: reports@adonis.osti.gov
}
Available to the public from the National Technical Information Service,
U.S. Department of Commerce, 5285 Port Royal Rd., Springfield, VA 22161
ph: (800) 553-6847
fax: (703) $605-6900$
email: orders@ntis.fedworld.gov
online ordering: http://www.ntis.gov/ordering.htm

This document was printed on recycled paper. 


\title{
Laboratory-Scale Bismuth Phosphate Extraction Process Simulation to Track Fate of Fission
}

\author{
R. J. Serne \\ M. J. Lindberg \\ T. E. Jones ${ }^{(a)}$ \\ H. T. Schaef \\ K. M. Krupka
}

February 2007

Prepared for CH2M HILL Hanford Group, Inc., and the U.S. Department of Energy under Contract DE-AC05-76RL01830

Pacific Northwest National Laboratory

Richland, Washington 99352

(a) Fluor Federal Services 
This page intentionally left blank. 


\section{Executive Summary}

From 2003 through 2006, Pacific Northwest National Laboratory undertook a study to better understand the fate of fission products through the plutonium precipitation process performed at the Hanford Site in the 1940s and '50s. This work was conducted as part of the Tank Farm Vadose Zone Project led by CH2M HILL Hanford Group, Inc., in support of the U.S. Department of Energy's Office of River Protection.

Four simulations of the bismuth phosphate $\left(\mathrm{BIPO}_{4}\right)$ precipitation process were performed to evaluate the fate of fission products through the first plutonium precipitation step and subsequent neutralization of the solution remaining (called metal waste solution) after plutonium precipitation. The fate of the fission products in various bismuth phosphate process streams was analyzed using inductively coupled plasmamass spectrometry (ICP-MS) and gamma energy analysis techniques. Results show that only trace amounts of technetium-99 ( $1 \pm 1 \%)$, cesium-135 and cesium-137 (0.1 to $<1 \%)$, and iodine-129 $(<0.5 \%)$ would precipitate with the bismuth phosphate product, used to capture plutonium from dissolved irradiated fuel. Thus, these isotopes should have remained almost exclusively within the metal waste stream which, after neutralization, was sent to Hanford's single-shell tanks. Using the gamma tracers, ${ }^{95 \mathrm{~m}} \mathrm{Tc},{ }^{137} \mathrm{Cs}$, ${ }^{125} \mathrm{I}$, and ${ }^{85} \mathrm{Sr}$, which are more precisely measured than the stable isotopes, we found that less than $0.1 \%$ of the technetium and iodide, about $1.3 \%$ of the cesium, and $2 \%$ of the strontium precipitated with the plutonium-bearing bismuth phosphate precipitate that ultimately is purified and that generates the $1^{\text {st }}$ and $2^{\text {nd }}$ Cycle waste streams that were disposed predominately to cribs. These results on the fate of these key fission products suggest that past estimates of quantities (10\% of each beta emitter) disposed to cribs with the $1^{\text {st }}$ and $2^{\text {nd }}$ Cycle waste streams are inflated.

We conclude that nearly all of the ${ }^{99} \mathrm{Tc}$ remains in the metal waste stream that was sent to the singleshell tanks and only trace amounts of the ${ }^{99} \mathrm{Tc}$ (certainly not $10 \%$ of the total) ended up going to the $1^{\text {st }}$ and $2^{\text {nd }}$ Cycle waste streams generated from re-dissolution/purification of the " $\mathrm{Pu}$ " bismuth phosphate solids. Past assumptions that these wastes contained $10 \%$ of all beta-emitting fission products are erroneous.

The results of our laboratory simulation of the first steps in the bismuth phosphate process have been incorporated into revisions of the Soil Inventory Model (Corbin et al. 2005) and new predictions of the waste disposed to the B-38 trench are in much better agreement with the observed distribution and concentrations of nitrate, ${ }^{99} \mathrm{Tc}$, and other fission products. Therefore, this work has helped to clear up the observed inconsistencies in field data for the distribution of contaminants, especially ${ }^{99} \mathrm{Tc}$, in the B-38 trench and other nearby facilities, in the vadose zone sediments below inactive cribs and trenches that received $1^{\text {st }}$ and $2^{\text {nd }}$ Cycle bismuth phosphate decontamination wastes.

In addition to determining the fate of fission products during the first bismuth phosphate precipitation step, which creates the metal waste solution and the unpurified plutonium product solid, we simulated the metal waste solution neutralization process that occurred prior to metal waste disposal to Hanford's single-shell tanks. The neutralized metal waste solids characterization and the chemical composition of the neutralized metal waste supernatant solution should prove valuable information to the ongoing studies of the uranium-rich fluids that were lost to the subsurface to the east of Tank BX-102 during an overfill event in 1951. 
The fate of other fission products in our laboratory simulation of the bismuth phosphate process is shown in Table ES-1. Measurable quantities ( $20 \%)$ of the lanthanide fission products, and by inference trivalent actinides (Am and $\mathrm{Cm}$ ) and zirconium, do precipitate with the plutonium product. Selenium tracer (added as selenate form) shows about $10 \%$ association with the $\mathrm{Pu} /$ bismuth phosphate solids, perhaps an indication that some selenate substitutes for phosphate in phosphate-rich precipitates. Our data for ${ }^{237} \mathrm{~Np}$ were a bit erratic but suggest approximately $2 \%$ to $9 \%$ is found in the plutonium-bearing bismuth phosphate solids.

Table ES-1. Summary of Fate of Key Risk Driver Constituents from Bismuth Phospate Process

\begin{tabular}{|c|c|c|c|c|}
\hline & Constituent & $\begin{array}{c}\% \text { To SST } \\
\text { Metal Waste }\end{array}$ & $\begin{array}{c}\% \text { To Cribs/Trenches } \\
\text { Extraction Product }\end{array}$ & $\begin{array}{l}\% \text { Material Unaccounted For }{ }^{\mathrm{b}} \\
(+) \text { mass missing }\end{array}$ \\
\hline & Tc-99 (ICP-MS) & $97.8 \pm 4.42$ & $<1.02 \pm 1.17$ & $1.34 \pm 3.75$ \\
\hline & Tc-95m ( $\gamma$ tracer $)$ & $100.7 \pm 2.22$ & $0.06 \pm 0.01$ & $-0.72 \pm 2.22$ \\
\hline & I-129 & 100 & $<0.65$ & $<-0.6$ \\
\hline & Se-79 & $88.6 \pm 5.3$ & $10.6 \pm 0.10$ & $0.87 \pm 5.2$ \\
\hline & Ru-106 & $97.4 \pm 0.6$ & $0.04 \pm 0.03$ & $2.6 \pm 0.6$ \\
\hline & $\mathrm{Sb}-125$ & $99.41 \pm 3.78$ & $1.32 \pm 0.02$ & $-0.73 \pm 3.8$ \\
\hline & $\mathrm{U}$ & 96.87 & 0.02 & 3.11 \\
\hline & $\mathrm{Np}-237$ & $89.5 \pm 6.5$ & $1.6 \pm 0.8$ & $8.8 \pm 6.9$ \\
\hline & Cs-137 & $97.5 \pm 3.1$ & $<1.3 \pm 0.03$ & $1.6 \pm 2.5$ \\
\hline & Sr-90 & $93.6 \pm 4.7$ & $<2.0 \pm 0.05$ & $4.4 \pm 4.6$ \\
\hline \multirow{2}{*}{\multicolumn{2}{|c|}{ Lanthanides }} & $80.9 \pm 6.5$ & $15.0 \pm 6.2$ & $4.1 \pm 2.3$ \\
\hline & & & & (-) mass "created" \\
\hline \multicolumn{5}{|c|}{$\begin{array}{l}\text { (a) The percent of Sr to cribs may be biased low; some Sr may coprecipitate with Ca and phosphate in actual bismuth phosphate } \\
\text { processing. See more discussion in text. } \\
\text { (b) Positive number means final measured mass balance was less than starting mass; negative number means final measured } \\
\text { mass balance was more than starting mass. }\end{array}$} \\
\hline
\end{tabular}

Thus past estimates, undoubtedly based on gross beta measurements that suggested $10 \%$ of the beta activity was found to carry down with the bismuth phosphate precipitate, are qualitatively supportable but individual beta emitters such as ${ }^{99} \mathrm{Tc},{ }^{129} \mathrm{I},{ }^{135,137} \mathrm{Cs}$, and ${ }^{90} \mathrm{Sr}$ remained predominately $(>98 \%)$ with the uranium metal waste stream that ultimately was disposed to single-shell tanks. Past estimates of the fate of specific beta emitters overestimate by at least one order of magnitude the technetium and iodide, and by a factor of five the strontium and cesium that were present in the $1^{\text {st }}$ and $2^{\text {nd }}$ Cycle waste streams, which were disposed to cribs/trenches. Our experiments may have underestimated the percentage of strontium that co-precipitated with the bismuth phosphate product because we used distilled/de-ionized water for solution make-up and our source of phosphoric acid was likely more pure than the commercial product available in the 1940s and 1950s. The key concern is that in the actual bismuth phosphate processing, both the make-up water and phosphoric acid likely contained dissolved calcium that could also precipitate during the bismuth phosphate precipitation stage. The calcium could have caused strontium $\left({ }^{90} \mathrm{Sr}\right)$ to co-precipitate into the plutonium-laden bismuth phosphate. With further purification, the co-precipitated strontium would have been disposed in the waste streams that went to Hanford cribs/trenches. Thus, our value of $2 \%$ of the ${ }^{90} \mathrm{Sr}$ precipitating with the plutonium product and ultimately being disposed to cribs/trenches may be the minimum value. More experiments with varying amounts of calcium added to the metal storage solution would be required to determine the effects of calcium on the fate of ${ }^{90} \mathrm{Sr}$ during the bismuth phosphate processing. The data for iodide only reflects iodine species that do not volatilize during the fuel decladding and fuel dissolution stages. As discussed in the introduction, $\sim 85 \%$ of the iodine escaped during these steps and thus was not present in the acidic metal storage 
solution used in the bismuth phosphate process. We did put only $15 \%$ of the total iodine produced in the fuel into the metal storage solution used to start the bismuth phosphate studies; thus, our iodide distribution values should be accurate for estimating inventories that went to single-shell tanks and cribs.

The chemical composition of the neutralized metal waste was determined by simulating the acid reduction with sodium hydroxide and sodium carbonate. The fate of key fission products present in the metal waste solution during neutralization is as follows. In general, greater than $99 \%$ of the technetium remains in solution and is ultimately found in the neutralized metal waste solution that was sent to the single-shell tanks. The technetium essentially remains in the dissolved state throughout the whole bismuth phosphate process from fuel dissolution through metal waste solution neutralization. At most, a few tenths of a percent of the technetium is found in the bismuth phosphate product solids and at most $<2 \%$ of the technetium is found in the precipitates that form during the metal waste solution neutralization process. The neutralized metal waste precipitates were sent to the single-shell tanks along with neutralized metal waste solution. However, any neutralized metal waste solids may have settled to the sludge layer in the tanks and not been released during over-fill events such as the BX-102 event in 1951.

The uranium mass balance throughout the whole bismuth phosphate simulation was fairly consistent with $20 \%$ to $40 \%$ of the uranium found in the metal waste solution remaining in the supernatant solution after neutralization. Because very little of the uranium associates with the bismuth phosphate product, almost all of the uranium ended up in the single-shell tanks. Much $(\sim 75 \%)$ of the uranium initially present in the dissolved fuel ends up precipitated in the solids formed by neutralization of the metal waste solution. However, the amount of uranium present in the metal storage solution is so large that tens of grams per liter remain in the supernatant metal waste solution after neutralization. The neutralized solids also contain significant percentages of uranium (between $48 \%$ and $70 \%$ as U(VI)-bearing solids). If the neutralized solids settled in the single-shell tanks, such as BX-102, before any over-fill, the amount of uranium still remaining in solution would represent $\sim 30 \%$ (range $20 \%$ to $40 \%$ ) of the initial uranium in the dissolved fuel. The concentration of dissolved uranium in the neutralized metal waste solution supernatant was $\sim 27,500 \mathrm{mg} / \mathrm{L}(27.5 \mathrm{~g} / \mathrm{L})$ in our lab-scale studies.

Both the radiotracer and stable Sr results suggest about $12 \%$ to $18 \%$ of the strontium present in the metal waste solution remains soluble while the rest precipitates during the neutralization stage. About $88 \%$ of the strontium in the metal waste solution precipitates during neutralization and, thus, would be found predominately in suspended solids that would settle in the single-shell tanks after disposal. The ultimate fate of strontium in dissolved irradiated fuel is that $\sim 2 \%$ is found in the bismuth phosphate product (based on our tests which may underestimate the impact of strontium co-precipitation with calcium in the actual 1940-1950 vintage bismuth phosphate processing); $87 \%$ precipitates in the neutralized metal waste solution, and $11 \%$ is found in the metal waste neutralized supernatant solution. The strontium that precipitates and the strontium found in the metal waste supernatant solution are both sent to single-shell tanks. At least $95 \%$ to $98 \%$ of the total cesium in the dissolved irradiated fuel ends up in the metal waste, which is disposed to single-shell tanks and, upon neutralization of the metal waste solution, $70 \%$ of the total cesium remains in the dissolved state.

Less than $0.6 \%$ of the iodide partitioned to the bismuth phosphate product and at least $99.4 \%$ (essentially all) of the iodide should be found in the neutralized waste stream disposed to single-shell tanks. However, we did not obtain data for iodide's distribution between solid and solution during the metal waste solution neutralization. The radiotracer ${ }^{152} \mathrm{Eu}$ data and all the ICP-MS data for stable isotopes of europium, cerium, lanthanum, and praseodymium show a consistent pattern with $<5 \%$ of the 
lanthanides originally present in the metal waste solution remaining in solution after neutralization. Greater than $95 \%$ of the lanthanides present in metal waste solution partition to the neutralized metal waste precipitate. From the original dissolved fuel (metal storage solution) only a few percent, at most, of the lanthanides remain in the dissolved state after the metal waste solution is neutralized. The same is true for yttrium and zirconium. About $10 \%$ to $20 \%$ of these elements associate with the bismuth phosphate product solids and the rest ends up in the neutralized metal waste precipitates that are slurried into single-shell tanks where they ultimately settle to form sludge. At most a few percent of these elements remain in the supernatant solution in the single-shell tanks.

Almost all the sulfate that is present in the metal waste solution remains in solution after neutralization, despite an indication that a sulfate-bearing solid may have precipitated during the metal waste solution neutralization. The phosphate present in the metal waste solution distributes about evenly between the neutralized supernatant solution and the precipitates that form during the neutralization steps. Phosphate-containing minerals were identified in the neutralized metal waste solids.

The solids that settled out of the neutralized metal waste solution were washed in distilled water and then characterized by $\mathrm{x}$-ray diffraction (XRD), scanning electron microscopy-energy dispersive $\mathrm{x}$-ray spectroscopy (SEM-EDS), and x-ray fluorescence (XRF). XRD patterns for the solids that precipitated upon neutralizing the metal waste with sodium hydroxide and sodium carbonate were sodium-uranyl phosphate hydrate, $\mathrm{NaPUO}_{6} \cdot 3 \mathrm{H}_{2} \mathrm{O}$, and possibly a minor amount of $\mathrm{NaUO}_{2} \mathrm{PO}_{4} \cdot 5 \mathrm{H}_{2} \mathrm{O}$ and trace amounts of hydrogen phosphate. Several minor reflections not assigned to the sodium uranyl phosphate phases were observed. A single minor reflection corresponding to the $100 \%$ reflection of uranium carbonate, $\mathrm{UO}_{2} \mathrm{CO}_{3}$, was found but other reflections associated with this carbonate phase were either below XRD detection limits or were positioned at the same reflections as some of the other crystalline phases, making positive identification of uranyl carbonate by XRD problematic. Another unassigned reflection was consistent with the primary reflection of the crystalline phase uranyl sulfate hydrate, $\mathrm{UO}_{2} \mathrm{SO}_{4} \cdot \mathrm{H}_{2} \mathrm{O}$. However, because of detection limitations, positive identification of this uranyl sulfate was not possible. No indications of amorphous material were observed in the XRD pattern for neutralized metal waste solids.

The neutralized metal waste precipitates contain fine-grained particles as well as aggregates of these particles. Individual particles ranged in size from several micrometers to less than a micrometer. At low magnification, the material is nondescript and lacks any apparent crystal faces, in contrast to the crystalline nature of the XRD characterization. These particles might be needle-like and/or feather-like at the sub-micrometer scale, which could not be characterized on our SEM system. To probe the sub-micron particles in more detail, TEM would be the preferred technique. The EDS analyses for the NaOH$\mathrm{Na}_{2} \mathrm{CO}_{3}$-neutralized metal waste precipitate indicate that it consists primarily of particles containing $\mathrm{U}-\mathrm{Na}-\mathrm{P}-\mathrm{O}-\mathrm{C} \pm \mathrm{H}$. The $\mathrm{x}$-ray emission peak for carbon suggests that carbonate was present in some of the U-rich particles. Trace peaks for Si and Al were also identified in some of the EDS spectra for the U-rich particles. The X-ray emission peak for sulfur was not detected in the EDS analyses of the U-rich particles. The XRF results are in general agreement with the XRD and SEM-EDS results. The precipitates appear to be dominated by uranyl, sodium, phosphate, carbonate, and sulfate. Trace amounts of iron, manganese, and chromium were also identified using SEM-EDS. These elements may have come from equipment and containers used in the lab-scale simulations. Overall, the process wherein acidic metal waste solution is neutralized prior to being sent to single-shell tanks caused the precipitation of sodium uranyl phosphates, and perhaps sodium-uranyl carbonate and sodium-uranyl sulfate solid phases. There may be some sulfate in the precipitates although the SEM-EDS did not indicate the presence of sulfur. 


\section{Acknowledgments}

This work was conducted as part of the Tank Farm Vadose Zone Project led by CH2M HILL Hanford Group, Inc., in support of the U.S. Department of Energy's Office of River Protection. The authors wish to acknowledge Anthony J. Knepp and Frank Anderson, both formerly with CH2M HILL Hanford Group, Inc., (CH2M HILL) for funding over the time span needed to complete this work. Marc I. Wood of Fluor Hanford, Inc., and Michelle Mandis, formerly of CH2M Hill, were helpful in reviewing the laboratory test plan and commenting on the original activities. Bruce Higley and Dave Place of CH2M HILL provided a very thorough review of the first version of this document and supplied many of the old Hanford documents and memos referenced in the introduction.

We would also like to thank Bill Deutsch of Pacific Northwest National Laboratory (PNNL), and Fred Mann and Mike Johnson of CH2M HILL, for their technical review of this revised report.

The authors also acknowledge the analytical support provided by PNNL's Applied Geology and Geochemistry staff, including Bob Orr and Igor Kutnyakov (radiocounting), Steve Baum (ICP analyses), and Keith Geiszler (ICP-MS analyses). 



\section{Contents}

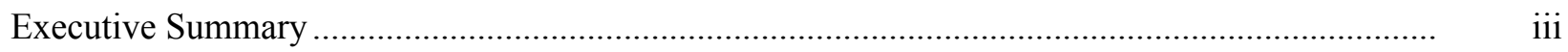

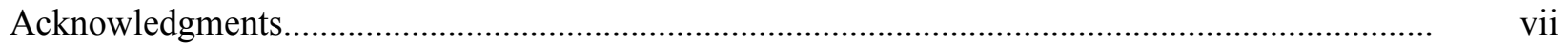

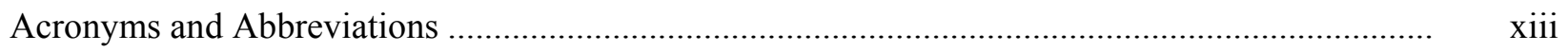

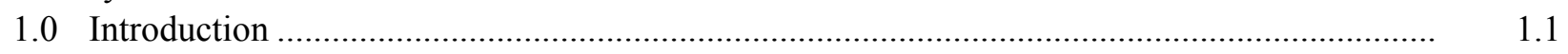

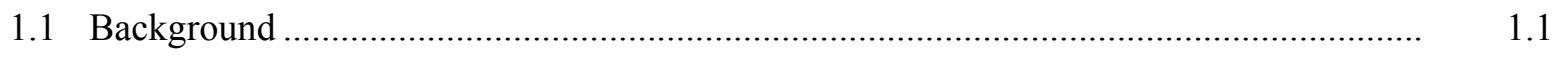

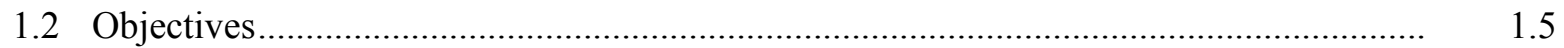

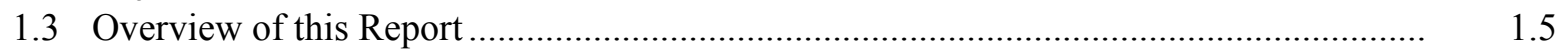

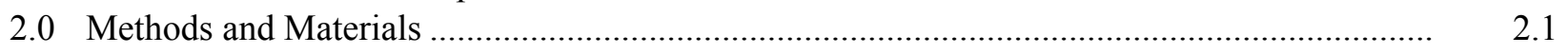

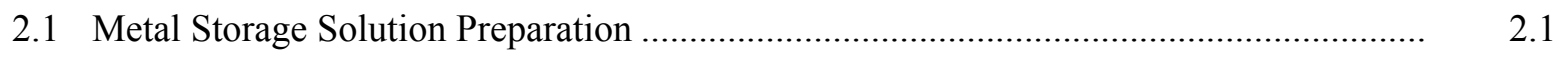

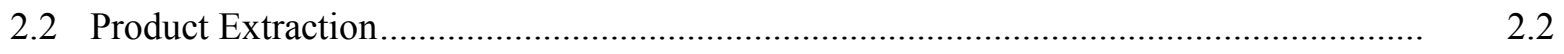

2.2.1 Initial Bismuth Phosphate Precipitation .......................................................... 2.2

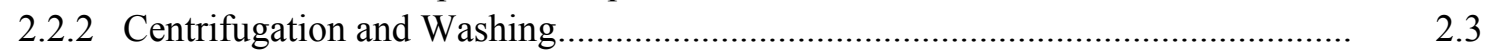

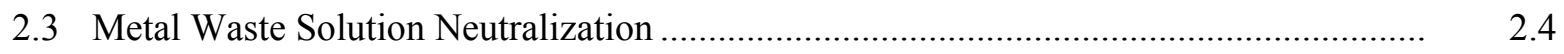

2.4 Solid Phase Characterization Using XRD, SEM-EDS and XRF ................................... 2.7

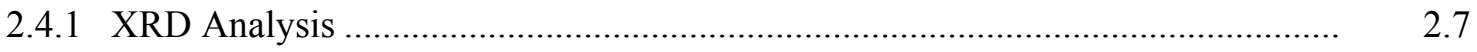

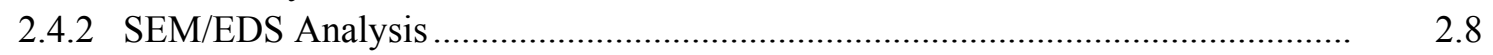

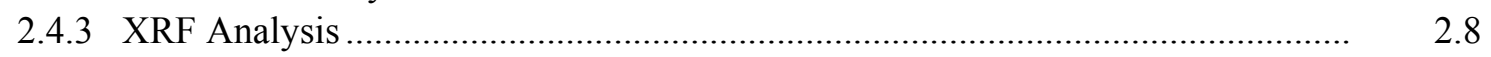

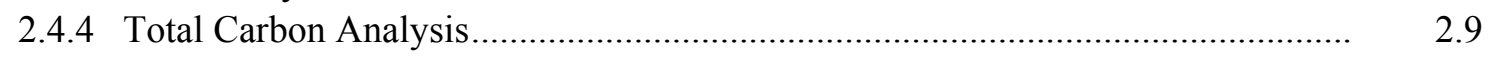

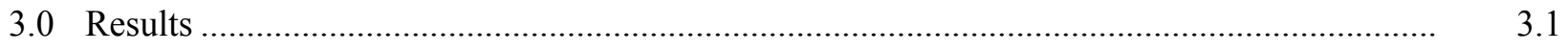

3.1 Bismuth Phosphate Precipitation and Precipitate Separation....................................... 3.1

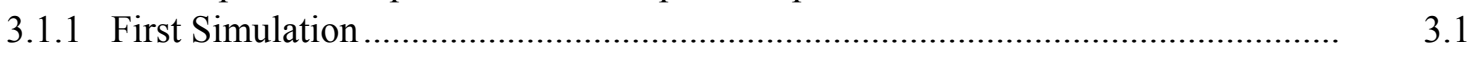

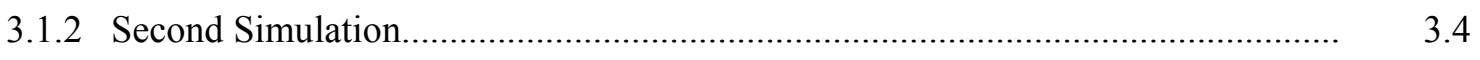

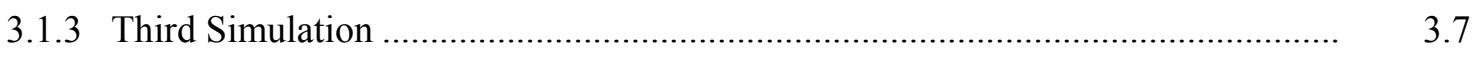

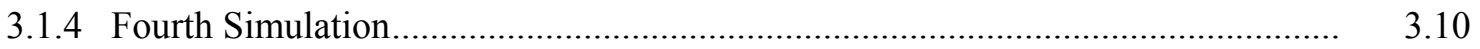

3.1.5 Compilation of the Data from all Four Simulations ........................................... 3.15

3.1.6 Mass Balance for Major Constituents in Bismuth Phosphate Process .................. 3.17

3.2 Results: Metal Waste Solution Neutralization ........................................................... 3.18

3.2.1 Discussion of the Neutralized Metal Waste Macro Chemistry ............................. 3.18

3.2.2 Fate of Radioactive Tracers and Trace Fission Products During Metal Waste Neutralization ............................................................................................. $\quad 3.21$

3.2.3 Identification of the Solids Formed During the Metal Waste Neutralization......... $\quad 3.24$

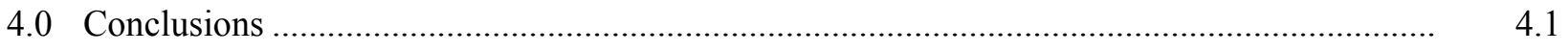

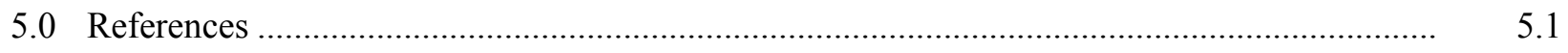

Appendix A - Precipitate Formed in Metal Storage Solution ................................................... A.1

Appendix B - Additional SEM-EDS Information for Other Precipitated Grains from the Metal

Storage Solution Precipitate ........................................................................................ B.

Appendix C - Additional SEM-EDS Spectra for Precipitates Formed during Neutralization of

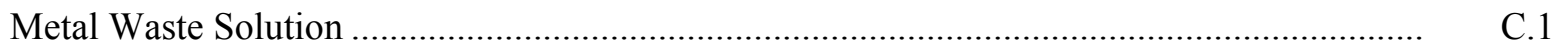

Appendix D - Specification Data Sheet for UNH Purity …................................................... D.1 


\section{Figures}

1.1 Location Map for B-38 Trench and Vadose Borehole C3104 from Which Samples Were Obtained

2.1 Initiation of the Bismuth Phosphate Precipitation Simulation Process Showing Metal Storage Solution with ${ }^{99} \mathrm{Tc}$ dissolved

2.2 Addition of Sodium Nitrite

2.3 Completion of Phosphoric Acid Addition. Note cloudy suspension indicative of precipitate formation

2.4 Bismuth Phosphate Solid after Rinsing

3.1 Background-Subtracted Bulk Powder XRD Tracing of Sample 011503B.

3.2 SEM BSE Micrographs of Particles in $\mathrm{KOH}-\mathrm{Na}_{2} \mathrm{CO}_{3}$ Neutralized Metal Waste Precipitate

3.3 SEM BSE Micrographs of Particles in $\mathrm{KOH}-\mathrm{Na} 2 \mathrm{CO} 3$ Neutralized Metal Waste Precipitate

3.4 EDS Spectra for Areas in Particle Aggregate of $\mathrm{KOH}-\mathrm{Na}_{2} \mathrm{CO}_{3}$ Neutralized Metal Waste Precipitate

3.5 EDS Spectra for Areas in Particle Aggregate of $\mathrm{KOH}-\mathrm{Na}_{2} \mathrm{CO}_{3}$ Neutralized Metal Waste Precipitate

3.6 Background-Subtracted Bulk Powder XRD Tracing of Sample 080205A

3.7 SEM BSE Micrographs of Particles in $\mathrm{NaOH}-\mathrm{Na}_{2} \mathrm{CO}_{3}$ Neutralized Metal Waste Precipitate.

3.8 SEM BSE Micrographs of Particles in $\mathrm{NaOH}-\mathrm{Na}_{2} \mathrm{CO}_{3}$ Neutralized Metal Waste Precipitate.

3.9 EDS Spectra for Areas in a Particle Aggregate of $\mathrm{NaOH}-\mathrm{Na}_{2} \mathrm{CO}_{3}$ Neutralized Metal Waste Precipitate.

3.10 EDS Spectrum for an Al-O $\pm \mathrm{C} \pm \mathrm{H}$ Particle in $\mathrm{NaOH}-\mathrm{Na}_{2} \mathrm{CO}_{3}$ Neutralized Metal Waste Precipitate 


\section{Tables}

2.1 Composition of Metal Storage Solution per Liter ….................................................... 2.2

3.1 Fate of Fission Product Mass in Simulation \#1 …........................................................

3.2 Projected Disposal Facility Receiving Fission Products and Mass Balance for

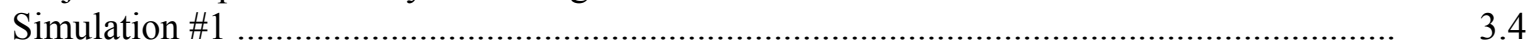

3.3 Activity of Gamma Tracers Found in Each Phase in Simulation \#2 ................................. 3.6

3.4 Distribution of Radiotracers/U Daughters in Waste Streams and Mass Recovery for

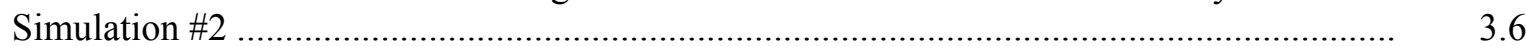

3.5 Fate of Fission Product Mass in Simulation \#2 …..........................................................

3.6 Projected Disposal Facility Receiving Fission Products and Mass Balance for

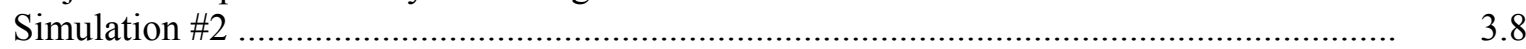

3.7 Distribution of Radiotracers in Waste Streams and Mass Recovery for Simulation \#3 ......... 3.9

3.8 Projected Disposal Facility Receiving Radiotracers and Mass Balance for Simulation \#3 ... 3.9

3.9 Distribution of Fission Products in Waste Streams and Mass Recovery for Simulation \#3... 3.10

3.10 Projected Disposal Facility Receiving Fission Products and Mass Balance for

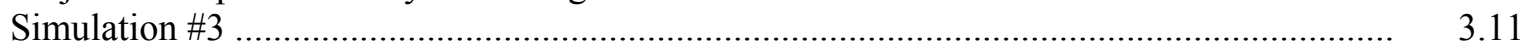

3.11 Distribution of Radiotracers in Waste Streams and Mass Recovery for Simulation \#4 ......... 3.12

3.12 Projected Disposal Facility Receiving Radiotracers and Mass Balance for Simulation \#4 ... 3.12

3.13 Distribution of Fission Products in Waste Streams and Mass Recovery for Simulation \#4... 3.13

3.14 Projected Disposal Facility Receiving Fission Products and Mass Balance for

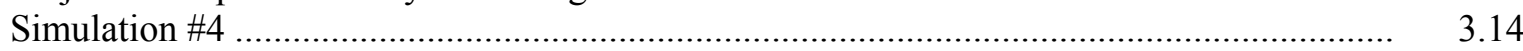

3.15 Summary Findings on the Fate of Fission Products .......................................................... 3.16

3.16 Mass Balance of Macro Constituents in Simulation \#4 ........................................................ 3.18

3.17 Volumes of Solutions Used for Metals Waste Neutralization.............................................. 3.20

3.18 Macro Chemical Composition of the Supernatant Solution from the Metals Waste Neutralization Process ................................................................................................. 3.20

3.19 Charge Balance for the Neutralized Supernatant Solution ................................................... 3.21

3.20 Fate of Radiotracers, Fission Products, and Selected Major Constituents after Neutralization of Simulation \#2

3.21 Fate of Radiotracers, Fission Products, and Selected Major Constituents After Neutralization of Simulation \#4

3.22 Distribution of Fission Products and Selected Major Constituents in Bismuth Phosphate and Neutralization Processes for Simulation \#2.

3.23. Distribution of Fission Products, and Selected Major Constituents in Overall Bismuth Phosphate and Neutralization Processes for Simulation \#4

3.24 Elemental Oxide Composition of the $\mathrm{KOH}-\mathrm{Na} 2 \mathrm{CO} 3$ Neutralized Metal Waste Precipitate . 3.36

3.25 Elemental Oxide Composition of the $\mathrm{NaOH}-\mathrm{Na}_{2} \mathrm{CO}_{3}$ Neutralized Metal Waste Precipitate. $\quad 3.43$ 



\section{Acronyms and Abbreviations}

\begin{tabular}{|c|c|}
\hline$\%$ & percent \\
\hline $2 \theta$ & angle of incidence (Bragg angle) \\
\hline am & amorphous \\
\hline ASTM & American Society for Testing and Materials Standards \\
\hline bgs & below ground surface \\
\hline BHI & Bechtel Hanford Inc. \\
\hline $\mathrm{BIPO}_{4}$ & $\begin{array}{l}\text { bismuth phosphate -first process used at Hanford to extract plutonium from irradiated } \\
\text { uranium fuel }\end{array}$ \\
\hline BSE & back scattered electron \\
\hline $\mathrm{C} \& \mathrm{~W}$ & centrifugation and washing \\
\hline $\mathrm{Ci}$ & curie \\
\hline $\mathrm{cm}$ & centimeters \\
\hline $\mathrm{cr}$ & crystalline \\
\hline DOE & U.S. Department of Energy \\
\hline EDS & energy-dispersive $\mathrm{x}$-ray spectroscopy \\
\hline ERC & environmental restoration contractor \\
\hline FIR & field investigation report \\
\hline $\mathrm{ft}$ & feet \\
\hline $\mathrm{g}$ & gram \\
\hline $\mathrm{g}$ force & gravitational force \\
\hline GEA & gamma energy analysis \\
\hline $\mathrm{HCl}$ & hydrochloric acid \\
\hline HDW & Hanford Defined Waste \\
\hline HPGe & high-purity germanium \\
\hline I/Io & relative intensity of an x-ray diffraction peak to the most intense peak \\
\hline IBPP & initial bismuth phosphate precipitation \\
\hline IC & ion chromatography or ion chromatograph \\
\hline ICP & $\begin{array}{l}\text { inductively coupled plasma (also called inductively coupled plasma - optical emission } \\
\text { spectroscopy }\end{array}$ \\
\hline ICP-MS & inductively coupled plasma-mass spectrometer \\
\hline ICP-OES & inductively coupled plasma-optical emission spectroscopy \\
\hline $\mathrm{keV}$ & 1,000 electron volts \\
\hline kgal & thousand gallons \\
\hline LEPS & Low Energy Photon Spectroscopy \\
\hline $\mathrm{m}$ & molality, moles of solute per $1000 \mathrm{~g}$ solvent) \\
\hline M & molarity, moles of solute per liter solvent \\
\hline $\mathrm{meq} / \mathrm{L}$ & milli-equivalent per liter \\
\hline $\mathrm{mg}$ & milligram \\
\hline $\mathrm{mL}$ & milliliter \\
\hline $\mathrm{mM}$ & millimolar \\
\hline $\mathrm{mN}$ & millinormal \\
\hline mol & mole \\
\hline $\mathrm{N}$ & Normal \\
\hline
\end{tabular}




$\begin{array}{ll}\text { NDIR } & \text { non-dispersive infrared } \\ { }^{\circ} \mathrm{C} & \text { temperature in degrees Celsius }\left[\mathrm{T}\left({ }^{\circ} \mathrm{C}\right)=\mathrm{T}(\mathrm{K})-273.15\right) \\ \text { OU } & \text { operable unit } \\ \text { pCi } & \text { picocurie } \\ \text { PDF } & \text { powder diffraction file } \\ \text { pH } & \text { negative logarithm of the hydrogen ion activity } \\ \text { PNL } & \text { Pacific Northwest Laboratory. In 1995, DOE formally changed the name of the Pacific } \\ & \text { Northwest Laboratory to the Pacific Northwest National Laboratory. } \\ \text { PNNL } & \text { Pacific Northwest National Laboratory } \\ \text { ppb } & \text { parts per billion (equivalent to } \mu \mathrm{g} / \mathrm{L}) \\ \text { ppm } & \text { parts per million (equivalent to mg/L) } \\ \text { REDOX } & \text { reduction-oxidation process- } 2^{\text {nd }} \text { irradiated fuel extraction process used at Hanford to } \\ & \text { obtain plutonium } \\ \text { REE } & \text { rare-earth element } \\ \text { RPM } & \text { revolutions per minute } \\ \text { SE } & \text { secondary electron } \\ \text { SEM } & \text { scanning electron microscopy } \\ \text { SST } & \text { single-shell tanks } \\ \text { t1 } 12 & \text { half life } \\ \text { TBP } & \text { tributyl phosphate } \\ \text { TEM } & \text { transmission electron microscope } \\ \text { UNH } & \text { uranyl nitrate } \\ \text { WMA } & \text { waste management area } \\ \text { wt } \% & \text { weight percent } \\ \text { XRD } & \text { x-ray diffraction } \\ \text { XRF } & \text { x-ray fluorescence (a technique to measure total element mass in solids) } \\ \lambda & \text { wavelength } \\ \mu & \text { micro (prefix, 10-6) } \\ \mu C i & \text { microcurie } \\ \mu \mathrm{gg} & \text { microgram } \\ \mu \mathrm{m} & \text { micrometer } \\ & \end{array}$




\subsection{Introduction}

From 2003 through 2006, Pacific Northwest National Laboratory undertook a study to better understand the fate of fission products in the bismuth phosphate plutonium precipitation process performed at the Hanford Site in the 1940s and '50s. This work was conducted as part of the Tank Farm Vadose Zone Project led by CH2M HILL Hanford Group, Inc., in support of the U.S. Department of Energy's Office of River Protection. The original bismuth phosphate process was simulated to attempt to verify the accuracy of the historically reported percentage of ${ }^{99}$ technetium and other key fission products estimated to have been separated (as metal waste solution) from the first bismuth phosphate precipitate and disposed after neutralization to single-shell tanks, and the percentages that remained with the plutonium "product", which were removed after further purification and ultimately sent to cribs and trenches.

\subsection{Background}

After the discovery of plutonium in 1941 at the University of California-Berkeley, Glenn Seaborg and co-workers in 1943 produced 40 micrograms of plutonium in UC-Berkeley's cyclotron. The initial plutonium $(\mathrm{Pu})$ recovery process at Hanford was developed from studies on this small quantity of plutonium. The process, based on the co-precipitation of $\mathrm{Pu}(\mathrm{IV})$ with a bismuth phosphate carrier, was simply a routine analytical precipitation procedure scaled up to an industrial separation process. Two facilities (B Plant and T Plant) were constructed at Hanford in the early 1940s and both plants were used to extract plutonium from irradiated fuel elements using the bismuth phosphate process. As implemented at Hanford, initially the aluminum cladding was dissolved from the irradiated uranium fuel with a solution of sodium hydroxide and sodium nitrate. The declad uranium fuel rods were then dissolved in a concentrated solution of nitric acid, which was further stabilized with sulfuric acid to keep uranium from precipitating. The plutonium present in the nitrate/sulfuric acid uranium-laden solution was reduced with nitrous acid then co-precipitated with bismuth phosphate. The plutonium-containing solids were recovered by centrifugation and thoroughly washed with water. The washed plutonium-bearing solids were re-dissolved and the plutonium recovered through a $2^{\text {nd }}$ Cycle of plutonium reduction to $\mathrm{Pu}(\mathrm{IV})$ and re-precipitation with bismuth phosphate. The plutonium dissolution/re-precipitation was repeated a third time. Finally, the plutonium-bearing solid was co-precipitated using lanthanum fluoride in the 224-T and 224-B buildings at Hanford. The plutonium-bearing lanthanum fluoride solid contained little of the highly radioactive fission products such that the Pu-bearing solids could be moved outside the shielded facilities (e.g., hot cells) for further processing. A number of waste streams were produced in rather large volume quantities.

The liquid waste stream coming from the first plutonium separation step contained essentially all of the uranium and most fission products. Since "metal" was used as the code word for uranium, this waste stream was called "metal waste." The so-called metal waste was stored in 530,000-gallon capacity underground storage tanks. In the early 1950s, the metal waste was removed from tanks and the uranium was recovered for reuse in making fuel elements to be irradiated in the Hanford reactors. A second waste stream, called $1{ }^{\text {st }}$ Cycle Waste, came from the first bismuth phosphate/plutonium precipitate cake dissolution-re-precipitation step (known as the first recycle step). So-called " $2{ }^{\text {nd }}$ Cycle waste" was generated from the second plutonium solids dissolution or recycle step. Both $1^{\text {st }} \mathrm{Cycle}$ and $2^{\text {nd }} \mathrm{Cycle}$ wastes were also sent to other 530,000 gal underground tanks. The de-cladding waste streams were added to the same tanks used for storing the $1^{\text {st }}$ Cycle wastes. Beginning in 1948, some $2^{\text {nd }}$ Cycle waste 
supernatants were sent directly to cribs. Later, $1^{\text {st }}$ Cycle waste supernatants were discharged to so-called specific retention trenches, which were dug in the shallow subsurface sediments (similar to the smaller cribs). The volume of waste disposed to specific retention trenches was strictly controlled to not exceed $10 \%$ of the volume of vadose sediments directly below the cross-sectional area of the trench. No such control was used on the volumes of liquid waste disposed to cribs. Another description of the bismuth phosphate process is found in Cleveland (1967).

In 1952, both the uranium recovery process (TBP Plant) and the reduction-oxidation (REDOX) plant came on line at Hanford and the bismuth phosphate process in B Plant was put on standby. With three major facilities (T Plant, REDOX, and TBP Plant) operating simultaneously, more waste was being generated than available tank space. This led to the decision to discharge significant volumes of tank waste supernatants to the soil column. Approximately 41 million gallons of scavenged (i.e., ${ }^{137} \mathrm{Cs}$ - and ${ }^{90} \mathrm{Sr}$-removed) uranium recovery waste and over 68 million gallons of various bismuth phosphate process waste streams were discharged to cribs and specific retention trenches in and around the 200 East and West Areas during the 1950s and 1960s. From groundwater measurements, it is well known that discharges to cribs have led to low levels of contaminants in the underlying unconfined aquifer. Groundwater impacts from liquid waste discharges to specific retention trenches are less well understood. Since the early 1990s there have been ongoing field characterization activities to better define environmental impacts of both intentional discharges and leaks from Hanford's single-shell tanks and tank infrastructure (see for example the three published Field Investigation Reports on Tank Farm Waste Management Areas (Knepp 2002a,b and Myers 2005) and numerous limited field investigation reports on inactive cribs and trenches (e.g., DOE-RL 2004, DOE/RL 1993, BHI 1995).

As part of Hanford waste sites characterization activities by various environmental restoration contractors (ERCs), a borehole was drilled through the specific retention trench 216-B-38. The 216-B-38 trench is one of the BX Trenches that received 1.43 million liters of $1^{\text {st }}$ Cycle waste in 1954 from waste tanks storing bismuth phosphate process wastes (Maxfield 1979 and Mirabella 1977). The BX Trenches are grouped in the Tank Waste Operable Unit (200-TW-2) and are located north of B Plant and west of the 241-BX Tank Farm (see Figure 1.1). The trenches are approximately $76 \mathrm{~m}(250 \mathrm{ft})$ in length by $3 \mathrm{~m}$ $(10 \mathrm{ft})$ in width and $3 \mathrm{~m}(10 \mathrm{ft})$ deep. The drill site within the 216-B-38 trench was selected to penetrate the highest gamma activity, based on spectral gamma logging results (suggesting the most highly contaminated zone).

Based on waste-stream inventory modeling studies (Simpson et al. 2001), it was estimated that approximately $2 \mathrm{Ci}$ of ${ }^{99} \mathrm{Tc}$ were present in the $378 \mathrm{kgal}$ of B Plant $1^{\text {st }}$ Cycle waste discharged to the 216-B-38 trench in 1954. However, using the new partitioning values for the fission products from the bismuth phosphate process reported herein, Corbin et al. (2005) revised this value to $0.29 \mathrm{Ci}$. Recent analytical data from 14 soil samples collected between 3.5 and $265.5 \mathrm{ft}$ bgs at the 216-B-38 trench borehole showed very low levels of ${ }^{99} \mathrm{Tc}$ in only three samples. Although ${ }^{99} \mathrm{Tc}$ values were reported in the intervals of 52-54 ft bgs, 97-100 ft bgs, and 147-150 ft bgs, none of the three ${ }^{99} \mathrm{Tc}$ values were above the laboratory "quantification limit." Other work performed by PNNL on samples at different depths from this borehole also shows little presence of ${ }^{99} \mathrm{Tc}$ in the vadose zone (see Lindenmeier et al. 2002). However, other contaminants such as nitrate were found in the vadose zone sediments in concentrations/ quantities similar to those expected based on the Simpson et al. (2001) estimates. Failure to find significant amounts of ${ }^{99} \mathrm{Tc}$ in soil samples from the 216-B-38 test borehole can be explained in a number of ways. 


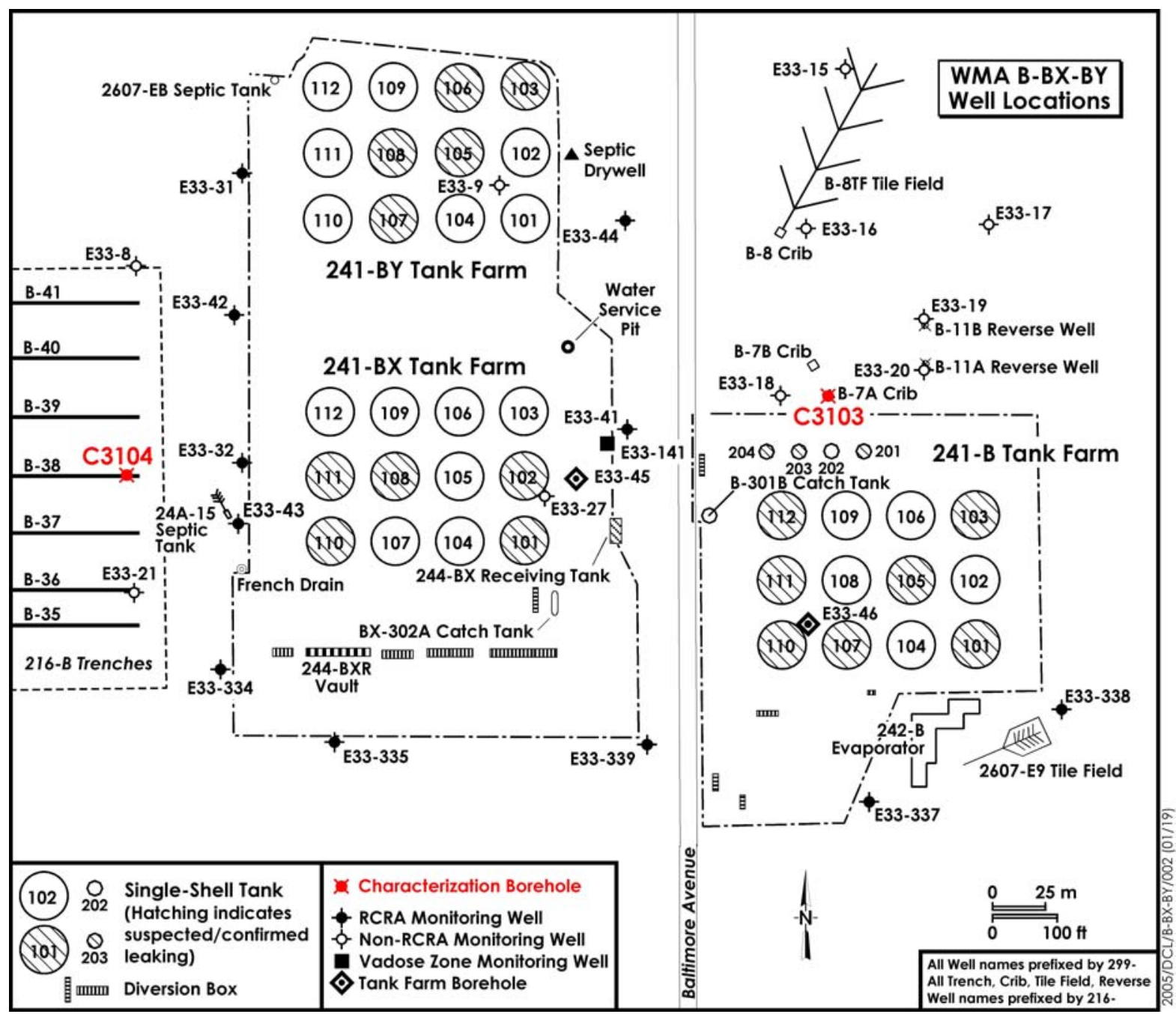

Figure 1.1. Location Map for B-38 Trench and Vadose Borehole C3104 from Which Samples Were Obtained

First, the selected sediment sampling locations may have missed regions of high ${ }^{99} \mathrm{Tc}$. However, as noted above, considerable efforts were expended to drill and sample in the region where most of the liquid waste was disposed (this assumes that the present day highest gamma activity location represents the location of maximum waste disposal). Further, significant nitrate concentrations were found in the same regions that contained the low concentrations of ${ }^{99} \mathrm{Tc}$. Major amounts of ${ }^{90} \mathrm{Sr}$ and ${ }^{137} \mathrm{Cs}$ were found at 18-20 ft and 13-21 ft bgs, respectively, and no detections of strontium and cesium were reported below $40 \mathrm{ft}$ and $60 \mathrm{ft}$ bgs, respectively (see Lindenmeier et al. 2002 for more details).

A second possibility is that the ${ }^{99} \mathrm{Tc}$ may have migrated to groundwater or laterally away from the drilling location. However, significant concentrations of nitrate were found in the regions where the low levels of ${ }^{99} \mathrm{Tc}$ were found. The high nitrate concentrations (1,900 to 3,500 mg/kg) strongly suggest that mobile contaminants discharged to this trench are still in the soil column under the trench. Numerous studies of contaminated sediments below other Hanford SST tanks, cribs, and trenches show that nitrate and ${ }^{99} \mathrm{Tc}$ do not appreciably interact with the Hanford sediments but instead travel together at the leading edge of liquid waste plumes (see Serne et al. 2002a,b and 2004a,b for details). 
Finally, the ${ }^{99} \mathrm{Tc}$ inventory estimate projected to be in the $1^{\text {st }}$ Cycle waste discharged to $216-\mathrm{B}-38$ may have been greatly exaggerated in earlier data assessments. It appears likely that assumptions used to generate the inventory estimate for ${ }^{99} \mathrm{Tc}$ in $\mathrm{BiPO}_{4}$ " $1{ }^{\text {st }} \mathrm{Cycle"} \mathrm{waste} \mathrm{are} \mathrm{incorrect} \mathrm{in} \mathrm{the} \mathrm{Hanford} \mathrm{Defined}$ Waste (HDW) -Revision 4 Model (Agnew 1997; Agnew et al. 1996) and thus, in the crib and trench discharge inventory estimates performed by Simpson et al. 2001. The rationale used by Agnew to estimate the fate of ${ }^{99} \mathrm{Tc}$ is traced back to a review document available in the 1980s in draft form and finally published (Anderson 1990). However, the original source for the estimate of percentages of beta emitters that precipitate with the plutonium product remains unknown. The Hanford Technical Manual Part C (HW-10475) (referred to here as the " $\mathrm{BiPO}_{4}$ Technical Manual") states that approximately $90 \%$ of the fission product "total beta activity" went with the metal waste, about $9 \%$ with the $1^{\text {st }}$ Cycle waste, and about $1 \%$ with the $2^{\text {nd }}$ Cycle waste. The assumption used in Agnew's HDW Model (and in other recent documents) partitions fission product radionuclides (including ${ }^{99} \mathrm{Tc}$ ) according to this $90 / 9 / 1$ total beta fission product distribution as found in the $\mathrm{BiPO}_{4}$ Process Technical Manual. This assumption has a major impact on fission product inventory estimates for all of the bismuth phosphate process waste streams, such as discharges of $\mathrm{BiPO}_{4}$ Process $1^{\text {st }}$ Cycle wastes to specific retention trenches (such as 216-B-38) and other inactive Hanford Central Plateau waste sites in operable units such as TW-2 OU. (See BHI 1996 and Fluor Hanford 2003 for details on the operable units' clean up designations.)

The notion that the ${ }^{99} \mathrm{Tc}$ inventory estimates in the $1^{\text {st }}$ Cycle waste stream are incorrect is supported by looking at the ratio of "nitrate to technetium" in both the projected discharge inventory (Simpson et al. 2001) and the analytical data in soil samples from the 216-B-38 borehole. Simpson et al. projected the ratio of nitrate to ${ }^{99} \mathrm{Tc}$ in the discharges to $216-\mathrm{B}-38$ to be $717 \mathrm{~kg}$ nitrate $/ \mathrm{Ci}{ }^{99} \mathrm{Tc}$ based on the 2001 data analysis. Corbin et al. (2005) projected a ratio of $5.30 \mathrm{E}+05 \mathrm{~kg} / \mathrm{Ci}$ in the improved analysis based on data presented in this report on Tc fate in the various bismuth phosphate waste streams. The same ratio for the vadose zone sediment sample from 52-54 ft bgs is $1.13 \times 10^{6} \mathrm{~kg} / \mathrm{Ci}$. The ratios for the other two zones that contained both ${ }^{99} \mathrm{Tc}$ and nitrate are much larger. The measured ratios in sediment samples suggest that there is far less ${ }^{99} \mathrm{Tc}$ in the soil column than would have been suggested from the projected $1^{\text {st }}$ Cycle waste composition in the Simpson et al. (2001) estimate of ${ }^{99} \mathrm{Tc}$ disposed to the 216-B-38 trench. The current estimate found in Corbin et al. (2005) agrees more closely with the nitrate-to-technetium-99 ratio measured in the recent sediment samples.

Much of the $\mathrm{BiPO}_{4}$ Process $1^{\text {st }}$ Cycle supernatants (from the $\mathrm{BiPO}_{4}$ process) were discharged to the soil column at the BX-specific retention trenches, T-specific retention trenches, TX-specific retention trenches, and one TY crib (Waite 1991). Once the uranium had been recovered from the "metal waste," most of the "scavenged uranium recovery" wastes were discharged to BY cribs and BC cribs and specific retention trenches (Waite 1991). Our $\mathrm{BiPO}_{4}$ process simulation laboratory tests described herein confirm that essentially all (>99.3 to $99.9 \%$ ) of the ${ }^{99} \mathrm{Tc}$ remained in the "metal waste" stream; thus the ${ }^{99} \mathrm{Tc}$ inventory estimates for discharges of scavenged uranium recovery waste to the soil column may rise about $11 \%$ (from $90 \%$ to $99.9 \%$ ) (probably well within the uncertainty around these numbers). Therefore, the ${ }^{99} \mathrm{Tc}$ inventory estimates for the $1^{\text {st }}$ Cycle waste discharges could be dramatically lowered (from $9 \%$ to $\sim 0.1$ to $0.7 \%$ ). Since the $1^{\text {st }}$ Cycle supernatant discharges to the soil column were very near to tank farms with known tank leaks, resolving questions about locations and inventory for ${ }^{99} \mathrm{Tc}$ discharges will enhance the quality of both the Tank Farm and the Past Liquid Disposal Facilities vadose zone characterization efforts.

A review of the chemical separations processes outlined in the $\mathrm{BiPO}_{4}$ Technical Manual leads to the conclusion that ${ }^{99} \mathrm{Tc}$ would only be retained in the "product cake" resulting from the initial precipitation 
of the metal solution only if the ${ }^{99} \mathrm{Tc}$ were reduced to a lower oxidation state than pertechnetate [Tc(VII)] and the reduced Tc precipitated with the $\mathrm{BiPO}_{4}$ solids carrying the plutonium product. Since nitrous acid was used as a "reducing agent" to assure that the $\mathrm{Pu}$ was in the +4 oxidation state just prior to the $\mathrm{BiPO}_{4}$ precipitation step, the fundamental question is whether or not nitrous acid reduces ${ }^{99} \mathrm{Tc}$ in this particular chemical matrix at the appropriate temperature $\left(85^{\circ} \mathrm{C}\right)$. Because historical analytical data for $\mathrm{BiPO}_{4}$ Process waste streams are rather limited, specific ${ }^{99} \mathrm{Tc}$ analyses in these waste types appear to be nonexistent in old analytical data archives and the thermodynamic redox data are highly unreliable for the components of this mixture at elevated temperatures, our laboratory simulation of the bismuth phosphate process provides the best choice to resolve this question.

\subsection{Objectives}

The objective of this work was to simulate the original bismuth phosphate process to better understand the fate of key risk driver fission products among the process waste streams, which went to various disposal facilities. The bismuth phosphate process was used to extract plutonium from irradiated fuel at Hanford's B and T Plants in the mid 1940s through 1951 and created a large percentage of the wastes currently stored and/disposed at Hanford. The key issue investigated was to determine what percentage of the key fission products would associate with the first bismuth phosphate precipitate, which contained the plutonium "product", and what percentage of the key fission products would remain in the resultant solution, which was called metal waste solution. Determining these two percentages is important because the resultant wastes from these to process streams ultimately went to two different disposal/storage facilities.

Inventory estimates for key fission products for the different disposal/storage facilities are necessary to evaluate future human and environmental risks. Several of these inventory estimates are based on historical/anecdotal information rather than actual measurements. Because recent sediment sampling from the bottoms to the groundwater table at a few inactive disposal sites has yielded data that does not agree with the historical inventory estimates, this lab-scale re-creation of the bismuth phosphate process was performed.

\subsection{Overview of this Report}

Chapter 2 describes the methods and materials used in our lab-scale simulation tests. Chapter 3 provides results. Chapter 4 is a discussion of results and our conclusions. References are provided in Chapter 5. Appendix A describes the precipitate formed during preparation of the metal storage solution. Appendix B and Appendix C provide scanning electron microscopy-energy-dispersive $\mathrm{x}$-ray spectroscopy (SEM-EDS) spectra for precipates from the neutralization of the metal waste solution. Appendix D is a specification sheet for the uranyl nitrate starting reagent used in the lab-scale simulations. 



\subsection{Methods and Materials}

\subsection{Metal (Uranium) Storage Solution Preparation}

To simulate the starting metal storage solution utilized in the bismuth phosphate $\left(\mathrm{BiPO}_{4}\right)$ process, we generated one liter of simulated metal storage solution by dissolving reagent-grade uranyl nitrate into nitric and sulfuric acid with the addition of stable nuclides of selected fission products. This stock metal storage solution was used in four separate experiments in which we added additional stable or radioactive isotopes of key risk driver fission products. The four experiments investigated the fate of the fission products throughout the first few steps (and waste streams produced) of the bismuth phosphate process. In both the stock metal storage solution and the individual batches used in the laboratory simulation, the fission product concentrations were based on fission content 90 days after discharge from the reactor (see Schwenneson 1950 for details on amount of fission products present in dissolved irradiated fuels). Most of the stable elements were added to the stock solution containing set portions of $70 \%$ nitric acid, 98\% sulfuric acid, uranyl nitrate hexhydrate, and deionized water (Table 2.1). We did not add several fission product elements that are very minor fission components (such as $\mathrm{Ge}, \mathrm{As}, \mathrm{Br}, \mathrm{Ag}$, $\mathrm{Cd}, \mathrm{Sn}, \mathrm{In}, \mathrm{Tb}, \mathrm{Gd}, \mathrm{Dy}$, and $\mathrm{Am})$, or inert gases ( $\mathrm{Kr}$ and $\mathrm{Xe}$ ), or the $\mathrm{Pu}$ "product" itself. In addition, because we used inductively coupled plasma-mass spectrometry (ICP-MS) to measure most of the fission products, to cut down on the number of isotopes in the mass spectra we did not add $\mathrm{Nd}$ and $\mathrm{Sm}$; two elements with many stable isotopes. Instead we added extra moles of Pr for the $\mathrm{Nd}$ and extra moles of Eu for the Sm because Pr and Eu have fewer stable isotopes. The amount of iodine, as iodide, added to the metal storage solution represents only $15 \%$ of the amount of iodine in the original irradiated fuel. The other $85 \%$ of iodine was assumed to have been released as volatile gas during the fuel decladding and acid dissolution steps based on volatilization studies described in Holm (1951) and Dreher (1945a).

Finally, we did not add Ru to the stock metal storage solution. Stable ruthenium was added to the metal storage solution for only the third simulation test to cut down mass 99 interferences for Tc. Note that natural $\mathrm{Ru}$ contains $12.7 \%$ mass 99 . Stable $\mathrm{Ru}$ was added to the third simulation and the measured mass at 99 was corrected for the contribution from natural $\mathrm{Ru}$ so that the true concentration of ${ }^{99} \mathrm{Tc}$ could be found.

The chemicals were obtained from the following sources. The uranium nitrate hexahydrate was from ProChem Inc., (Rockford, IL). Most other fission products were certified single element $1000-\mu \mathrm{g} / \mathrm{mL}$ standards from CPI International (Santa Rosa, CA). Trace metal-free nitric acid was from Fisher Scientific (Hampton, NH). ACS-grade sulfuric acid was from Allied Chemical (Minneapolis, MN). Reagent-grade sodium molybdate was from Fisher Scientific. Reagent-grade sodium iodide was from Spectrum Chemical Mfg. Corp. (New Brunswick, NJ). We used ASTM Type II deionized water. It should be noted that one of the reviewers of this document commented that in the actual bismuth phosphate processing at Hanford, potable water from the Columbia River was used for make up water instead of distilled water. This fact might impact the fate of ${ }^{90} \mathrm{Sr}$ in the various waste streams produced because strontium will act like calcium. The concern is that our simulations might not have included as much calcium in the tests as was actually present in the actual bismuth phosphate processing of irradiated fuels. There may have been more co-precipitation of ${ }^{90} \mathrm{Sr}$ with calcium, especially in the first bismuth phosphate precipitation step that will be described below. The potable water and Columbia River water at Hanford contains several tens of parts per million dissolved calcium. Further, the phosphoric acid 
available in the 1940s was not as pure as today's reagents (see discussion below). Therefore there were two sources of calcium in the actual Hanford bismuth phosphate activities that were not considered in these lab-scale simulations.

The acid metal storage solution is shown in Table 2.1. When 498.71 grams of ACS grade uranium oxynitrate (UNH) [uranyl nitrate; $\mathrm{UO}_{2}\left(\mathrm{NO}_{3}\right)_{2} \cdot 6 \mathrm{H}_{2} \mathrm{O}$ ] was added, the mixture became cloudy with a white precipitate. The solution was heated to $85^{\circ} \mathrm{C}$ while stirring for 4 hours. The solution was allowed to cool and was stirred continuously overnight. All of the precipitate did not dissolve after heating so the metal storage slurry was brought to exactly 1.00 liter volume and allowed to sit for three days at which time it was gravity-filtered with Whatman \# 5 filter paper to remove the residual precipitate. The mass of precipitate, $5.88 \mathrm{~g}$, was oven dried and further characterized as discussed in Appendix A.

Table 2.1. Composition of Metal Storage Solution per Liter (present in all four simulations)

\begin{tabular}{|c|}
\hline $544.59 \mathrm{~g} \mathrm{H} 2 \mathrm{O}$ \\
\hline 7.51 g $70 \%$ HNO3 \\
\hline 77.29 g $96 \%$ H2SO4 \\
\hline $498.71 \mathrm{~g} \mathrm{UO}_{2}\left(\mathrm{NO}_{3}\right)_{2} \cdot 6 \mathrm{H}_{2} \mathrm{O}$ \\
\hline $0.28 \mathrm{~mL} 1000$ PPM Se \\
\hline $1.91 \mathrm{~mL} 1000$ PPM Rb \\
\hline $5.64 \mathrm{~mL} 1000$ PPM Sr \\
\hline $2.91 \mathrm{~mL} 1000$ PPM Y \\
\hline $19.23 \mathrm{~mL} 1000$ PPM Zr \\
\hline $14.73 \mathrm{~mL} 1000 \mathrm{PPM} \mathrm{MoO}_{4}$ \\
\hline 1.66 mL 1000 PPM Pd \\
\hline 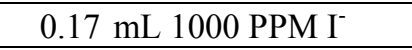 \\
\hline $12.94 \mathrm{~mL} 1000$ PPM Cs \\
\hline $6.25 \mathrm{~mL} 1000 \mathrm{PPM} \mathrm{Ba}$ \\
\hline $5.97 \mathrm{~mL} 1000 \mathrm{PPM} \mathrm{La}$ \\
\hline $16.06 \mathrm{~mL} 1000 \mathrm{PPM} \mathrm{Ce}$ \\
\hline $20.00 \mathrm{~mL} 1000$ PPM Pr \\
\hline $2.41 \mathrm{~mL} 1000 \mathrm{PPM} \mathrm{Eu}$ \\
\hline
\end{tabular}

The ratio of chemicals in the filtered solution is representative of the Metal Storage Solution determined from T \& B Plant Tech Spec manual (HW-10475-C, pages 434-435) and the mass concentrations of fission products based on Schwenneson (1950), with the exception of $50 \mathrm{~mL}$ of water, which was left out to allow for batch-wise additions of other analytes of interest in the four bismuth phosphate precipitation simulations.

\subsection{Product Extraction}

As per the Technical Manual (HW-10475-C), extraction of the plutonium product was a two-step procedure requiring carrier-precipitation of the plutonium with BiPO4 and solid-liquid separation.

\subsubsection{Initial Bismuth Phosphate Precipitation (IBPP)}

To simulate the precipitation step, we scaled down the process to a starting volume of $60 \mathrm{~mL}$ of the metal storage solution as described below: 
1. Add $57.0 \mathrm{~mL}$ of the metal storage solution (Table 2.1) to a $125-\mathrm{mL}$ glass serum bottle.

2. Add analytes of interest $\left({ }^{99} \mathrm{Tc}\right.$, stable $\mathrm{Ru}, \mathrm{Np}-237$, gamma emitting tracers, etc.) and water to a final volume of $60 \mathrm{~mL}$ using distilled water.

3. Add $24.28 \mathrm{~mL}$ of de-ionized water to flask.

4. Heat solution to $85^{\circ} \mathrm{C}$.

5. Add $2.20 \mathrm{~mL}$ of $25 \%$ sodium nitrite solution at a rate of $0.1 \mathrm{~mL} / \mathrm{min}$ (takes 22 minutes.)

6. Digest for 1 hour.

7. Add $1.05 \mathrm{~mL}$ of $24 \%$ bismuth nitrate $/ 19 \%$ nitric acid solution in one addition.

8. Wait 15 minutes.

9. Add $8.05 \mathrm{~mL}$ of $73.5 \%$ phosphoric acid $/ 1.2 \%$ nitric acid solution at a rate of $0.05 \mathrm{~mL} / \mathrm{min}$. This step takes 161 minutes.

10. Digest for 2 hours.

11. Cool slurry to $50^{\circ} \mathrm{C}$.

The precipitation reagents (steps 5, 7, and 9) were prepared from reagent-grade sodium nitrite (Fisher), reagent-grade bismuth subnitrate (Mallincrodt Baker, Phillipsburg, NJ), trace metal-free grade nitric acid (Fisher), reagent-grade phosphoric acid (JT Baker), and ASTM Type II water. The sodium nitrite (Step \#5) and phosphoric acid (step \#9) solutions were added using a Kloehn Ltd (Las Vegas, NV) programmable syringe pump set to meet the prescribed flow rates. One of the reviewers commented that the source of phosphoric acid in the 1940s and 1950s would not have been as pure as today's reagentgrade acid. Back then phosphoric acid was obtained by "wet" processing phosphate-rich rock that contained significant amounts of calcium. The final phosphoric acid product would have undoubtedly contained more dissolved calcium than the reagent-grade acid that we used. Thus our data on the fate of ${ }^{90} \mathrm{Sr}$ may not accurately consider co-precipitation with calcium into the bismuth phosphate precipitate, which also contains the plutonium product. This caveat should be considered in our discussion of the results.

\subsubsection{Centrifugation and Washing $(\mathrm{C} \& \mathrm{~W})$}

The following plutonium $(\mathrm{Pu})$ precipitation separation steps were also scaled down from T\&B Plant Tech Spec (HW-10475-C):

1. Transfer the bismuth phosphate precipitate/slurry solution to two $50-\mathrm{mL}$ glass centrifuge tubes.

2. Spin at 870 revolutions per minute $(\mathrm{RPM})$ in a centrifuge with a 15 -centimeter $(\mathrm{cm})$ arm radius ( $\sim 130$ g relative centrifugal force) for 5 minutes to allow separation of solids.

3. Remove all but about $0.5 \mathrm{~mL}$ of the supernatant from each centrifuge tube and save for mass balance analyses.

4. Decant moist solid from one centrifuge tube and add it to second tube.

5. Add $3.0 \mathrm{~mL}$ of de-ionized water to $125 \mathrm{~mL}$ serum bottle (from precipitation process, see above) to rinse any residual solid and solution. 
6. Add rinsate from step \#5 to first centrifuge tube and swirl to suspend any residual solids.

7. Add rinsate from step \#6 to second centrifuge tube and shake by hand to re-suspend the "Pu-bismuth phosphate" solids.

8. Spin the slurry in the second centrifuge tube at 870 RPMs $(\sim 130 \mathrm{~g}$ force $)$ in the centrifuge for 5 minutes.

9. Remove all but $0.5 \mathrm{~mL}$ of supernatant being careful not to remove any solids.

10. Combine the supernatant from step 9 with the supernatant in step 3.

11. Add $1.5 \mathrm{~mL}$ of de-ionized water to the centrifuge tube and shake by hand.

12. Spin the centrifuge tube at 870 RPMs ( $\sim 130 \mathrm{~g}$ force) for 2 minutes in the centrifuge. Shake by hand. Spin for an additional 2 minutes in the centrifuge.

13. Remove all but $0.5 \mathrm{~mL}$ of supernatant solution; be careful not to remove the solids.

14. Combine the supernatant solutions from steps 10 and 13.

15. Repeat steps $11,12,13$, and 14 one more time. The final supernate solution is the metal waste solution that was sent to single-shell tanks after neutralization with sodium hydroxide and sodium carbonate.

Figures 2.1 through 2.4 show the bismuth phosphate precipitation simulation.

\subsection{Metal Waste Solution Neutralization (Neut)}

The metal waste solution contains most of the uranium and most of the fission products that do not readily form phosphate precipitates. Prior to disposal into single-shell tanks, the acidic metal waste solution was neutralized with two caustic reagents, sodium hydroxide and sodium carbonate. The goal of the neutralization process was to create a near-neutral $\mathrm{pH}$ waste stream, compatible with storage in the single-shell tanks, which means waste should be mostly soluble with minimum formation of solids. It was known that uranyl carbonates were highly soluble and thus sodium carbonate was used. The main reason for using sodium hydroxide was to minimize the final volume of waste generated; but it was also known that too much sodium hydroxide would lead to formation of solids that were hard to re-dissolve. The original developers of the neutralization process noted that metal waste solution with less than $0.6 \mathrm{M}$ phosphate produced $15 \%$ to $30 \%$ solids after neutralization, but that metal waste solution containing $>0.6 \mathrm{M}$ phosphate only produced $0 \%$ to $4 \%$ solids (HW-10475-C; pg 925). The developers also noted that, if the sodium hydroxide was added rapidly, a gelatinous precipitate formed but it readily re-dissolved upon addition of the sodium carbonate. So the practice was to add the sodium hydroxide as rapidly as possible, while controlling the temperature to less than $75^{\circ} \mathrm{C}$ and keeping the $\mathrm{pH}$ between 2 and 6 . The developers also noted that the soda ash (sodium carbonate) was heated to $30^{\circ} \mathrm{C}$ to keep it soluble (at temperatures below $27^{\circ} \mathrm{C}$, the $30 \%$ solution started to form "slush"). The developers also noted that, should the neutralized metal waste reach temperatures above $75^{\circ} \mathrm{C}$ after transfer to single-shell tanks because of radiogenic self-heating, as much as $50 \%$ to $75 \%$ of the uranium would precipitate as a mixed uranium phosphate carbonate solid. 


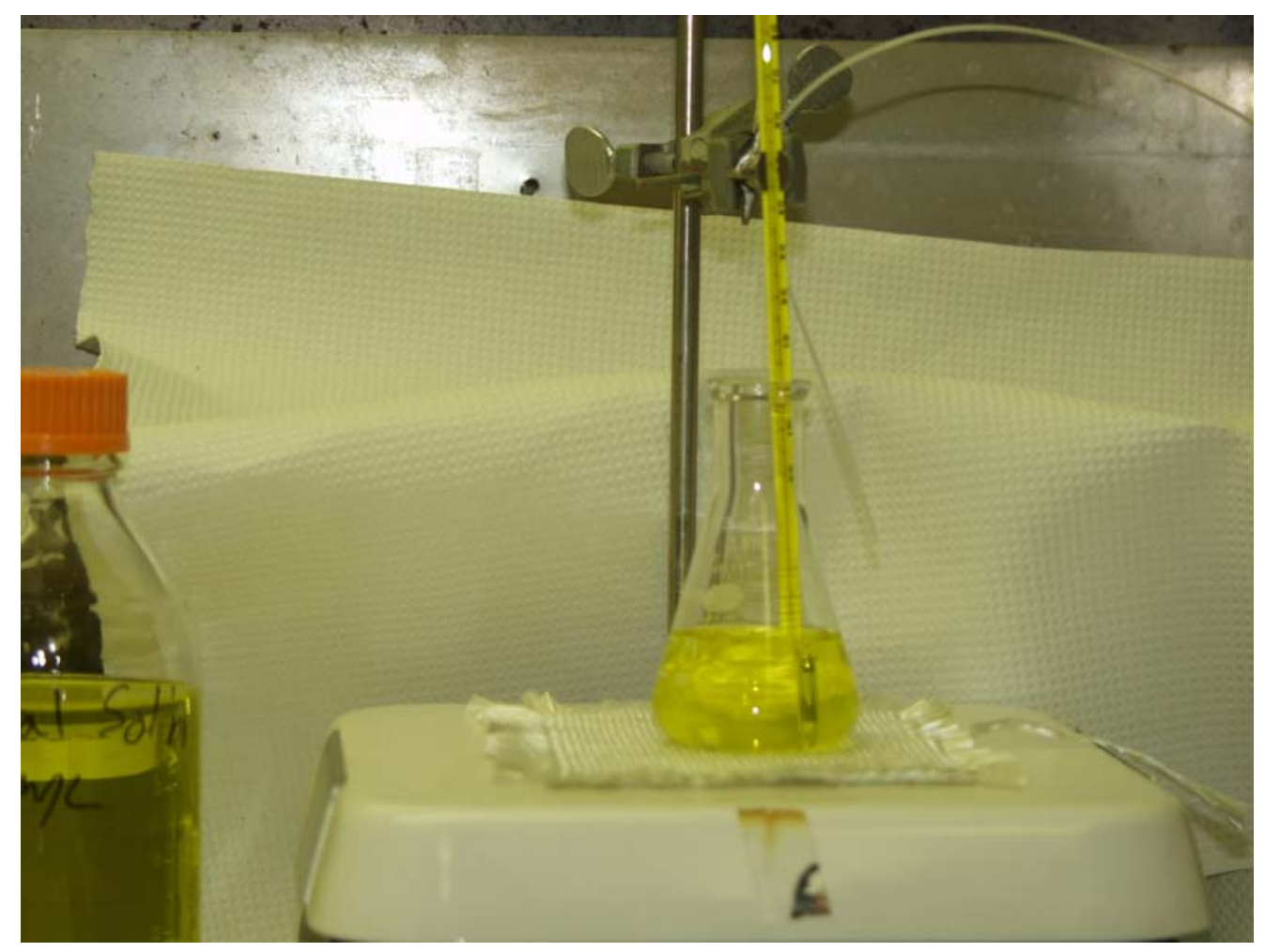

Figure 2.1. Initiation of the Bismuth Phosphate Precipitation Simulation Process Showing Metal Storage Solution with ${ }^{99} \mathrm{Tc}$ dissolved (IBPP step \#2)

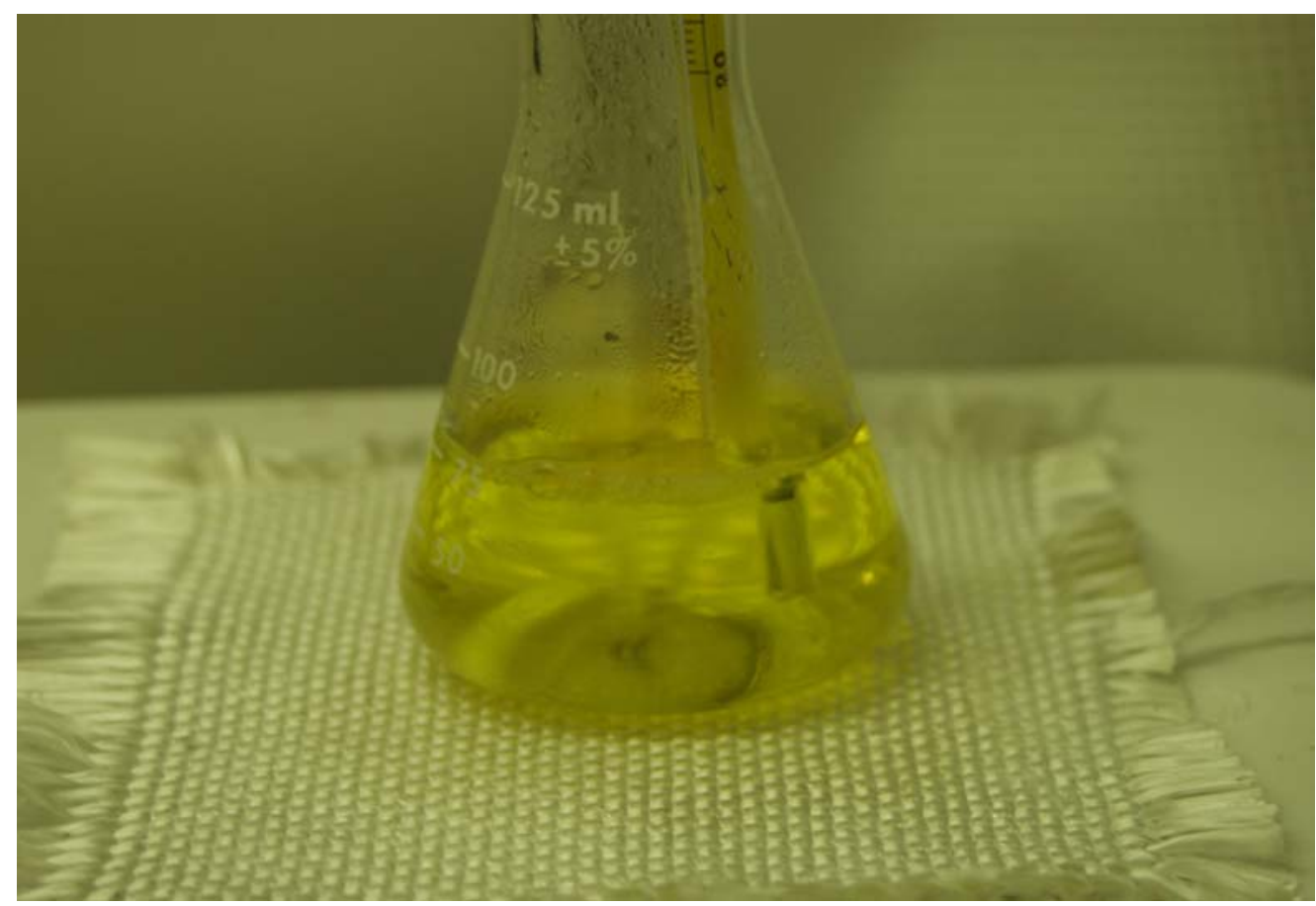

Figure 2.2. Addition of Sodium Nitrite (IBPP step \#5) 


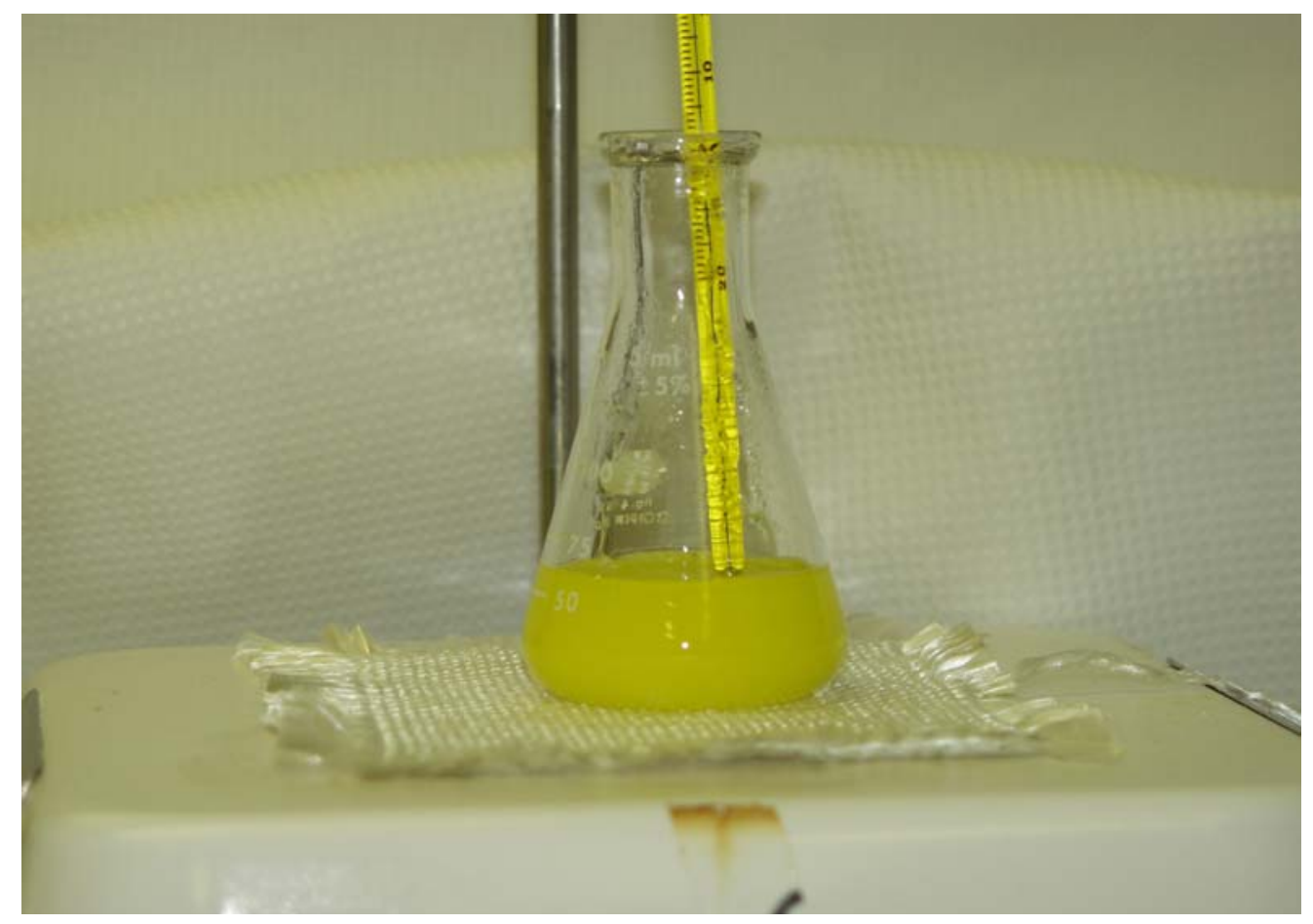

Figure 2.3. Completion of Phosphoric Acid Addition (IBPP step \#7/8). Note cloudy suspension indicative of precipitate formation.

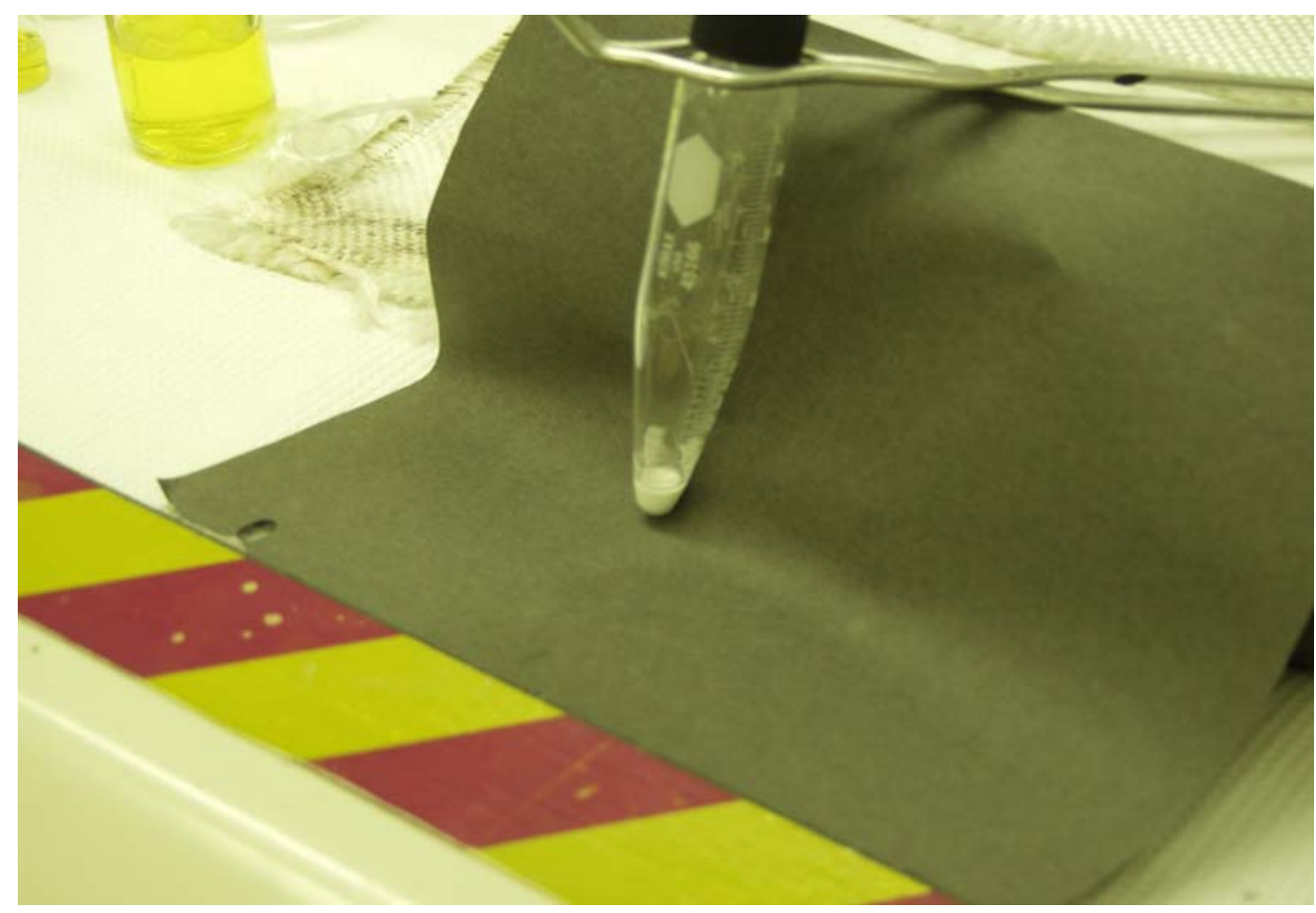

Figure 2.4. Bismuth Phosphate (Product) Solid after Rinsing (C\&W step \#13/15) 
In our metal waste neutralization simulation, $50 \%$ sodium hydroxide and $30 \%$ sodium carbonate solutions are added to each volume of metal waste solution obtained after centrifugation and washing of the final product solids. The amounts of sodium hydroxide and sodium carbonate added to each run were determined from the ratio of reagents added in the actual process (details taken from HW-10475-C, page 925$)$.

In our lab-scale simulation, the metal waste solution was placed in a $250-\mathrm{mL}$ Erlenmeyer flask with a stir bar. Potassium hydroxide solution (50\%) was inadvertently used instead of 50\% sodium hydroxide for the neutralization of the first three batches but should not affect the fate of uranium or ${ }^{99} \mathrm{Tc}$, which were our key interests. For the fourth test, sodium hydroxide was correctly used. The potassium or sodium hydroxide solution was added in a stepwise manner with continuous stirring in batches of $0.5 \mathrm{~mL}$ to avoid excess heat build up and excessive reaction. Once the appropriate volume of hydroxide had been added, the sodium carbonate was added, in batches of $0.2 \mathrm{~mL}$, to the solution in a stepwise manner to control splattering and bubbling over the lip of the flask as carbon dioxide gas evolved. In order to keep the $30 \%$ sodium carbonate in solution, the temperature of the reagent solution was kept at $30^{\circ} \mathrm{C}$. In general, about $17 \%$ and $66 \%$ by volume hydroxide and carbonate solutions were added to the acidic metal waste in sequence, respectively. Although not part of the original bismuth phosphate process, the neutralized waste for tests 2 and 4 was later centrifuged and the supernatant was removed from the solids. The neutralized metal waste supernatant was analyzed for specific gravity and $\mathrm{pH}$; tests included gamma energy analysis (GEA), ICP-MS, and inductively coupled plasma-optical emission spectro (ICP-OES). The neutralized metal waste solid from simulation \#2 was analyzed for percent moisture, and then aliquots of the solids formed after neutralization of both simulations \#2 and \#4 were analyzed by x-ray diffraction, SEM-EDS, semi-quantitative x-ray fluorescence (XRF) and carbon analyzer. A separate aliquot of the dried solids from simulation \#2 was then dissolved in concentrated nitric acid and uranium content was determined.

\subsection{Solid Phase Characterization Using XRD, SEM-EDS and XRF}

The various solids formed during preparation of the metal storage solution and neutralization of the metal waste solutions were characterized by various techniques.

\subsubsection{XRD Analysis}

The mineralogy of each precipitate was determined using powder XRD analysis. A 2-g aliquot of the bulk sample was prepared by grinding in a ball mill. All powdered samples were analyzed on a Scintag XRD unit equipped with a Pelter thermoelectrically cooled detector and a copper x-ray tube. Powdered samples were characterized using monochromated $\mathrm{Cu} \mathrm{K \alpha}$ radiation $(\lambda=1.5418 \AA)$. RandomLy oriented bulk samples were scanned from $2^{\circ}$ to $65^{\circ} 2 \theta$ with a dwell time of 14 seconds. Scans were collected automatically and processed using commercial software (JADE ${ }^{\circledR}$ XRD pattern processing software). Mineral identification was based on powder diffraction files published by the Joint Committee for Powder Diffraction Standards. The software fits a diffraction model to the analytical data by non-linear least-square optimization in which crystallographic parameters are varied to improve the fit between the sample and theoretical mixed mineral patterns. Success of the refinement process is measured by a ratio of the residual and total errors. The value referred to as "goodness of fit" is expected to be close to one in the case of an ideal refinement. 


\subsubsection{SEM/EDS Analysis}

Samples of the $\mathrm{NaOH}-\mathrm{Na}_{2} \mathrm{CO}_{3}$ neutralized metal waste precipitate, $\mathrm{KOH}-\mathrm{Na}_{2} \mathrm{CO}_{3}$ neutralized metal waste precipitate, and metal storage solution precipitate were characterized by SEM/EDS. The sample mounts used for SEM/EDS consisted of double-sided carbon tape attached to standard aluminum mounting stubs. For each mount, small aliquots of each precipitate were placed on the exposed upper surface of the carbon tape using a micro spatula. Each mount was then coated with carbon using a vacuum sputter-coater to improve the conductivity of the samples and thus the quality of the SEM images and EDS signals.

A JEOL JSM-840 SEM was used for high-resolution imaging of micrometer/submicrometer-sized particles in the precipitates. The SEM system is equipped with an Oxford INCA Energy EDS System that was used for qualitative element analysis. Operating conditions consisted of $20 \mathrm{keV}$ for SEM imaging and $20 \mathrm{keV}$ and 100 live seconds for the EDS analyses. EDS analyses are limited to elements with atomic weights heavier than boron. Compositions determined by EDS are qualitative and have large uncertainties resulting from alignment artifacts caused by the variable sample and detector configurations that exist when different particles are imaged by SEM.

To help identify particles that contain elements with large atomic numbers, the SEM was operated in the backscattered electron (BSE) mode as opposed to the secondary electron (SE) mode. Secondary electrons are low-energy electrons ejected from the probed specimen as a result of inelastic collisions with beam electrons, whereas backscattered electrons are primary electrons emitted as a result of elastic collisions. Backscattered electron emission intensity is a function of the element's atomic number - the larger the atomic number, the brighter the signal. Backscattered electron images are obtained in exactly the same way as secondary electron images.

The entire area of each SEM mount was examined by SEM at low magnification (typically 50 to $100 x$ ) to identify particles that were typical or unusual for the sample. Within these imaged regions, additional SEM micrographs were recorded of several particles at greater magnifications to provide a more detailed representation of the particles' characteristics, and selected points on these particles were then analyzed by EDS. Depending on the perceived importance of such particles, regions on these particles were sometimes analyzed by SEM and EDS at even greater magnifications.

Photomicrographs of high-resolution BSE images were obtained as digital images and stored in electronic format. The name of each digital image file, sample identification number, and a size scale bar are given, respectively, at the bottom left, center, and right of each SEM micrograph in this report. The BSE label near the digital image file name indicates that the micrograph was collected with backscattered electrons.

\subsubsection{XRF Analysis}

The reagent-grade uranium nitrate hexahydrate and the two precipitates from the $\mathrm{KOH}-\mathrm{Na}_{2} \mathrm{CO}_{3}$ and $\mathrm{NaOH}-\mathrm{Na}_{2} \mathrm{CO}_{3}$ neutralized metal waste simulations were also analyzed on a Bruker Pioneer model XRF using the semi-quantitative standard-less software that is part of the instrument operating package. The XRF cannot detect light elements such as nitrogen, carbon, or hydrogen. Thus the nitrate and water portion of the uranium nitrate hexahydrate compound and the carbonate content in the two precipitates formed during the metal waste neutralization processes are not considered in the calculation of the oxide 
composition of the solid. But for the carbonate we did measure total carbon so that we have a measure of carbonate in the neutralized precipitates. The overall accuracy of the semi-quantitative analysis for solids using the standardless technique is $\sim 20 \%$.

\subsubsection{Total Carbon Analysis}

The total carbon concentration in the two precipitates from the $\mathrm{KOH}-\mathrm{Na}_{2} \mathrm{CO}_{3}$ and $\mathrm{NaOH}-\mathrm{Na}_{2} \mathrm{CO}_{3}$ neutralized metal waste precipitates was measured with a Shimadzu TOC-V CSN instrument with a SSM-5000A Total Organic Carbon Analyzer by combustion at approximately $900^{\circ} \mathrm{C}$ based on ASTM Method Standard Test Methods for Analysis of Metal Bearing Ores and Related Materials by Combustion Infrared Absorption Spectrometry (ASTM E1915-01). Aliquots of sediment were placed into pre-combusted, pre-weighed ceramic combustion sample holders and weighed on a calibrated balance. After the combustion sample holders were placed into the furnace introduction tube, approximately 2 minutes waiting period was allowed for the ultra-pure oxygen carrier gas to remove any carbon dioxide introduced to the system from the atmosphere during sample placement. After this sparging process, the sample was moved into the combustion furnace and the combustion was begun. The carrier gas then delivered the sample combustion products to the cell of a non-dispersive infrared (NDIR) gas analyzer, where the carbon dioxide $\left(\mathrm{CO}_{2}\right)$ was detected and measured. The amount of $\mathrm{CO}_{2}$ measured is proportional to the total carbon content of the sample. Adequate system performance was confirmed by analyzing known quantities of a calcium carbonate standard. We assume that there is no significant contribution of organic carbon in the precipitates because there are no organics used in the entire bismuth phosphate process. The total carbon values were converted to carbonate to add to the oxide composition tables in the main text. 



\subsection{Results}

The results of the four lab-scale simulations of the bismuth phosphate process and the subsequent neutralization of the metal waste solution are presented in this section. Additional characterization of precipitates and the chemical composition of the various process solution streams are described. The overall goal was to determine the fate (the distribution of the starting mass into the various precipitates and process waste solutions) of key risk-driving fission products and of the uranium from the dissolved fuel. The fate of less important (from a risk standpoint) fission and activation products was also tracked and is discussed.

\subsection{Bismuth Phosphate Precipitation and Precipitate Separation}

In this subsection we discuss the results of the four simulations for precipitating the "plutonium" product from the metal storage solution.

\subsubsection{First Simulation (included Table 2.1 solution plus ${ }^{99} \mathrm{Tc}$ )}

The first bismuth phosphate precipitation simulation was performed by adding $0.212 \mathrm{~mL}$ of $1169 \mathrm{ppm}{ }^{99} \mathrm{Tc}$ to $57 \mathrm{~mL}$ of the metal storage solution (see Table 2.1) and bringing the final volume to $60 \mathrm{~mL}$ with distilled water (see step \#2 IBPP). After adding the ${ }^{99} \mathrm{Tc}$ and diluting to $60 \mathrm{mLs}$, a small aliquot, $0.1 \mathrm{~mL}$, of the starting metal storage solution was taken, preserved in ultra-pure dilute nitric acid and analyzed by ICP-MS to establish the actual starting concentrations of fission products. Steps 3-11 from the Bismuth Phosphate Precipitation (Section 2.2.1) and steps 1-15 from the Centrifugation and Washing (Section 2.2.2) were then carried out. The final volume for the bismuth phosphate slurry was $60.02 \mathrm{~mL}$, which showed a discrepancy from the anticipated volume of $95.57 \mathrm{~mL}$. At first we assumed that a preparation error was made by not adding the $24.28 \mathrm{~mL}$ of water from step 3, Bismuth Phosphate Precipitation (Section 2.2.1). However, we also found a similar discrepancy in the third and fourth simulations where we are quite sure the additional water was added. In the third simulation the weight of the $125 \mathrm{~mL}$ glass serum bottle was monitored at steps \#3 and \#11 in the Bismuth Phosphate Precipitation process (see Section 2.2.1) and the results confirm that water evaporation was occurring during Bismuth Phosphate Precipitation steps, which were performed inside open vessels in fume hoods at elevated temperature. The fume hood environment promotes evaporation during the bismuth phosphate precipitate formation and digestion steps. However, the water evaporation should not have changed the fate of the

${ }^{99} \mathrm{Tc}$ or other non-volatile fission products during the precipitation and solids washing steps. The actual vessels used in Hanford's bismuth phosphate processing in the 221-B and 221-T Plants were connected to a ventilation system that would have allowed water vapor to escape during the bismuth phosphate precipitation step similar to our lab experiments.

An aliquot of the metal waste solution (C\&W step \#15 in Section 2.2.2) was analyzed for ${ }^{99} \mathrm{Tc}$ and other fission products by ICP-MS. The concentrations of ${ }^{99} \mathrm{Tc}$ measured in the starting metal storage solution and two aliquots of metal waste solution (metal waste analysis was run in duplicate) using ICP-MS were converted to mass by multiplying by the volumes of starting metal storage solution (60.0 $\mathrm{mL}$ ) and ending supernatant solution after removing the bismuth phosphate solids $(60.02 \mathrm{~mL})$. The calculated masses of each fission product are shown in Table 3.1 along with the amounts theoretically added from the reagents used to form the metal storage solution. 
The original metal storage solution was "theoretically" spiked with $247.83 \mu \mathrm{g}$ of ${ }^{99} \mathrm{Tc}$ based on the known volume of standard used. After filtering the metal storage solution to remove the unexpected precipitate (see discussions in Sections 2.1 and Appendix A), the metal storage solution used in simulation \#1 contained $236.8 \mu \mathrm{g}$ of ${ }^{99} \mathrm{Tc}$. After performing the first bismuth phosphate precipitation step, duplicate measurements of the metal waste solution yielded $263 \mu \mathrm{g}$ and $212 \mu \mathrm{g}$ of ${ }^{99} \mathrm{Tc}(106 \%$ and $86 \%$ of the theoretically added ${ }^{99} \mathrm{Tc}$, respectively). Given the complexity of the metal storage and metal waste solution matrices this first attempt at measuring the fate of fission products using ICP-MS for ${ }^{99} \mathrm{Tc}$, recovery of $86 \%$ to $106 \%$ is considered to be an acceptable mass balance. More precise mass balances were expected when we used the gamma tracer ${ }^{95 \mathrm{~m}} \mathrm{Tc}$ (obtained from Oak Ridge National Laboratory Isotope Sales) in simulation tests \#3 and \#4, which are discussed below.

The bismuth phosphate solid that precipitated (which would contain the plutonium if it had been present) was rinsed into a $10-\mathrm{mL}$ volumetric flask and excess water was removed. Concentrated ultrapure nitric acid was added dropwise into the flask until the solids dissolved, then the dissolved product was brought to a final volume of $10 \mathrm{~mL}$. A $0.100 \mathrm{~mL}$ aliquot of the dissolved product was analyzed by ICP-MS for ${ }^{99} \mathrm{Tc}$ and the stable fission metals originally added to the metal storage solution.

The fates of other fission products in the first simulation are also shown in Table 3.1 and mass balance calculations are found in Table 3.2 for the distribution of mass that is expected to end up in single-shell tanks (metal waste solution results) and the mass expected to end up in cribs and trenches (we assume that fission products associated with the re-dissolved $\mathrm{Pu}$-bearing $\mathrm{BiPO}_{4}$ solids end up in these facilities). The values in Table 3.2 were calculated based on assuming that the three solutions that were measured (the starting metal storage solution, the ending metal waste solution, and the re-dissolved bismuth phosphate solids) represent two "independent" measures of the total mass for each element. The starting metal storage solution contains all the mass and the sum of the other two solutions should also sum to the total mass of each element present in the tests. The sum of the three measurements was divided by two to get an average for the total mass in the test. The ratio of the mass in the metal waste solution (supernatant solution after the bismuth phosphate precipitation step) to the average total mass represents the fraction of each element that would end up being disposed in single-shell tanks. The ratio of the mass of each element present in the re-dissolved bismuth phosphate precipitate (called the product in the Technical Manual) to the average total mass represents the fraction that would end up being disposed to cribs. The difference between these two values and the average total mass present represents the mass balance error term. A positive error means that mass was lost during our bismuth phosphate simulation activities and a negative error means that more mass was accounted for than was supposedly present. The mass balance error can be considered an indication of the quality of our analytical data if we assume that we did not lose any material to volatilization or inadvertently during all the steps involved in creating the solid product, washing the product, dissolving the product, and analyzing the three resultant solutions.

The measured $\mathrm{Ba}$ and $\mathrm{Pd}$ concentrations in the metal storage solution are much lower than the amounts added to the solution (see Table 3.1 second and third columns from the left). We suspect that barium sulfate may have precipitated in the metal storage solution (more discussion is found in Appendix A). We do not know why the measured Pd concentration in the starting solution is so low and why the mass balance is so poor. It appears that the mass channel 100 is not accurately quantifying molybdenum in the metal storage solution and we are hesitant to use this isotope to quantify the fate of molybdenum. Our ICP-MS instrument does not measure total selenium adequately in the complicated matrices (see poor Se-82 mass balances in Table 3.2). The amount of selenium produced during the 
Table 3.1. Fate of Fission Product Mass in Simulation \#1

\begin{tabular}{|c|c|c|c|c|c|c|}
\hline \multicolumn{7}{|c|}{ Total $\mu \mathrm{g}$ in Each Phase-Simulation \#1 } \\
\hline Element & $\begin{array}{l}\text { "Theoretical" } \\
\text { Metal Storage }\end{array}$ & $\begin{array}{l}\text { Measured Initial } \\
\text { Metal Storage }\end{array}$ & $\begin{array}{l}\text { Measured Final } \\
\text { Metal Waste Sol }\end{array}$ & "Pu"solid & $\begin{array}{c}\text { Ending Mass } \\
\text { Final Liq. }+ \text { Solid }\end{array}$ & $\begin{array}{l}\text { Mass Lost } \\
\text { Initial-End }\end{array}$ \\
\hline Tc99 & 247.83 & 236.84 & 262.74 & $<5.0$ & $<267.74$ & $<-12.2 \%$ \\
\hline Tc99 dup & 247.83 & 236.84 & 211.87 & $<5.0$ & $<216.87$ & $<8.8 \%$ \\
\hline Ba136 & 356.25 & $(35)$ & $(57)$ & 29.6 & 86.23 & $-85.1 \%$ \\
\hline Ba137 & 356.25 & $<2850$ & (16) & 27.7 & 43.55 & $194.0 \%$ \\
\hline Ce140 & 915.42 & 1000.8 & 542.5 & 134 & 676.41 & $38.7 \%$ \\
\hline $\mathrm{Ce} 142$ & 915.42 & 1009.0 & 531.2 & 135 & 665.75 & $41.0 \%$ \\
\hline Cs133 & 737.58 & 744.6 & 563.9 & $(0.2)$ & 564.10 & $27.6 \%$ \\
\hline Eu151 & 137.37 & 194.4 & 122.8 & $(23)$ & 146.14 & $28.3 \%$ \\
\hline Eu153 & 137.37 & 196.9 & 125.8 & (23) & 149.01 & $27.7 \%$ \\
\hline La139 & 340.29 & 412.4 & 281.6 & 23.1 & 304.71 & $30.0 \%$ \\
\hline Mo100 & 503.64 & $(222)$ & $(165)$ & $(0.32)$ & 165.73 & $29.0 \%$ \\
\hline Mo95 & 503.64 & (494) & $(301)$ & $(0.45)$ & 301.84 & $48.4 \%$ \\
\hline Mo98 & 503.64 & 475.7 & 356.2 & $(0.31)$ & 356.47 & $28.6 \%$ \\
\hline Pd105 & 94.62 & $(50)$ & (19) & 12.4 & 31.18 & $46.1 \%$ \\
\hline Pd106 & 94.62 & $(58)$ & (17) & 0.25 & 17.69 & $106.9 \%$ \\
\hline Pr141 & 1140.00 & 1291.9 & 651.5 & 209 & 860.41 & $40.1 \%$ \\
\hline $\mathrm{Rb} 85$ & 108.87 & $(112)$ & (61) & $(0.11)$ & 61.15 & $59.1 \%$ \\
\hline Se82 & 15.96 & (272) & (129) & $(3.03)$ & 132.20 & $69.3 \%$ \\
\hline Sr86 & 321.48 & 378.6 & 291.4 & $(3.43)$ & 294.87 & $24.9 \%$ \\
\hline Sr88 & 321.48 & 379.8 & 290.3 & $(3.12)$ & 293.47 & $25.6 \%$ \\
\hline Y89 & 165.87 & 186.4 & 131.3 & 4.88 & 136.23 & $31.1 \%$ \\
\hline $\mathrm{Zr90}$ & 1096.11 & (956) & (140) & 30.1 & 170.17 & $139.6 \%$ \\
\hline $\mathrm{Zr91}$ & 1096.11 & 997.5 & $(172)$ & 29.4 & 201.62 & $132.7 \%$ \\
\hline \multicolumn{7}{|c|}{$\begin{array}{l}\text { Values in parentheses signify values that are below quantification limits but above detection limits. Less-than values reflect detection } \\
\text { limits. Elements with several stable masses were measured by the ICP-MS and converted to total concentration of the element based } \\
\text { on natural abundances. Entries with tan highlight are not useful because of detection limit problems or large discrepancies between } \\
\text { mass added and mass measured in the metal storage solution. }\end{array}$} \\
\hline
\end{tabular}

fission process is much lower than the other elements present in the metal storage solution and selenium is not sensitively measured by ICP-MS, thus we will not use the reported Se- 82 information to address selenium fate.

No detectable ${ }^{99} \mathrm{Tc}$ was found in the re-dissolved Pu-bearing /bismuth phosphate solid from simulation \#1. Thus we conclude that nearly all the ${ }^{99} \mathrm{Tc}$ remains in the metal waste that was sent to the single shell tanks and perhaps only trace amounts of ${ }^{99} \mathrm{Tc}$ (certainly not $10 \%$ of the total) ended up going to the $1^{\text {st }}$ and $2^{\text {nd }}$ Cycle waste streams generated from re-dissolution/ purification of the "Pu" bismuth phosphate solids. The $1^{\text {st }}$ and $2^{\text {nd }}$ Cycle waste solutions were neutralized and cascaded through a series of tanks to settle and collect solids before being disposed to cribs. Past assumptions that these wastes contained $10 \%$ of all beta-emitting fission products are erroneous, at least in regards to ${ }^{99} \mathrm{Tc}$. More discussion of the fate of the other fission products is found below where we compile the data from all four simulations. 
Table 3.2. Projected Disposal Facility Receiving Fission Products and Mass Balance for Simulation \#1

\begin{tabular}{|c|c|c|c|}
\hline Fission Products & $\begin{array}{l}\text { To SSTs }(\%) \\
\text { Metal Waste } \\
\end{array}$ & $\begin{array}{c}\text { To Cribs (\%) } \\
\text { Extraction Product (1st, 2nd Cycle) } \\
\end{array}$ & $\begin{array}{c}\text { Mass Unaccounted }(\%) \\
(+) \text { mass missing, }(-) \text { mass "created" }\end{array}$ \\
\hline Tc99 & $10105.19 \%$ & $<1.94 \%{ }^{*}$ & $-7.13 \%$ \\
\hline Tc99 dup & $93.40 \%$ & $<2.20 \%{ }^{*}$ & $4.40 \%$ \\
\hline Ba136 & $93.69 \%$ & $48.84 \%$ & $-42.53 \%$ \\
\hline Ba137 & $1.09 \%$ & $1.92 \%$ & $96.99 \%$ \\
\hline Ce140 & $64.70 \%$ & $15.96 \%$ & $19.34 \%$ \\
\hline Ce142 & $63.44 \%$ & $16.06 \%$ & $20.50 \%$ \\
\hline Cs133 & $86.19 \%$ & $0.02 \%$ & $13.79 \%$ \\
\hline Eu151 & $72.10 \%$ & $13.73 \%$ & $14.16 \%$ \\
\hline Eu153 & $72.70 \%$ & $13.44 \%$ & $13.85 \%$ \\
\hline La139 & $78.55 \%$ & $6.44 \%$ & $15.02 \%$ \\
\hline Mo100 & $85.35 \%$ & $0.17 \%$ & $14.49 \%$ \\
\hline Mo95 & $75.70 \%$ & $0.11 \%$ & $24.19 \%$ \\
\hline Mo98 & $85.60 \%$ & $0.07 \%$ & $14.32 \%$ \\
\hline Pd105 & $46.39 \%$ & $30.55 \%$ & $23.06 \%$ \\
\hline Pd106 & $45.91 \%$ & $0.66 \%$ & $53.43 \%$ \\
\hline Pr141 & $60.54 \%$ & $19.41 \%$ & $20.05 \%$ \\
\hline $\mathrm{Rb} 85$ & $70.33 \%$ & $0.13 \%$ & $29.54 \%$ \\
\hline $\mathrm{Se} 82$ & $63.84 \%$ & $1.50 \%$ & $34.66 \%$ \\
\hline Sr86 & $86.55 \%$ & $1.02 \%$ & $12.44 \%$ \\
\hline Sr88 & $86.26 \%$ & $0.93 \%$ & $12.82 \%$ \\
\hline Y89 & $81.43 \%$ & $3.03 \%$ & $15.55 \%$ \\
\hline $\mathrm{Zr90}$ & $24.86 \%$ & $5.34 \%$ & $69.79 \%$ \\
\hline Zr91 & $28.72 \%$ & $4.90 \%$ & $66.37 \%$ \\
\hline
\end{tabular}

\subsubsection{Second Simulation (included Table 2.1 solution plus Tc-99, Cs-137, I-125, Sr-85, Se-75, Eu-152, and Np-237)}

The second simulation was performed by adding $0.214 \mathrm{~mL}$ of $1169 \mathrm{ppm}$ of ${ }^{99} \mathrm{Tc}$ and $0.500 \mathrm{~mL}$ of $14,745 \mathrm{ppm}^{237} \mathrm{~Np}$ to $57 \mathrm{~mL}$ of the metal storage solution. The solution was then spiked with the radioisotopes ${ }^{137} \mathrm{Cs},{ }^{125} \mathrm{I},{ }^{85} \mathrm{Sr},{ }^{75} \mathrm{Se}$, and ${ }^{152} \mathrm{Eu}$, and brought to a final volume of $60 \mathrm{~mL}$ with distilled water. After equilibration for a few hours, an aliquot, $0.100 \mathrm{~mL}$, was removed from the radio-traced metal storage solution, diluted in weak acid to a volume of $10 \mathrm{mLs}$ and analyzed for gamma emitters using both intrinsic Ge and low energy photon (LEPS) detectors and for the isotopes Np-237 and Tc-99 using ICP-MS. These results represent the starting activities for all the tracers and fission products in the metal storage solution prior to precipitation of the plutonium product. The mass of the radiotracers was insignificant compared to the mass of stable cesium, iodide, strontium, selenium, and europium present in the metal storage solution (see Table 2.1).

Steps 3 through 11 from the Bismuth Phosphate Precipitation (Section 2.2.1) and steps 1 through 15 from the Centrifugation and Washing (Section 2.2.2) were then carried out. The final volume for the metal waste/bismuth phosphate slurry was $90.17 \mathrm{~mL}$, which is slightly less than the anticipated volume of $95.57 \mathrm{~mL}$, based on the Technical Manual details. We suspect that some water evaporated during the various heating steps during the processing. After following all 15 steps in the Centrifugation and Washing (Section 2.2.2), the resultant supernatant (metal waste solution) was analyzed for the gamma tracers, stable fission products, and ${ }^{99} \mathrm{Tc}$ and ${ }^{237} \mathrm{~Np}$. A small aliquot of the metal waste solution, 
$0.100 \mathrm{~mL}$, was diluted to the standard $10-\mathrm{mL}$ counting geometry and gamma and low energy photon (LEPS) measurements were performed. The final mass and activity of the stable and radioactive analytes in the metal waste solution was compared with the starting mass and activities in the starting metal storage solution.

The resultant "Pu"/bismuth phosphate precipitate was also re-dissolved in nitric acid as discussed in the first simulation and an appropriate aliquot was placed in the standard $10 \mathrm{~mL}$ gamma and/or LEPS counting geometry. The gamma and/or low energy photon activity of each tracer and several U daughter products were measured. The concentration of the stable fission elements, ${ }^{99} \mathrm{Tc}$ and ${ }^{237} \mathrm{~Np}$, was also measured in the nitric acid solution used to dissolve the Pu product. The results are shown in Tables 3.3 through 3.6. The same methodology for distributing the nuclides between disposal facilities (i.e., tanks versus cribs) as was described for Table 3.2 was used to populate Tables 3.4 and 3.6.

Table 3.3 shows that we obtained a good mass balance (we recovered almost all the starting mass in the measured sum of the mass in the final metal waste solution and bismuth phosphate solids) for all the tracers except ${ }^{237} \mathrm{~Np}$. Because the ${ }^{237} \mathrm{~Np}$ activity measurement relies on counting the gamma emission of its daughter ${ }^{233} \mathrm{~Pa}$, which has completely different chemistry than neptunium, we suspect that nonequilibrium parent-daughter conditions caused by ${ }^{233} \mathrm{~Pa}$ precipitation complications were occurring such that we can account for only $20 \%$ to $30 \%$ of the neptunium originally in the spiked metal storage solution using radiocounting techniques.

In general, at least $98 \%$ of the strontium-, cesium- and iodide-gamma tracers remained in solution and did not precipitate with the plutonium product. Some of the ${ }^{152} \mathrm{Eu}$ gamma tracer (we believe that the Eu represents all of the lanthanides and trivalent actinides in the irradiated fuel) and ${ }^{75} \mathrm{Se}$ tracer did precipitate into the bismuth phosphate solids and thus would be found in $1^{\text {st }}$ Cycle and later purification waste streams that were disposed to cribs/trenches.

Table 3.4 uses the same data but calculates into which of the waste disposal facilities the fission products and uranium daughter products would be disposed based on the protocols in place at Hanford during the time period bismuth phosphate wastes were discharged. The quality of the data is reflected in the last column where we show whether we can account for the fate of the tracers' mass originally added to the metal storage solution. A positive value in the last column signifies that the sum of tracer recovered in the metal waste solution and the re-dissolved solid adds up to less than the amount originally put into the test. A negative value means that by the end of the test we seemed to have "created" some additional tracer (i.e., the ending mass balance is larger than starting mass/activity used). The results in Table 3.4 show that we got adequate to very good mass balance except for the ${ }^{237} \mathrm{~Np}$ for which the bulk of the activity added to the test cannot be accounted for. The ${ }^{233} \mathrm{~Pa}$ daughter of ${ }^{237} \mathrm{~Np}$ has a 27 -day half-life. It apparently associates with the solids during the bismuth phosphate precipitation. Most of the ${ }^{238} \mathrm{U}$ daughter $\left({ }^{234} \mathrm{Th}\right)$ associates with the solids also.

The data for the other fission products, as determined from the stable nuclides using ICP-MS techniques, added to the metal storage solution are shown in Table 3.5 and Table 3.6. The agreement between Tables 3.4 and 3.6 for Cs and Sr is very good. The gamma tracer and stable isotope data for both are of good quality and show that $90 \%$ to $95 \%$ of both elements remain in the centrifuged supernatant (metal waste) solution sent to the single-shell tanks. Less than $2 \%$ of these elements are associated with the bismuth phosphate precipitate whose wastes (after further plutonium purification) were sent to cribs and trenches. 
Table 3.3. Activity of Gamma Tracers Found in Each Phase in Simulation \#2

\begin{tabular}{||l|c|c|c|c|c||}
\hline \multicolumn{5}{|c|}{ Values of Activity (Total uCi in Each Phase) - Simulation \#2 } \\
\hline & $\begin{array}{c}\text { Initial } \\
\text { Metal Storage }\end{array}$ & $\begin{array}{c}\text { Final } \\
\text { Metal Waste Sol }\end{array}$ & "Pu"solid & $\begin{array}{c}\text { Ending Mass } \\
\text { Final Liq. + Solid }\end{array}$ & $\begin{array}{c}\text { Mass Balance Material } \\
\text { Unaccounted For Initial - End }\end{array}$ \\
\hline \hline Eu152 & $2.83 \mathrm{E}+01$ & $2.03 \mathrm{E}+01$ & $6.14 \mathrm{E}+00$ & $2.64 \mathrm{E}+01$ & $6.60 \%$ \\
\hline Se75 & $6.80 \mathrm{E}+00$ & $5.51 \mathrm{E}+00$ & $6.92 \mathrm{E}-01$ & $6.21 \mathrm{E}+00$ & $8.70 \%$ \\
\hline Cs137 & $2.71 \mathrm{E}+00$ & $2.45 \mathrm{E}+00$ & $<3.44 \mathrm{E}-02$ & $2.48 \mathrm{E}+00$ & $8.50 \%$ \\
\hline Cs137-LEPS & $2.56 \mathrm{E}+00$ & $2.58 \mathrm{E}+00$ & ND & $2.58 \mathrm{E}+00$ & $-0.60 \%$ \\
\hline Sr85 & $1.36 \mathrm{E}+00$ & $1.14 \mathrm{E}+00$ & $<2.54 \mathrm{E}-02$ & $1.17 \mathrm{E}+00$ & $14.20 \%$ \\
\hline Np237 & $6.24 \mathrm{E}-01$ & $<8.90 \mathrm{E}-02$ & $1.89 \mathrm{E}-01$ & $2.78 \mathrm{E}-01$ & $55.51 \%$ \\
\hline Np237-LEPS & $6.09 \mathrm{E}-01$ & $4.52 \mathrm{E}-03$ & $1.11 \mathrm{E}-01$ & $1.15 \mathrm{E}-01$ & $1.10 \%$ \\
\hline Th234 & $4.61 \mathrm{E}+00$ & $1.18 \mathrm{E}+00$ & $2.66 \mathrm{E}+00$ & $3.84 \mathrm{E}+00$ & $16.70 \%$ \\
\hline I-125-LEPS & $1.54 \mathrm{E}-01$ & $1.55 \mathrm{E}-01$ & $<1.0 \mathrm{E}-03$ & $1.56 \mathrm{E}-01$ & $-0.81 \%$ \\
\hline ND=not detected & & & \\
\hline
\end{tabular}

Table 3.4. Distribution of Radiotracers/U Daughters in Waste Streams and Mass Recovery for Simulation \#2

\begin{tabular}{|c|c|c|c|}
\hline & $\begin{array}{c}\text { To SST } \\
\text { Metals Waste } \\
\end{array}$ & $\begin{array}{c}\text { To Cribs and Trenches } \\
\text { Solids (1st Cycle }+2 \text { nd Cycle }+ \text { etc) } \\
\end{array}$ & $\begin{array}{l}\text { Error }(+) \text { mass missing, } \\
(-) \text { mass "created" } \\
\end{array}$ \\
\hline Eu152 & $74.1 \%$ & $22.5 \%$ & $3.4 \%$ \\
\hline $\mathrm{Se} 75$ & $84.8 \%$ & $10.6 \%$ & $4.6 \%$ \\
\hline Cs137 & $94.2 \%$ & $<1.3 \%$ & $>4.5 \%$ \\
\hline Cs137 -LEPS & $100.3 \%$ & ND & $-0.3 \%$ \\
\hline $\mathrm{Sr} 85$ & $90.3 \%$ & $<2.0 \%$ & $>7.7 \%$ \\
\hline $\mathrm{Np} 237$ & $19.73 \%$ & $41.91 \%$ & $38.36 \%$ \\
\hline Np237 -LEPS & $1.2 \%$ & $30.5 \%$ & $68.2 \%$ \\
\hline Th234 & $27.9 \%$ & $63.0 \%$ & $9.1 \%$ \\
\hline $\mathrm{Pa} 233$ & $0.7 \%$ & $109.9 \%$ & $-10.5 \%$ \\
\hline I125 -LEPS & $100.0 \%$ & $<0.65 \%$ & $<-0.6 \%$ \\
\hline
\end{tabular}

The radiotracer mass balance data for ${ }^{75} \mathrm{Se}$ and ${ }^{152} \mathrm{Eu}$ are better than the stable isotope mass balance data and suggest that $75 \%$ to $85 \%$ of each remains in the metal waste solution that went to single-shell tanks and $10 \%$ to $20 \%$ associates with the bismuth phosphate solids that went ultimately to cribs and trenches. The second simulation showed that $96 \%$ to $98 \%$ of the ${ }^{99} \mathrm{Tc}$ stays in the metal waste solution and only $\sim 2 \%$ of the ${ }^{99} \mathrm{Tc}$ would end up in wastes that went to cribs and trenches in $1^{\text {st }}$ and $2^{\text {nd }}$ Cycle waste streams. The ICP-MS data for ${ }^{237} \mathrm{~Np}$ suggests that $86 \%$ to $96 \%$ stays in the metal waste solution and only a few percent associates with the bismuth phosphate precipitate. The ICP-MS Np data is more in line with some historical information (see Dreher 1945b) that suggests $80 \%$ of the ${ }^{237} \mathrm{~Np}$ left the bismuth phosphate plants with the metal waste. Thus we recommend not using the gamma and LEPS data for neptunium found in Tables 3.3 and 3.4.

There is a large difference between simulations \#1 and \#2 for zirconium fate. In simulation \#2 based on ICP-MS measurements of the metal storage solution, the zirconium did not seem to remain in solution prior to starting the bismuth phosphate precipitation steps. It is not clear whether there was a slow zirconium precipitation from the starting solution that did not manifest itself that did not occur earlier in the first simulation. 
Table 3.5. Fate of Fission Product Mass in Simulation \#2

\begin{tabular}{|c|c|c|c|c|c|c|}
\hline \multicolumn{7}{|c|}{ Total $\mu \mathrm{g}$ in Each Phase for Simulation \#2 } \\
\hline Element & $\begin{array}{l}\text { "Theoretical" } \\
\text { Metal Storage }\end{array}$ & $\begin{array}{c}\text { Measured Initial } \\
\text { Metal Storage }\end{array}$ & $\begin{array}{l}\text { Measured Final } \\
\text { Metal Waste Sol }\end{array}$ & "Pu"solid & $\begin{array}{c}\text { Ending Mass } \\
\text { Final Liq. }+ \text { Solid }\end{array}$ & $\begin{array}{l}\text { Mass Lost } \\
\text { Initial-End }\end{array}$ \\
\hline Tc99 & 250.17 & 249.3 & 233.5 & $<4.52$ & $<238.06$ & $<4.6 \%$ \\
\hline U-238 & $1.35 \mathrm{E}+07$ & $1.49 \mathrm{E}+07$ & NM & $4.72 \mathrm{E}+03$ & NA & NA \\
\hline $\mathrm{Np} 237$ & 884.67 & 912 & 780.87 & 16.0 & 796.86 & $13.5 \%$ \\
\hline Ba136 & 356.25 & $(19)$ & $(285)$ & 28.0 & 312.73 & $-176.9 \%$ \\
\hline Ba137 & 356.25 & $(17)$ & $(210)$ & 23.0 & 233.06 & $-173.1 \%$ \\
\hline $\mathrm{Ce} 140$ & 915.42 & 938.0 & 683.0 & 214 & 897.44 & $4.4 \%$ \\
\hline Ce142 & 915.42 & 944.1 & 665.0 & 218 & 882.84 & $6.7 \%$ \\
\hline Cs133 & 737.58 & 701.0 & 618.1 & $(0.8)$ & 618.87 & $12.4 \%$ \\
\hline Eu151 & 137.37 & 205.2 & 187.3 & 38.7 & 226.06 & $-9.7 \%$ \\
\hline Eu153 & 137.37 & 191.1 & 204.7 & 34.5 & 239.22 & $-22.4 \%$ \\
\hline La139 & 340.29 & 389.6 & 344.2 & 38.3 & 382.52 & $1.8 \%$ \\
\hline Mo100 & 503.64 & $(216)$ & (206) & $(0.67)$ & 206.71 & $4.3 \%$ \\
\hline Mo95 & 503.64 & $(461)$ & $(417)$ & $(1.41)$ & 418.00 & $9.7 \%$ \\
\hline Mo98 & 503.64 & 454.2 & $(402)$ & $(1.29)$ & 403.45 & $11.8 \%$ \\
\hline Pd105 & 94.62 & $(48)$ & $(41)$ & 1.94 & 43.42 & $9.7 \%$ \\
\hline Pd106 & 94.62 & (49) & $(45)$ & 2.11 & 47.20 & $3.5 \%$ \\
\hline Pr141 & 1140.00 & 1204.2 & 833.4 & 332 & 1165.69 & $3.3 \%$ \\
\hline $\mathrm{Rb} 85$ & 108.87 & 293.9 & 265.6 & $(0.39)$ & 265.94 & $10.0 \%$ \\
\hline $\mathrm{Se} 82$ & 15.96 & $(304)$ & (179) & $(2.51)$ & 181.95 & $50.1 \%$ \\
\hline Sr86 & 321.48 & 360.9 & 354.1 & $(4.83)$ & 358.97 & $0.5 \%$ \\
\hline Sr88 & 321.48 & 363.8 & 347.2 & $(4.52)$ & 351.67 & $3.4 \%$ \\
\hline Y89 & 165.87 & 173.1 & 154.2 & 8.09 & 162.28 & $6.5 \%$ \\
\hline $\mathrm{Zr90}$ & 1096.11 & $(61)$ & $(375)$ & 190 & 564.86 & $-161.0 \%$ \\
\hline $\mathrm{Zr91}$ & 1096.11 & (69) & $(411)$ & 192 & 603.77 & $-159.0 \%$ \\
\hline \multicolumn{7}{|c|}{$\begin{array}{l}\mathrm{NM}=\text { not measured. } \mathrm{NA}=\text { not available because of missing data. Elements with several stable masses were measured by the ICP- } \\
\mathrm{MS} \text { and converted to total concentration of the element based on natural abundances. Entries with tan highlight are not useful } \\
\text { because of detection limit problems for most samples or large discrepancies between amounts added to starting solution and } \\
\text { measured values in metal storage solution. Values in parentheses signify values that are below quantification limits but above } \\
\text { detection limits. Less than values reflect detection limits. }\end{array}$} \\
\hline
\end{tabular}

\subsubsection{Third Simulation (included Table 2.1 solution plus stable Ru, Tc-99, Tc-95m, Sb-125, and Np-237)}

The third simulation was performed by adding $0.51 \mathrm{~mL}$ of $1000 \mathrm{ppm}$ of stable $\mathrm{Ru}, 0.214 \mathrm{~mL}$ of $1169 \mathrm{ppm}$ of ${ }^{99} \mathrm{Tc}$, and $0.50 \mathrm{~mL}$ of $14,744.5 \mathrm{ppm}{ }^{237} \mathrm{~Np}$ to $57 \mathrm{~mL}$ of the metal storage solution. The solution was then spiked with ${ }^{95 \mathrm{~m}} \mathrm{Tc}$ and ${ }^{125} \mathrm{Sb}$ gamma tracers and brought to a final volume of $60 \mathrm{~mL}$ using metal storage solution as opposed to distilled water, which was used in the other three simulations to reach the final volume of $60 \mathrm{~mL}$. The total volume of metal storage solution in this simulation was $58.676 \mathrm{~mL}$ and the rest was radionuclide stock solutions. After equilibration for a few hours, an aliquot, $0.100 \mathrm{~mL}$, was removed from the radio-traced metal storage solution, diluted in weak ultra-pure nitric acid to a volume of $10 \mathrm{mLs}$ and analyzed for gamma emitters using a gamma energy detector. These results represent the starting activities for all the radiotracers. The diluted radio-traced metal storage solution was also analyzed for the various stable metals by ICP-MS. 
Table 3.6. Projected Disposal Facility Receiving Fission Products and Mass Balance for Simulation \#2

\begin{tabular}{||l|c|c|c||}
\hline \hline Fission Products & $\begin{array}{c}\text { To SSTs(\%) } \\
\text { Metal Waste }\end{array}$ & $\begin{array}{c}\text { To Cribs(\%) } \\
\text { Extraction Product (1st, 2nd Cycle) }\end{array}$ & $\begin{array}{c}\text { Mass Unaccounted (\%) } \\
(+) \\
\text { mass missing, (-) mass "created" }\end{array}$ \\
\hline \hline Tc99 & $95.84 \%$ & $<1.85 \%$ & $>2.31 \%$ \\
\hline Np237 & $91.39 \%$ & $1.87 \%$ & $6.74 \%$ \\
\hline Ba136 & $171.55 \%$ & $16.88 \%$ & $-88.43 \%$ \\
\hline Ba137 & $168.17 \%$ & $18.38 \%$ & $-86.55 \%$ \\
\hline Ce140 & $74.43 \%$ & $23.36 \%$ & $2.21 \%$ \\
\hline Ce142 & $72.80 \%$ & $23.85 \%$ & $3.35 \%$ \\
\hline Cs133 & $93.67 \%$ & $0.11 \%$ & $6.22 \%$ \\
\hline Eu151 & $86.88 \%$ & $17.96 \%$ & $-4.84 \%$ \\
\hline Eu153 & $95.13 \%$ & $16.05 \%$ & $-11.18 \%$ \\
\hline La139 & $89.17 \%$ & $9.92 \%$ & $0.91 \%$ \\
\hline Mo100 & $97.52 \%$ & $0.32 \%$ & $2.16 \%$ \\
\hline Mo95 & $94.81 \%$ & $0.32 \%$ & $4.87 \%$ \\
\hline Mo98 & $93.78 \%$ & $0.30 \%$ & $5.92 \%$ \\
\hline Pd105 & $90.89 \%$ & $4.25 \%$ & $4.86 \%$ \\
\hline Pd106 & $93.83 \%$ & $4.39 \%$ & $1.77 \%$ \\
\hline Pr141 & $70.33 \%$ & $28.04 \%$ & $1.63 \%$ \\
\hline Rb85 & $94.87 \%$ & $0.14 \%$ & $4.99 \%$ \\
\hline Se82 & $73.91 \%$ & $1.03 \%$ & $25.05 \%$ \\
\hline Sr86 & $98.39 \%$ & $1.34 \%$ & $0.27 \%$ \\
\hline Sr88 & $97.05 \%$ & $1.26 \%$ & $1.69 \%$ \\
\hline Y89 & $91.95 \%$ & $4.82 \%$ & $3.23 \%$ \\
\hline Zr90 & $119.72 \%$ & $60.78 \%$ & $-80.49 \%$ \\
\hline Zr91 & $122.30 \%$ & $57.19 \%$ & $-79.49 \%$ \\
\hline $\begin{array}{l}\text { Elements with several stable masses were measured by the ICP-MS and converted to total concentration of the element based on } \\
\text { natural abundances. Entries with tan highlight are suspect because of sample stability, low concentrations }(\text { detection limit } \\
\text { problems), or matrix problems. }\end{array}$ & & \\
\hline
\end{tabular}

Steps 3 through 11 from the Bismuth Phosphate Precipitation (Section 2.2.1) and steps 1 through 15 from the Centrifugation and Washing (Section 2.2.2) were then carried out. The final volume for the third metal waste/bismuth phosphate slurry was $67.5 \mathrm{~mL}$, which is considerably less than the anticipated volume of $95.57 \mathrm{~mL}$. We determined by weighing the $125-\mathrm{mL}$ serum bottle (reaction container) that some water evaporated during the various heating steps during the simulation. As mentioned for simulation \#1, this evaporation should not impact the partitioning of the fission products between the metal waste solution and the bismuth phosphate precipitate. After following all 15 steps in the Centrifugation and Washing section, the resulting supernatant (metal waste solution) was analyzed. A small aliquot, $0.100 \mathrm{~mL}$, was diluted to the standard $10 \mathrm{~mL}$ counting geometry and gamma measurements were performed. Using the measured volumes for the initial metal storage and final metal waste solutions, the masses and radioactivity for the two solutions were compared. In addition, the re-dissolved bismuth phosphate product was analyzed by ICP-MS and gamma counting to determine the mass and activity present in the solid and thus the fate of various fission products.

The results for the gamma-emitting tracers are shown in Tables 3.7 and 3.8 and the fission products and ${ }^{237} \mathrm{~Np}$ measured by ICP-MS are shown in Tables 3.9 and 3.10. We value the radiotracer data more than the ICP-MS data, except for ${ }^{237} \mathrm{~Np}$, because of the simplicity in analyzing gamma tracers and the more accurate counting statistics for the radiocounting. 
Table 3.7. Distribution of Radiotracers in Waste Streams and Mass Recovery for Simulation \#3

\begin{tabular}{||l|c|c|c|c|c||}
\hline \multicolumn{2}{||c|}{ Values of Activity (Total uCi in Each Phase) } \\
\hline & $\begin{array}{c}\text { Initial } \\
\text { Metal Storage }\end{array}$ & $\begin{array}{c}\text { Final } \\
\text { Metal Waste Sol }\end{array}$ & $\begin{array}{c}\text { Ending Mass } \\
\text { "Pu"solid }\end{array}$ & $\begin{array}{c}\text { Mass Lost } \\
\text { Final Liq. + Solid }\end{array}$ & Initial-End \\
\hline \hline Tc-95m & $2.80 \mathrm{E}+01$ & $2.93 \mathrm{E}+01$ & $1.38 \mathrm{E}-02$ & $2.93 \mathrm{E}+01$ & $-4.58 \%$ \\
\hline Tc-95 & $3.25 \mathrm{E}+01$ & $3.36 \mathrm{E}+01$ & $2.43 \mathrm{E}-02$ & $3.36 \mathrm{E}+01$ & $-3.40 \%$ \\
\hline Sb-125 & $3.87 \mathrm{E}+01$ & $4.09 \mathrm{E}+01$ & $5.35 \mathrm{E}-01$ & $4.14 \mathrm{E}+01$ & $-6.83 \%$ \\
\hline $\mathrm{Np}-237$ & $1.27 \mathrm{E}+00$ & $1.34 \mathrm{E}+00$ & $9.35 \mathrm{E}-02$ & $1.43 \mathrm{E}+00$ & $-12.10 \%$ \\
\hline \hline
\end{tabular}

Table 3.8. Projected Disposal Facility Receiving Radiotracers and Mass Balance for Simulation \#3

\begin{tabular}{||l|c|c|c||}
\hline & $\begin{array}{c}\text { To SST } \\
\text { Metals Waste }\end{array}$ & $\begin{array}{c}\text { To Cribs and Trenches } \\
\text { Extraction Product }\end{array}$ & $\begin{array}{c}\text { Error } \\
(+) \text { mass missing, }(-) \text { mass "created" }\end{array}$ \\
\hline \hline Tc-95m & $102.24 \%$ & $0.05 \%$ & $-2.29 \%$ \\
\hline Tc-95 & $101.63 \%$ & $0.07 \%$ & $-1.70 \%$ \\
\hline Sb-125 & $102.08 \%$ & $1.34 \%$ & $-3.41 \%$ \\
\hline Np-237 & $99.13 \%$ & $6.92 \%$ & $-6.05 \%$ \\
\hline
\end{tabular}

As shown in Tables 3.7 and 3.8, the fate of technetium using the ${ }^{95 \mathrm{~m}} \mathrm{Tc}$ radiotracer is unequivocal. Almost all of the technetium remains in the metal waste solution after bismuth phosphate precipitation. Only $0.05 \%$ to $0.07 \%$ of the technetium was detected in the solid precipitate that would ultimately be disposed to cribs and trenches. The radiocounting data for ${ }^{125} \mathrm{Sb}$ suggests that $\sim 100 \%$ remains in the metal waste solution that ends up being disposed in the tanks and no more than $1.4 \%$ is found in the bismuth phosphate precipitate, which after several more purification steps would be cascaded through tanks to cribs or directly disposed to cribs and trenches. Although the second simulation radiocounting data for neptunium was not satisfactory, the radiocounting data from the third simulation appears useable and suggests that $90 \%$ to $100 \%$ of the neptunium remains in the metal waste solution that gets disposed to single shell tanks and $\sim 7 \%$ may be carried down in the bismuth phosphate precipitate which, upon purification to collect the plutonium product, is cascaded through tanks and then goes to the cribs and trenches.

The third simulation contained stable ruthenium, which has $12.7 \%$ natural abundance at mass 99 . After determining the concentrations of ruthenium, using the ICP-MS data for masses 101, 102, and 104, that was present in the various phases shown in Table 3.9 corrections were made to remove the ruthenium-99 contribution for measured mass 99. The net result of subtracting out the ruthenium mass 99 contribution gives the value for technetium-99. After the correction, the technetium data shown in Tables 3.9 and 3.10 are of equal quality to the results of the first two simulations where no ruthenium was present. The ICP-MS data for technetium for simulation \#3 suggest that at least $95 \%$ to $97.5 \%$ of the technetium remains in the supernatant solution (metal storage waste) that goes to the single-shell tanks.

The ICP-MS results for the re-dissolution of the bismuth phosphate precipitate for simulation \#3 show less than $0.03 \%$ of the technetium co-precipitates with the bismuth phosphate-plutonium solids. 
Table 3.9. Distribution of Fission Products in Waste Streams and Mass Recovery for Simulation \#3

\begin{tabular}{|c|c|c|c|c|c|c|}
\hline \multicolumn{7}{|c|}{ Total $\mu \mathrm{g}$ in Each Phase for Simulation \#3 } \\
\hline Element & $\begin{array}{l}\text { "Theoretical" } \\
\text { Metal Storage }\end{array}$ & $\begin{array}{c}\text { Measured Initial } \\
\text { Metal Storage }\end{array}$ & $\begin{array}{l}\text { Measured Final } \\
\text { Metal Waste Sol }\end{array}$ & "Pu"solid & $\begin{array}{c}\text { Ending Mass } \\
\text { Final Liq. + Solid }\end{array}$ & $\begin{array}{l}\text { Mass Lost } \\
\text { Initial-End }\end{array}$ \\
\hline Mass 99 & & 319 & 303.1 & $<0.120$ & $<303.2$ & $5.08 \%$ \\
\hline Tc99 & 250.2 & 249.5 & 237.2 & $<0.083$ & $<237.31$ & $5.01 \%$ \\
\hline Np237 & 884.67 & 1266.6 & 898.43 & 7.73 & 906.15 & $33.18 \%$ \\
\hline Ba136 & 366.73 & $(161)$ & $(165)$ & 47.1 & 211.87 & $-27.29 \%$ \\
\hline Ba137 & 366.73 & $(156)$ & (149) & 45.9 & 194.96 & $-22.20 \%$ \\
\hline Ce140 & 942.34 & 1065 & 962 & 103 & 1064.94 & $0.01 \%$ \\
\hline Ce142 & 942.34 & 1101 & 975 & 105 & 1080.23 & $1.90 \%$ \\
\hline Cs133 & 759.27 & 766 & 776 & $(0.9)$ & 776.77 & $-1.40 \%$ \\
\hline Eu151 & 141.41 & $(166)$ & (152) & (16) & 168.01 & $-1.20 \%$ \\
\hline Eu153 & 141.41 & $(165)$ & (152) & (16) & 168.12 & $-1.87 \%$ \\
\hline La139 & 350.30 & 407.7 & 385.43 & 21 & 406.38 & $0.32 \%$ \\
\hline Mo100 & 864.30 & 622 & 546.3 & $(0.41)$ & 546.68 & $12.89 \%$ \\
\hline Mo95 & 864.30 & 662 & 531.1 & $(0.71)$ & 531.83 & $21.81 \%$ \\
\hline Mo98 & 864.30 & 653 & 531.1 & $(0.6)$ & 531.65 & $20.49 \%$ \\
\hline Pd105 & 97.40 & 8.1 & 41.31 & 0.343 & 41.65 & $-134.87 \%$ \\
\hline Pd106 & 97.40 & 8.4 & 40.87 & 0.908 & 41.78 & $-133.04 \%$ \\
\hline Pr141 & 1173.52 & 1360 & 1210 & 155 & 1364.84 & $-0.36 \%$ \\
\hline $\mathrm{Rb85}$ & 112.07 & 133.8 & 130.7 & $(0.16)$ & 130.91 & $2.18 \%$ \\
\hline Ru101 & 498.75 & 600 & 563.5 & $(0.32)$ & 563.84 & $6.21 \%$ \\
\hline Ru102 & 498.75 & 586 & 554.2 & $(0.34)$ & 554.51 & $5.52 \%$ \\
\hline Ru104 & 498.75 & 455 & 437.7 & 0 & 437.89 & $3.83 \%$ \\
\hline $\mathrm{Se} 82$ & 16.43 & $<300.0$ & $(45)$ & (10) & 54.89 & $138.13 \%$ \\
\hline Sr86 & 330.93 & $(563)$ & $(386)$ & $(4.7)$ & 390.9 & $36.08 \%$ \\
\hline Sr88 & 330.93 & $(564)$ & (391) & $(4.5)$ & 395.69 & $35.08 \%$ \\
\hline Y89 & 170.75 & 213 & 199 & 4.5 & 203.49 & $4.57 \%$ \\
\hline $\mathrm{Zr90}$ & 1128.34 & (241) & (127) & 90.1 & 217.02 & $10.47 \%$ \\
\hline Zr91 & 1128.34 & $(260)$ & (124) & 88.3 & 212.46 & $20.12 \%$ \\
\hline
\end{tabular}

\subsubsection{Fourth Simulation (included Table 2.1 solution plus Tc-99, Tc-95m, Cs-137, Sr-85, Sb-125, and Np-237)}

The fourth simulation was performed by adding $0.214 \mathrm{~mL}$ of $1169 \mathrm{ppm}$ of ${ }^{99} \mathrm{Tc}$ and $0.06 \mathrm{~mL}$ of $14,744.5 \mathrm{ppm}{ }^{237} \mathrm{~Np}$ to $57 \mathrm{~mL}$ of the metal storage solution. The solution was then spiked with ${ }^{95 \mathrm{~m}} \mathrm{Tc}$, ${ }^{137} \mathrm{Cs}$, ${ }^{85} \mathrm{Sr}$, and ${ }^{125} \mathrm{Sb}$ gamma tracers and brought to a final volume of $60 \mathrm{~mL}$ using distilled water. After equilibration for a few hours, an aliquot, $0.100 \mathrm{~mL}$, was removed from the radio-traced metal storage solution, diluted in weak ultra-pure nitric acid to a volume of $10 \mathrm{mLs}$ and analyzed for gamma emitters. These results represent the starting activities for all the tracers. The diluted radio-traced metal storage solution was also analyzed for the stable metals, ${ }^{99} \mathrm{Tc}$, and ${ }^{237} \mathrm{~Np}$ by ICP-MS. Steps 3 through 11 from the Bismuth Phosphate Precipitation (Section 2.2.1) and steps 1 through 15 from the Centrifugation and Washing (Section 2.2.2) were then carried out. 
Table 3.10. Projected Disposal Facility Receiving Fission Products and Mass Balance for Simulation \#3

\begin{tabular}{|c|c|c|c|}
\hline Fission Products & $\begin{array}{l}\text { To SSTs }(\%) \\
\text { Metal Waste }\end{array}$ & $\begin{array}{c}\text { To Cribs }(\%) \\
\text { Extraction Product (1st, 2nd Cycle) }\end{array}$ & $\begin{array}{c}\text { Mass Unaccounted }(\%) \\
(+) \text { mass missing, }(-) \text { mass "created" }\end{array}$ \\
\hline Tc99 & $97.46 \%$ & $<<0.03 \%$ & $\sim 2.51 \%$ \\
\hline Np237 & $82.70 \%$ & $0.71 \%$ & $16.59 \%$ \\
\hline Ba136 & $88.45 \%$ & $25.25 \%$ & $-13.70 \%$ \\
\hline Ba137 & $84.92 \%$ & $26.16 \%$ & $-11.09 \%$ \\
\hline Ce140 & $90.33 \%$ & $9.67 \%$ & $0.00 \%$ \\
\hline Ce142 & $89.41 \%$ & $9.63 \%$ & $0.96 \%$ \\
\hline Cs133 & $100.59 \%$ & $0.12 \%$ & $-0.71 \%$ \\
\hline Eu151 & $91.02 \%$ & $9.58 \%$ & $-0.60 \%$ \\
\hline Eu153 & $91.29 \%$ & $9.61 \%$ & $-0.90 \%$ \\
\hline La139 & $94.69 \%$ & $5.16 \%$ & $0.16 \%$ \\
\hline Mo100 & $93.49 \%$ & $0.07 \%$ & $6.44 \%$ \\
\hline Mo95 & $88.98 \%$ & $0.12 \%$ & $10.91 \%$ \\
\hline Mo98 & $89.66 \%$ & $0.10 \%$ & $10.24 \%$ \\
\hline Pd105 & $166.06 \%$ & $1.38 \%$ & $-67.44 \%$ \\
\hline Pd106 & $162.90 \%$ & $3.62 \%$ & $-66.52 \%$ \\
\hline $\operatorname{Pr} 141$ & $88.81 \%$ & $11.38 \%$ & $-0.18 \%$ \\
\hline $\mathrm{Rb} 85$ & $98.77 \%$ & $0.12 \%$ & $1.11 \%$ \\
\hline Ru101 & $96.84 \%$ & $0.05 \%$ & $3.11 \%$ \\
\hline Ru102 & $97.18 \%$ & $0.06 \%$ & $2.76 \%$ \\
\hline Ru104 & $98.06 \%$ & $0.00 \%$ & $1.94 \%$ \\
\hline $\mathrm{Se} 82$ & NA & NA & NA \\
\hline Sr86 & $80.95 \%$ & $0.99 \%$ & $18.07 \%$ \\
\hline Sr88 & $81.50 \%$ & $0.94 \%$ & $17.56 \%$ \\
\hline Y89 & $95.56 \%$ & $2.16 \%$ & $2.28 \%$ \\
\hline $\mathrm{Zr90}$ & $55.45 \%$ & $39.34 \%$ & $5.22 \%$ \\
\hline Zr91 & $52.51 \%$ & $37.39 \%$ & $10.10 \%$ \\
\hline
\end{tabular}

The final volume for the supernatant solution from the fourth simulation was $65.3 \mathrm{~mL}$, which is considerably less than the anticipated volume of $95.57 \mathrm{~mL}$. We conclude based on weighing the reaction flask during the third simulation at various steps during the Bismuth Phosphate Precipitation process that water evaporated during the various heating steps. As mentioned, this evaporation should not impact the partitioning of the fission products between the metal waste solution and the bismuth phosphate precipitate. After following all 15 steps in the Centrifugation and Washing (Section 2.2.2), the resultant supernatant (metal waste solution) was analyzed. A small aliquot, $0.100 \mathrm{~mL}$, was diluted to the standard $10 \mathrm{~mL}$ counting geometry and gamma measurements were performed. Another aliquot of the $10 \mathrm{~mL}$ solution was analyzed by ICP-MS to quantify the stable fission products and long-lived ${ }^{99} \mathrm{Tc}$ and ${ }^{237} \mathrm{~Np}$. Using the measured volumes for the initial metal storage and final metal waste solutions, the masses and radioactivity or concentration of each constituent for the two solutions (starting metal storage and ending metal waste) were compared. In addition, the re-dissolved bismuth phosphate product was analyzed by ICP-MS, gamma counting, and ICP-OES to determine the mass and activity of fission products, tracers and some of the macro constituents present in the solid. The fate of various fission products were then calculated as for the first three simulations. The analysis of the re-dissolved solid using ICP-OES allows us to qualitatively determine many of the major constituents present in the solid. 
The simulation \#4 results for the gamma emitting tracers are shown in Tables 3.11 and 3.12 and the fission products measured by ICP-MS are shown in Tables 3.13 and 3.14. The ${ }^{95 \mathrm{~m}} \mathrm{Tc}$ radiotracer data for simulation \#4 was not as precise as for simulations \#3 because about one year had transpired between the first three simulations and the fourth. Our supply of ${ }^{95 \mathrm{~m}} \mathrm{Tc}$ had decayed substantially making counting statistics less precise. However the results of simulation \#4 for the other four radionuclides were quite similar to earlier simulations, especially for the percentage that associates with the bismuth phosphate solid product. In general $96+\%$ of the ${ }^{137} \mathrm{Cs}, 95 \%$ of the ${ }^{85} \mathrm{Sr}$, and $99 \%$ of the ${ }^{125} \mathrm{Sb}$ remains in the metal waste stream that after neutralization went directly to single-shell tanks. Less than $2 \%$ of these fission products associate with the bismuth phosphate product, which after $\mathrm{Pu}$ purification would have been disposed to cribs and trenches.

Table 3.11. Distribution of Radiotracers in Waste Streams and Mass Recovery for Simulation \#4

\begin{tabular}{|c|c|c|c|c|c||}
\hline \hline & $\begin{array}{c}\text { Initial } \\
\text { Metal Storage }\end{array}$ & $\begin{array}{c}\text { Final } \\
\text { Metal Waste Sol }\end{array}$ & "Pu"solid & $\begin{array}{c}\text { Ending Mass } \\
\text { Final Liq. + Solid }\end{array}$ & $\begin{array}{c}\text { Mass Balance } \\
\text { Material Unaccounted For } \\
\text { Initial - End }\end{array}$ \\
\hline \hline Se75 & $1.02 \mathrm{E}+00$ & $9.66 \mathrm{E}-01$ & $1.10 \mathrm{E}-01$ & $1.08 \mathrm{E}+00$ & $-5.64 \%$ \\
\hline Sr85 & $1.25 \mathrm{E}+00$ & $1.20 \mathrm{E}+00$ & $2.40 \mathrm{E}-02$ & $1.22 \mathrm{E}+00$ & $2.23 \%$ \\
\hline Tc95m & $6.52 \mathrm{E}-01$ & $5.67 \mathrm{E}-01$ & $3.00 \mathrm{E}-04$ & $5.68 \mathrm{E}-01$ & $13.79 \%$ \\
\hline Sb125 & $4.43 \mathrm{E}+00$ & $4.20 \mathrm{E}+00$ & $5.70 \mathrm{E}-02$ & $4.26 \mathrm{E}+00$ & $3.91 \%$ \\
\hline Cs137 & $3.51 \mathrm{E}+00$ & $3.42 \mathrm{E}+00$ & $4.50 \mathrm{E}-02$ & $3.47 \mathrm{E}+00$ & $1.23 \%$ \\
\hline
\end{tabular}

Table 3.12. Projected Disposal Facility Receiving Radiotracers and Mass Balance for Simulation \#4

\begin{tabular}{||c|c|c|c||}
\hline \hline & $\begin{array}{c}\text { To SST } \\
\text { Metals Waste }\end{array}$ & $\begin{array}{c}\text { To Cribs and Trenches } \\
\text { Solids (1st Cycle+2nd Cycle + etc) }\end{array}$ & $\begin{array}{c}\text { Error } \\
(+) \text { mass missing, (-) mass "created" }\end{array}$ \\
\hline \hline Se75 & $92.31 \%$ & $10.51 \%$ & $-2.82 \%$ \\
\hline Sr85 & $96.94 \%$ & $1.94 \%$ & $1.12 \%$ \\
\hline Tc95m & $93.06 \%$ & $0.05 \%$ & $6.89 \%$ \\
\hline Sb125 & $96.73 \%$ & $1.31 \%$ & $1.95 \%$ \\
\hline Cs137 & $98.09 \%$ & $1.29 \%$ & $0.62 \%$ \\
\hline
\end{tabular}

Both simulations of the bismuth phosphate process that included the radiotracer ${ }^{95 \mathrm{~m}} \mathrm{Tc}$ showed $\sim 0.05 \%$ of the technetium associated with the bismuth phosphate product and between $93 \%$ and $99.6 \%$ remained in the metal waste stream. The overall mass balance for simulation \#3 was excellent while the mass balance for simulation \#4 shows $6.9 \%$ of the original ${ }^{95 \mathrm{~m}} \mathrm{Tc}$ added to the metal storage solution has been lost. Again we attribute the decay of our ${ }^{95 \mathrm{~m}} \mathrm{Tc}$ tracer to the point that we did not have an ideal activity available in the test to take full advantage of the strength of using gamma-emitting tracers.

Table 3.13 and Table 3.14 show that the ${ }^{99} \mathrm{Tc}$, measured by ICP-MS, had less than detection limit amounts of ${ }^{99} \mathrm{Tc}$ associated with the bismuth phosphate precipitate. The metal waste solution, which was sent to single-shell tanks after neutralization, contained at least $97+\%$ of the ${ }^{99} \mathrm{Tc}$ with a mass balance error for simulation $\# 4$ of $\sim 3 \%$. Thus essentially all of the technetium may remain in the metal waste stream. 
Table 3.13. Distribution of Fission Products in Waste Streams and Mass Recovery for Simulation \#4

\begin{tabular}{|c|c|c|c|c|c|c|}
\hline \multicolumn{7}{|c|}{ "Total $\mu \mathrm{g}$ in Each Phase in Simulation \#4 } \\
\hline Element & $\begin{array}{l}\text { "Theoretical" } \\
\text { Metal Storage }\end{array}$ & $\begin{array}{l}\text { Measured Initial } \\
\text { Metal Storage }\end{array}$ & $\begin{array}{c}\text { Measured Final } \\
\text { Metal Waste Sol }\end{array}$ & “Pu”solid & $\begin{array}{c}\text { Ending Mass } \\
\text { Final Liq. + Solid }\end{array}$ & $\begin{array}{l}\text { Mass Lost } \\
\text { Initial-End }\end{array}$ \\
\hline Tс99 & 250.20 & $2.75 \mathrm{E}+02$ & $2.60 \mathrm{E}+02$ & $<<1.02 \mathrm{E}-02$ & 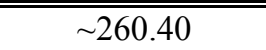 & 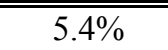 \\
\hline $\mathrm{U} 238$ & $1.35 \mathrm{E}+07$ & $1.60 \mathrm{E}+07$ & $1.50 \mathrm{E}+07$ & $2.69 \mathrm{E}+03$ & $1.50 \mathrm{E}+07$ & $6.2 \%$ \\
\hline Np237 & 884.67 & $4.93 \mathrm{E}+03$ & $4.51 \mathrm{E}+03$ & $1.09 \mathrm{E}+02$ & 4623.82 & $6.5 \%$ \\
\hline Ba137 & 356.25 & $2.51 \mathrm{E}+02$ & $2.12 \mathrm{E}+02$ & $7.71 \mathrm{E}+00$ & 219.38 & $13.5 \%$ \\
\hline Ba138 & 356.25 & $2.50 \mathrm{E}+02$ & $2.08 \mathrm{E}+02$ & $8.37 \mathrm{E}+00$ & 216.19 & $14.5 \%$ \\
\hline Ce140 & 915.42 & $1.04 \mathrm{E}+03$ & $8.52 \mathrm{E}+02$ & $1.52 \mathrm{E}+02$ & 1004.05 & $3.4 \%$ \\
\hline Cs133 & 737.58 & $7.63 \mathrm{E}+02$ & $7.25 \mathrm{E}+02$ & $1.14 \mathrm{E}+00$ & 725.87 & $4.9 \%$ \\
\hline Eu151 & 137.37 & $1.59 \mathrm{E}+02$ & $1.32 \mathrm{E}+02$ & $2.57 \mathrm{E}+01$ & 157.33 & $1.2 \%$ \\
\hline Eu153 & 137.37 & $1.59 \mathrm{E}+02$ & $1.31 \mathrm{E}+02$ & $2.54 \mathrm{E}+01$ & 156.64 & $1.3 \%$ \\
\hline La139 & 340.29 & $3.85 \mathrm{E}+02$ & $3.40 \mathrm{E}+02$ & $3.12 \mathrm{E}+01$ & 371.51 & $3.6 \%$ \\
\hline Mo100 & 503.64 & $1.04 \mathrm{E}+02$ & $(2.44 \mathrm{E}+02)$ & NA & NA & NA \\
\hline Mo98 & 503.64 & $2.24 \mathrm{E}+02$ & $5.22 \mathrm{E}+02$ & $1.21 \mathrm{E}+00$ & 523.35 & $-80.1 \%$ \\
\hline Pd105 & 94.62 & $3.31 \mathrm{E}+01$ & $3.37 \mathrm{E}+01$ & $3.17 \mathrm{E}+01$ & 65.41 & $-65.7 \%$ \\
\hline Pr141 & 1140.00 & $1.29 \mathrm{E}+03$ & $1.03 \mathrm{E}+03$ & $2.27 \mathrm{E}+02$ & 1261.28 & $2.4 \%$ \\
\hline Rb85 & 108.87 & $1.25 \mathrm{E}+02$ & $1.21 \mathrm{E}+02$ & $1.25 \mathrm{E}-01$ & 121.39 & $3.3 \%$ \\
\hline $\mathrm{Rb} 87$ & 108.87 & $1.77 \mathrm{E}+02$ & $1.71 \mathrm{E}+02$ & $1.39 \mathrm{E}+00$ & 172.34 & $2.8 \%$ \\
\hline Se82 & 15.96 & $(6.75 \mathrm{E}+00)$ & $<1.63 \mathrm{E}+02$ & $<1.50 \mathrm{E}+01$ & NA & NA \\
\hline Sr88 & 321.48 & $3.74 \mathrm{E}+02$ & $3.52 \mathrm{E}+02$ & $6.10 \mathrm{E}+00$ & 358.53 & $4.2 \%$ \\
\hline Y89 & 165.87 & $1.87 \mathrm{E}+02$ & $1.75 \mathrm{E}+02$ & $5.20 \mathrm{E}+00$ & 179.72 & $4.2 \%$ \\
\hline $\mathrm{Zr90}$ & 1096.11 & $1.31 \mathrm{E}+03$ & $1.25 \mathrm{E}+02$ & $6.10 \mathrm{E}+02$ & 735.29 & $56.1 \%$ \\
\hline Zr94 & 1096.11 & $1.58 \mathrm{E}+03$ & $3.85 \mathrm{E}+02$ & $4.01 \mathrm{E}+02$ & 786.10 & $66.9 \%$ \\
\hline \multicolumn{7}{|c|}{$\begin{array}{l}\text { Elements with several stable masses were measured by the ICP-MS and converted to total concentration of the element based on } \\
\text { natural abundances. NA = analyte not reported in raw data files because of instrument problems. Values in parentheses are } \\
\text { present above the detection limit but below the quantification limit. Entries with tan highlight are suspect because of low } \\
\text { concentrations near detection limits or large discrepancies between known masses added and masses measured in the metal } \\
\text { storage solution. }\end{array}$} \\
\hline
\end{tabular}

The ICP-MS results for simulation \#4 showed some discrepancy between the amount of ${ }^{237} \mathrm{~Np}$ that we thought was added to the metal storage solution and the measured quantity before performing the precipitation steps (highlighted number is amount of ${ }^{237} \mathrm{~Np}$ actually added; we should have added $884 \mu \mathrm{g}$. We believe that we inadvertently used a different stock ${ }^{237} \mathrm{~Np}$ solution to spike the fourth batch of metal storage solution than was used for the second and third simulations. Again, the year's delay between the first three simulations and the fourth may have resulted in choosing the wrong ${ }^{237} \mathrm{~Np}$ stock solution to spike the metal storage solution. We had been doing many experiments that utilized ${ }^{237} \mathrm{~Np}$ in the year's duration between the first three experiments and the fourth so that it was quite possible that the wrong stock vial was used and not noted. However, the three measured final solutions containing ${ }^{237} \mathrm{~Np}$ for simulation \#4 yield consistent results to the other simulations containing ${ }^{237} \mathrm{~Np}$ such that we believe we have identified why neptunium found in the fourth simulation does not agree with the original mass thought to be present. 
Table 3.14. Projected Disposal Facility Receiving Fission Products and Mass Balance for Simulation \#4

\begin{tabular}{||c|c|c|c||}
\hline Element & $\begin{array}{c}\text { To SST } \\
\text { Metals Waste }\end{array}$ & $\begin{array}{c}\text { To Cribs and Trenches } \\
\text { Solids (1st Cycle+2nd Cycle + etc) }\end{array}$ & $\begin{array}{c}\text { Error } \\
(+) \text { mass missing, (-) mass "created" }\end{array}$ \\
\hline \hline Tc99 & $97.32 \%$ & $0.004 \%$ & $2.68 \%$ \\
\hline U238 & $96.87 \%$ & $0.02 \%$ & $3.11 \%$ \\
\hline Np237 & $94.49 \%$ & $2.28 \%$ & $3.24 \%$ \\
\hline Ba137 & $89.97 \%$ & $3.28 \%$ & $6.75 \%$ \\
\hline Ba138 & $89.15 \%$ & $3.59 \%$ & $7.26 \%$ \\
\hline Ce140 & $83.36 \%$ & $14.92 \%$ & $1.72 \%$ \\
\hline Cs133 & $97.38 \%$ & $0.15 \%$ & $2.46 \%$ \\
\hline Eu151 & $83.20 \%$ & $16.21 \%$ & $0.59 \%$ \\
\hline Eu153 & $83.22 \%$ & $16.12 \%$ & $0.65 \%$ \\
\hline La139 & $89.94 \%$ & $8.25 \%$ & $1.82 \%$ \\
\hline Mo100 & NA & NA & NA \\
\hline Mo98 & $139.75 \%$ & $0.32 \%$ & $-40.07 \%$ \\
\hline Pd105 & $68.44 \%$ & $64.41 \%$ & $-32.85 \%$ \\
\hline Pr141 & $81.02 \%$ & $17.76 \%$ & $1.22 \%$ \\
\hline Rb85 & $98.26 \%$ & $0.10 \%$ & $1.64 \%$ \\
\hline Rb87 & $97.82 \%$ & $0.79 \%$ & $1.38 \%$ \\
\hline Se82 & NA & NA & NA \\
\hline Sr88 & $96.25 \%$ & $1.67 \%$ & $2.09 \%$ \\
\hline Y89 & $95.05 \%$ & $2.83 \%$ & $2.11 \%$ \\
\hline Zr90 & $12.25 \%$ & $59.72 \%$ & $28.03 \%$ \\
\hline Zr94 & $32.57 \%$ & $33.99 \%$ & $33.44 \%$ \\
\hline $\begin{array}{l}\text { Elements with several stable masses were measured by the ICP-MS and converted to total concentration of the element based on } \\
\text { natural abundances. Entries with tan highlight are suspect because of detection limit problems (Se) and large discrepancies } \\
\text { between known masses added to the metal storage solution and measured concentrations (Np, Mo, Pd), or matrix/instrument } \\
\text { problems (Mo). }\end{array}$ & & \\
\hline \hline
\end{tabular}

The total uranium in the fourth simulation metal storage, metal waste, and re-dissolved bismuth phosphate solid was determined by ICP-MS on highly diluted aliquots of the three solutions. The amount of uranium measured in the metal storage solution was somewhat larger than the amount added if one assumes the chemical used was uranyl nitrate hexahydrate. As will be discussed in Appendix A, x-ray diffraction of the original chemical reagent shows x-ray diffraction peaks for both uranyl nitrate hexahydrate and uranyl nitrate trihydrate. If all of the uranium nitrate reagent used to make up the metal storage solution had been the trihydrate, the total uranium mass in the metal storage solution aliquots used for each simulation $(57 \mathrm{~mL})$ would increase from $1.35 \mathrm{E}+07$ to $1.51 \mathrm{E}+07$ micrograms. The actual measured mass in the starting metal storage solution for simulation \#4 was $1.60 \mathrm{E}+07$ micrograms (see Table 3.13), suggesting that our analytical results are biased slightly positively. However, the final metal waste solution measurement also has about the same mass as the metal storage solution and the sum of the uranium mass in the metal waste and re-dissolved bismuth phosphate are quite close to the measured starting mass so we believe that our distribution of uranium between single-shell tanks and cribs/trenches is accurate.

The ICP-MS data for simulation \#4 was similar to the other three simulations in that selenium data were not usable because of detection limit problems, and the palladium data suggest loss of palladium before starting the bismuth phosphate precipitation steps. Different from the first three simulations' results, much more barium was observed in the starting metal storage solution than in the first three 
simulations, the molybdenum data for simulation \#4 were more variable than for the other simulations (however mass 95 was not reported for simulation \#4 and was the best isotope for quantifying Mo in the other three simulations) and the zirconium data do not show significant loss of zirconium before starting the bismuth phosphate precipitation steps. Both simulations \#2 and \#3 suggest loss of zirconium before starting the bismuth phosphate precipitation but simulations \#1 and \#4 show that most of the zirconium was present in the measured metal storage solution. We do not have an explanation for this erratic behavior for zirconium, especially since the metal storage solution was prepared once and kept stored between each simulation, when $\sim 57 \mathrm{~mL}$ was sub-sampled and used for each test.

\subsubsection{Compilation of the Data from all Four Simulations}

Performing the bismuth phosphate process four times allowed us to improve our ICP-MS techniques, especially after the first simulation, such that for some fission products a fairly clear and likely accurate picture was obtained for determining the distributions for each fission product to each waste stream. For a few of the fission products, the distributions to waste streams and overall mass balance varied significantly from simulation to simulation and the average of all four simulations was quite variable. High variability in results amongst the four simulations suggests that caution is warranted for predicting the fate of certain elements. Table 3.15 is a summarization of all four simulations with the radiocounting data separated from the ICP-MS data. In general, we put more trust in the accuracy of the radiocounting data in situations where there is significant difference between the two measurement techniques. We favor the radiocounting data because there is less chance for matrix interferences (such as mass interferences due to complex molecular species that can form in the plasma of the ICP) and the generally more precise counting statistics for gamma counting. The values in Table 3.15 represent averages and one standard deviation for the four bismuth phosphate simulations. The data are presented in an order that bunches together elements with similar aqueous speciation in strong acid solutions, which is the environment throughout the bismuth phosphate process. Table 3.15 starts with technetium, the key element of interest to Hanford's risk assessment, then lists data for other anionic species followed by cation species from monovalent to quadravalent. We are not sure what the speciation would be for some of the elements (Mo, Ru, and Pd) in a strong acid that may be slightly reducing in redox state because of the addition of nitrite to drive the plutonium to the (IV) oxidation state. We guesstimate the valence state for these three elements based on how they distributed between the supernate (metal waste solution) and bismuth phosphate precipitate.

Based on the data in Table 3.15, we conclude that much more than the previously assumed $90 \%$ and perhaps up to $99.9 \%$ of the ${ }^{99} \mathrm{Tc},{ }^{129} \mathrm{I}$, and ${ }^{106} \mathrm{Ru}$ and $\sim 98 \%$ of the ${ }^{90} \mathrm{Sr},{ }^{137} \mathrm{Cs}$, and ${ }^{125} \mathrm{Sb}$ fission products would remain in the metal waste solution that was disposed to single-shell tanks. It is possible that our laboratory lab-scale tests allowed for better separations of the two waste streams than 1940s to 1950s vintage large-scale plant separations, but the basic chemistry inherent to the bismuth phosphate precipitation process was the same. As mentioned previously, one reviewer pointed out two differences between our tests and the actual bismuth phosphate processing, the use of distilled water instead of Columbia River water and the use of reagent-grade phosphoric acid versus 1940s vintage commercialgrade phosphoric acid. The key concern is that our solutions likely contained less calcium than the actual solutions present in the actual bismuth phosphate processing. Some calcium and ${ }^{90} \mathrm{Sr}$ could have coprecipitated with the bismuth phosphate solid used to capture the plutonium. Thus we may underestimate the fraction of ${ }^{90} \mathrm{Sr}$ that ended up going to cribs and trenches after the plutonium product was purified. 
Table 3.15. Summary Findings on the Fate of Fission Products

\begin{tabular}{|c|c|c|c|c|c|}
\hline $\begin{array}{c}\text { Likely } \\
\text { Dominant } \\
\text { Speciation }\end{array}$ & & $\begin{array}{c}\% \text { to SST } \\
\text { Metals } \\
\text { Waste }\end{array}$ & $\begin{array}{c}\% \text { to } \\
\text { Cribs/Trenches } \\
\text { Extraction } \\
\text { Product }\end{array}$ & $\begin{array}{c}\text { \% Material } \\
\text { Unaccounted For } \\
(+) \text { mass missing, } \\
\text { (-) mass "created" }\end{array}$ & Comments \\
\hline \multirow[t]{2}{*}{$\mathrm{TcO}_{4}^{-}$} & Tc-99 (ICP-MS) & $97.8 \pm 4.42$ & $1.02 \pm 1.17$ & $1.34 \pm 3.75$ & \multirow{2}{*}{$\begin{array}{l}<1 \% \text { in } \mathrm{BiPO}_{4} \text { precipitate; quality very good; ICP-MS consistently }>97 \% \text { in } \\
\text { metal waste;very good agreement between two measurement methods }\end{array}$} \\
\hline & (tracer) & $100.7 \pm 2.22$ & $0.06 \pm 0.01$ & $-0.72 \pm 2.22$ & \\
\hline $\mathrm{I}^{-}$ & I-125 (I-129) tracer & 100 & $<0.65$ & -0.6 & $<1 \%$ in $\mathrm{BiPO}_{4}$ precipitate; quality very good; but only one data set \\
\hline \multirow[t]{2}{*}{$\mathrm{SeO}_{4}{ }^{2-}$} & Se (ICP-MS) & NA & NA & NA & \multirow{2}{*}{$\begin{array}{l}\text { ICP-MS not useable (poor sensitivity); radiocounting data suggests } 11 \% \text { in } \\
\mathrm{BiPO}_{4} \text { precipitate maybe subs for phosphate }\end{array}$} \\
\hline & tracer & $88.6 \pm 5.3$ & $10.6 \pm 0.10$ & $0.87 \pm 5.2$ & \\
\hline $\mathrm{MoO}_{4}^{2-}(?)$ & Mo (ICP-MS) & $89.4 \pm 6.6$ & $0.2 \pm 0.1$ & $10.4 \pm 6.7$ & $\leq 0.2 \%$ in $\mathrm{BiPO}_{4}$ precipitate; quality is good \\
\hline $\mathrm{RuO}_{4}{ }^{2-}(?)$ & $\mathrm{Ru}$ (ICP-MS) & $97.4 \pm 0.6$ & $0.04 \pm 0.03$ & $2.6 \pm 0.6$ & $\leq 1 \%$ in $\mathrm{BiPO}_{4}$ precipitate; quality good; only one test performed \\
\hline $\mathrm{SbO}_{4}^{3-}$ & $\mathrm{Sb}$ (tracer) & $99.41 \pm 3.78$ & $1.32 \pm 0.02$ & $-0.73 \pm 3.8$ & $1 \%$ in $\mathrm{BiPO}_{4}$ precipitate; Quality very good; only one data set \\
\hline $\mathrm{UO}_{2}{ }^{2+}$ & U-238 (ICP-MS) & 96.87 & 0.02 & 3.11 & $<1 \%$ in $\mathrm{BiPO}_{4}$ precipitate; Quality very good; only one data set \\
\hline \multirow[t]{2}{*}{$\mathrm{NpO}_{2}^{+}$} & Np-237 (ICP-MS) & $89.5 \pm 6.5$ & $1.6 \pm 0.8$ & $8.8 \pm 6.9$ & \multirow{2}{*}{$\begin{array}{l}\text { ICP-MS data is better: agreement between two measurement methods fair; < } \\
5 \% \text { in } \mathrm{BiPO}_{4} \text { precipitate }\end{array}$} \\
\hline & (rad) & 99.2 & 6.9 & -6.9 & \\
\hline \multirow[t]{2}{*}{$\mathrm{Cs}^{+}$} & Cs (ICP-MS) & $94.5 \pm 6.2$ & $0.1 \pm 0.05$ & $5.4 \pm 6.2$ & \multirow{2}{*}{$\begin{array}{l}\leq 1 \% \text { in BiPO4 precipitate; quality very good; counting and ICP-MS agreement } \\
\text { is excellent }\end{array}$} \\
\hline & tracer & $97.5 \pm 3.1$ & $<1.3 \pm 0.03$ & $1.6 \pm 2.5$ & \\
\hline $\mathrm{Rb}^{+}$ & $\mathrm{Rb}$ (ICP-MS) & $92.0 \pm 12.2$ & $0.3 \pm 0.3$ & $7.7 \pm 12.3$ & $\leq 0.5 \%$ in $\mathrm{BiPO}_{4}$ precipitate; quality very good; agrees with $\mathrm{Cs}$ \\
\hline \multirow[t]{2}{*}{$\mathrm{Sr}^{2+}$} & Sr (ICP-MS) & $89.6 \pm 7.5$ & $1.2 \pm 0.3$ & $9.3 \pm 7.7$ & \multirow{2}{*}{$\begin{array}{l}<2 \% \text { in } \mathrm{BiPO}_{4} \text { precipitate, Quality excellent; good agreement between } \\
\text { radiocounting and ICP-MS }\end{array}$} \\
\hline & tracer & $93.6 \pm 4.7$ & $<2.0 \pm 0.05$ & $4.4 \pm 4.6$ & \\
\hline $\mathrm{Ba}^{2+}$ & $\mathrm{Ba}$ (ICP-MS) & $98.4 \pm 53.6$ & $18.0 \pm 15.83$ & $-16.4 \pm 59.5$ & $\begin{array}{l}\text { Inconsistent ICP-MS results; most suggest loss of Ba from metal storage } \\
\text { solution before testing }\end{array}$ \\
\hline $\mathrm{Pd}^{2+}(?)$ & Pd (ICP-MS) & $96.4 \pm 50.2$ & $15.6 \pm 23.9$ & $-12 \pm 45.6$ & $\begin{array}{l}\text { Quality poor; all simulations suggest loss of Pd from metal storage solution } \\
\text { before testing }\end{array}$ \\
\hline $\mathrm{La}^{3+}$ & La (ICP-MS) & $88.1 \pm 6.8$ & $7.4 \pm 2.1$ & $4.5 \pm 7.1$ & $\sim 10 \%$ in $\mathrm{BiPO}_{4}$ precipitate; all Lanthanides similar; Data Quality very good \\
\hline $\mathrm{Ce}^{3+}$ & Ce (ICP-MS) & $76.9 \pm 11.0$ & $16.2 \pm 5.7$ & $6.9 \pm 9.0$ & $\sim 15 \%$ in $\mathrm{BiPO}_{4}$ precipitate; all Lanthanides similar; Data Quality very good \\
\hline $\operatorname{Pr}^{3+}$ & $\operatorname{Pr}(\mathrm{ICP}-\mathrm{MS})$ & $75.2 \pm 12.4$ & $19.2 \pm 6.9$ & $5.7 \pm 9.6$ & $\sim 20 \%$ in $\mathrm{BiPO}_{4}$ precipitate; all Lanthanides similar; Data Quality good \\
\hline \multirow[t]{2}{*}{$\mathrm{Eu}^{3+}$} & Eu (ICP-MS) & $84.4 \pm 8.5$ & $14.1 \pm 3.1$ & $1.5 \pm 8.7$ & \multirow{2}{*}{$\begin{array}{l}15 \text { to } 20 \% \text { in } \mathrm{BiPO}_{4} \text { precipitate; all Lanthanides similar; Data Quality good; } \\
\text { adequate agreement between ICP-MS and radiocounting }\end{array}$} \\
\hline & (tracer) & 74.1 & 22.5 & 3.4 & \\
\hline $\mathrm{Y}^{3+}$ & Y (ICP-MS) & $91.0 \pm 6.6$ & $3.2 \pm 1.1$ & $5.8 \pm 6.5$ & Quality very good; $\sim 3 \%$ in $\mathrm{BiPO}_{4}$ precipitate \\
\hline $\mathrm{Zr}^{+4}$ & $\mathrm{Zr}$ (ICP-MS) & $56.0 \pm 42.5$ & $37.3 \pm 22.5$ & $6.6 \pm 58.3$ & $\begin{array}{l}\text { ICP-MS data inconsistent; two simulations suggest } \mathrm{Zr} \text { precipitated in metal } \\
\text { storage solution with time; significant amount in } \mathrm{BiPO}_{4} \text { precipitate }\end{array}$ \\
\hline
\end{tabular}


Excepting the concern over the fate of ${ }^{90} \mathrm{Sr}$, we believe that the results of this work, to simulate the bismuth phosphate process used in the early days to separate plutonium from irradiated fuel, are a good measure of the distribution of fission products between the two major waste streams disposed originally to the two different disposal facilities; single-shell tanks and cribs/trenches. For instance, we know from actual process records found in declassified reports and memos (see http://www2.hanford.gov/declass; in particular a 1945 memo titled "Decontamination of Fission Elements in the Separation Process" from J. A. Swartout dated January 22,1945 ) that about $1.6 \%$ of the iodine and $25 \%$ up to $65 \%$ of the Ba, La, and $\mathrm{Zr}$ were carried or entrained with the $\mathrm{BiPO}_{4}$-bearing solids. These records are in relative agreement with our estimates, which indicate $<0.65 \%$ of the iodide and $20 \%$ to $40 \%$ of the $\mathrm{Ba}$, La, and $\mathrm{Zr}$ were found with the $\mathrm{BiPO}_{4}$ solids.

Our findings should be considered as an improvement to the previously used assumption that $10 \%$ of every beta-emitting fission product partitions to the bismuth phosphate solids after the first precipitation step. This original assumption that $10 \%$ of all fission isotopes carried down with the bismuth phosphate precipitation is an erroneous interpretation of a statement in the $\mathrm{BiPO}_{4}$ Technical Manual, which stated that $10 \%$ of the total beta activity in the dissolved irradiated fuel was retained in the bismuth phosphate precipitate. It is not realistic to assume that $10 \%$ of each beta-emitting isotope would be in the bismuth phosphate precipitation product since the chemical properties of each fission product can vary significantly from each other. The original assumption that $10 \%$ of each fission isotope precipitated with the plutonium product results in projections that significantly overestimate the quantity of some key betaemitting radioisotopes disposed to cribs and trenches.

Based on the results shown in Table 3.15, the main sources of beta activity in the bismuth phosphate precipitate-derived wastes that remain today are stable and long-lived isotopes of the lanthanides $\left({ }^{145} \mathrm{Pm}\right.$, $\left.{ }^{151} \mathrm{Sm},{ }^{152} \mathrm{Eu},{ }^{154} \mathrm{Eu},{ }^{155} \mathrm{Eu}\right), \mathrm{Nb}$ and $\mathrm{Zr}$ long-lived isotopes $\left({ }^{93 \mathrm{~m}} \mathrm{Nb},{ }^{93} \mathrm{Zr}\right)$, barium, palladium and to lesser extents ${ }^{90} \mathrm{Sr}$ and its daughter ${ }^{90} \mathrm{Y},{ }^{137} \mathrm{Cs}$, and ${ }^{79} \mathrm{Se}$. (At the time of discharge from the B- and T-Plants, the mix of radionuclides was appreciably different than today given all the short-lived isotopes that have completely decayed). We suspect that some ${ }^{79} \mathrm{Se}$ co-precipitated with the bismuth phosphate precipitate because the chemistry of the selenate anion is similar to phosphate. It does not appear that the oxyanion pertechnetate $\left({ }^{99} \mathrm{TcO}_{4}{ }^{-}\right)$, partitions like the phosphate or selenate. Because the mobility and associated risk of ${ }^{79} \mathrm{Se}$ are not well established, if there was a convenient radioanalytical or ICP-MS method for determining ${ }^{79} \mathrm{Se}$, it would be useful to look for ${ }^{79} \mathrm{Se}$ in contaminated sediments below crib and trench disposal facilities that received the $1^{\text {st }}$ and $2^{\text {nd }}$ Cycle waste streams from the purification of the bismuth phosphate product and in contaminated groundwater below such facilities. Unfortunately, ${ }^{79} \mathrm{Se}$ is a low energy beta emitter that is difficult to separate from other common beta emitters such that it can be easily measured by radiocounting. Also natural bromine at mass 79 makes the use of ICP-MS challenging. However, if separation techniques or improved ICP-MS methods are developed, such as using reactive gases to form compounds with $\mathrm{Br}$ or Se that move the measured mass to a unique position in the mass spectra, such measurements should be considered.

\subsubsection{Mass Balance for Major Constituents in Bismuth Phosphate Process}

The starting metal storage solution, metal waste solution, and bismuth phosphate precipitate (after dissolution in nitric acid) from the fourth simulation were analyzed by both ICP-OES and ICP-MS. This information was used to estimate the composition of the solid precipitate and to check the mass balance of some of the major constituents in the bismuth phosphate process. The bismuth phosphate solid (product) 
was dissolved while still in the wet state after several washings in distilled water and, along with the analyses of the metal waste solution, allows us to calculate a mass balance for the major constituents uranium, bismuth, phosphate, and sulfate. Because the bismuth phosphate solid was re-dissolved in nitric acid, no mass balance can be calculated for the nitrate or nitrite present in the original metal solution (see Table 2.1) and in the chemicals used to form the precipitate (see Bismuth Phosphate Precipitation, Section 2.2.1). The mass balance calculations for the macro constituents are shown in Table 3.16.

The calculations in Table 3.16 show very good mass balance for uranium, phosphate, sulfate, and sodium but we appear to have somewhat low recovery of bismuth. All in all though, based on the data presented in Table 3.1, Table 3.5, Table 3.9, Table 3.13 and Table 3.16, the recoveries suggest that the ICP-MS and ICP-OES analyses of the concentrated metal storage solution, metal waste solution, and re-dissolved bismuth phosphate solid are very good for most of the key risk-driving fission products and major constituents used in the bismuth phosphate process.

\subsection{Results: Metal Waste Solution Neutralization}

This section discusses the findings for the neutralization of the metal waste solution generated by the first bismuth phosphate precipitation step to obtain plutonium. It is the neutralized metal waste solution and its suspended solids that were disposed in the single-shell tanks. This neutralized metal waste was the fluid lost in the 1951 overfill event at BX-102, which has been under study for many years (see Serne et al. $2002 \mathrm{~b}$ and Knepp $2002 \mathrm{~b}$ for details on the overfill event and the fate of contaminants therein).

Table 3.16. Mass Balance of Macro Constituents in Simulation \#4 (units are grams)

\begin{tabular}{|c|c|c|c|c|c|c|c|c|}
\hline Constituent & $\begin{array}{l}\text { Metal } \\
\text { Storage } \\
\text { "added" }\end{array}$ & measured & Agreement & $\begin{array}{c}\text { Metal Storage } \\
+ \text { Chemicals } \\
\text { for } \\
\text { Precipitation } \\
\text { "added" }\end{array}$ & $\begin{array}{c}\text { Metal Waste } \\
\text { Solution } \\
\text { measured }\end{array}$ & $\mid \begin{array}{c}\text { Dissolved } \\
\text { Solid } \\
\text { measured }\end{array}$ & \begin{tabular}{|c|} 
Sum of \\
Measured \\
Metal \\
Waste+BiPO \\
Solids \\
measured
\end{tabular} & Agreement \\
\hline uranium & 15.10 & 16.00 & $\begin{array}{l}5.77 \% \\
\end{array}$ & 15.10 & 15.028 & 0.003 & 15.03 & $-0.48 \%$ \\
\hline nitrate & 8.77 & NA & NA & 9.65 & NA & NA & NA & NA \\
\hline sulfate & 4.14 & 4.73 & $13.27 \%$ & 4.14 & 4.60 & 0.01 & 4.61 & $10.71 \%$ \\
\hline phosphate & 0 & $\overline{<}$ & $\overline{\mathrm{OK}}$ & 8.82 & 7.85 & 0.21 & 8.06 & $-9.08 \%$ \\
\hline bismuth & 0 & $<$ & OK & 0.64 & 0.03 & 0.45 & 0.48 & $-27.54 \%$ \\
\hline sodium & 0 & $\overline{<}$ & $\overline{\mathrm{OK}}$ & 0.21 & 0.19 & 0.00 & 0.19 & $-9.53 \%$ \\
\hline nitrite & 0 & NA & OK & 0.43 & NA & NA & NA & NA \\
\hline
\end{tabular}

\subsubsection{Discussion of the Neutralized Metal Waste Macro Chemistry}

The metal waste solution that is generated after the first bismuth phosphate precipitation step in the process used to separate plutonium from the irradiated fuel contains most of the fission products and uranium. This highly radioactive acidic solution was transferred to large tanks in the bismuth phosphate plants (B and T plants) where neutralization was performed using sodium hydroxide followed by sodium carbonate (soda ash). The neutralized metal waste was then transferred to single-shell tanks, generally in a cascade fashion (as the first tank was filled, suspended solids would settle and the supernatant solution 
would cascade to a second tank and then a third tank at the selected tank farm). Details on the neutralization process are found in Section 2.3.

The metal waste solution from all four bismuth phosphate simulations was neutralized but only the solids and resultant neutralized solution from simulations \#2 and \#4 were characterized. The metal waste solutions from the simulations were neutralized individually as shown in Table 3.17. Potassium hydroxide solution was inadvertently used instead of sodium hydroxide for the first step of the neutralization process for the first three metal waste solutions. The metal waste solution from the fourth simulation, which was performed about a year after the first three simulations, was correctly neutralized using sodium hydroxide. The correct amount of sodium carbonate, as the second step of the neutralization, was used for all four of the neutralization simulations. The details on amount of neutralizing agents used for all four simulations are also shown in Table 3.17.

The neutralized solutions were allowed to settle for several days, then they were centrifuged so that the clear supernatant solution could be decanted. The supernatant solution was then further filtered through $0.45-\mu \mathrm{m}$ filter membranes and saved for characterization or future use in sediment adsorption studies. The macro chemical composition of the neutralized metal waste supernatant from batches \#2 and \#4 are shown in Table 3.18. The cations were measured by ICP-OES and the anions were measured by IC. Total alkalinity and total inorganic carbon were also measured because we were not confident that the IC was correctly quantifying carbonate in this complicated matrix. The $\mathrm{pH}$ of the neutralized supernatant solution was measured with a solid-state $\mathrm{pH}$ electrode.

The macro chemistry of the neutralized metal waste solution contains high dissolved sodium (and potassium because of the inadvertent use of $\mathrm{KOH}$ in runs \#1 through \#3) from the neutralization process and high concentrations of nitrate, sulfate, and uranium from the starting metal storage solution (the dissolved fuel rods) and phosphate from the bismuth phosphate precipitation step. The neutralized solution also contains significant dissolved carbonate from the soda ash used to keep uranium soluble during the neutralization process. The cation-anion balance for the two neutralized solutions is acceptable but not precise; analyzing such a complex and highly concentrated solution is challenging. For neutralized solution \#2 there was a large difference between the total anions charge between the IC value for carbonate and both the alkalinity and total carbon analyzer data; we thus ignored the IC carbonate data. The electrical charge balance for the supernatant solution from neutralization of the metal waste solution from simulation $\# 2$ was $-16 \%$, where the negative value represents an excess in anions. For neutralized solution \#4, the various analyses of anions, especially carbonate using different techniques show fairly good agreement; however, the charge balance shows a significant excess of anions (-24\% meaning an excess of anions). The charge balance wherein we average the total anion charge measured by different instrumentation is shown in Table 3.19. The determination of soluble inorganic carbon was most problematical in these solutions, especially neutralized metal waste solution \#2. We do not have an explanation for why the data for the neutralized solutions \#2 and \#4 show such a large discrepancy in charge balance.

As shown in Table 3.17, the volumes of neutralized solution varied significantly between the two runs and thus the final concentrations varied as shown in Table 3.18, with run \#4 being significantly more concentrated in dissolved solids. We believe the large differences in final volumes and concentrations reflect varying degrees of evaporation of water during the neutralization process, which occurred in open 
Table 3.17. Volumes of Solutions Used for Metals Waste Neutralization

\begin{tabular}{|c|c|c|c|c|}
\hline & Sim \#1 & Sim \#2 & Sim \#3 & Sim \#4 \\
\hline "Date BiPO4 Precipitation Performed & 4/3/2002 & 4/17/2002 & 6/26/2002 & 5/19/2003 \\
\hline Date Metal Waste was Neutralized & $5 / 13 / 2002$ & $6 / 12 / 2002$ & $7 / 2 / 2002$ & $5 / 21 / 2003$ \\
\hline Solution & \multicolumn{4}{|c|}{$\mathrm{mL}$ of solution used } \\
\hline Starting Metals Waste & 45.49 & 90.17 & 67.5 & 65.3 \\
\hline $50 \% \mathrm{KOH}$ & 7.58 & 15 & 11 & -- \\
\hline $50 \% \mathrm{NaOH}$ & -- & -- & -- & 10.8 \\
\hline $30 \% \mathrm{Na}_{2} \mathrm{CO}_{3}$ & 29.7 & 60 & 44 & 42.6 \\
\hline Final Neutralized Supernate $(\mathrm{mL})$ & ND & 209.7 & ND & 104.19 \\
\hline Final Neutralized Solids (g dry weight) & ND & 18.86 & ND & 20.24 \\
\hline Final Neutralized Solids (\% wt) & ND & $13.49 \%$ & ND & $7.16 \%$ \\
\hline Final Neutralized Liquids (\%wt) & ND & $86.51 \%$ & ND & $92.84 \%$ \\
\hline
\end{tabular}

Table 3.18. Macro Chemical Composition of the Supernatant Solution from the Metals Waste Neutralization Process

\begin{tabular}{|c|c|c|c|c|c|}
\hline Analyte: ICP & $\begin{array}{c}\begin{array}{c}\text { Neut Run \#2 } \\
(\mathrm{mg} / \mathrm{L})\end{array} \\
\end{array}$ & $\begin{array}{c}\begin{array}{c}\text { Neut Run \#4 } \\
(\mathrm{mg} / \mathrm{L})\end{array} \\
\end{array}$ & Analyte:IC & $\begin{array}{c}\text { Neut Run } \\
\# 2 \\
\end{array}$ & $\begin{array}{c}\text { Neut Run } \\
\# 4 \\
\end{array}$ \\
\hline $\mathrm{Al}$ & $(3.06)$ & $<5$ & $\mathrm{Cl}^{-}$ & 63.51 & ND \\
\hline As & $(1.49)$ & $(8)$ & $\mathrm{NO}_{2}{ }^{-}$ & ND & 69.8 \\
\hline $\mathrm{B}$ & $(13.24)$ & 412 & $\mathrm{NO}_{3}^{-}$ & 42,041 & 94,850 \\
\hline $\mathrm{Ba}$ & $<0.3$ & 1 & $\mathrm{SO}_{4}^{2-}$ & 22,243 & 51,120 \\
\hline $\mathrm{Be}$ & $<0.5$ & $<0.5$ & $\mathrm{PO}_{4}^{3-}$ & 24,030 & 43,160 \\
\hline $\mathrm{Bi}$ & $<5$ & $<5$ & $\mathrm{CO}_{3}{ }^{2-}$ & 1433 & 42,520 \\
\hline $\mathrm{Ca}$ & $(11.21)$ & $(14)$ & Analyte:titration & & \\
\hline $\mathrm{Cd}$ & $<0.3$ & $(0)$ & Alkalinity (as $\mathrm{CO}_{3}{ }^{2-}$ ) & 32,860 & NA \\
\hline $\mathrm{Co}$ & 11.71 & 5 & Analyte: Carbon & & \\
\hline $\mathrm{Cr}$ & $<0.6$ & $<0.6$ & $\mathrm{TIC}\left(\right.$ as $\left.\mathrm{CO}_{3}{ }^{2-}\right)$ & 33,300 & 38,640 \\
\hline $\mathrm{Cu}$ & $<2.5$ & $<2.5$ & & & \\
\hline $\mathrm{Fe}$ & $(3.25)$ & $(5)$ & $\mathrm{pH}$ & 10.5 & 9.7 \\
\hline $\mathrm{K}$ & 21,381 & $(35)$ & & & \\
\hline $\mathrm{Li}$ & $(29)$ & (4) & & & \\
\hline $\mathrm{Mg}$ & $<1$ & $(0)$ & & & \\
\hline $\mathrm{Mn}$ & 3.41 & 4 & & & \\
\hline Mo & 13.17 & (17) & & & \\
\hline $\mathrm{Ni}$ & $(2.94)$ & (9) & & & \\
\hline $\mathrm{P}\left(\right.$ as $\left.\mathrm{PO}_{4}\right)$ & 21,971 & 38,063 & & & \\
\hline $\mathrm{Pb}$ & $(17.66)$ & 18 & & & \\
\hline $\mathrm{Sr}$ & $(1.16)$ & 1 & & & \\
\hline $\mathrm{Tl}$ & $(0.99)$ & $<1$ & & & \\
\hline $\mathrm{V}$ & $<50$ & $<50$ & & & \\
\hline $\mathrm{Zn}$ & $(1.25)$ & (2) & & & \\
\hline $\mathrm{Na}$ & 39,482 & 88,402 & & & \\
\hline $\mathrm{Si}$ & $<500$ & $(356)$ & & & \\
\hline $\mathrm{S}\left(\right.$ as $\left.\mathrm{SO}_{4}\right)$ & 21,642 & 48,019 & & & \\
\hline $\mathrm{Ti}$ & $(10.38)$ & (1) & & & \\
\hline $\mathrm{Zr}$ & $<1.3$ & $<1.3$ & & & \\
\hline $\mathrm{U}$ & 26,130 & 28,575 & & & \\
\hline \multicolumn{6}{|c|}{$\begin{array}{l}\text { ICP analytes in red type were not added to starting metal storage solution or during various processes. Their presence is likely } \\
\text { either contamination in reagents or spurious spectral interference signal cause by high U concentration. } \\
\text { ND = not detected in IC chromatogram } \\
\mathrm{NA}=\text { not analyzed for this sample }\end{array}$} \\
\hline
\end{tabular}


Table 3.19. Charge Balance for the Neutralized Supernatant Solution

\begin{tabular}{|c|c|c|}
\hline & Neut Liquid Run $\# 2$ meq/L & Neut Liquid Run \#4 meq/L \\
\hline \multicolumn{3}{|l|}{ cations } \\
\hline K & 546.82 & 0.90 \\
\hline $\mathrm{Na}$ & 1716.59 & 3843.56 \\
\hline $\mathrm{Ca}$ & 0.56 & 0.72 \\
\hline $\mathrm{U}\left(\right.$ as $\left.\mathrm{UO}_{2}{ }^{2+}\right)$ & 219.58 & 240.13 \\
\hline Tot Cations & 2483.55 & 4085.32 \\
\hline \multicolumn{3}{|l|}{ anions } \\
\hline $\mathrm{Cl}^{-}$ & 1.79 & ND \\
\hline $\mathrm{NO}_{2}^{-}$ & ND & 1.52 \\
\hline $\mathrm{NO}_{3}^{-}$ & 678.08 & 1529.84 \\
\hline $\mathrm{SO}_{4}{ }^{2-}(\mathrm{IC})$ & 463.40 & 1065.00 \\
\hline $\mathrm{SO}_{4}^{2-}$ (ICP) & 450.87 & 1000.41 \\
\hline $\mathrm{PO}_{4}^{3-}(\mathrm{IC})$ & 758.84 & 1362.95 \\
\hline $\mathrm{PO}_{4}^{3-}(\mathrm{ICP})$ & 694.39 & 1203.01 \\
\hline $\mathrm{CO}_{3}{ }^{2-}(\mathrm{IC})$ & 47.77 & 1417.33 \\
\hline $\mathrm{CO}_{3}{ }^{2-}(\mathrm{Alk} / \mathrm{TIC})$ & 1103 & 1288.00 \\
\hline Tot Anions (IC) & 1949.88 & 5376.64 \\
\hline Tot Anions (ICP) & 2928 & 5022.78 \\
\hline Charge Balance & $-16 \%$ & $-24 \%$ \\
\hline
\end{tabular}

containers in a negative pressure fume hood. On an absolute mass basis, the amount of nitrate, phosphate, sulfate, sodium (potassium), and carbonate in solution for the two supernatant solutions is quite similar; thus, it appears that evaporation of water is the cause of the differences in concentrations. It should be noted that the concentration of dissolved uranium does not vary dramatically between the two neutralized solutions, suggesting that a solubility limit may have been controlling the dissolved uranium concentration. In both solutions, the final concentration of dissolved phosphate is above $0.6 \mathrm{M}$, which is the minimum concentration of phosphate that the developers of the bismuth phosphate process suggested was needed to be present to keep high percentages of uranium from precipitating during the neutralization step.

\subsubsection{Fate of Radioactive Tracers and Trace Fission Products During Metal Waste Neutralization}

The chemical composition of the trace fission products in supernatant solution remaining after neutralization of the metal waste for simulation \#2 and \#4, obtained by centrifugation and removal of the precipitated solids, were determined by ICP-MS and gamma energy analysis (for added radiotracers).

These data were combined with the data from measuring the metal storage solution, metal waste solution, and re-dissolved "plutonium" product (bismuth phosphate precipitate) to allow us to estimate the fate of each fission product in the original fuel. Tables 3.20 through 3.23 show the fate of the constituents that were measured either by gamma energy analysis (radiotracers added to $\# 2$ were ${ }^{152} \mathrm{Eu},{ }^{75} \mathrm{Se},{ }^{137} \mathrm{Cs}$, ${ }^{85} \mathrm{Sr}$, and ${ }^{125} \mathrm{I}$ and to $\# 4$ were ${ }^{75} \mathrm{Se},{ }^{85} \mathrm{Sr},{ }^{95 \mathrm{~m}} \mathrm{Tc},{ }^{125} \mathrm{Sb}$, and ${ }^{137} \mathrm{Cs}$ ), ICP (macro constituents), or ICP-MS (stable fission products). Tables 3.20 and 3.21 show the distribution (percentages) of each element in the various bismuth phosphate process streams and their fate during the metal waste neutralization process. Tables 3.22 and 3.23 track, from the dissolved irradiated fuel through the metal waste neutralization step, 
the distribution of key fission products, uranium, and a few other major components present in the bismuth phosphate process. Emphasis was placed on determining the tendency for the constituent to partition to one of the two solids formed in these tests, the bismuth phosphate product and the precipitates that form upon neutralization of the metal waste solution. We did not measure the composition of the precipitates that form upon neutralization of the metal waste solution, excepting uranium in simulation \#2. We have assumed that a reasonable estimate of the composition of the precipitates is to subtract the masses of each constituent found in the neutralized supernatant solution from the starting masses in the metal waste solution. Thus the values in the "neutralized solids" column in Tables 3.22 and 3.23 are not measured values, excepting the uranium value in Table 3.22. The data for iodide only reflects iodine species that do not volatilize during the fuel decladding and fuel dissolution stages. As discussed previously $\sim 85 \%$ of the iodine escaped during these steps and thus was not present in the acidic metal storage solution used in the bismuth phosphate process.

The fate of key fission products present in the metal waste solution during neutralization are as follows. We have three measurements of the distribution of technetium in Table 3.23. There is some variability but in general greater than $99 \%$ of the technetium remains in solution and is ultimately found in the neutralized metal waste solution that was sent to the single-shell tanks. The technetium essentially remains in the dissolved state throughout the whole bismuth phosphate process from fuel dissolution through metal waste solution neutralization. The available data (three measurements) suggest $88 \%$ to $107 \%$ of the technetium in dissolved irradiated fuel remains in solution and would have been disposed in the single-shell tanks. At most, a few tenths of a percent of the technetium is found in the bismuth phosphate product solids and at most $<2 \%$ of the technetium is found in the precipitates that form during the metal waste neutralization process. Recall that the neutralized metal waste precipitates also were sent to the single-shell tanks suspended in the neutralized supernatant solution.

The uranium mass balance throughout the whole bismuth phosphate simulation was fairly consistent with $20 \%$ to $40 \%$ of the uranium found in the metal waste solution remaining in the supernatant solution after neutralization. For the original metal storage solution (dissolved fuel), 19\% to $37 \%$ of the uranium remains in the neutralized metal waste supernatant solution. Much $(75 \%)$ of the uranium initially present in the dissolved fuel ends up precipitated in the solids formed by neutralization of the metal waste solution as will be discussed in Section 3.2.3. Based on Table 3.15 results, $0 \%$ to at most 3\% (if we assume the uncertainty in our mass balance is dominated by the plutonium solid precipitate) of the uranium appears to precipitate with the plutonium product. Because very little of the uranium associates with the bismuth phosphate product, almost all ended up in the single-shell tanks with much of it in the neutralized metal waste precipitates. However, this leaves substantial concentrations of uranium remaining in solution (see Table 3.18).

The fate of other potentially mobile fission and activation products such as ${ }^{79} \mathrm{Se},{ }^{125} \mathrm{Sb},{ }^{237} \mathrm{~Np}$, and ${ }^{90} \mathrm{Sr}$ as determined from the two neutralization simulations yielded somewhat variable results. Selenium showed highly variable partitioning between the neutralized metal waste supernatant solution and neutralized metal waste precipitates in simulations \#2 and \#4. In simulation \#2, 80\% of the selenium precipitated with the solids formed, but in simulation \#4 none precipitated. We suspect some analytical measurement problems occurred in our tests. Regardless, the fate of selenium, as shown in Table 3.15, has $\sim 90 \%$ ending up in single-shell tanks in either the suspended solids or dissolved state. Upon neutralization of the metal waste, which contains more than $99 \%$ of the antimony present in dissolved irradiated fuel, antimony partitions nearly equally between the neutralized metal waste supernatant solution and the neutralized metal waste precipitate (55\% remaining dissolved and $45 \%$ precipitating). 
Neptunium's fate during neutralization of metal waste is also variable. In simulation \#2, about two-thirds of the neptunium present in the metal waste solution precipitates during the neutralization step whereas in simulation $\# 4$ about $85 \%$ precipitates during the neutralization step. About $2 \%$ to $7 \%$ (see Table 3.15 ) of the total neptunium is found to associate with the bismuth phosphate product solid also. Thus neptunium's overall fate in the bismuth phosphate processing is to be associated with solids more so than the liquid waste streams.

The fate of strontium during metal waste solution neutralization also showed variation between simulations \#2 and \#4. For the \#2 simulation, the radiotracer ${ }^{85} \mathrm{Sr}$ partitions mostly into the solid precipitate whereas the stable Sr results suggest that about one-third of the Sr remains in the supernatant solution during neutralization, but because simulation $\# 2$ erroneously used $\mathrm{KOH}$ we favor the results of simulation \#4. For simulation \#4 both the radiotracer and stable Sr neutralization results suggest about $12 \%$ to $18 \%$ of the strontium present in the metal waste solution remains soluble while the rest precipitates during the neutralization stage. About $88 \%$ of the strontium in the metal waste solution precipitates during neutralization and thus would be found predominately in suspended solids that would settle in the single-shell tanks after disposal. Based on Table 3.15 and Table 3.23, the ultimate fate of strontium in dissolved irradiated fuel is that $2 \%$ is found in the bismuth phosphate product, $87 \%$ is in the neutralized metal waste precipitates, and $11 \%$ is in the neutralized supernatant solution. The latter two fractions were sent to single-shell tanks.

The cesium results are also quite variable with simulation \#2 neutralization showing most of the radiotracer ${ }^{137} \mathrm{Cs}$ precipitating during neutralization but the stable Cs results suggest that cesium remains in the dissolved state during neutralization. This suggests some analytical problem might be present in the simulation \#2 neutralization activities. The stable cesium remained in the supernatant solution during the neutralization step but $90 \%$ of the radiotracer ${ }^{137} \mathrm{Cs}$, present at very trace amounts in the metal waste solution, associated with the neutralized precipitates. Neutralization of simulation \#4 metal waste solution showed good agreement between the radiotracer and stable Cs results with $63 \%$ to $73 \%$ of the cesium present in the metal waste solution remaining in the dissolved state after neutralization. Conversely, during the neutralization of simulation \#4 metal waste solution, both the stable and radiotracer form of cesium show $\sim 30 \%$ associates with the neutralized solids that precipitate. We suspect that the high potassium concentration in simulation $\# 2$, present because of the incorrect use of $\mathrm{KOH}$ to initiate the $\mathrm{pH}$ neutralization of the metal waste, caused a problem. We thus favor simulation \#4 neutralization results, which when combined with data in Table 3.15 show at least $95 \%$ to $98 \%$ of the cesium in the dissolved irradiated fuel ends up in the metal waste, which is disposed to single-shell tanks, and upon neutralization $70 \%$ of the cesium in the metal waste stream remains in the dissolved state and $30 \%$ associates with suspended solids.

The fate of ${ }^{125} \mathrm{I}$ as iodide (our gamma-emitting surrogate for ${ }^{129} \mathrm{I}$ ) could not be determined because a key measurement (neutralized supernatant solution for simulation \#2) could not be performed when the LEPS detector became inoperable. However, as shown in Table 3.15, less than $0.6 \%$ of the iodide partitioned to the bismuth phosphate product and essentially all of the iodide should be found in the neutralized waste stream disposed to single-shell tanks.

The radiotracer ${ }^{152} \mathrm{Eu}$ data and all the ICP-MS data for europium, cerium, lanthanum, and praseodymium (data shown in Table 3.15 and Tables 3.20 through 3.23) show a consistent pattern with $<5 \%$ of the lanthanides present in the metal waste solution remaining in solution after neutralization. Essentially, $>95 \%$ of the lanthanides that remain in the metal waste precipitates upon neutralization and 
from the original dissolved fuel (metal storage solution) only a few percent, at most, of the lanthanides remain in the dissolved state in the neutralized waste. About $10 \%$ to $20 \%$ of the lanthanide elements in dissolved irradiated fuel associate with the bismuth phosphate product solids and the rest ends up in the neutralized metal waste precipitates that are slurried into single-shell tanks where they ultimately settle to form sludge. At most a few percent of these elements remain in the supernatant solution in the singleshell tanks. The same is true for zirconium.

Rubidium, as measured by ICP-MS, yielded erratic results for the neutralized supernatant solution for simulation \#2, perhaps because of some mass interference from a complex (potassium-oxide-argide) caused by the high potassium present. It appears that rubidium in simulation \#4 is approximately evenly split between remaining in the neutralized metal waste supernatant solution and in the neutralized metal waste precipitates. This result is similar to the fate of cesium in the neutralization of test \#4. The barium results, using ICP-MS, were highly variable throughout the bismuth phosphate process simulation. Barium remains slightly more soluble during the neutralization process with $75 \%$ to $84 \%$ remaining in solution; based on the amount of barium present in the dissolved fuel (metal storage solution) about 65\% to $75 \%$ of the barium remains in solution all the way through the metal waste neutralization step. A higher percentage of the barium appears to remain in the dissolved state than strontium during metal waste neutralization, which does not seem logical. We thus do not put much confidence in the barium measurements for any of the solutions analyzed for the whole bismuth phosphate simulation.

Table 3.23 suggests that all of the sulfate present in the metal waste solution remains dissolved during the neutralization process; however, as described in the next section, a small amount of sulfate is likely present in the solids that precipitate during the neutralization process. The phosphate present in the metal waste solution distributes about evenly between the neutralized supernatant solution and the precipitates that form during the metal waste neutralization steps. Phosphate-containing minerals were identified in the neutralized metal waste solids as discussed in the next section.

\subsubsection{Identification of the Solids Formed During the Metal Waste Neutralization}

The solids that settled out of the neutralized metal waste solution were washed several times in distilled water. The washed and dried solids from the neutralized metal waste batches \#2 and \#4 were characterized by XRD and the uranium content in the solids from simulation \#2 was determined by digesting/dissolving a known mass aliquot (1.57 $\mathrm{g}$ out of the $18.86 \mathrm{~g}$ total) in nitric acid and measuring the uranium concentration by ICP-MS. The amount of uranium found in the neutralized metal waste solids from simulation \#2 was $0.4 \mathrm{~g}$ of uranium per gram of dry solid. As shown in Table 3.17, the neutralization of the metal waste solution generated $13.5 \%$ and $7.2 \%$ solids on a dry weight basis for batches \#2 and \#4, respectively. Batch \#4 was performed correctly whereas batch \#2 used $\mathrm{KOH}$ inadvertently instead of $\mathrm{NaOH}$. The amount of solids generated in batch $\# 4$ was within the range expected based on information found in the original technical manual HW-10475-C.

XRD patterns were obtained for the solids separated from the second bismuth phosphate simulation metal waste after neutralization. Recall that this batch of metal waste was incorrectly neutralized with potassium hydroxide instead of sodium hydroxide. The second step of the neutralization of simulation \#2 and \#4 correctly used sodium carbonate. Figure 3.1 shows the XRD for solids from the second metal waste neutralization test. Results from the XRD tracing indicate the presence of three uranium-rich crystalline phases. The background subtracted XRD pattern was compared to PDFs \# 49-0433, \#25-0679, $\# 71-1853$, and \#11-0252 as presented in Figure 3.1. 
Table 3.20. Fate of Radiotracers, Fission Products, and Selected Major Constituents after Neutralization of Simulation \#2

\begin{tabular}{|c|c|c|c|c|c|c|c|c|}
\hline \multicolumn{9}{|c|}{ Total $\mu \mathrm{g}$ in Each Phase in Simulation \#2 } \\
\hline Element & $\begin{array}{l}\text { "Theoretical" } \\
\text { Metal Storage }\end{array}$ & $\begin{array}{c}\text { Measured Initial } \\
\text { Metal Storage }\end{array}$ & $\begin{array}{l}\text { Measured Final } \\
\text { Metal Waste Sol }\end{array}$ & "Pu" Solid & $\begin{array}{l}\text { Neutralized } \\
\text { Supernate }\end{array}$ & $\begin{array}{l}\text { Neutralized } \\
\text { Solids }\end{array}$ & $\begin{array}{l}\% \text { of Metal } \\
\text { Storage Mass } \\
\text { Remaining in } \\
\text { Neutralized } \\
\text { Supernate }\end{array}$ & $\begin{array}{c}\% \text { of Metal Waste } \\
\text { Remaining in } \\
\text { Neutralized } \\
\text { Supernate }\end{array}$ \\
\hline \multicolumn{9}{|l|}{ ICP-MS } \\
\hline Tc99 & 250.17 & 249.3 & 233.5 & $<4.52$ & 220.21 & $\mathrm{NM}^{(\mathrm{b})}$ & $88 \%$ & $94 \%$ \\
\hline $\mathrm{Np} 237$ & 884.67 & 912 & 780.87 & 16.0 & 283.12 & NM & $31 \%$ & $36 \%$ \\
\hline Ba136 & 356.25 & (19) & $(285)$ & 28.0 & (3) & NM & $16 \%$ & $1 \%$ \\
\hline Ba137 & 356.25 & $(17)$ & $(210)$ & 23.0 & $(62)$ & NM & $368 \%$ & $29 \%$ \\
\hline Ce140 & 915.42 & 938.0 & 683.0 & 214 & $(45.1)$ & NM & $5 \%$ & $7 \%$ \\
\hline Ce142 & 915.42 & 944.1 & 665.0 & 218 & $(50)$ & NM & $5 \%$ & $8 \%$ \\
\hline Cs133 & 737.58 & 701.0 & 618.1 & $(0.8)$ & 670.1 & NM & $96 \%$ & $108 \%$ \\
\hline Eu151 & 137.37 & 205.2 & 187.3 & 38.7 & $(0)$ & NM & $0 \%$ & $0 \%$ \\
\hline Eu153 & 137.37 & 191.1 & 204.7 & 34.5 & (0) & NM & $0 \%$ & $0 \%$ \\
\hline La139 & 340.29 & 389.6 & 344.2 & 38.3 & $(14.7)$ & NM & $4 \%$ & $4 \%$ \\
\hline Mo100 & 503.64 & $(216)$ & (206) & $(0.67)$ & (199) & NM & $92 \%$ & $97 \%$ \\
\hline Mo95 & 503.64 & (461) & $(417)$ & $(1.41)$ & $(482)$ & NM & $105 \%$ & $116 \%$ \\
\hline Mo98 & 503.64 & 454.2 & (402) & $(1.29)$ & $(429)$ & NM & $94 \%$ & $107 \%$ \\
\hline Pd105 & 94.62 & $(48)$ & (41) & 1.94 & $(0)$ & NM & $0 \%$ & $0 \%$ \\
\hline Pd106 & 94.62 & (49) & (45) & 2.11 & 1.0 & NM & $2 \%$ & $2 \%$ \\
\hline Pr141 & 1140.00 & 1204.2 & 833.4 & 332 & (14.7) & NM & $1 \%$ & $2 \%$ \\
\hline $\mathrm{Rb85}$ & 108.87 & 293.9 & 265.6 & $(0.39)$ & 685.8 & NM & $233 \%$ & $258 \%$ \\
\hline \multicolumn{9}{|l|}{ ICP-MS } \\
\hline Se82 & 15.96 & (304) & (179) & $(2.51)$ & $<1048.6$ & NM & $345 \%$ & $584 \%$ \\
\hline Sr86 & 321.48 & 360.9 & 354.1 & $(4.83)$ & $(135)$ & NM & $37 \%$ & $38 \%$ \\
\hline Sr88 & 321.48 & 363.8 & 347.2 & $(4.52)$ & $(108)$ & NM & $30 \%$ & $31 \%$ \\
\hline Y89 & 165.87 & 173.1 & 154.2 & 8.09 & $(4.2)$ & NM & $2 \%$ & $3 \%$ \\
\hline $\mathrm{Zr90}$ & 1096.11 & (61) & $(375)$ & 190 & (669) & NM & $1096 \%$ & $179 \%$ \\
\hline Zr91 & 1096.11 & (69) & (411) & 192 & (718) & NM & $1041 \%$ & $175 \%$ \\
\hline ICP & & & & & & & & \\
\hline
\end{tabular}


Table 3.20. (contd)

\begin{tabular}{|c|c|c|c|c|c|c|c|c|}
\hline \multicolumn{9}{|c|}{ "Total $\mu \mathrm{g}$ in Each Phase in Simulation \#2 } \\
\hline Element & $\begin{array}{l}\text { "Theoretical" } \\
\text { Metal Storage }\end{array}$ & $\begin{array}{c}\text { Measured Initial } \\
\text { Metal Storage }\end{array}$ & $\begin{array}{l}\text { Measured Final } \\
\text { Metal Waste Sol }\end{array}$ & "Pu" Solid & $\begin{array}{l}\text { Neutralized } \\
\text { Supernate }\end{array}$ & $\begin{array}{c}\text { Neutralized } \\
\text { Solids }\end{array}$ & $\begin{array}{c}\text { \% of Metal } \\
\text { Storage Mass } \\
\text { Remaining in } \\
\text { Neutralized } \\
\text { Supernate } \\
\end{array}$ & $\begin{array}{c}\% \text { of Metal Waste } \\
\text { Remaining in } \\
\text { Neutralized } \\
\text { Supernate }\end{array}$ \\
\hline$\overline{\mathrm{Ba}}$ & 356.25 & NM & NM & NM & $\overline{<<}$ & NM & NA & NA \\
\hline $\mathrm{Sr}$ & 321.48 & NM & NM & NM & 242.8 & NM & NA & NA \\
\hline $\mathrm{SO}_{4}$ & $4.14 \mathrm{E}+06$ & NM & NM & NM & $4.54 \mathrm{E}+06$ & NM & NA & NA \\
\hline $\mathrm{PO}_{4}$ & $8.82 \mathrm{E}+06$ & NM & NM & NM & $4.41 \mathrm{E}+06$ & NM & NA & NA \\
\hline $\mathrm{U}$ & $1.35 \mathrm{E}+07$ & $1.49 \mathrm{E}+07$ & $1.42 \mathrm{E}+07^{*}$ & $4.72 \mathrm{E}+03$ & $5.48 \mathrm{E}+06$ & $7.50 \mathrm{E}+06$ & $37 \%$ & $39 \%$ \\
\hline GEA & & Total uCi & Total uCi & Total uCi & Total uCi & Total uCi & & \\
\hline Eu152 & --- & $2.8 \mathrm{E}+01$ & $2.0 \mathrm{E}+01$ & $6.1 \mathrm{E}+00$ & $1.2 \mathrm{E}-02$ & NM & $0.04 \%$ & $0.06 \%$ \\
\hline Se75 & --- & $6.8 \mathrm{E}+00$ & $5.5 \mathrm{E}+00$ & $6.9 \mathrm{E}-01$ & $7.6 \mathrm{E}-01$ & NM & $11.21 \%$ & $13.83 \%$ \\
\hline Cs137 & --- & $2.7 \mathrm{E}+00$ & $2.5 \mathrm{E}+00$ & $3.4 \mathrm{E}-02$ & $2.7 \mathrm{E}-01$ & NM & $10.04 \%$ & $11.10 \%$ \\
\hline Sr85 & --- & $1.4 \mathrm{E}+00$ & $1.1 \mathrm{E}+00$ & $2.5 \mathrm{E}-02$ & $3.9 \mathrm{E}-02$ & NM & $2.87 \%$ & $3.42 \%$ \\
\hline I-125 & --- & $1.5 \mathrm{E}-01$ & $1.6 \mathrm{E}-01$ & $1.0 \mathrm{E}-03$ & NM & NM & NA & NA \\
\hline
\end{tabular}


Table 3.21. Fate of Radiotracers, Fission Products, and Selected Major Constituents After Neutralization of Simulation \#4

\begin{tabular}{|c|c|c|c|c|c|c|c|c|}
\hline \multicolumn{9}{|c|}{ Total $\mu \mathrm{g}$ in Each Phase } \\
\hline Element & $\begin{array}{l}\text { "Theoretical" } \\
\text { Metal Storage }\end{array}$ & $\begin{array}{l}\text { Measured Initial } \\
\text { Metal Storage } \\
\end{array}$ & $\begin{array}{c}\text { Measured Final } \\
\text { Metal Waste Sol } \\
\end{array}$ & "Pu" Solid & $\begin{array}{l}\text { Neutralized } \\
\text { Supernate } \\
\end{array}$ & $\begin{array}{c}\text { Neutralized } \\
\text { Solids } \\
\end{array}$ & $\begin{array}{c}\% \text { of Metal Storage } \\
\text { Mass Remaining in } \\
\text { Neutralized } \\
\text { Supernate } \\
\end{array}$ & $\begin{array}{c}\% \text { of Metal Waste } \\
\text { Remaining in } \\
\text { Neutralized } \\
\text { Supernate } \\
\end{array}$ \\
\hline \multicolumn{9}{|l|}{ ICP-MS } \\
\hline Tc99 & 250.20 & $2.75 \mathrm{E}+02$ & $2.60 \mathrm{E}+02$ & $<1.02 \mathrm{E}-02$ & $2.59 \mathrm{E}+02$ & NM & $94 \%$ & $99 \%$ \\
\hline U238 & $1.35 \mathrm{E}+07$ & $1.60 \mathrm{E}+07$ & $1.50 \mathrm{E}+07$ & $2.69 \mathrm{E}+03$ & $2.98 \mathrm{E}+06$ & NM & $19 \%$ & $20 \%$ \\
\hline Np237 & $\mathrm{UNK}^{(*)}$ & $4.93 \mathrm{E}+03$ & $4.51 \mathrm{E}+03$ & $1.09 \mathrm{E}+02$ & $7.28 \mathrm{E}+02$ & NM & $15 \%$ & $16 \%$ \\
\hline Ba137 & 356.25 & $2.51 \mathrm{E}+02$ & $2.12 \mathrm{E}+02$ & $7.71 \mathrm{E}+00$ & $1.59 \mathrm{E}+02$ & NM & $63 \%$ & $75 \%$ \\
\hline Ba138 & 356.25 & $2.50 \mathrm{E}+02$ & $2.08 \mathrm{E}+02$ & $8.37 \mathrm{E}+00$ & $(1.58 \mathrm{E}+02)$ & NM & $63 \%$ & $76 \%$ \\
\hline $\mathrm{Ce} 140$ & 915.42 & $1.04 \mathrm{E}+03$ & $8.52 \mathrm{E}+02$ & $1.52 \mathrm{E}+02$ & $(3.01 \mathrm{E}+01)$ & NM & $3 \%$ & $4 \%$ \\
\hline Cs133 & 737.58 & $7.63 \mathrm{E}+02$ & $7.25 \mathrm{E}+02$ & $1.14 \mathrm{E}+00$ & $4.60 \mathrm{E}+02$ & NM & $60 \%$ & $63 \%$ \\
\hline Eu151 & 137.37 & $1.59 \mathrm{E}+02$ & $1.32 \mathrm{E}+02$ & $2.57 \mathrm{E}+01$ & $\begin{array}{l}(9.53 \mathrm{E}-01) \\
\end{array}$ & NM & $1 \%$ & $1 \%$ \\
\hline Eu153 & 137.37 & $1.59 \mathrm{E}+02$ & $1.31 \mathrm{E}+02$ & $2.54 \mathrm{E}+01$ & $9.53 \mathrm{E}-01$ & NM & $1 \%$ & $1 \%$ \\
\hline La139 & 340.29 & $3.85 \mathrm{E}+02$ & $3.40 \mathrm{E}+02$ & $3.12 \mathrm{E}+01$ & $1.70 \mathrm{E}+00$ & NM & $0 \%$ & $1 \%$ \\
\hline Mo100 & 503.64 & $1.04 \mathrm{E}+02$ & $(2.44 \mathrm{E}+02)$ & NA & $3.44 \mathrm{E}+02$ & NM & $331 \%$ & $141 \%$ \\
\hline Mo98 & 503.64 & $2.24 \mathrm{E}+02$ & $5.22 \mathrm{E}+02$ & $1.21 \mathrm{E}+00$ & $7.30 \mathrm{E}+02$ & NM & $326 \%$ & $140 \%$ \\
\hline Pd105 & 94.62 & $3.31 \mathrm{E}+01$ & $3.37 \mathrm{E}+01$ & $3.17 \mathrm{E}+01$ & $1.75 \mathrm{E}+01$ & NM & $53 \%$ & $52 \%$ \\
\hline Pr141 & 1140.00 & $1.29 \mathrm{E}+03$ & $1.03 \mathrm{E}+03$ & $2.27 \mathrm{E}+02$ & $<2.27 \mathrm{E}+00$ & NM & $0 \%$ & $0 \%$ \\
\hline $\mathrm{Rb} 85$ & 108.87 & $1.25 \mathrm{E}+02$ & $1.21 \mathrm{E}+02$ & $1.25 \mathrm{E}-01$ & $(6.46 \mathrm{E}+01)$ & NM & $51 \%$ & $53 \%$ \\
\hline Rb87 & 108.87 & $1.77 \mathrm{E}+02$ & $1.71 \mathrm{E}+02$ & $1.39 \mathrm{E}+00$ & $6.04 \mathrm{E}+01$ & NM & $34 \%$ & $35 \%$ \\
\hline Se82 & 15.96 & $(6.75 \mathrm{E}+00)$ & $<1.63 \mathrm{E}+02$ & $<1.50 \mathrm{E}+01$ & $3.02 \mathrm{E}+00$ & NM & $45 \%$ & $2 \%$ \\
\hline Sr88 & 321.48 & $3.74 \mathrm{E}+02$ & $3.52 \mathrm{E}+02$ & $6.10 \mathrm{E}+00$ & $4.65 \mathrm{E}+01$ & NM & $12 \%$ & $13 \%$ \\
\hline Y89 & 165.87 & $1.87 \mathrm{E}+02$ & $1.75 \mathrm{E}+02$ & $5.20 \mathrm{E}+00$ & $7.39 \mathrm{E}+00$ & NM & $4 \%$ & $4 \%$ \\
\hline \multicolumn{9}{|l|}{ ICP-MS } \\
\hline $\mathrm{Zr} 90$ & 1096.11 & $1.31 \mathrm{E}+03$ & $1.25 \mathrm{E}+02$ & $6.10 \mathrm{E}+02$ & $2.30 \mathrm{E}+01$ & NM & $2 \%$ & $18 \%$ \\
\hline $\mathrm{Zr} 94$ & 1096.11 & $1.58 \mathrm{E}+03$ & $3.85 \mathrm{E}+02$ & $4.01 \mathrm{E}+02$ & $2.63 \mathrm{E}+02$ & NM & $17 \%$ & $68 \%$ \\
\hline \multicolumn{9}{|l|}{ ICP } \\
\hline $\mathrm{Ba}$ & 356.25 & 178 & 160 & 7.03 & $1.34 \mathrm{E}+02$ & NM & $75 \%$ & $84 \%$ \\
\hline $\mathrm{Sr}$ & 321.48 & 683 & 661 & 5.68 & $1.17 \mathrm{E}+02$ & NM & $17 \%$ & $18 \%$ \\
\hline $\mathrm{SO}_{4}$ & $4.14 \mathrm{E}+06$ & $4.76 \mathrm{E}+06$ & $4.60 \mathrm{E}+06$ & $1.00 \mathrm{E}+04$ & $5.01 \mathrm{E}+06$ & NM & $105 \%$ & $109 \%$ \\
\hline $\mathrm{PO}_{4}$ & $8.82 \mathrm{E}+06$ & NM & $7.85 \mathrm{E}+06$ & $2.10 \mathrm{E}+05$ & $3.97 \mathrm{E}+06$ & NM & $45 \%$ & $51 \%$ \\
\hline
\end{tabular}


Table 3.21. (contd)

\begin{tabular}{|c|c|c|c|c|c|c|c|c|}
\hline \multicolumn{9}{|c|}{ Total $\mu \mathrm{g}$ in Each Phase } \\
\hline Element & $\begin{array}{l}\text { "Theoretical" } \\
\text { Metal Storage } \\
\end{array}$ & $\begin{array}{c}\text { Measured Initial } \\
\text { Metal Storage } \\
\end{array}$ & $\begin{array}{c}\text { Measured Final } \\
\text { Metal Waste Sol } \\
\end{array}$ & "Pu" Solid & $\begin{array}{c}\text { Neutralized } \\
\text { Supernate } \\
\end{array}$ & $\begin{array}{c}\text { Neutralized } \\
\text { Solids } \\
\end{array}$ & $\begin{array}{c}\% \text { of Metal Storage } \\
\text { Mass Remaining in } \\
\text { Neutralized } \\
\text { Supernate } \\
\end{array}$ & $\begin{array}{c}\% \text { of Metal Waste } \\
\text { Remaining in } \\
\text { Neutralized } \\
\text { Supernate } \\
\end{array}$ \\
\hline GEA & & Total uCi & Total uCi & Total uCi & Total uCi & Total uCi & & \\
\hline $\mathrm{Se} 75$ & --- & $1.02 \mathrm{E}+00$ & $9.66 \mathrm{E}-01$ & $1.10 \mathrm{E}-01$ & $1.03 \mathrm{E}+00$ & NM & $101 \%$ & $107 \%$ \\
\hline Sr85 & --- & $1.25 \mathrm{E}+00$ & $1.20 \mathrm{E}+00$ & $2.40 \mathrm{E}-02$ & $1.48 \mathrm{E}-01$ & $\mathrm{NM}$ & $12 \%$ & $12 \%$ \\
\hline $\mathrm{Tc} 95 \mathrm{~m}$ & --- & $6.72 \mathrm{E}-01$ & $6.47 \mathrm{E}-01$ & $3.00 \mathrm{E}-04$ & $7.21 \mathrm{E}-01$ & NM & $107 \%$ & $111 \%$ \\
\hline Sb125 & --- & $4.43 \mathrm{E}+00$ & $4.20 \mathrm{E}+00$ & $5.70 \mathrm{E}-02$ & $2.31 \mathrm{E}+00$ & $\mathrm{NM}$ & $52 \%$ & $55 \%$ \\
\hline Cs137 & --- & $3.51 \mathrm{E}+00$ & $3.42 \mathrm{E}+00$ & $4.50 \mathrm{E}-02$ & $2.50 \mathrm{E}+00$ & NM & $71 \%$ & $73 \%$ \\
\hline
\end{tabular}


Table 3.22. Distribution of Fission Products and Selected Major Constituents in Bismuth Phosphate and Neutralization Processes for Simulation \#2

\begin{tabular}{|c|c|c|c|c|c|c|c|c|c|c|}
\hline \multicolumn{11}{|c|}{ "Total $\mu \mathrm{g}$ in Each Phase in Simulation \#2 } \\
\hline Element & $\begin{array}{c}\text { Measured Initial } \\
\text { Metal Storage }\end{array}$ & $\begin{array}{l}\text { Measured Final } \\
\text { Metal Waste Sol }\end{array}$ & "Pu" Solid & $\begin{array}{l}\text { Neutralized } \\
\text { Supernate }\end{array}$ & $\begin{array}{c}\text { Neutralized } \\
\text { Solids }\end{array}$ & $\begin{array}{l}\% \text { of Metal } \\
\text { Waste } \\
\text { Remaining in } \\
\text { Neutralized } \\
\text { Supernate }\end{array}$ & $\begin{array}{c}\% \text { of } \\
\text { Metal } \\
\text { Storage } \\
\text { Mass in } \\
\text { All } \\
\text { Solids } \\
\end{array}$ & $\begin{array}{c}\% \text { of Metal } \\
\text { Waste in } \\
\text { Neutralized } \\
\text { Solids } \\
\end{array}$ & $\begin{array}{c}\% \text { of Metal } \\
\text { Storage Mass } \\
\text { in } \\
\text { Neutralized } \\
\text { Solids } \\
\end{array}$ & $\begin{array}{l}\% \text { of Metal } \\
\text { Storage in } \\
\text { Pu Solids }\end{array}$ \\
\hline \multicolumn{11}{|c|}{ 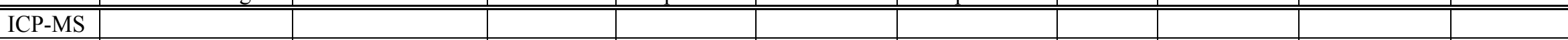 } \\
\hline Tc99 & 249.3 & 233.5 & $<4.52$ & 220.21 & 13.29 & $94 \%$ & $7.1 \%$ & $5.7 \%$ & $5.3 \%$ & $1.8 \%$ \\
\hline Np237 & 912 & 780.87 & 16 & 283.12 & 497.75 & $36 \%$ & $56.3 \%$ & $63.7 \%$ & $54.6 \%$ & $1.8 \%$ \\
\hline Ce140 & 938 & 683 & 214 & 45.1 & 637.9 & $7 \%$ & $90.8 \%$ & $93.4 \%$ & $68.0 \%$ & $22.8 \%$ \\
\hline Ce142 & 944.1 & 665 & 218 & 50 & 615 & $8 \%$ & $88.2 \%$ & $92.5 \%$ & $65.1 \%$ & $23.1 \%$ \\
\hline Cs133 & 701 & 618.1 & 0.8 & 670.1 & -52 & $108 \%$ & $-7.3 \%$ & $-8.4 \%$ & $-7.4 \%$ & $0.1 \%$ \\
\hline Eu151 & 205.2 & 187.3 & 38.7 & 0 & 187.3 & $0 \%$ & $110.1 \%$ & $100.0 \%$ & $91.3 \%$ & $18.9 \%$ \\
\hline Eu153 & 191.1 & 204.7 & 34.5 & 0 & 204.7 & $0 \%$ & $125.2 \%$ & $100.0 \%$ & $107.1 \%$ & $18.1 \%$ \\
\hline La139 & 389.6 & 344.2 & 38.3 & 14.7 & 329.5 & $4 \%$ & $94.4 \%$ & $95.7 \%$ & $84.6 \%$ & $9.8 \%$ \\
\hline $\begin{array}{l}P r 141 \\
\text { Pr14 }\end{array}$ & 1204.2 & 833.4 & 332 & 14.7 & 818.7 & $2 \%$ & $95.6 \%$ & $98.2 \%$ & $68.0 \%$ & $27.6 \%$ \\
\hline Sr86 & 360.9 & 354.1 & 4.83 & 135 & 219.1 & $38 \%$ & $62.0 \%$ & $61.9 \%$ & $60.7 \%$ & $1.3 \%$ \\
\hline Sr88 & 363.8 & 347.2 & 4.52 & 108 & 239.2 & $31 \%$ & $67.0 \%$ & $68.9 \%$ & $65.8 \%$ & $1.2 \%$ \\
\hline Y89 & 173.1 & 154.2 & 8.09 & 4.2 & 150 & $3 \%$ & $91.3 \%$ & $97.3 \%$ & $86.7 \%$ & $4.7 \%$ \\
\hline \multicolumn{11}{|l|}{ ICP } \\
\hline $\mathrm{U}$ & $1.49 \mathrm{E}+07$ & $1.42 \mathrm{E}+07$ & $4.72 \mathrm{E}+03$ & $5.48 \mathrm{E}+06$ & $7.50 \mathrm{E}+06$ & $39 \%$ & $50.4 \%$ & $52.8 \%$ & $50.3 \%$ & $0.0 \%$ \\
\hline GEA & Total uCi & Total uCi & Total uCi & Total uCi & Total uCi & & & & & \\
\hline Eu152 & $2.80 \mathrm{E}+01$ & $2.00 \mathrm{E}+01$ & $6.10 \mathrm{E}+00$ & $1.20 \mathrm{E}-02$ & 19.988 & $0.06 \%$ & $93.2 \%$ & $99.9 \%$ & $71.4 \%$ & $21.8 \%$ \\
\hline Se75 & $6.80 \mathrm{E}+00$ & $5.50 \mathrm{E}+00$ & $6.90 \mathrm{E}-01$ & 7.60E-01 & 4.74 & $13.83 \%$ & $79.9 \%$ & $86.2 \%$ & $69.7 \%$ & $10.1 \%$ \\
\hline Cs137 & $2.70 \mathrm{E}+00$ & $2.50 \mathrm{E}+00$ & $3.40 \mathrm{E}-02$ & $2.70 \mathrm{E}-01$ & 2.23 & $11.10 \%$ & $83.9 \%$ & $89.2 \%$ & $82.6 \%$ & $1.3 \%$ \\
\hline Sr85 & $1.40 \mathrm{E}+00$ & $1.10 \mathrm{E}+00$ & $2.50 \mathrm{E}-02$ & $3.90 \mathrm{E}-02$ & 1.061 & $3.42 \%$ & $77.6 \%$ & $96.5 \%$ & $75.8 \%$ & $1.8 \%$ \\
\hline
\end{tabular}


Table 3.23. Distribution of Fission Products, and Selected Major Constituents in Overall Bismuth Phosphate and Neutralization Processes for Simulation \#4

\begin{tabular}{|c|c|c|c|c|c|c|c|c|c|c|}
\hline \multicolumn{11}{|c|}{ Total $\mu \mathrm{g}$ in Each Phase in Simulation \#4 } \\
\hline Element & $\begin{array}{l}\text { Measured Initial } \\
\text { Metal Storage }\end{array}$ & $\begin{array}{l}\text { Measured Final } \\
\text { Metal Waste Sol }\end{array}$ & "Pu" Solid & $\begin{array}{l}\text { Neutralized } \\
\text { Supernate }\end{array}$ & $\begin{array}{c}\text { Neutralized } \\
\text { Solids } \\
\end{array}$ & $\begin{array}{l}\% \text { of Metal } \\
\text { Waste } \\
\text { Remaining in } \\
\text { Neutralized } \\
\text { Supernate } \\
\end{array}$ & $\begin{array}{c}\text { \% of } \\
\text { Metal } \\
\text { Storage } \\
\text { Mass in } \\
\text { All Solids } \\
\end{array}$ & $\begin{array}{c}\% \text { of Metal } \\
\text { Waste in } \\
\text { Neutralized } \\
\text { Solids } \\
\end{array}$ & \begin{tabular}{|c|}
$\%$ of Metal \\
Storage \\
Mass in \\
Neutralized \\
Solids \\
\end{tabular} & $\begin{array}{c}\% \text { of } \\
\text { Metal } \\
\text { Storage } \\
\text { in Pu } \\
\text { Solids } \\
\end{array}$ \\
\hline Tc99 & $2.75 \mathrm{E}+02$ & $2.60 \mathrm{E}+02$ & $1.02 \mathrm{E}-02$ & $2.59 \mathrm{E}+02$ & $1.00 \mathrm{E}+00$ & $99 \%$ & $0.4 \%$ & $0.4 \%$ & $0.4 \%$ & $0.0 \%$ \\
\hline $\mathrm{U} 238$ & $1.60 \mathrm{E}+07$ & $1.50 \mathrm{E}+07$ & $2.69 \mathrm{E}+03$ & $2.98 \mathrm{E}+06$ & $1.20 \mathrm{E}+07$ & $20 \%$ & $75.1 \%$ & $80.1 \%$ & $75.1 \%$ & $0.0 \%$ \\
\hline $\mathrm{Np} 237$ & $4.93 \mathrm{E}+03$ & $4.51 \mathrm{E}+03$ & $1.09 \mathrm{E}+02$ & $7.28 \mathrm{E}+02$ & $3.78 \mathrm{E}+03$ & $16 \%$ & $78.9 \%$ & $83.9 \%$ & $76.7 \%$ & $2.2 \%$ \\
\hline Ba137 & $2.51 \mathrm{E}+02$ & $2.12 \mathrm{E}+02$ & $7.71 \mathrm{E}+00$ & $1.59 \mathrm{E}+02$ & $5.30 \mathrm{E}+01$ & $75 \%$ & $24.2 \%$ & $25.0 \%$ & $21.1 \%$ & $3.1 \%$ \\
\hline $\mathrm{Ba} 138$ & $2.50 \mathrm{E}+02$ & $2.08 \mathrm{E}+02$ & $8.37 \mathrm{E}+00$ & $1.58 \mathrm{E}+02$ & $5.00 \mathrm{E}+01$ & $76 \%$ & $23.3 \%$ & $24.0 \%$ & $20.0 \%$ & $3.3 \%$ \\
\hline Ce140 & $1.04 \mathrm{E}+03$ & $8.52 \mathrm{E}+02$ & $1.52 \mathrm{E}+02$ & $3.01 \mathrm{E}+01$ & $8.22 \mathrm{E}+02$ & $4 \%$ & $93.6 \%$ & $96.5 \%$ & $79.0 \%$ & $14.6 \%$ \\
\hline Cs133 & $7.63 \mathrm{E}+02$ & $7.25 \mathrm{E}+02$ & $1.14 \mathrm{E}+00$ & $4.60 \mathrm{E}+02$ & $2.65 \mathrm{E}+02$ & $63 \%$ & $34.9 \%$ & $36.6 \%$ & $34.7 \%$ & $0.1 \%$ \\
\hline Eu151 & $1.59 \mathrm{E}+02$ & $1.32 \mathrm{E}+02$ & $2.57 \mathrm{E}+01$ & $9.53 \mathrm{E}-01$ & $1.31 \mathrm{E}+02$ & $1 \%$ & $98.6 \%$ & $99.3 \%$ & $82.4 \%$ & $16.2 \%$ \\
\hline Eu153 & $1.59 \mathrm{E}+02$ & $1.31 \mathrm{E}+02$ & $2.54 \mathrm{E}+01$ & $9.53 \mathrm{E}-01$ & $1.30 \mathrm{E}+02$ & $1 \%$ & $97.8 \%$ & $99.3 \%$ & $81.8 \%$ & $16.0 \%$ \\
\hline La139 & $3.85 \mathrm{E}+02$ & $3.40 \mathrm{E}+02$ & $3.12 \mathrm{E}+01$ & $1.70 \mathrm{E}+00$ & $3.38 \mathrm{E}+02$ & $1 \%$ & $96.0 \%$ & $99.5 \%$ & $87.9 \%$ & $8.1 \%$ \\
\hline Pr141 & $1.29 \mathrm{E}+03$ & $1.03 \mathrm{E}+03$ & $2.27 \mathrm{E}+02$ & $2.27 \mathrm{E}+00$ & $1.03 \mathrm{E}+03$ & $0 \%$ & $97.3 \%$ & $99.8 \%$ & $79.7 \%$ & $17.6 \%$ \\
\hline $\mathrm{Rb} 85$ & $1.25 \mathrm{E}+02$ & $1.21 \mathrm{E}+02$ & $1.25 \mathrm{E}-01$ & $6.46 \mathrm{E}+01$ & $5.64 \mathrm{E}+01$ & $53 \%$ & $45.2 \%$ & $46.6 \%$ & $45.1 \%$ & $0.1 \%$ \\
\hline Rb87 & $1.77 \mathrm{E}+02$ & $1.71 \mathrm{E}+02$ & $1.39 \mathrm{E}+00$ & $6.04 \mathrm{E}+01$ & $1.11 \mathrm{E}+02$ & $35 \%$ & $63.3 \%$ & $64.7 \%$ & $62.5 \%$ & $0.8 \%$ \\
\hline Sr88 & $3.74 \mathrm{E}+02$ & $3.52 \mathrm{E}+02$ & $6.10 \mathrm{E}+00$ & $4.65 \mathrm{E}+01$ & $3.06 \mathrm{E}+02$ & $13 \%$ & $83.3 \%$ & $86.8 \%$ & $81.7 \%$ & $1.6 \%$ \\
\hline Y89 & $1.87 \mathrm{E}+02$ & $1.75 \mathrm{E}+02$ & $5.20 \mathrm{E}+00$ & $7.39 \mathrm{E}+00$ & $1.68 \mathrm{E}+02$ & $4 \%$ & $92.4 \%$ & $95.8 \%$ & $89.6 \%$ & $2.8 \%$ \\
\hline Zr90 & $1.31 \mathrm{E}+03$ & $1.25 \mathrm{E}+02$ & $6.10 \mathrm{E}+02$ & $2.30 \mathrm{E}+01$ & $1.02 \mathrm{E}+02$ & $18 \%$ & $54.4 \%$ & $81.6 \%$ & $7.8 \%$ & $46.6 \%$ \\
\hline Zr94 & $1.58 \mathrm{E}+03$ & $3.85 \mathrm{E}+02$ & $4.01 \mathrm{E}+02$ & $2.63 \mathrm{E}+02$ & $1.22 \mathrm{E}+02$ & $68 \%$ & $33.1 \%$ & $31.7 \%$ & $7.7 \%$ & $25.4 \%$ \\
\hline $\mathrm{Ba}$ & 178 & 160 & 7.03 & $1.34 \mathrm{E}+02$ & $2.60 \mathrm{E}+01$ & $84 \%$ & $18.6 \%$ & $16.3 \%$ & $14.6 \%$ & $3.9 \%$ \\
\hline $\mathrm{Sr}$ & 683 & 661 & 5.68 & $1.17 \mathrm{E}+02$ & $5.44 \mathrm{E}+02$ & $18 \%$ & $80.5 \%$ & $82.3 \%$ & $79.6 \%$ & $0.8 \%$ \\
\hline $\mathrm{SO}_{4}$ & $4.76 \mathrm{E}+06$ & $4.60 \mathrm{E}+06$ & $1.00 \mathrm{E}+04$ & $5.01 \mathrm{E}+06$ & $-4.10 \mathrm{E}+05$ & $109 \%$ & $-8.4 \%$ & $-8.9 \%$ & $-8.6 \%$ & $0.2 \%$ \\
\hline $\mathrm{PO}_{4}$ & $8.82 \mathrm{E}+06$ & $7.85 \mathrm{E}+06$ & $2.10 \mathrm{E}+05$ & $3.97 \mathrm{E}+06$ & $3.88 \mathrm{E}+06$ & $51 \%$ & $46.4 \%$ & $49.4 \%$ & $44.0 \%$ & $2.4 \%$ \\
\hline GEA & Total uCi & Total uCi & Total uCi & Total uCi & Total uCi & & & & & \\
\hline $\mathrm{Se} 75$ & $1.02 \mathrm{E}+00$ & $9.66 \mathrm{E}-01$ & $1.10 \mathrm{E}-01$ & $1.03 \mathrm{E}+00$ & $-6.40 \mathrm{E}-02$ & $107 \%$ & $4.5 \%$ & $-6.6 \%$ & $-6.3 \%$ & $10.8 \%$ \\
\hline Sr85 & $1.25 \mathrm{E}+00$ & $1.20 \mathrm{E}+00$ & $2.40 \mathrm{E}-02$ & $1.48 \mathrm{E}-01$ & $1.05 \mathrm{E}+00$ & $12 \%$ & $86.1 \%$ & $87.7 \%$ & $84.2 \%$ & $1.9 \%$ \\
\hline Tc95m & $6.72 \mathrm{E}-01$ & $6.47 \mathrm{E}-01$ & $3.00 \mathrm{E}-04$ & $7.21 \mathrm{E}-01$ & $-7.40 \mathrm{E}-02$ & $111 \%$ & $-11.0 \%$ & $-11.4 \%$ & $-11.0 \%$ & $0.0 \%$ \\
\hline Sb125 & $4.43 \mathrm{E}+00$ & $4.20 \mathrm{E}+00$ & $5.70 \mathrm{E}-02$ & $2.31 \mathrm{E}+00$ & $1.89 \mathrm{E}+00$ & $55 \%$ & $44.0 \%$ & $45.0 \%$ & $42.7 \%$ & $1.3 \%$ \\
\hline Cs137 & $3.51 \mathrm{E}+00$ & $3.42 \mathrm{E}+00$ & $4.50 \mathrm{E}-02$ & $2.50 \mathrm{E}+00$ & $9.20 \mathrm{E}-01$ & $73 \%$ & $27.5 \%$ & $26.9 \%$ & $26.2 \%$ & $1.3 \%$ \\
\hline
\end{tabular}




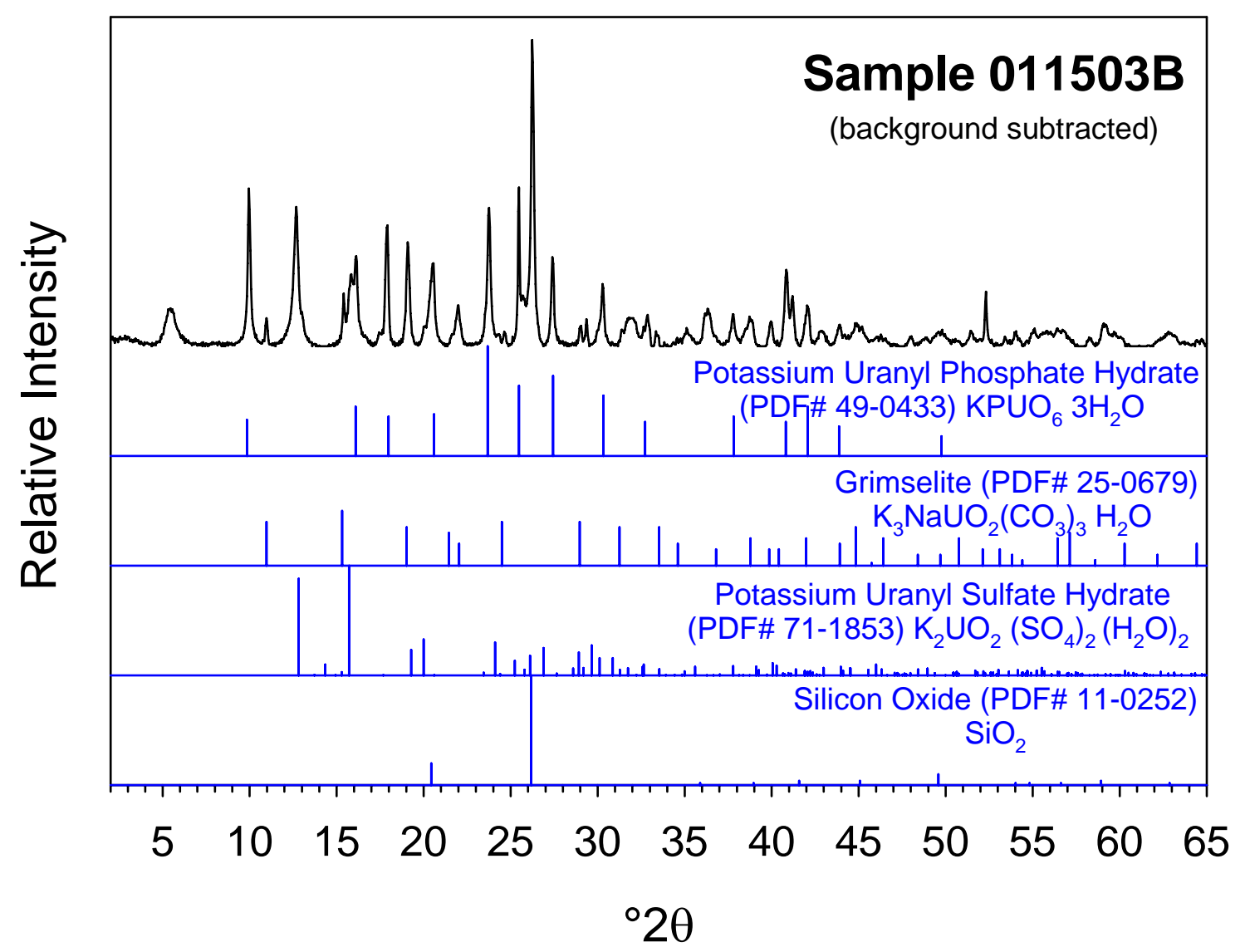

Figure 3.1. Background-Subtracted Bulk Powder XRD Tracing of Sample 011503B (Solids that Precipitated During Neutralization of Metal Waste Solution Simulation \#2 Using KOH and $\mathrm{Na}_{2} \mathrm{CO}_{3}$ ). Also shown are diagnostic peaks for the four minerals tentatively matching the pattern.

Potassium uranyl phosphate hydrate $\left(\mathrm{KPUO}_{6} \bullet 3 \mathrm{H}_{2} \mathrm{O}\right)$ was identified based on XRD data in PDF\# 49-0433, which includes 14 diffracted peaks between 2 and $65^{\circ} 2 \theta$. The primary reflection for $\mathrm{KPUO}_{6} \cdot 3 \mathrm{H}_{2} \mathrm{O}$ is positioned at $23.68^{\circ} 2 \theta$ with less intense reflections at $27.43,25.48,30.33,42.01,16.09$, 20.59 , and $37.82^{\circ} 2 \theta$. Potassium uranyl sulfate hydrate $\left[\mathrm{K}_{2} \mathrm{UO}_{2}\left(\mathrm{SO}_{4}\right)_{2} \bullet 2\left(\mathrm{H}_{2} \mathrm{O}\right)\right]$ was also identified based on significant reflections positioned at 12.81 and $1582^{\circ} 2 \theta$. This phase was also supported by SEM analysis of the same sample. Reflections consistent with the uranium carbonate mineral Grimselite $\left[\mathrm{K}_{3} \mathrm{NaUO}_{2}\left(\mathrm{CO}_{3}\right)_{3} \cdot \mathrm{H}_{2} \mathrm{O}\right]$ were also detected in the XRD tracing (Figure 3.1). The characteristic reflections positioned at 10.97, 15.32, 19.03, and 21.45 20 matched well with PDF\# 25-0679 (Grimselite).

Other crystalline phases were detected by XRD in the solids separated from the neutralized metal waste solution. Reflections consistent with silicon dioxide $\left(\mathrm{SiO}_{2}\right)(\mathrm{PDF} \# 11-0252)$ were observed at $20.45,26.19$, and $49.58^{\circ} 2 \theta$. The presence of silicon dioxide in the sample possibly indicates a reaction with the glass beakers used during the bismuth phosphate simulations. The broad reflection at $5.39^{\circ} 2 \theta$ observed in the XRD pattern was not matched to an inorganic crystalline compound in the PDF database. No indications of amorphous material were observed in the XRD pattern. 
The solids from the XRD mount were further characterized using SEM-EDS, XRF, and a total carbon analyzer. Figure 3.2 and Figure 3.3 show SEM-BSE (backscatter electron) micrographs of particles present in the $\mathrm{KOH}-\mathrm{Na}_{2} \mathrm{CO}_{3}$ neutralized metal waste precipitates. This material is very similar in appearance to the $\mathrm{NaOH}-\mathrm{Na}_{2} \mathrm{CO}_{3}$ neutralized metal waste precipitate to be discussed next. The $\mathrm{KOH}$ neutralized metal waste precipitate contains fine-grained particles as well as aggregates of these particles. Individual particles ranged in size from several micrometers to less than a micrometer. EDS analyses (Figure 3.4) indicate that the $\mathrm{KOH}$-neutralized metal waste precipitate consists primarily of poorly descript particles of $\mathrm{U}-\mathrm{K}-\mathrm{Na}-\mathrm{P}-\mathrm{O} \pm \mathrm{C} \pm \mathrm{H}$. The $\mathrm{KOH}$ neutralized metal waste precipitate also contains particles of $\mathrm{Fe}-\mathrm{O}$, which usually had lesser amounts of $\mathrm{Cr}, \mathrm{Mn}$, and possibly $\mathrm{Ni}$, and some (but rare) particles of Si-O (Figure 3.5). The Fe-O particles are less abundant than the U-rich particles. The EDS spectra shown in Figures 3.4 and 3.5 do not have labels on the small peaks of $\mathrm{K}$ which are present. Other EDS spectra not placed in this report do show small presence of potassium; however, because major potassium $\mathrm{x}$-ray emission lines overlap with the major $\mathrm{x}$-ray emission lines for $\mathrm{U}$ and $\mathrm{O}$ it is difficult to identify potassium in these uranium-rich precipitates using EDS. More EDS spectra for $\mathrm{KOH}-\mathrm{Na}_{2} \mathrm{CO}_{3}$ neutralized metal waste precipitates are shown in Appendix C.

An aliquot of the $\mathrm{KOH}-\mathrm{Na}_{2} \mathrm{CO}_{3}$ neutralized metal waste precipitate was ground to a powder and analyzed by XRF and by a total carbon analyzer to get a semi-quantitative estimate of the total elemental composition as oxides. The XRF cannot detect light elements below sodium such that carbon present as carbonate would not be detected. We also analyzed an aliquot of the precipitate on a total carbon analyzer so that the carbonate contribution could be estimated. Table 3.24 lists the results of the semiquantitative analysis of the precipitate normalized to $100 \mathrm{wt} \%$ as oxides. As mentioned, an aliquot of the dried precipitate was completely dissolved in concentrated nitric acid and analyzed for uranium content by ICP-MS. The value measured was $0.4 \mathrm{~g}$ of $\mathrm{U}$ per gram of solid. This value equates to $0.481 \mathrm{~g} \mathrm{UO}_{3}$ per gram of solid or $48.1 \mathrm{wt} \%$. The agreement between the total digestion (48.1 wt $\%)$ and semiquantitative XRF results (73.2 wt \%) as $\mathrm{U}(\mathrm{VI})$ oxide is not very good. We put more reliance on the former value obtained by traditional digestion and analysis rather than the semi-quantitative XRF results.

The XRF results are in general agreement with the XRD and SEM-EDS results. The precipitate appears to be dominated by uranyl, potassium, phosphate with some sodium, carbonate, and sulfate also being present. It is not clear what the source of the calcium found in the precipitate is. The trace amounts of iron, manganese, and chromium are consistent with the trace amount of iron oxide particles observed by SEM-EDS. These elements may have come from equipment and containers used during the bismuth phosphate process lab-scale simulations.

XRD patterns for the solids that were separated from the fourth bismuth phosphate simulation metal waste after neutralization were also obtained. This batch of metal waste was correctly neutralized with sodium hydroxide and sodium carbonate. Figure 3.6 shows the XRD pattern for solids from the fourth simulation metal waste solution neutralization. The XRD pattern measured for the $\mathrm{NaOH}-\mathrm{Na}_{2} \mathrm{CO}_{3}$ neutralized metal waste solution from our fourth simulation of the bismuth phosphate process is compared with schematic database (PDF) patterns to tentatively identify minerals. The XRD results indicate that these solids consist of a mixture of sodium uranyl phosphate hydrate, $\mathrm{NaPUO}_{6} \cdot 3 \mathrm{H}_{2} \mathrm{O}$ (PDF\# 49-0432) and possibly a minor amount of $\mathrm{NaUO}_{2} \mathrm{PO}_{4} \cdot 5 \mathrm{H}_{2} \mathrm{O}$ (PDF\# 13-0063) as well as trace amounts of a hydrogen phosphate phase similar to PDF\# 03-0201. 

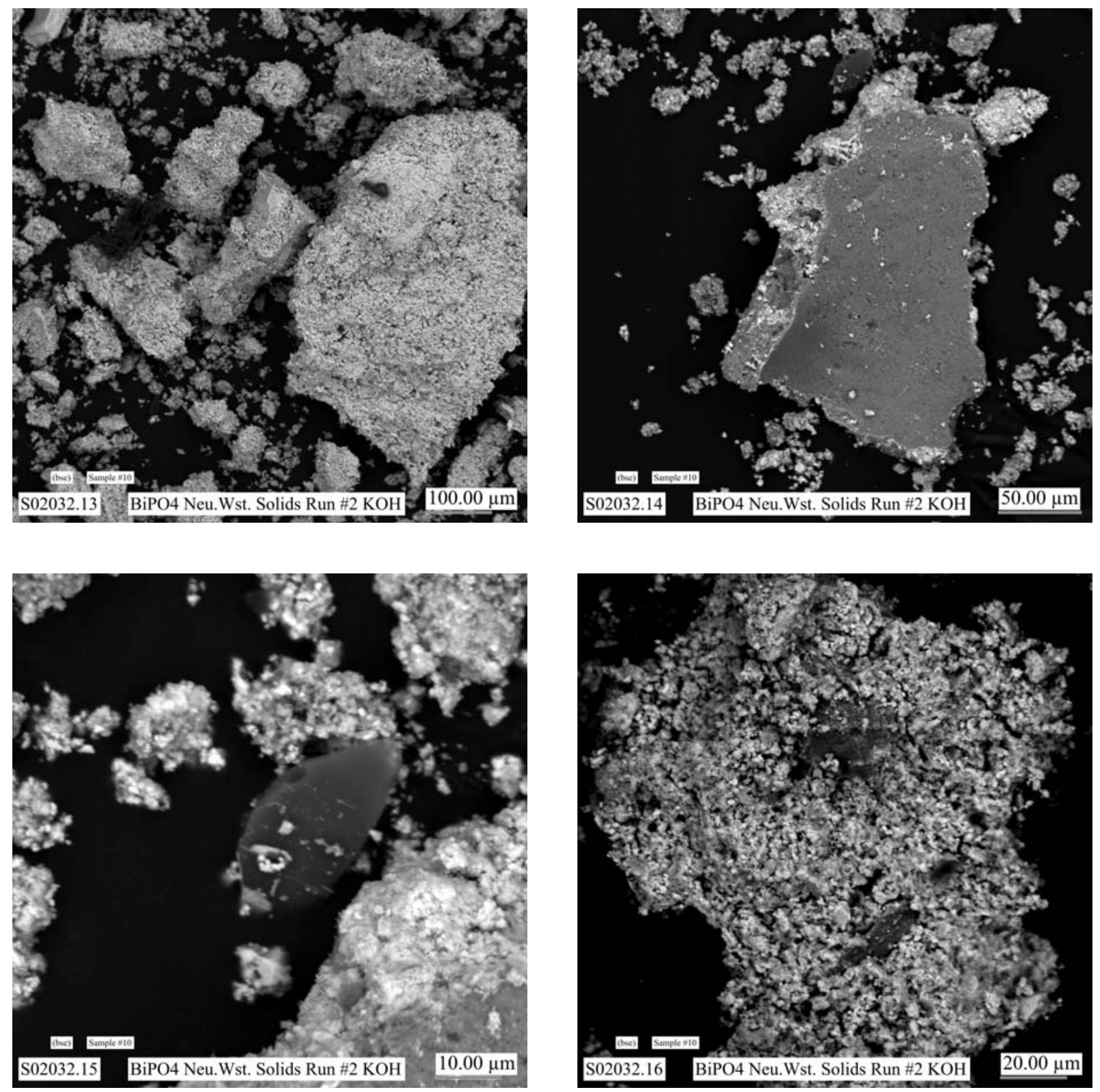

Figure 3.2. SEM BSE Micrographs of Particles in $\mathrm{KOH}-\mathrm{Na}_{2} \mathrm{CO}_{3}$ Neutralized Metal Waste Precipitate. (The name of each digital image file, sample identification number, and a size scale bar are given, respectively, at the bottom left, center, and right of each SEM micrograph in this and all subsequent SEM figures.) 

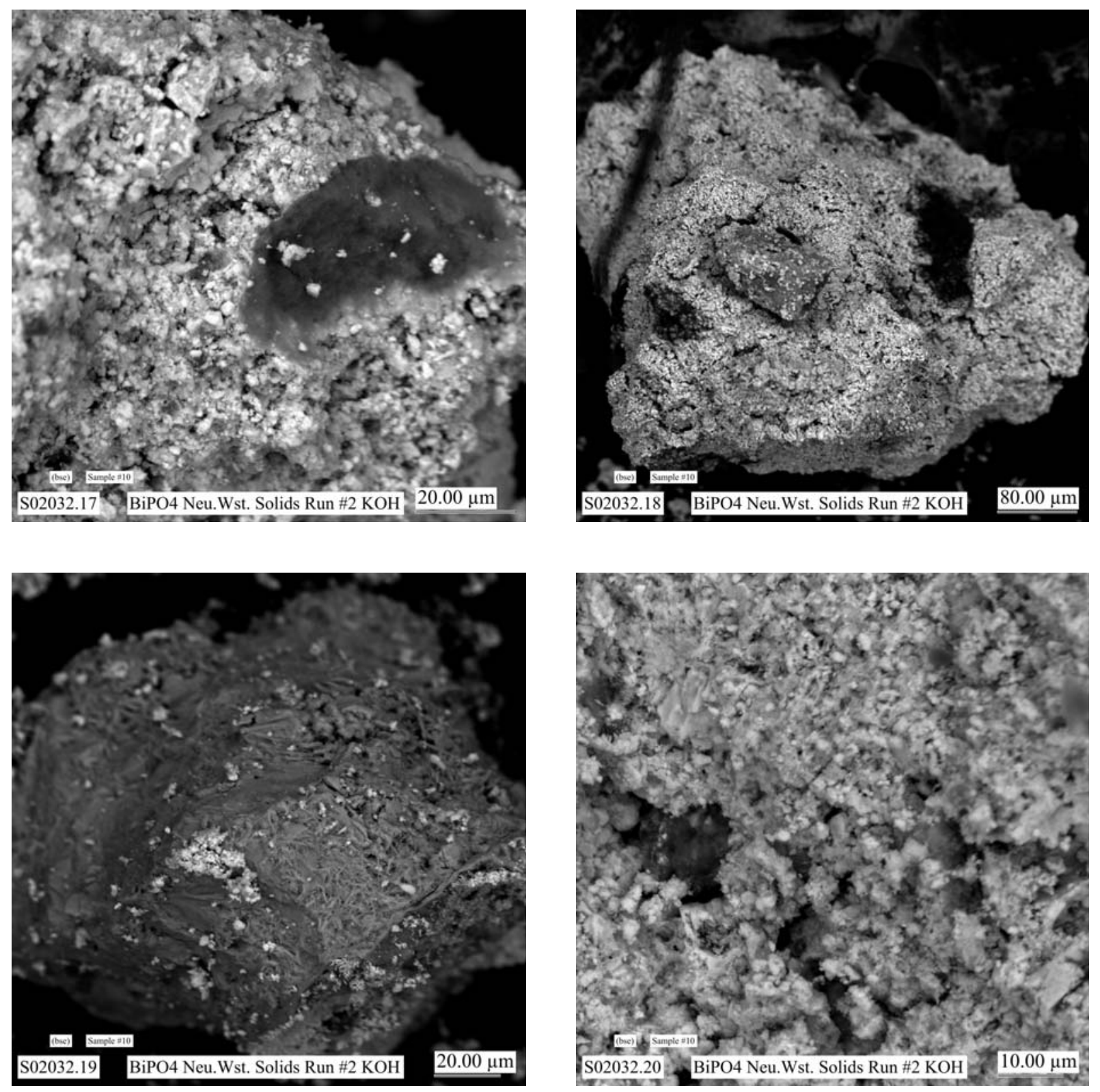

Figure 3.3. SEM BSE Micrographs of Particles in $\mathrm{KOH}-\mathrm{Na} 2 \mathrm{CO} 3$ Neutralized Metal Waste Precipitate 


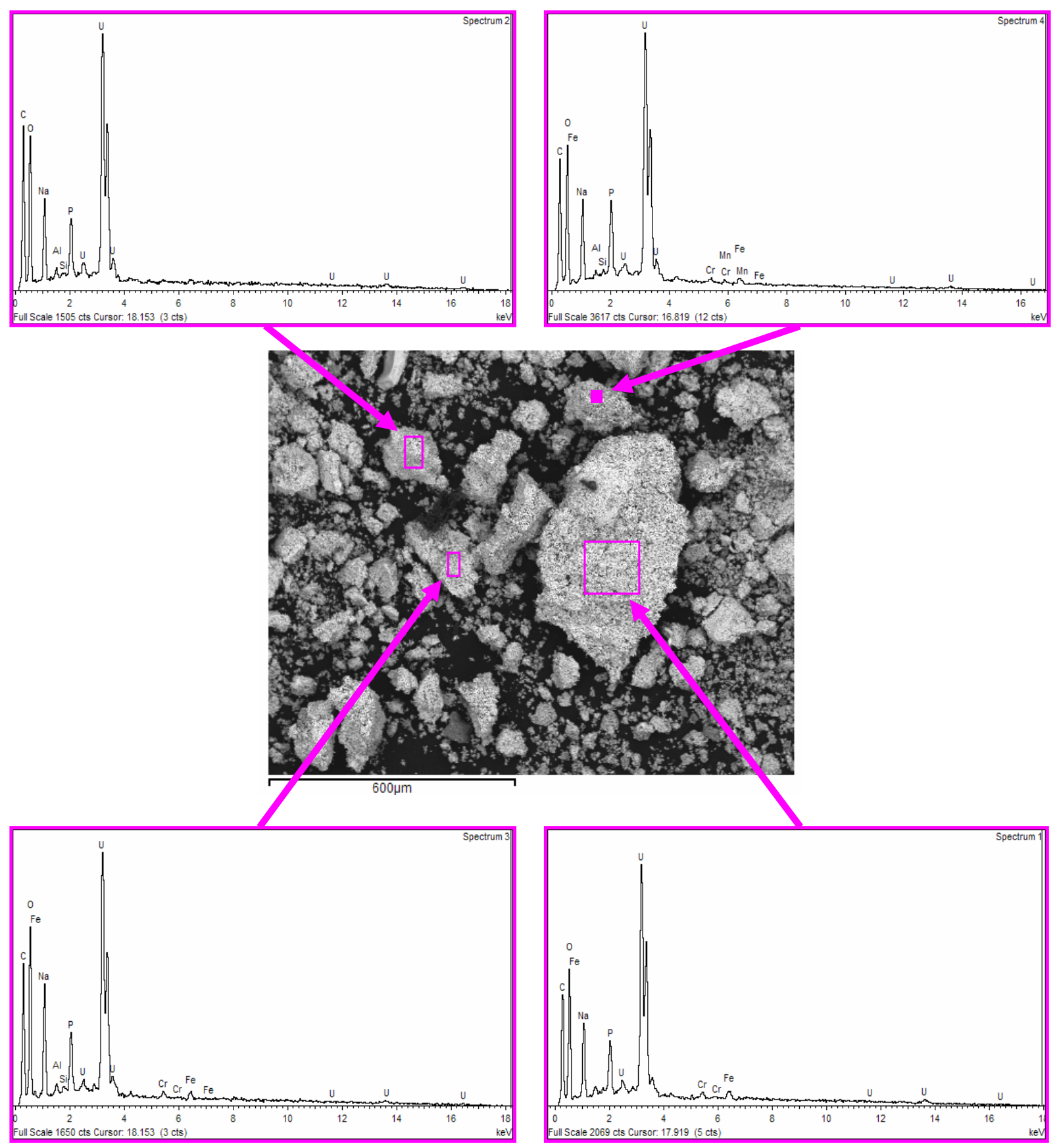

Figure 3.4. EDS Spectra for Areas in Particle Aggregate of $\mathrm{KOH}-\mathrm{Na}_{2} \mathrm{CO}_{3}$ Neutralized Metal Waste Precipitate 


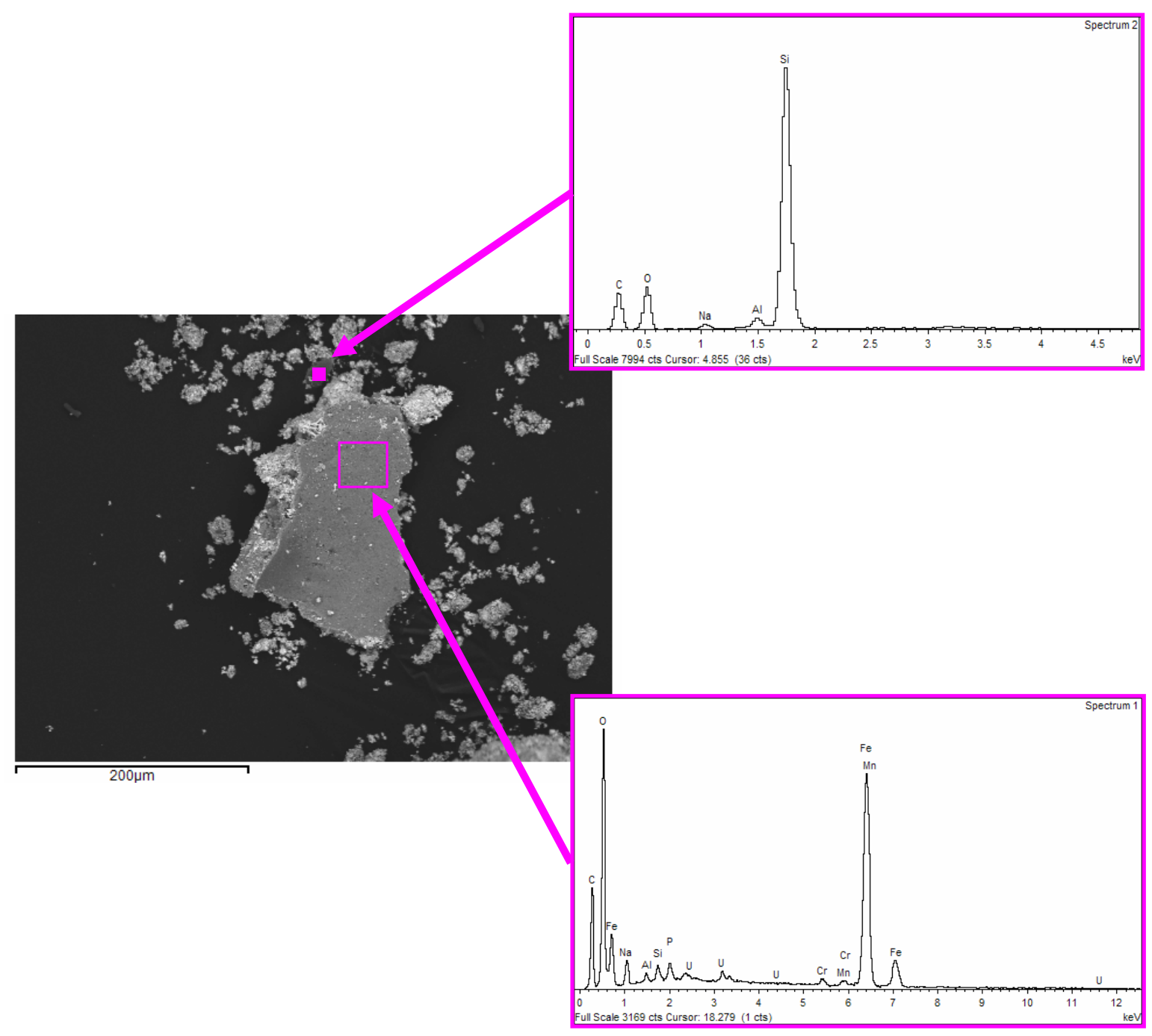

Figure 3.5. EDS Spectra for Areas in Particle Aggregate of $\mathrm{KOH}-\mathrm{Na}_{2} \mathrm{CO}_{3}$ Neutralized Metal Waste Precipitate.

Table 3.24. Elemental Oxide Composition of the KOH-Na2CO3 Neutralized Metal Waste Precipitate

\begin{tabular}{||c|c|c|c|c|c|c|c|c|c|c|c|c||}
\hline Oxide & $\mathrm{CO}_{3}$ & $\mathrm{Na}_{2} \mathrm{O}$ & $\mathrm{SiO}_{2}$ & $\mathrm{P}_{2} \mathrm{O}_{5}$ & $\mathrm{SO}_{3}$ & $\mathrm{~K}_{2} \mathrm{O}$ & $\mathrm{CaO}$ & $\mathrm{Cr}_{2} \mathrm{O}_{3}$ & $\mathrm{MnO}$ & $\mathrm{Fe}_{2} \mathrm{O}_{3}$ & $\mathrm{SrO}$ & $\mathrm{UO}_{3}$ \\
\hline $\mathrm{W} \mathrm{t} \%$ & 2.776 & 1.505 & 0.023 & 8.787 & 1.028 & 11.871 & 0.701 & 0.026 & 0.017 & 0.045 & 0.05 & 73.17 \\
\hline
\end{tabular}




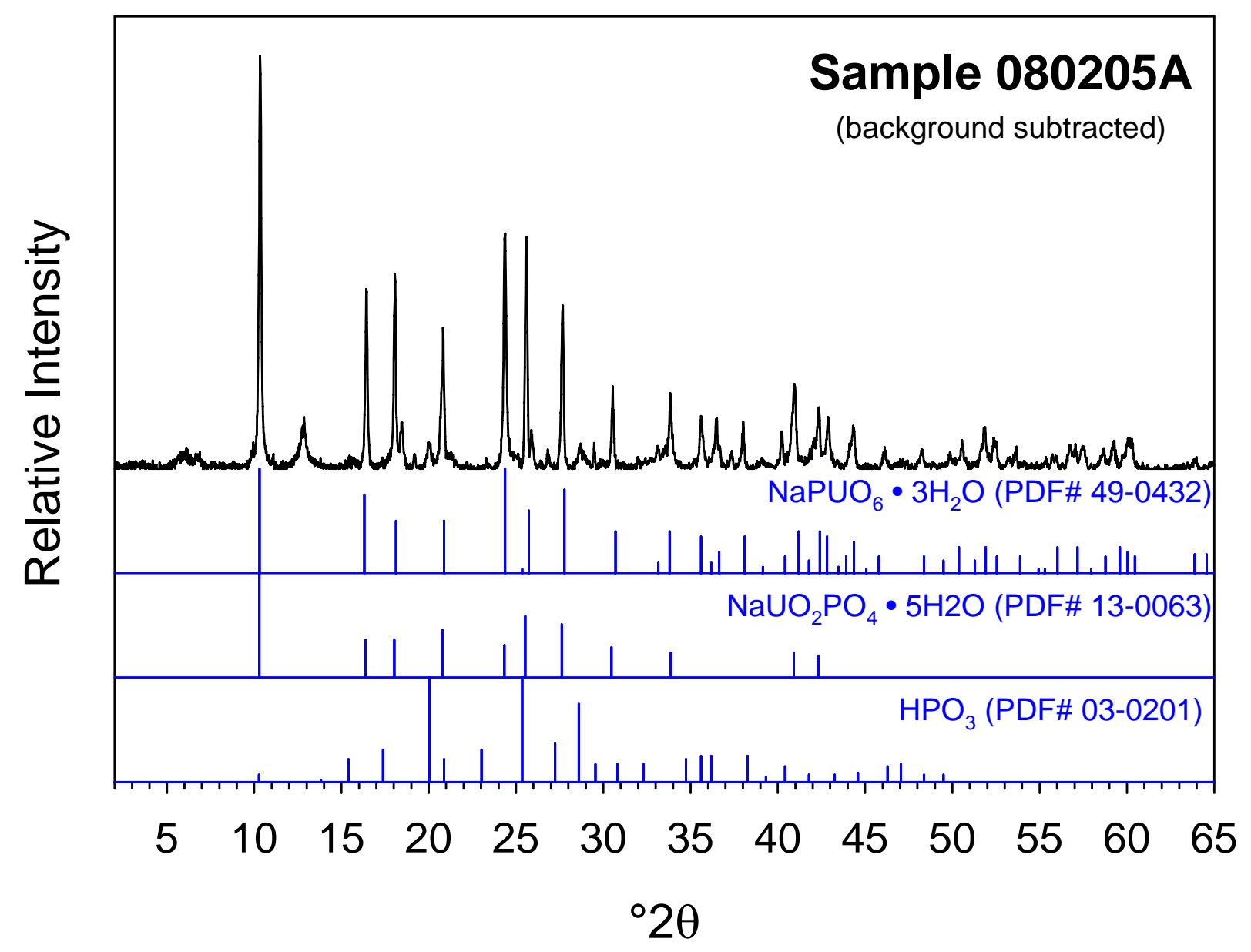

Figure 3.6. Background-Subtracted Bulk Powder XRD Tracing of Sample 080205A (solids that precipitated during neutralization of metal waste solution simulation \#4 using $\mathrm{NaOH}-\mathrm{Na}_{2} \mathrm{CO}_{3}$.) Also shown are diagnostic peaks for three minerals tentatively matching the pattern.

As can be seen from Figure 3.6, both sodium-uranyl phases have similar XRD patterns. The primary reflection characteristic to both phases is positioned at $\sim 10.30^{\circ} 2 \theta$. While all reflections produced by $\mathrm{NaUO}_{2} \mathrm{PO}_{4} \cdot 5 \mathrm{H}_{2} \mathrm{O}$ (PDF\# 13-0063) are similar to reflections produced by $\mathrm{NaPUO}_{6} \cdot 3 \mathrm{H}_{2} \mathrm{O}$ (PDF\# 49-0432), the opposite is not true. For example, reflections positioned at 35.55, 38.06, and $42.36^{\circ} 2 \theta$ are unique only to $\mathrm{NaPUO}_{6} \cdot 3 \mathrm{H}_{2} \mathrm{O}$ ( $\mathrm{PDF} \#$ 49-0432) and these three reflections are present in the XRD pattern for this $\mathrm{NaOH}-\mathrm{Na}_{2} \mathrm{CO}_{3}$ neutralized metal waste precipitate. Thus, it is evident that the XRD data are consistent with the presence of both sodium uranyl compounds containing three waters (PDF\# 49-0432) and five waters (PDF\# 13-0063), respectively.

Several minor reflections not assigned to the sodium uranyl phosphate phases discussed above were observed on the XRD tracing as well. A single minor reflection positioned at $19.237^{\circ} 2 \theta$ corresponds to the $100 \%$ reflection of uranium carbonate, $\mathrm{UO}_{2} \mathrm{CO}_{3}$ (PDF\# 11-0263). Other reflections associated with this carbonate phase were either below XRD detection limits or were positioned at the same reflections as some of those for the other crystalline phases, making positive identification of uranyl carbonate by XRD 
problematic. The unassigned reflection positioned at $18.39^{\circ} 2 \theta$ was consistent with the primary reflection of the crystalline phase uranyl sulfate hydrate, $\mathrm{UO}_{2} \mathrm{SO}_{4} \cdot \mathrm{H}_{2} \mathrm{O}(\mathrm{PDF} \# 28-1418)$. However, again because of detection limits, positive identification for this uranyl sulfate was not possible. The broad reflection positioned at $12.94^{\circ} 2 \theta$ was not assigned to a crystalline phase. No indications of amorphous material were observed in the XRD data.

Figure 3.7 and Figure 3.8 show SEM BSE micrographs of particles present in the $\mathrm{NaOH}-\mathrm{Na}_{2} \mathrm{CO}_{3}$ neutralized metal waste precipitate formed during the neutralization of batch \#4 metal waste solution. The $\mathrm{NaOH}-\mathrm{Na}_{2} \mathrm{CO}_{3}$ neutralized metal waste precipitate contains fine-grained particles as well as aggregates of these particles. The individual particles are several micrometers to sub-micrometers in size. The material is nondescript and lacks any apparent crystal faces. These particles might be needle-like and/or dendritic (feather-like) at the sub-micrometer scale.

Figure 3.9 shows the EDS spectra for several areas of the particle aggregate shown in the micrograph in the upper left of Figure 3.7. The EDS analyses indicate that the $\mathrm{NaOH}-\mathrm{Na}_{2} \mathrm{CO}_{3}$-neutralized metal waste precipitate consists primarily of particles containing $\mathrm{U}-\mathrm{Na}-\mathrm{P}-\mathrm{O}-\mathrm{C} \pm \mathrm{H}$. In the U-rich particles, the $\mathrm{x}$-ray emission peak for $\mathrm{C}(0.277 \mathrm{keV})$ is typically as large as or larger than that for $\mathrm{O}(0.525 \mathrm{keV})$, which suggests that $\mathrm{C}$ (possibly as carbonate) was present in these U-rich particles. Trace peaks for $\mathrm{Si}$ and $\mathrm{Al}$ were also identified in some of the EDS spectra for the U-rich particles. The x-ray emission peak for $\mathrm{S}$ $(2.308 \mathrm{keV})$ was not detected in the EDS analyses of the U-rich particles.

Initial SEM/EDS studies also showed the presence of some $\mathrm{Al}$ (major)- $\mathrm{O} \pm \mathrm{C} \pm \mathrm{H}$ particles (possibly also containing some $\mathrm{P}$ and $\mathrm{U}$ ) in the $\mathrm{NaOH}-\mathrm{Na}_{2} \mathrm{CO}_{3}$-neutralized metal waste precipitate (Figure 3.10). Because these particles are fine grained, the peaks for $\mathrm{P}$ and $\mathrm{U}$ in the EDS spectra for these $\mathrm{Al}-\mathrm{O} \pm \mathrm{C} \pm \mathrm{H}$ particles probably come from $\mathrm{x}$-ray emissions from adjacent $\mathrm{U}-\mathrm{Na}-\mathrm{P}-\mathrm{O} \pm \mathrm{C} \pm \mathrm{H}$ particles. The $\mathrm{NaOH}-$ $\mathrm{Na}_{2} \mathrm{CO}_{3}$ neutralized metal waste precipitate also contains particles of $\mathrm{Fe}-\mathrm{O}$, which usually had lesser amounts of $\mathrm{Cr}, \mathrm{Mn}$, and possibly Ni (Figure 3.9). The same Fe-O particles were found in the SEM spectra for the $\mathrm{KOH}-\mathrm{Na}_{2} \mathrm{CO}_{3}$-neutralized metal waste precipitates. The Fe-O particles are less abundant than the U-rich particles in precipitates from both neutralization processes. Additional EDS spectra for $\mathrm{NaOH}-\mathrm{Na}_{2} \mathrm{CO}_{3}$ - neutralized metal waste precipitate are shown in Appendix C. 

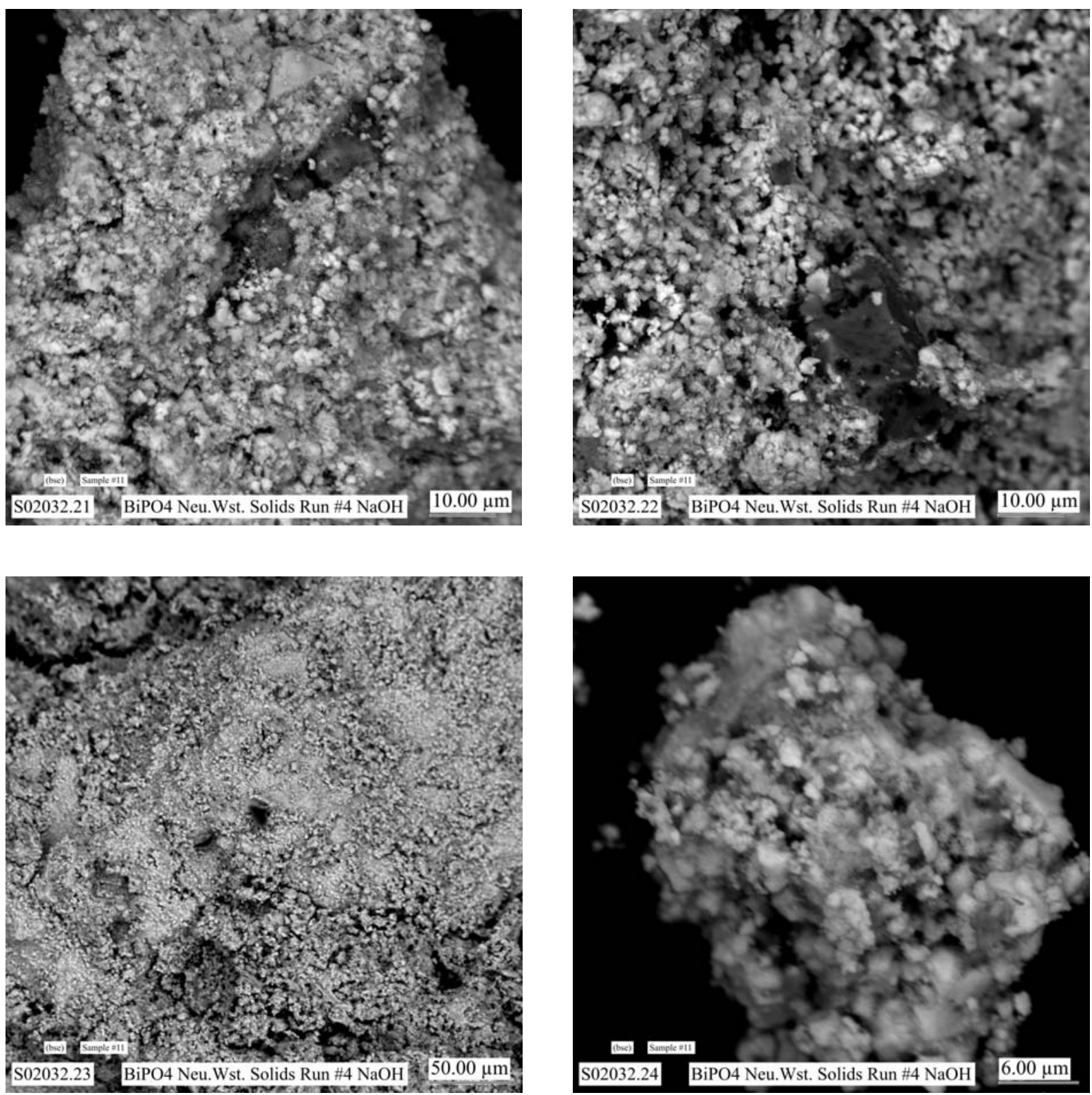

Figure 3.7. SEM BSE Micrographs of Particles in $\mathrm{NaOH}-\mathrm{Na}_{2} \mathrm{CO}_{3}$ Neutralized Metal Waste Precipitate. (The name of each digital image file, sample identification number, and a size scale bar are given, respectively, at the bottom left, center, and right of each SEM micrograph in this and all subsequent SEM figures.) 

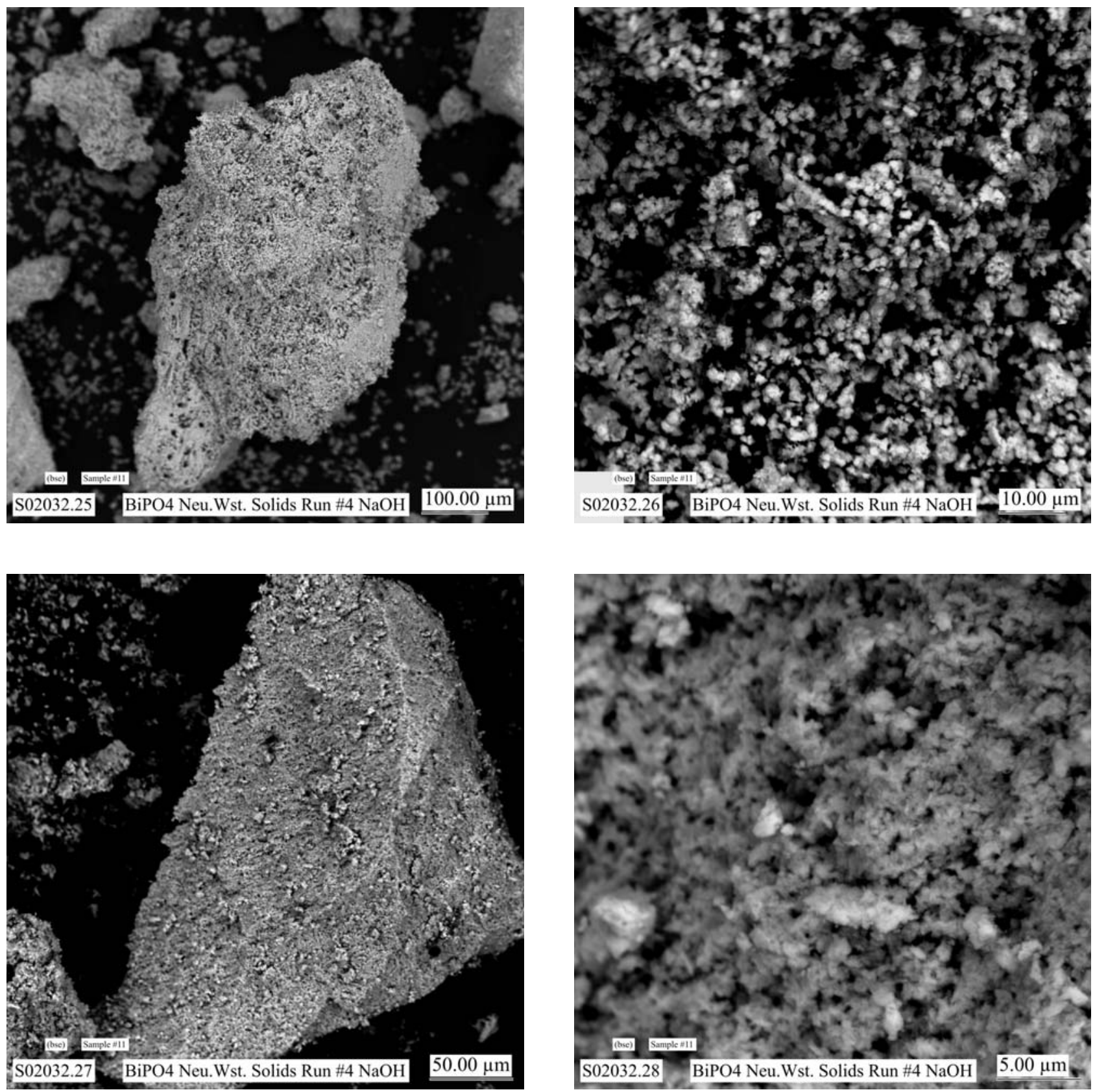

Figure 3.8. SEM BSE Micrographs of Particles in $\mathrm{NaOH}-\mathrm{Na}_{2} \mathrm{CO}_{3}$ Neutralized Metal Waste Precipitate. 


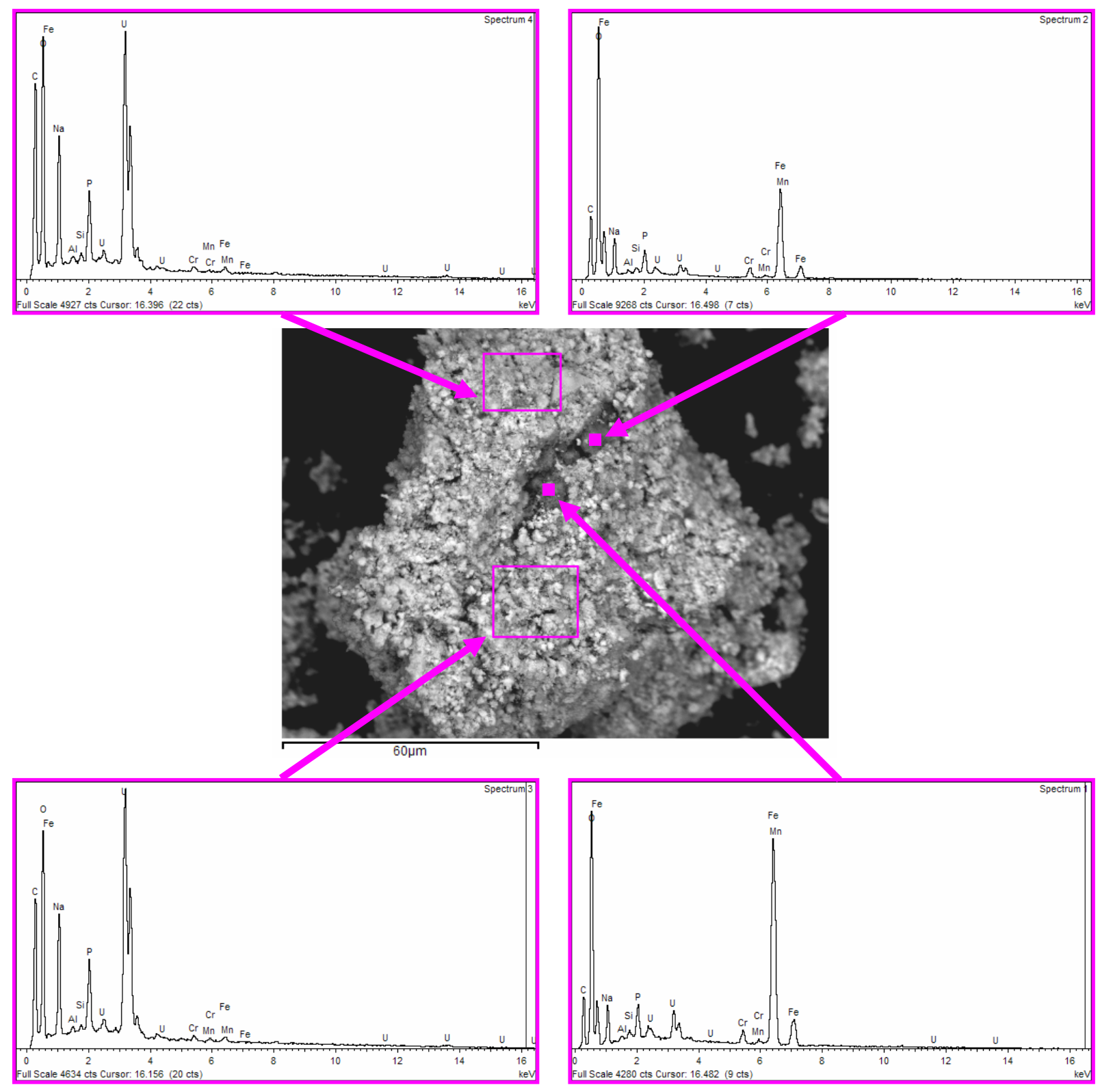

Figure 3.9. EDS Spectra for Areas in a Particle Aggregate of $\mathrm{NaOH}-\mathrm{Na}_{2} \mathrm{CO}_{3}$ Neutralized Metal Waste Precipitate 


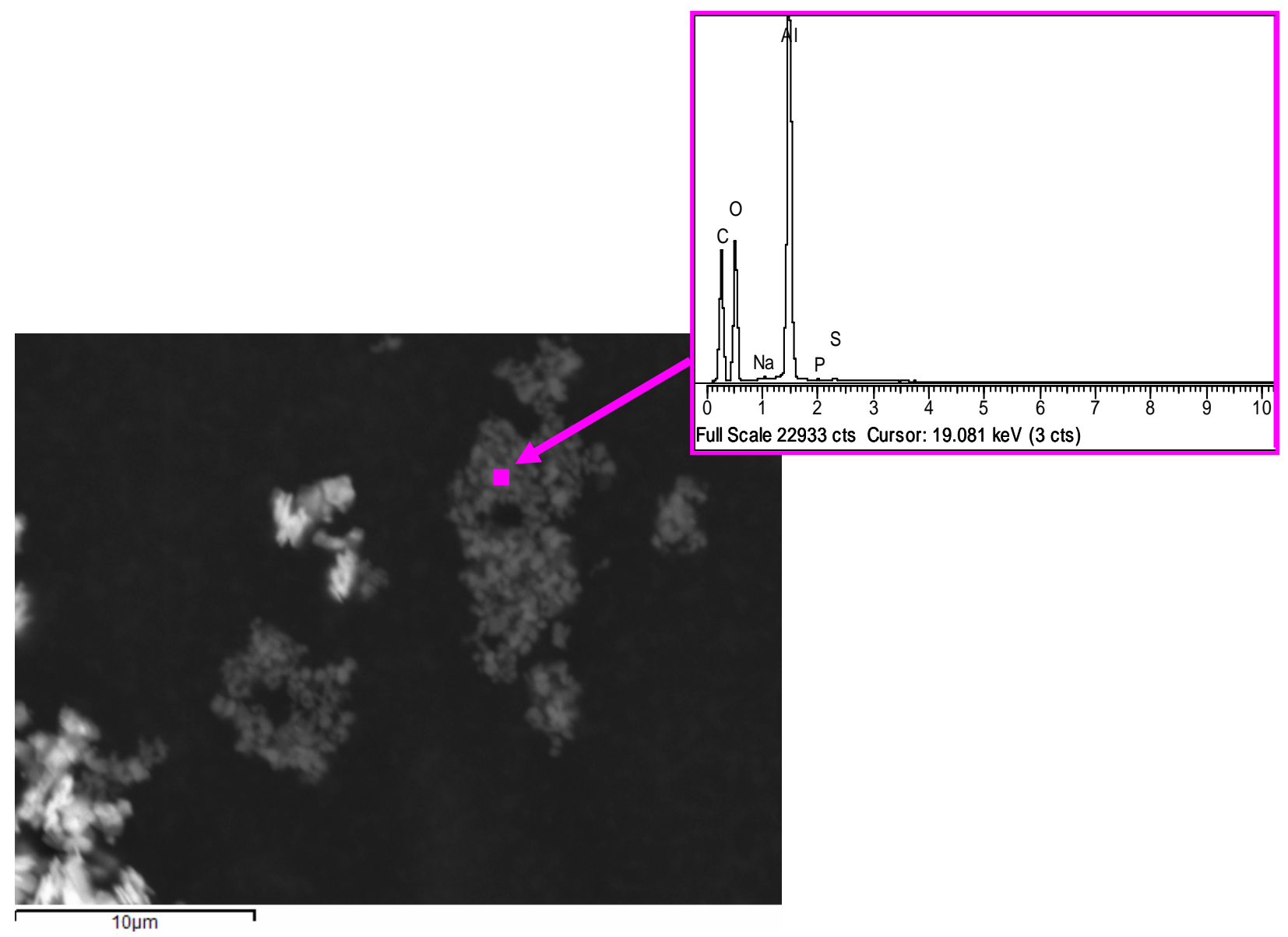

Figure 3.10. EDS Spectrum for an $\mathrm{Al}-\mathrm{O} \pm \mathrm{C} \pm \mathrm{H}$ Particle in $\mathrm{NaOH}-\mathrm{Na}_{2} \mathrm{CO}_{3}$ Neutralized Metal Waste Precipitate

An aliquot of the $\mathrm{NaOH}-\mathrm{Na}_{2} \mathrm{CO}_{3}$-neutralized metal waste precipitate was ground to a fine powder and analyzed by semi-quantitative XRF and by total carbon analyzer to determine the elemental composition (as oxides). The XRF results are shown in Table 3.25. In general, the XRF results are in agreement with the XRD results, which suggest sodium uranyl phosphates and perhaps uranyl carbonate are present. As mentioned, XRF cannot detect light elements such as carbon so the XRF results cannot corroborate the presence of uranyl carbonate but the carbon analyzer found that carbon was present. The $\mathrm{KOH}-\mathrm{Na}_{2} \mathrm{CO}_{3}$ neutralized solids contained higher carbon concentrations than the $\mathrm{NaOH}-\mathrm{Na}_{2} \mathrm{CO}_{3}$ and the $\mathrm{XRD}$ results for the former solid were more conclusive in identifying a carbonate-bearing phase. The SEM-EDS results on uranium-rich phases suggest carbonate is present in both precipitates. Thus all three characterization tools, XRD, SEM-EDS, and total carbon analyzer yield a consistent story, given the varying detection limits of the three techniques, that some carbonate is present in the precipitates. The lower sulfate content in the $\mathrm{NaOH}-\mathrm{Na}_{2} \mathrm{CO}_{3}$ neutralized metal waste precipitate in comparison with the $\mathrm{KOH}-\mathrm{Na}_{2} \mathrm{CO}_{3}$-neutralized solid also is consistent with the characterization results that show fairly strong indications of a sulfate mineral being present in the $\mathrm{KOH}-\mathrm{Na}_{2} \mathrm{CO}_{3}$-neutralized solids (XRD and SEMEDS), but both techniques yielded no or uncertain indications of sulfate minerals in the $\mathrm{NaOH}-\mathrm{Na}_{2} \mathrm{CO}_{3}$ neutralized metal waste precipitate. The XRF data suggesting lower sulfate in the $\mathrm{NaOH}-\mathrm{Na}_{2} \mathrm{CO}_{3}-$ neutralized metal waste precipitate would help explain why the XRD and SEM-EDS results are inconclusive. As found via SEM-EDS, the XRF results also suggest the presence of trace amounts of iron 
and chromium in both neutralized metal waste precipitates. Again there may be some sulfate in the $\mathrm{NaOH}-\mathrm{Na}_{2} \mathrm{CO}_{3}$ - neutralized metal waste precipitate, although the SEM-EDS did not observe the presence of sulfur.

The $\mathrm{NaOH}-\mathrm{Na}_{2} \mathrm{CO}_{3}$-neutralized metal waste precipitate also appears to contain trace amounts of bismuth, which was not observed in the $\mathrm{KOH}-\mathrm{Na}_{2} \mathrm{CO}_{3}$-neutralized metal waste precipitate. The bismuth might be residual bismuth phosphate solids not separated during the removal of the metal waste solution from the plutonium-bearing product. The major difference between the XRF results for the two precipitates from the metal waste solution neutralization processes is the higher potassium in the first neutralization, which was caused by the inadvertent use of $\mathrm{KOH}$ instead of $\mathrm{NaOH}$, and the lower sulfate content in the $\mathrm{NaOH}-\mathrm{Na}_{2} \mathrm{CO}_{3}$-neutralized metal waste precipitate. The XRD results for the $\mathrm{KOH}-$ $\mathrm{Na}_{2} \mathrm{CO}_{3}$-neutralized metal waste precipitates did identify potassium uranyl sulfate as being present but, for the $\mathrm{NaOH}-\mathrm{Na}_{2} \mathrm{CO}_{3}$ - neutralized metal waste precipitate, XRD results were much more tentative on whether a uranyl sulfate mineral was present. Overall, the process wherein acidic metal waste solution is neutralized prior to being sent to single-shell tanks for storage caused the precipitation of sodium uranyl phosphates and perhaps sodium(?)-uranyl carbonate and alkali metal-uranyl sulfate solid phases.

Table 3.25. Elemental Oxide Composition of the $\mathrm{NaOH}-\mathrm{Na}_{2} \mathrm{CO}_{3}$ Neutralized Metal Waste Precipitate

\begin{tabular}{||c|c||}
\hline Oxide & $\mathrm{Wt} \%$ \\
\hline \hline $\mathrm{CO}_{3}$ & 1.576 \\
\hline $\mathrm{Na}_{2} \mathrm{O}$ & 2.706 \\
\hline $\mathrm{SiO}_{2}$ & 0.000 \\
\hline $\mathrm{P}_{2} \mathrm{O}_{5}$ & 10.159 \\
\hline $\mathrm{SO}_{3}$ & 0.664 \\
\hline $\mathrm{K}_{2} \mathrm{O}$ & 0.098 \\
\hline $\mathrm{CaO}$ & 0.723 \\
\hline $\mathrm{Cr}_{2} \mathrm{O}_{3}$ & 0.026 \\
\hline $\mathrm{MnO}_{2} \mathrm{O}$ & 0.000 \\
\hline $\mathrm{Fe}_{2} \mathrm{O}_{3}$ & 0.078 \\
\hline $\mathrm{SrO}_{2}$ & 0.049 \\
\hline $\mathrm{Bi}_{2} \mathrm{O}_{3}$ & 0.527 \\
\hline $\mathrm{UO}_{3}$ & 83.394 \\
\hline
\end{tabular}





\subsection{Conclusions}

Four simulations of the bismuth phosphate precipitation process show that only trace amounts of ${ }^{99} \mathrm{Tc}$ $(1 \pm 1 \%),{ }^{135,137} \mathrm{Cs}(0.1$ to $<1 \%),{ }^{103,106} \mathrm{Ru}(<0.1 \%)$, and ${ }^{129} \mathrm{I}(<0.5 \%)$ would precipitate with the bismuth phosphate product used to capture plutonium from dissolved irradiated fuel. Thus, these isotopes should have remained mostly within the metal waste stream that after neutralization was sent to single-shell tanks. Very little $(\sim 1$ to $<2 \%)$ of the ${ }^{90} \mathrm{Sr}$ and $\sim 1.3 \%{ }^{125} \mathrm{Sb}$ (antimony) would precipitate with the bismuth phosphate product. Certainly less than the $10 \%$ of any of these isotopes would partition into the bismuth phosphate solids; it was this value (10\%) that had been used, until the results herein were made available, to develop the inventories that were disposed to cribs and trenches from the $1^{\text {st }}$ and $2^{\text {nd }}$ Cycle wastes of the bismuth phosphate product $(\mathrm{Pu})$ purification process. Stated differently, significant quantities (up to $10 \%$ ) of these isotopes should not be found in the $1^{\text {st }}$ and $2^{\text {nd }}$ Cycle and subsequent plutonium purification waste streams that went to Hanford's cribs and some trenches.

We conclude that nearly all of the ${ }^{99} \mathrm{Tc}$ remains in the metal waste stream that was sent to single-shell tanks and only trace amounts of ${ }^{99} \mathrm{Tc}$ (certainly not $10 \%$ of the total) ended up going to the $1^{\text {st }}$ and $2^{\text {nd }}$ Cycle waste streams generated from re-dissolution/purification of the " $\mathrm{Pu}$ " bismuth phosphate solids. The $1^{\text {st }}$ and $2^{\text {nd }}$ Cycle waste solutions were neutralized and cascaded through a series of tanks to settle and collect solids before being disposed to cribs. Past assumptions that these wastes contained $10 \%$ of all beta-emitting fission products are erroneous. Based on the fact that so little ${ }^{99} \mathrm{Tc}$ was found to associate with the bismuth phosphate solids, we infer that technetium is not reduced to a lower and more insoluble valence state by the nitrite used in the first bismuth phosphate precipitation step to reduce all the plutonium to $\mathrm{Pu}(\mathrm{IV})$

The results of our laboratory simulation of the first steps in the bismuth phosphate process have been incorporated into revisions of the Soil Inventory Model (Corbin et al. 2005) and new predictions of the waste disposed to the B-38 trench are in much better agreement with the observed distribution and concentrations of nitrate, ${ }^{99} \mathrm{Tc}$ and other fission products. Therefore, this work has helped to clear up the observed inconsistencies in field data for the distribution of contaminants, especially ${ }^{99} \mathrm{Tc}$ in the B-38 trench and other nearby facilities, in the vadose zone sediments below inactive cribs and trenches that received $1^{\text {st }}$ and $2^{\text {nd }}$ Cycle bismuth phosphate decontamination wastes.

Measurable quantities ( 20 to $30 \%$ ) of the lanthanide fission products and trivalent actinides (Am and $\mathrm{Cm}$ ) do precipitate with the bismuth phosphate solids, which contain the plutonium product. Selenium tracer (added as selenate) also shows about $10 \%$ association with the $\mathrm{Pu} /$ bismuth phosphate solids. The bulk of the U daughter product ${ }^{234} \mathrm{Th}$ and ${ }^{237} \mathrm{~Np}$ daughter product ${ }^{233} \mathrm{~Pa}$ also associates with the Pu-bearing bismuth phosphate solids. We suspect that the protactinium daughter products of $U\left({ }^{234} \mathrm{~Pa}\right.$ and $\left.{ }^{231} \mathrm{~Pa}\right)$ would also co-precipitate with the bismuth phosphate solids. Our data for ${ }^{237} \mathrm{~Np}$ was a bit erratic but suggest a few to $7 \%$ is found in the Pu-bearing bismuth phosphate solids.

The quality of the analytical data for the four simulations of the bismuth phosphate process shows very good mass balance for uranium, phosphate, sulfate, and sodium but we appear to have somewhat low recovery of bismuth. All in all though, the mass recoveries suggest that the ICP-MS and ICP-OES analyses of the concentrated metal storage solution, metal waste solution, and re-dissolved bismuth phosphate solid are very good for most of the key risk-driving fission products and major constituents used in the bismuth phosphate process. 
The metal waste solution that is generated after the first bismuth phosphate precipitation step in the process used to separate plutonium from the irradiated fuel contains most of the fission products and the dissolved uranium. This highly radioactive acidic solution was transferred to large tanks in the bismuth phosphate plants (B and T Plants) where neutralization was performed using sodium hydroxide followed by sodium carbonate (soda ash). The neutralized waste was then transferred to single-shell tanks generally in a cascade fashion (as the first tank was filled, suspended solids would settle and the supernatant solution would cascade to a second tank and then a third tank at selected tank farms).

The metal waste solution from all four bismuth phosphate simulations was neutralized but only the solids and resultant neutralized solution from simulations \#2 and \#4 were characterized. Inadvertently, potassium hydroxide solution was used incorrectly for neutralization of the first three simulations. The metal waste solution from the fourth simulation, which was performed about a year after the first three simulations, was correctly neutralized using sodium hydroxide. The correct amount of sodium carbonate, as the second step of the neutralization, was used for all four of the neutralization simulations. The neutralized metal waste solutions were allowed to settle for several days, then centrifuged so that the clear supernatant solution could be decanted and further filtered through $0.45-\mu \mathrm{m}$ filter membranes. The macro chemical composition of the neutralized supernatant from batches \#2 and \#4 contained high dissolved sodium (and potassium because of the inadvertent use of $\mathrm{KOH}$ in runs \#1 through \#3) and high concentrations of nitrate, sulfate, and uranium from the starting metal storage solution (the dissolved fuel rods) and phosphate from the bismuth phosphate precipitation step. The neutralized metal waste solution also contained significant dissolved carbonate from the soda ash used to keep uranium soluble during the neutralization process.

The volumes of the two neutralized metal waste solutions that were characterized varied significantly and thus the final concentrations varied, with neutralized run $\# 4$ being significantly more concentrated in dissolved solids. We believe the large differences in final volumes and concentrations reflect varying degrees of evaporation of water during the neutralization process, which were performed in open containers in a negative pressure fume hood. On an absolute mass basis the amount of nitrate, phosphate, sulfate, sodium (potassium), and carbonate in solution for the two neutralized supernatant solutions was quite similar; thus it appears that evaporation of water is the cause of the differences in concentrations. It should be noted that the concentration of dissolved uranium does not vary dramatically between the two neutralized solutions, suggesting that a solubility limit may have been controlling the dissolved uranium concentration. In both neutralized metal waste solutions, the final concentration of dissolved phosphate was above $0.6 \mathrm{M}$, which is the minimum concentration of phosphate that the developers of the bismuth phosphate process suggested was needed to keep high percentages of uranium from precipitating during the neutralization step.

The fate of key fission products present in the metal waste solution during neutralization are as follows. In general, greater than $99 \%$ of the technetium remains in solution and is ultimately found in the neutralized metal waste solution that was sent to single-shell tanks. The technetium essentially remains in the dissolved state throughout the whole bismuth phosphate process from fuel dissolution through metal waste solution neutralization. At most a few tenths of a percent of the technetium is found in the bismuth phosphate product solids and at most $<2 \%$ of the technetium is found in the precipitates that form during the metal waste neutralization process. Recall that the neutralized metal waste precipitates also were sent to the single-shell tanks suspended in the neutralized supernatant solution. 
The uranium mass balance throughout the whole bismuth phosphate simulation was well characterized and $20 \%$ to $40 \%$ of the uranium found in the metal waste solution remained in the supernatant solution after neutralization. From the perspective of the original metal storage solution (dissolved fuel), $19 \%$ to $37 \%$ of the uranium remains in the neutralized metal waste supernatant solution. Much (75\%) of the uranium initially present in the dissolved fuel ends up precipitated in the solids formed by neutralization of the metal waste solution. Only about $0 \%$ to at most $3 \%$ of the uranium appears to precipitate with the plutonium product. Because very little of the uranium associates with the bismuth phosphate product, almost all of it ended up in single-shell tanks with much of it in the neutralized precipitates. However, substantial concentrations (see Table 3.18) of uranium remain in the neutralized metal waste supernatant solution. This is the solution that escaped BX-102 during the 1951 tank overfill event.

The fate of other potentially mobile fission and activation products such as ${ }^{79} \mathrm{Se},{ }^{125} \mathrm{Sb},{ }^{237} \mathrm{~Np}$, and ${ }^{90} \mathrm{Sr}$ as determined from the two metal waste neutralization simulations yielded somewhat variable results. Selenium showed highly variable partitioning between the neutralized metal waste supernatant solution and the neutralized metal waste precipitates in simulations $\# 2$ and $\# 4$. In simulation $\# 2,80 \%$ of the selenium precipitated with the solids formed but in simulation \#4 none precipitated. We suspect some analytical problems occurred in our radiocounting data for the ${ }^{75} \mathrm{Se}$ tracer. Regardless, the fate of selenium has $\sim 90 \%$ ending up in single-shell tanks in either the suspended solids or dissolved state. Upon neutralization of the metal waste, which contains more than $99 \%$ of the antimony present in dissolved irradiated fuel, antimony partitions nearly equally between the neutralized metal waste supernatant solution and the neutralized metal waste precipitate (55\% remaining dissolved and $45 \%$ precipitating). Neptunium's fate during neutralization of metal waste is also variable. In simulation \#2 about two-thirds of the neptunium present in the metal waste solution precipitates during the neutralization step whereas in simulation \#4 about $85 \%$ precipitates. About $2 \%$ to $7 \%$ of the total neptunium is found to associate with the bismuth phosphate product solid also. Thus neptunium's overall fate is to be associated with solids more so than the liquid waste streams from the first bismuth phosphate step.

The fate of strontium during metal waste solution neutralization also showed variation between simulations \#2 and \#4. For the \#2 simulation, the radiotracer ${ }^{85} \mathrm{Sr}$ partitions mostly into the solid precipitate whereas the stable strontium results suggest that about one-third of the strontium remains in the neutralized metal waste supernatant solution during neutralization, but because simulation \#2 erroneously used $\mathrm{KOH}$, we favor the results of simulation \#4. For simulation \#4 both the radiotracer and stable strontium neutralization results suggest about $12 \%$ to $18 \%$ of the strontium present in the metal waste solution remains soluble while the rest precipitates during the neutralization stage. About $88 \%$ of the strontium in the metal waste solution precipitates during neutralization and thus would be found predominately in suspended solids that would settle in the single-shell tanks after disposal. The ultimate fate of strontium in dissolved irradiated fuel is that $2 \%$ is found in the bismuth phosphate product, $87 \%$ precipitates in the neutralized metal waste, and $11 \%$ is found in the neutralized metal waste supernatant. The latter two fractions were both sent to single-shell tanks. However, our experiments may have underestimated the percentage of strontium that co-precipitated with the bismuth phosphate product because we used distilled/de-ionized water as make-up water and our source of phosphoric acid was likely more pure than the commercial product available in the 1940s and 1950s. The key concern is that in the actual bismuth phosphate processing, both the make-up water and phosphoric acid likely contained dissolved calcium that could also precipitate during the bismuth phosphate precipitation stage. The calcium could have caused strontium $\left({ }^{90} \mathrm{Sr}\right)$ to co-precipitate into the plutonium-laden bismuth phosphate. 
With further purification, the co-precipitated strontium would have been disposed in the waste streams that went to Hanford cribs and trenches. Thus, our value of $2 \%$ of the ${ }^{90} \mathrm{Sr}$ precipitating with the plutonium product and ultimately being disposed to cribs/trenches may be the minimum value. More experiments with varying amounts of calcium added to the metal storage solution would be required to determine the effects of calcium on the fate of ${ }^{90} \mathrm{Sr}$ during the bismuth phosphate processing.

The cesium results are also quite variable with simulation \#2 neutralization showing most of the radiotracer ${ }^{137} \mathrm{Cs}(90 \%)$ precipitating during neutralization but the stable Cs results suggest that cesium remains in the dissolved state during neutralization. This suggests some analytical problem might be present in the simulation \#2 neutralization activities. Neutralization of simulation \#4 metal waste solution showed good agreement between the radiotracer and stable Cs results with $63 \%$ to $73 \%$ of the cesium present in the metal waste solution remaining in the dissolved state after neutralization. Conversely, in the neutralization of simulation \#4 metal waste solution, both the stable and radiotracer form of cesium show $\sim 30 \%$ associates with the neutralized solids that precipitate. We suspect that the high potassium concentration in simulation \#2, present because of the incorrect use of $\mathrm{KOH}$ to initiate the $\mathrm{pH}$ neutralization of the metal waste, caused a problem. We thus favor simulation \#4 results which, when combined with data in Table 3.15, show at least $95 \%$ to $98 \%$ of the cesium in the dissolved irradiated fuel ends up in the metal waste, which is disposed to single-shell tanks, and upon neutralization $70 \%$ of the cesium in the metal waste remains in the dissolved state and $30 \%$ associates with suspended solids.

The fate of iodide during metal waste solution neutralization could not be determined because a key measurement (neutralized supernatant solution for simulation \#2) could not be performed when the LEPS detector became inoperable. However, based on the other available data on the distribution of iodide during the bismuth phosphate processing, less than $0.6 \%$ of the iodide partitioned to the bismuth phosphate product and essentially all of the iodide should be found in the neutralized waste stream (either in supernatant solution or as neutralized solids suspended in the supernate), which is disposed to single-shell tanks. The data for iodide only reflects iodine species that do not volatilize during the fuel decladding and fuel dissolution stages. As discussed in the introduction, $\sim 85 \%$ of the iodine escaped during these steps and thus was not present in the acidic metal storage solution used in the bismuth phosphate process.

The radiotracer ${ }^{152} \mathrm{Eu}$ data and all the ICP-MS data for europium, cerium, lanthanum, and praseodymium show a consistent pattern with $<5 \%$ of the lanthanides present in the metal waste solution remaining in solution after neutralization. Essentially $>95 \%$ of the lanthanides present in the metal waste precipitate upon neutralization and from the perspective of the original dissolved fuel (metal storage solution), only a few percent, at most, of the lanthanides remain in the dissolved state in the neutralized waste. About $10 \%$ to $20 \%$ of the lanthanide elements associate with the bismuth phosphate product solids and the rest ends up in the neutralized metal waste precipitates that are slurried into single-shell tanks where they ultimately settle to form sludge. At most, a few percent of these elements remain in the supernatant solution in the single-shell tanks, which would have constituted the fluids leaked from singleshell tanks containing bismuth phosphate waste. The same is true for yttrium and zirconium.

Rubidium, as measured by ICP-MS, yielded erratic results for the neutralized metal waste supernatant solution for simulation \#2, perhaps because of some mass interference from a complex species caused by the high potassium present. It appears that rubidium in simulation \#4 is approximately evenly split between remaining in the neutralized metal waste supernatant solution and in the neutralized metal waste solids. This result is similar to the fate of cesium in the neutralization of test \#4. The barium results, 
using ICP-MS, were highly variable throughout the bismuth phosphate process simulation. Barium remains slightly more soluble during the metal waste neutralization process with $75 \%$ to $84 \%$ remaining in solution; based on the amount of barium present in the dissolved fuel (metal storage solution), about $65 \%$ to $75 \%$ of the barium remains in solution all the way through the neutralization step. A higher percentage of the barium appears to remain in the dissolved state than strontium during neutralization, which does not seem logical. We thus do not put much confidence in the barium measurements for any of the solutions analyzed for the whole bismuth phosphate simulation.

Almost all of the sulfate present in the metal waste solution remains dissolved during the neutralization process; however, a small amount of sulfate is likely present in the solids that precipitate during the metal waste neutralization process. The phosphate present in the metal waste solution distributes about evenly between the neutralized supernatant solution and the precipitates that form during the neutralization steps. Phosphate containing minerals were identified in the neutralized solids.

The solids that settled out of the neutralized metal waste solution were washed several times in distilled water. The washed and dried solids from neutralized batches \#2 and \#4 were characterized by XRD, SEM-EDS, and XRF. The neutralization of the metal waste solution generated $13.5 \%$ and $7.2 \%$ solids on a dry weight basis for batches \#2 and \#4, respectively. Batch \#4 was performed correctly whereas batch $\# 2$ used potassium hydroxide $(\mathrm{KOH})$ inadvertently instead of sodium hydroxide $(\mathrm{NaOH})$. The amount of solids generated in batch \#4 was within the range desired and strived for based on discussion in the original bismuth phosphate technical manual. XRD results for the neutralized solids from batch \#2 indicate the presence of three uranium-rich crystalline phases: potassium uranyl phosphate hydrate $\left(\mathrm{KPUO}_{6} \cdot 3 \mathrm{H}_{2} \mathrm{O}\right)$, potassium uranyl sulfate hydrate $\left[\mathrm{K}_{2} \mathrm{UO}_{2}\left(\mathrm{SO}_{4}\right)_{2} \cdot 2\left(\mathrm{H}_{2} \mathrm{O}\right)\right.$, and the uranium carbonate mineral Grimselite $\left[\mathrm{K}_{3} \mathrm{NaUO}_{2}\left(\mathrm{CO}_{3}\right)_{3} \cdot \mathrm{H}_{2} \mathrm{O}\right]$. One other crystalline phase was detected in trace amounts by XRD in the batch \#2 neutralized solids; silicon dioxide $\left(\mathrm{SiO}_{2}\right)$. XRD patterns for the solids from the fourth bismuth phosphate simulation metal waste after neutralization indicate that sodium uranyl phosphate hydrate, $\mathrm{NaPUO}_{6} \cdot 3 \mathrm{H}_{2} \mathrm{O}$, and possibly a minor amount of $\mathrm{NaUO}_{2} \mathrm{PO}_{4} \cdot 5 \mathrm{H}_{2} \mathrm{O}$ as well as trace amounts of hydrogen phosphate are present. Several minor reflections not assigned to the sodium uranyl phosphate phases were observed in the XRD tracing from the neutralization of batch \#4. A single minor reflection corresponds to the $100 \%$ reflection of uranium carbonate, $\mathrm{UO}_{2} \mathrm{CO}_{3}$. Other reflections associated with this carbonate phase were either below XRD detection limits or were positioned at the same reflections as some of those for the other crystalline phases, making positive identification of uranyl carbonate by XRD problematic. Another unassigned reflection was consistent with the primary reflection of the crystalline phase uranyl sulfate hydrate, $\mathrm{UO}_{2} \mathrm{SO}_{4} \bullet \mathrm{H}_{2} \mathrm{O}$. However, again because of detection limits, positive identification for this uranyl sulfate was not possible. No indications of amorphous material were observed in the XRD pattern for either neutralized solids.

The solids from the XRD mounts were further characterized using SEM-EDS, XRF, and a total carbon analyzer. Both the neutralization \#2 and \#4 precipitates are very similar in appearance using the SEM, which can distinguish down to a micron size. The neutralized metal waste precipitates contain finegrained particles as well as aggregates of these particles. Individual particles ranged in size from several micrometers to less than a micrometer. The material is nondescript and lacks any apparent crystal faces, in contrast to the crystalline nature of the XRD characterization. The neutralized metal waste particles might be needle-like and/or dendritic (feather-like) at the sub-micrometer scale but could not be characterized on our SEM system, which is old and relegated to characterizing radioactive samples. To probe the sub-micron particles in more detail, TEM would be the preferred technique. 
EDS analyses indicate that the $\mathrm{KOH}-$ neutralized metal waste precipitate consists primarily of poorly descript particles of U-K-Na-P-O $\pm \mathrm{C} \pm \mathrm{H}$. The EDS analyses for the $\mathrm{NaOH}-\mathrm{Na}_{2} \mathrm{CO}_{3}$ neutralized metal waste precipitate indicate that it consists primarily of particles containing $\mathrm{U}-\mathrm{Na}-\mathrm{P}-\mathrm{O}-\mathrm{C} \pm \mathrm{H}$. In the U-rich particles, the x-ray emission peak for carbon is typically as large as or larger than that for oxygen, which suggests that carbonate was present in some of the U-rich particles. Trace peaks for Si and Al were also identified in some of the EDS spectra for the U-rich particles. The x-ray emission peak for sulfur was not detected in the EDS analyses of the U-rich particles. Both neutralized metal waste precipitates also contain particles of Fe-O, which usually had lesser amounts of chromium, manganese, and possibly nickel. The Fe-O particles are less abundant than the U-rich particles in precipitates from both metal waste neutralization tests that were characterized.

Aliquots of the two neutralized metal waste precipitates were analyzed by XRF and by a total carbon analyzer to get a semi-quantitative estimate of the total elemental composition as oxides. The XRF results are in general agreement with the XRD and SEM-EDS results. The precipitates appear to be dominated by uranyl, potassium, or sodium depending on which caustic was used - phosphate, carbonate, or sulfate. The trace amounts of iron, manganese, and chromium are consistent with the trace amount of iron oxide particles observed by SEM-EDS. These elements may have come from equipment and containers used during the bismuth phosphate process lab-scale simulations.

The $\mathrm{KOH}-\mathrm{Na}_{2} \mathrm{CO}_{3}$ - neutralized solids contained higher carbon concentrations than the $\mathrm{NaOH}$ $\mathrm{Na}_{2} \mathrm{CO}_{3}$-neutralized solids and the XRD results for the former solid were more conclusive in identifying a carbonate-bearing phase. The SEM-EDS results on uranium-rich phases suggest carbonate is present in both precipitates. Thus all three characterization tools, XRD, SEM-EDS, and total carbon analyzer, yield a consistent story, given the varying detection limits of the three techniques, that some carbonate is present in the neutralized metal waste precipitates.

The lower sulfate content in the $\mathrm{NaOH}-\mathrm{Na}_{2} \mathrm{CO}_{3}$-neutralized metal waste precipitate in comparison with the $\mathrm{KOH}-\mathrm{Na}_{2} \mathrm{CO}_{3}$-neutralized solid also is consistent with the characterization results, which show fairly strong indications of a sulfate mineral being present in the $\mathrm{KOH}-\mathrm{Na}_{2} \mathrm{CO}_{3}$-neutralized solids (XRD and SEM-EDS), but both techniques yielded no or uncertain indications of sulfate minerals in the $\mathrm{NaOH}-\mathrm{Na}_{2} \mathrm{CO}_{3}$-neutralized metal waste precipitate. The XRF data suggesting lower sulfate in the $\mathrm{NaOH}-\mathrm{Na}_{2} \mathrm{CO}_{3}$-neutralized metal waste precipitate would help explain why the XRD and SEM-EDS results are inconclusive for this solid. Overall, the process wherein acidic-metal waste solution is neutralized prior to being sent to single-shell tanks for storage caused the precipitation of sodium uranyl phosphates, perhaps sodium(?)-uranyl carbonate, and perhaps alkali metal-uranyl sulfate solid phases. There may be some sulfate in the precipitates, although the SEM-EDS did not observe the presence of sulfur. The neutralized solids characterization and the chemical composition of the neutralized supernatant solution should prove valuable information to the ongoing studies of the uranium-rich fluids that were lost to the subsurface to the east of Tank BX-102 during an overfill event in 1951. 


\subsection{References}

Agnew, SF. 1995. "Hanford Defined Wastes: Chemical and Radionuclide Compositions."

LA-UR-94-2657, Rev 2, Los Alamos National Laboratory, Los Alamos, New Mexico.

Agnew, SF, J Boyer, RACorbin, TB Duran, JR FitzPatrick, KA Jurgensen, TP Ortiz, and BL Young. 1996. "Hanford Tank Chemical and Radionuclide Inventories: HDW Model Rev. 3. LA-UR-96-858, Los Alamos National Laboratory, Los Alamos, New Mexico.

Agnew, SF, J Boyer, RACorbin, TB Duran, JR FitzPatrick, KA Jurgensen, TP Ortiz, and BL Young. 1997. "Hanford Tank Chemical and Radionuclide Inventories: HDW Model Rev. 4. LA-UR-96-3860, Los Alamos National Laboratory, Los Alamos, New Mexico.

Anderson, JD. 1990. "A History of the 200 Area Tank Farms." WHC-MR-0132, Westinghouse Hanford Company, Richland, Washington.

Anonymous. 1944. "Hanford Technical Manual Part C.” HW-10475-C, Hanford Works (General Electric), Richland, Washington.

BHI. 1995. B Plant Aggregate Area Management Study Technical Baseline Report. BHI-00179,Rev. 00, Bechtel Hanford, Inc., Richland, Washington.

BHI. 1996. 200 Areas Soil Remediation Strategy - Environmental Restoration Program.

DOE/RL-96-67, Rev. 0, Bechtel Hanford, Inc., Richland, Washington.

Browne, WG. 1952. "Brief Summary of Separation Processes.” HW-26365, Hanford Works (General Electric), Richland, Washington. declassified memo dated November 25, 1952 and accessed as $H W-26365$ in http://www2.hanford.gov/declass

Cleveland, JM. 1967. Plutonium Handbook: A Guide to the Technology, O. J. Wick, ed., Gordon and Breach, New York.

Corbin, RA, BC Simpson, MJ Anderson, WF Danielson III, JG Field, TE Jones, and CT Kincaid. 2005. Hanford Soil Inventory Model, Rev 1. RPP-26744, CH2M-Hill Hanford Group, Inc., Richland, Washington. (also published as PNNL-15367)

DOE/RL. 1994. 200-BP-11 Operable Unit RFI/CMS and 216-B-3 Main Pond, 216-B-63, Trench and 216-A-29 Ditch Work/Closure Plan. DOE/RL-93-74, U. S. Department of Energy, Richland Operations Office, Richland, Washington.

DOE-RL. 2003. Focused Feasibility Study for the U Plant Closure Area Waste Sites, Draft A. DOE/RL-2003-23, U.S. Department of Energy, Richland Operations Office, Richland, Washington.

Dreher, JL. 1945a. "Memorandum Report SE-PC-36 --Cause and Prevention of Uranium Precipitates in the Extraction of Neptunium." HW-3-253, Hanford Works (General Electric), Richland, Washington. Also called CN-3176, and accessed at http://www2.hanford.gov/declass 
Dreher, JL. 1945b. "Memo Report SE-PC-70 -The Evolution of Iodine during Metal Dissolution." HW-3-3003, Hanford Works (General Electric), Richland, Washington. Also called CN-3285, and accessed at http://www2.hanford.gov/declass

Fluor Hanford. 2003. Optimization Strategy for Central Plateau Closure. WMP-18061, Rev. 0, Fluor Hanford, Inc., Richland, Washington.

Holm, CH. 1951. "Retention of Iodine in Process Solutions by Mercuric Salts.” HW-21103, Hanford Works (General Electric), Richland, Washington.

Knepp, AJ. 2002a. Field Investigation Report for Waste Management Area S-SX. RPP-7884, CH2M Hill Hanford Group, Inc., Richland, Washington.

Knepp, AJ. 2002b. Field Investigation Report for Waste Management Area B-BX-BY. RPP-10098, CH2M Hill Hanford Group, Inc., Richland, Washington.

Lindenmeier, CW, RJ Serne, BN Bjornstad, DC Lanigan, MJ Lindberg, RE Clayton, VL LeGore, IV Kutnyakov, SR Baum, KN Geiszler,MM Valenta, and TS Vickerman. 2002. "Characterization of Vadose Zone Sediment: Borehole C3103 Located in the 216-B-7A Crib Near the B Tank Farm." PNNL-14128, Pacific Northwest National Laboratory, Richland, Washington.

Maxfield, HL. 1979. “Handbook 200 Area Waste Sites.” RHO-CD-673, Vols. I-III, Rockwell Hanford Operations, Richland, Washington.

Myers, DA. 2005. Field Investigation Report for Waste Management Areas T and TX-TY. RPP-10098, CH2M Hill Hanford Group, Inc., Richland, Washington.

Mirabella, JE. 1977. "Radioactive Liquid Waste Discharged to Ground in the 200 Areas during 1976." ARH-CD-743, 4Q, Atlantic Richfield Hanford Company, Richland, Washington.

Schwenneson, JL. 1950. "Activity of Fission Products as a Function of Decay Time, and Relationship to the TBP Process.” HW-17091, Hanford Works (General Electric), Richland, Washington.

Serne, RJ, GV Last, GW Gee, HT Schaef, DC Lanigan, CW Lindenmeier, MJ Lindberg, RE Clayton, VL LeGore, RD Orr, IV Kutnyakov, SR Baum, KN Geiszler, CF Brown, MM Valenta, and TS Vickerman. 2002a. "Characterization of Vadose Zone Sediment: Borehole 299-E33-45 Near BX-102 in the B-BX-BY Waste Management Area." PNNL-14083, Pacific Northwest National Laboratory, Richland, Washington.

Serne, RJ, BN Bjornstad, GW Gee, HT Schaef, RG McCain, DC Lanigan, CW Lindenmeier, RD Orr, VL LeGore, RE Clayton, MJ Lindberg, IV Kutnyakov, SR Baum, KN Geiszler, MM Valenta, TS Vickerman, and LJ Royack. 2002b. "Characterization of Vadose Zone Sediment: Borehole 299-E33-46 Near B-110 in the B-BX-BY Waste Management Area." PNNL-14119, Pacific Northwest National Laboratory, Richland, Washington.

Serne, RJ, BN Bjornstad, DG Horton, DC Lanigan, CW Lindenmeier, MJ Lindberg, RE Clayton, VL LeGore, RD Orr, IV Kutnyakov, SR Baum, KN Geiszler, MM Valenta, TS Vickerman and HT Schaef. 2004a. "Characterization of Vadose Zone Sediments Below the T Tank Farm: Boreholes 
C4104, C4105, 299-W10-196 and RCRA Borehole 299-W11-39.” PNNL-14849, Pacific Northwest National Laboratory, Richland, Washington.

Serne, RJ, BN Bjornstad, DG Horton, DC Lanigan, CW Lindenmeier, MJ Lindberg, RE Clayton, VL LeGore, RD Orr, IV Kutnyakov, SR Baum, KN Geiszler, MM Valenta, and TS Vickerman. 2004b. "Characterization of Vadose Zone Sediments Below the TX Tank Farm: Boreholes C3830, C3831, C3832 and RCRA Borehole 299-W10-27.” PNNL-14594, Pacific Northwest National Laboratory, Richland, Washington.

Simpson, B. C., R. A. Corbin, and S.F. Agnew. 2001 "Groundwater/Vadose Zone Integration Project Hanford Soil Inventory Model.” BHI-01496, Rev. 0, Bechtel Hanford Inc, Richland, Washington.

Swartout, J. A. 1945. "Decontamination of Fission Elements in the Separation Process" declassified memo dated January 22, 1945 and accessed as HW-3-1493 in http://www2.hanford.gov/declass

Waite, JL. 1991. "Tank Wastes Discharged Directly to the Soil at the Hanford Site." WHC-MR-0227, Westinghouse Hanford Company, Richland, Washington. 



\section{Appendix A}

\section{Precipitate Formed in Metal Storage Solution}





\section{Appendix A - Precipitate Formed in Metal Storage Solution}

During the preparation of the metal storage solution (see Table 2.1 in main text), as the uranyl nitrate hexahydrate was being added to the sulfuric and nitric acid solution containing stable fission products, a precipitate formed. The solid was removed, washed, oven dried, weighed and examined by bulk powder XRD. The oven dry weight of the precipitate was $5.88 \mathrm{~g}$.

The XRD pattern of precipitate (labeled sample 010703D) compared to PDF\# 21-1276 and PDF\# 26-0096 is presented in Figure A.1. The main crystalline compound identified in the precipitate was uranyl sulfate hydrate $\left(\mathrm{UO}_{2} \mathrm{SO}_{4} \cdot 2.5 \mathrm{H}_{2} \mathrm{O}\right)$, which was a perfect match to PDF\# 26-0996 (Figure A.1).

A second crystalline phase appearing in the precipitate produced reflections at 27.398, 36.086, 41.234 , and $54.241^{\circ} 2 \theta$. These intense reflections matched rutile (Figure A.1), a titanium dioxide mineral belonging to the tetragonal crystal system. Although titanium was not added with any of the reagents used to create the metal storage solution (the starting solution that represents dissolved irradiated fuel), we originally thought it was plausible that other tetravalent cations, such as $\mathrm{Zr}, \mathrm{Pd}, \mathrm{Pr}$, and $\mathrm{Ce}$ which were added to the metal storage solution, could have precipitated into a rutile-like structure and formed a crystalline phase that is not documented in the powder diffraction database. We were perplexed because the XRD patterns for the common oxides of $\mathrm{Zr}, \mathrm{Pd}, \mathrm{Pr}$, and $\mathrm{Ce}$ are known and they are not similar to rutile and further, the observed XRD peak that was identified as rutile is quite large suggesting a large mass formed. We know the mass of stable fission products added and they were relatively small. Additionally, the broad reflection positioned at $6.0^{\circ} 2 \theta$ indicates a poorly crystalline $14 \AA$ phyllosilicate phase that might have formed during the precipitation process. Additionally analysis using preferred oriented mounting techniques would be required before positively identifying the presumed rutile phase by XRD.

After the unexpected XRD results were obtained, the metal storage solution precipitate in the XRD mounts were used to perform SEM-EDS characterization in hopes of determining the identity of the rutile-like structured phase. Figures A.2 through A.5 show SEM BSE micrographs of particles present in metal storage solution precipitate. The material is coarse to very fine grained and appears nondescript and amorphous or poorly crystalline at the scale imaged by SEM. Figure A.5 shows EDS spectra for several areas of the particle aggregate shown in the micrograph in the lower left of Figure A.2.

The EDS analyses indicate that the metal storage solution precipitate contains two major phases. The most dominant phase contains Ti-O (gray particles in Figures A.2 through A.4). The second important phase is made up of U-S-O (bright white particles/areas in Figures A.2 through A.4). Ti was common (based on $\mathrm{K}_{\alpha}$ alpha and $\mathrm{K}_{\beta} \mathrm{X}$-ray emission peaks at 4.511 and $4.932 \mathrm{keV}$, respectively) in all of the aggregate material of metal storage solution precipitate studied by SEM/EDS. Most of the EDS spectra also contained $\mathrm{Si}$ (peak at $1.740 \mathrm{keV}$ ) and probably lesser amounts of $\mathrm{Fe}$ (peak at $6.402 \mathrm{keV}$ ). Additional EDS spectra for metal storage solution precipitate grains are shown in Appendix B.

The EDS information is consistent with the XRD data, which concluded the precipitate was a mixture of uranyl sulfate and rutile $\left(\mathrm{TiO}_{2}\right)$ with minor amounts of a silica-bearing phase. No iron oxide phases were identified by XRD, which is consistent with the much more sensitive EDS finding of low occurrences of iron. 


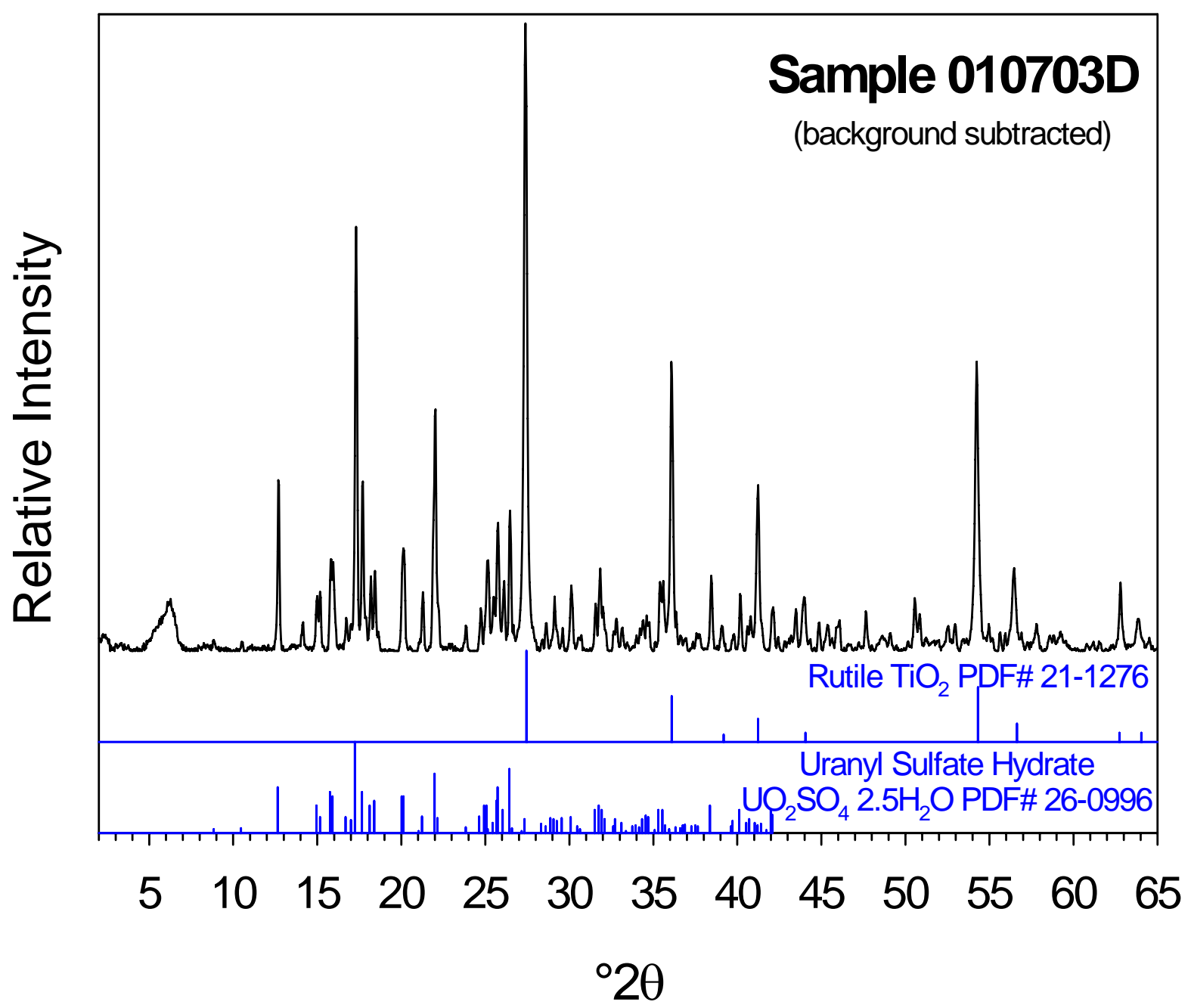

Figure A.1. Background-subtracted Bulk Powder XRD Tracing of Sample 010703D Shown with XRD Data for Uranyl Sulfate Hydrate (PDF\# 26-0996) and Rutile, TiO2, (PDF\# 21-1206). 


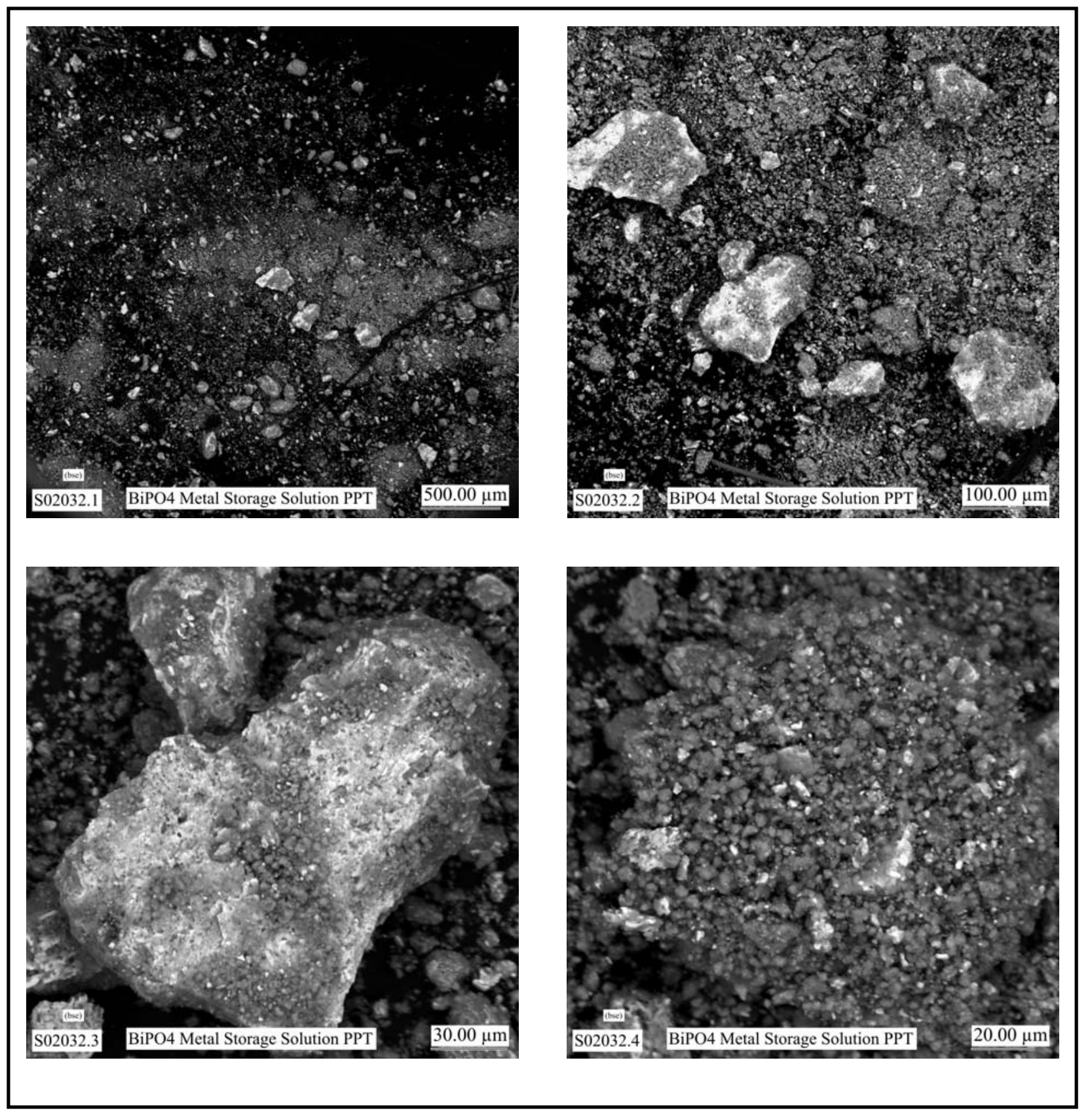

Figure A.2. SEM BSE Micrographs of Particles of Metal Storage Solution Precipitate 


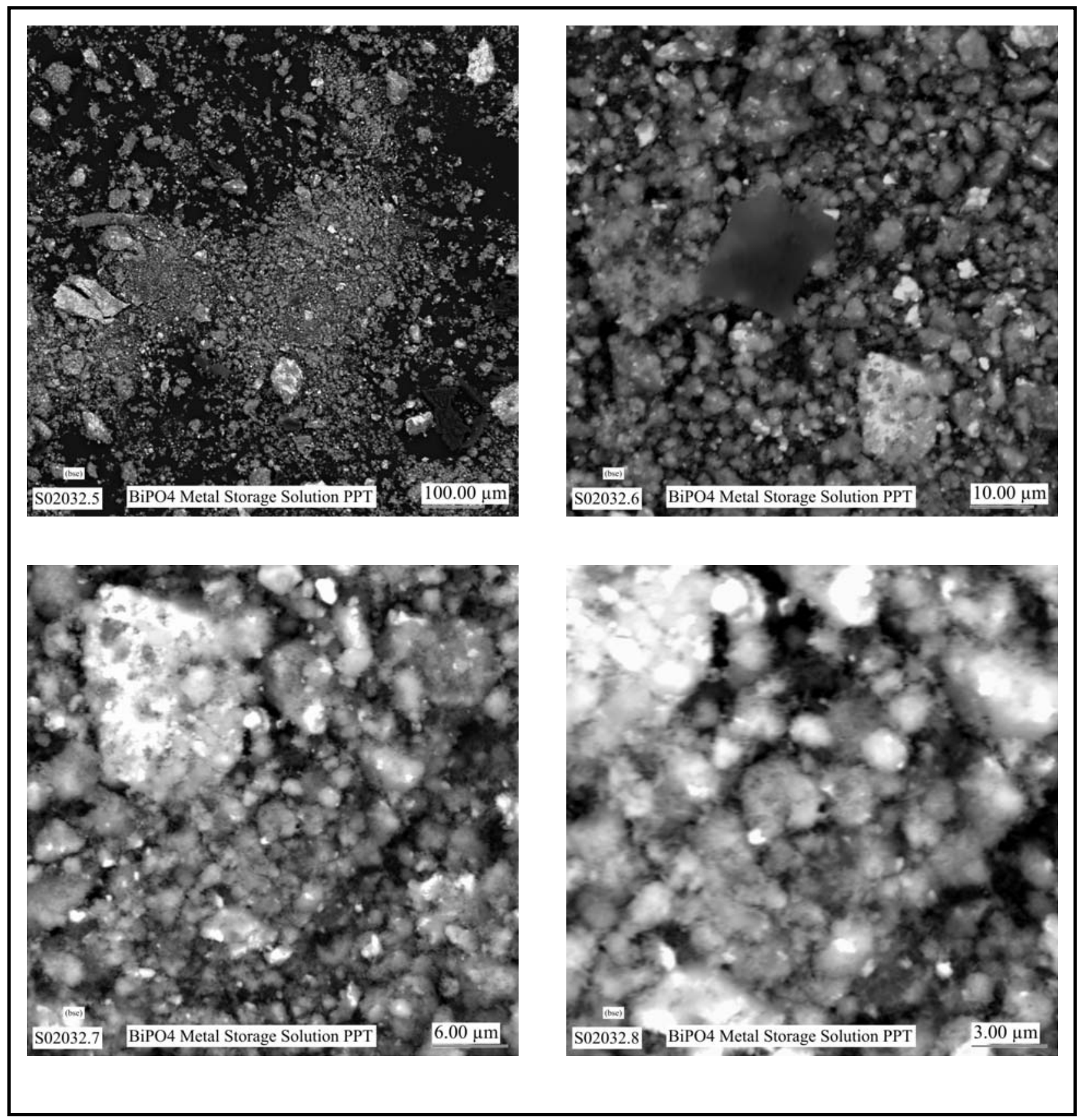

Figure A.3. SEM BSE Micrographs of Particles of Metal Storage Solution Precipitate 


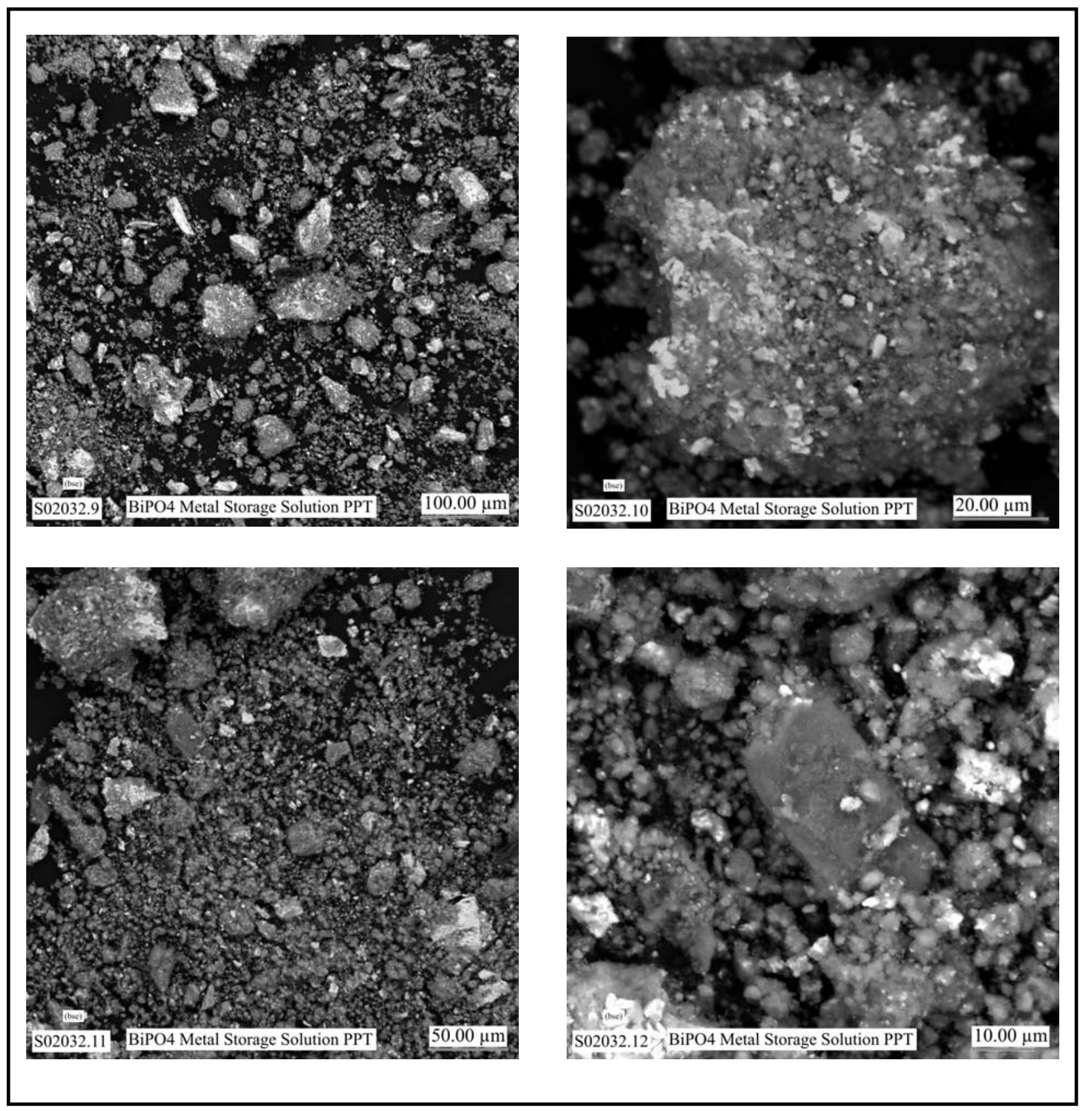

Figure A.4. SEM BSE Micrographs of Particles of Metal Storage Solution Precipitate 


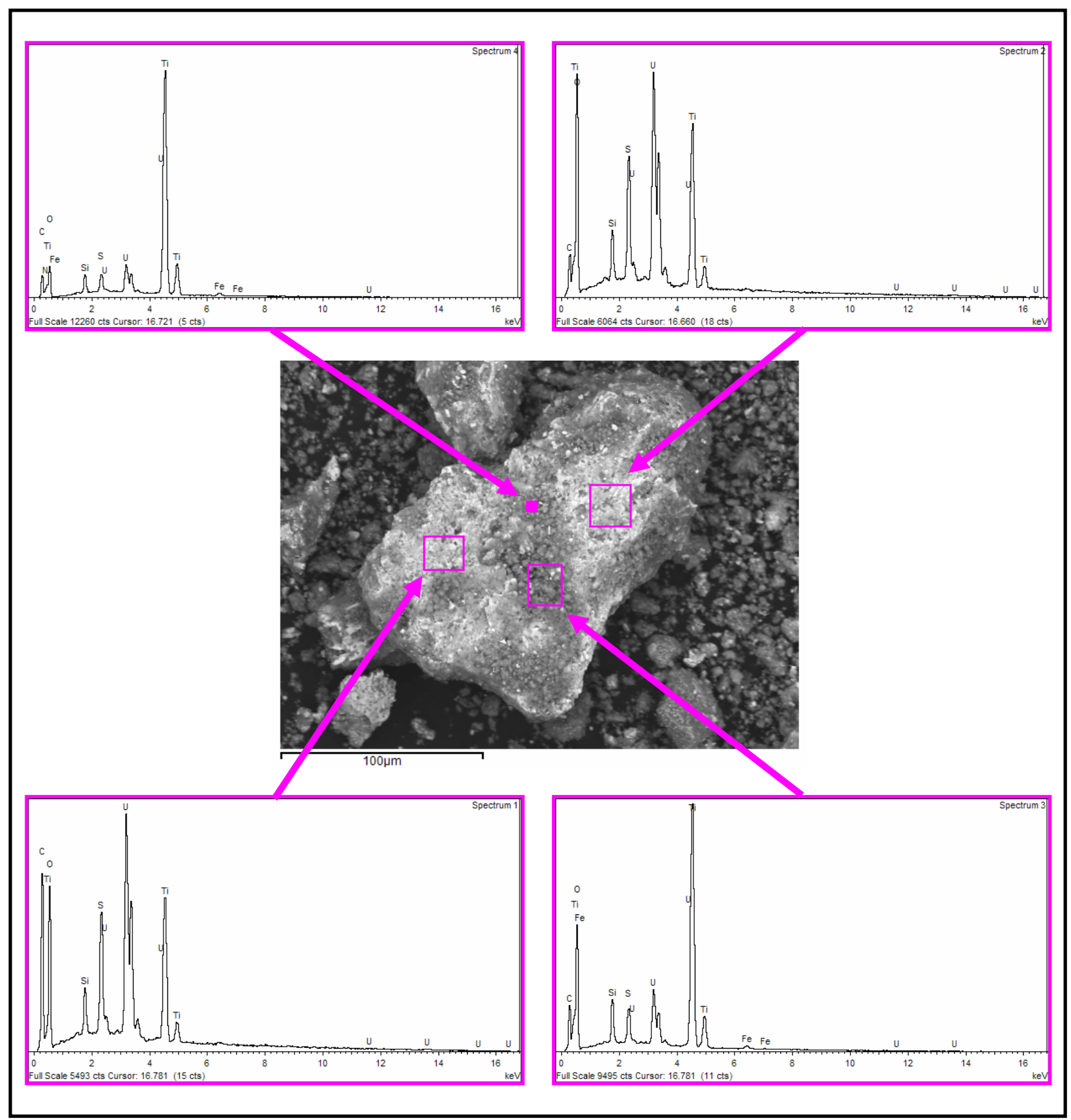

Figure A.5. EDS Spectra for Areas in a Particle Aggregate of Metal Storage Solution Precipitate

After some discussions, we realized that we could measure semi-quantitatively the chemical composition of the precipitate from the metal storage solution preparation using $\mathrm{x}$-ray fluorescence (XRF). This was done on a several-gram aliquot of the precipitate, after pulverizing the particles to a powder as preferred for XRF analysis. The powdered solid was then placed in a standard sample cup and analyzed on a Bruker Pioneer XRF using the vendor-provided standard-less algorithm/software. The results of the analysis are shown in Table A.1. The semi-quantitative XRF results show the precipitate is dominated by rutile and uranyl sulfate as suggested by the XRD patterns. There are also small amounts of silica, in agreement with the XRD suggestion that a phyllosilicate mineral is present, in agreement with 
the SEM-EDS analysis. The ratio of uranium to sulfate based on the XRF semi-quantitative results is enriched in uranium compared to the stochiometric ratio in the crystalline uranyl sulfate mineral identified in the XRD pattern. Thus we are do not know how accurate the semi-quantitative XRD data are that are based on a standard-less data reduction of the raw signals. Nonetheless, it is apparent that rutile makes up a large portion of the precipitate formed during the creation of the metals storage solution (see Table A.1) using reagent-grade sulfuric and nitric acids and uranium nitrate hexahydrate.

Table A.1. Semi-Quantitative Oxide Composition of the Metal Storage Precipitate

\begin{tabular}{||c|c||}
\hline Oxide & \% wt \\
\hline \hline $\mathrm{Al}_{2} \mathrm{O}_{3}$ & 0.04 \\
\hline $\mathrm{SiO}_{2}$ & 5.75 \\
\hline $\mathrm{SO}_{4}$ & 5.30 \\
\hline $\mathrm{TiO}_{2}$ & 62.22 \\
\hline $\mathrm{Fe}_{2} \mathrm{O}_{3}$ & 1.07 \\
\hline $\mathrm{UO}_{3}$ & 25.61 \\
\hline
\end{tabular}

Finding rutile solids in the metals storage solution lead us to investigate the original chemical reagent uranium nitrate hexahydrate. The manufacturer's spec sheet (attached as Appendix D) gave no indication that there was measurable titanium, iron, or silica impurity. We analyzed the reagent-grade uranium hexahydrate using both XRD and semi-quantitative XRF. Material was taken directly from one of the one-pound glass jars that the reagent was shipped in. Figure A.6 shows the XRD pattern.

The XRD pattern for the uranyl nitrate hydrate (UNH) $\left[\mathrm{UO}_{2}\left(\mathrm{NO}_{3}\right)_{2} \bullet 6 \mathrm{H}_{2} \mathrm{O}\right]$ indicates the presence of two crystalline uranyl phases: uranyl nitrate hydrate $\left[\mathrm{UO}_{2}\left(\mathrm{NO}_{3}\right)_{2} \bullet 6 \mathrm{H}_{2} \mathrm{O}\right](\mathrm{PDF} \# 27-0936)$ and uranyl nitrate hydrate $\mathrm{UO}_{2}\left(\mathrm{NO}_{3}\right)_{2} \bullet 3 \mathrm{H}_{2} \mathrm{O}$ (PDF\# 27-0937). Reflections corresponding to the uranyl phase with three waters appear to be slightly shifted, indicating a hydration state slightly different than three waters. No other crystalline solids were identified in the purchased uranyl nitrate hydrate compound. The fact that the reagent chemical appears to be a mixture of two nitrate minerals with differing waters of hydration complicates the calculation of the concentration of uranium in the metals storage solution. In addition, the fact that all the added uranium did not remain dissolved as evidenced by the presence of uranium sulfate in the precipitate removed from the metal storage solution requires that the starting uranium concentration in the metal storage solution be directly measured. See additional discussion in the main text.

The reagent-grade uranium nitrate hexahydrate was also analyzed by XRF using the semi-quantitative standard-less software used by the Bruker Pioneer model XRF. The results are shown in Table A.2. The XRF cannot detect light elements such as nitrogen or hydrogen so the nitrate and water portion of the uranium nitrate hexahydrate compound are not considered in the calculation of the oxide composition of the solid. Therefore the absolute weight percent derived from the XRF software is not correct. However, it is apparent that there is titanium impurity in the reagent chemical with a concentration of perhaps a few percent. It is quite possible that a few percent rutile impurity in the starting reagent could have formed the major mass found in the solid removed from the metal storage solution. The mass of UNH used to create the liter of metal storage solution was $498.7 \mathrm{~g}$. If this chemical contained $1 \%$ by weight rutile impurity there would have been $\sim 5 \mathrm{~g}$ of rutile available. The total mass of precipitate removed from the 


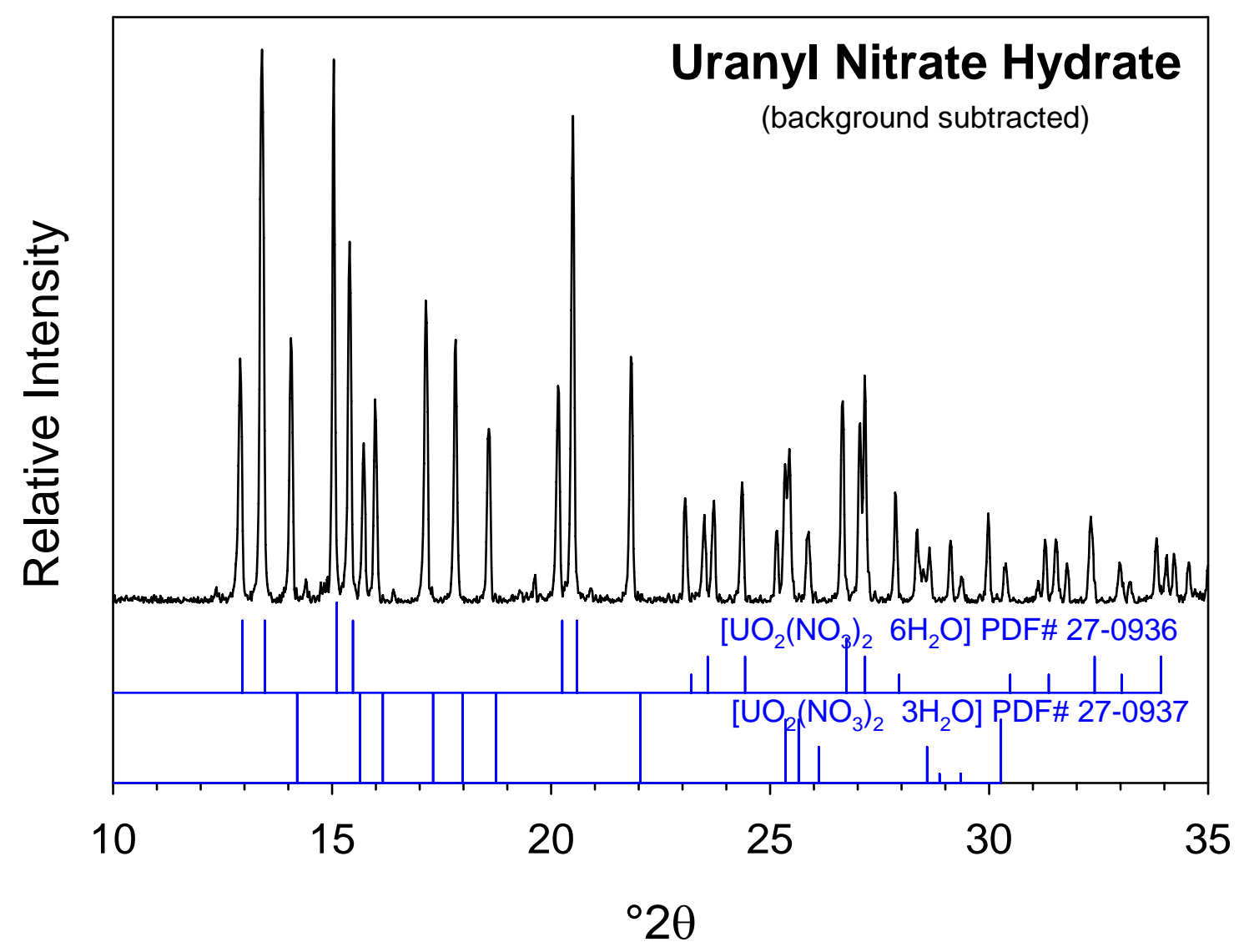

Figure A.6. Background-Subtracted Bulk Powder XRD Tracing of UNH (obtained from ProChem) Shown with XRD Data from PDF\# 27-0936 and PDF\# 27-0937

liter of metal storage solution was $5.88 \mathrm{~g}$. As shown in Table A.1 the precipitate contained $\sim 60 \%$ by weight rutile. This would result in about $\sim 3.5 \mathrm{~g}$ of the precipitate being rutile. This suggests that the weight percent of rutile shown in Table A. 2 appears to be inflated and that the starting UNH reagent might contain $\sim 0.5 \%$ rutile impurity that could all remain insoluble during the preparation of the metal storage solution and yield the quantity found in the separated precipitate which, based on XRF results shown in Table A.1, represents $\sim 60 \%$ of the solid.

Table A.2. Semi-Quantitative Oxide Composition of the Reagent Uranium Nitrate Hexahydrate

\begin{tabular}{||c|c||}
\hline Oxide & $\%$ wt \\
\hline \hline $\mathrm{SiO}_{2}$ & 0.21 \\
\hline $\mathrm{TiO}_{2}$ & 2.79 \\
\hline $\mathrm{UO}_{3}$ & 98.40 \\
\hline $\mathrm{NO}_{3}$ & $\mathrm{NM}$ \\
\hline
\end{tabular}




\section{Appendix B}

\section{Additional SEM-EDS Information for Other Precipitated Grains from the Metal Storage Solution Precipitate}





\section{Appendix B - Additional SEM-EDS Information for Other Precipitated Grains from the Metal Storage Solution Precipitate}

Appendix B contains additional scanning electron microscopy images and energy dispersive spectroscopic measurements of the total elemental composition of discrete spots on grains of the unexpected precipitate found in the metal storage solution that were imaged by SEM.

B. 1 


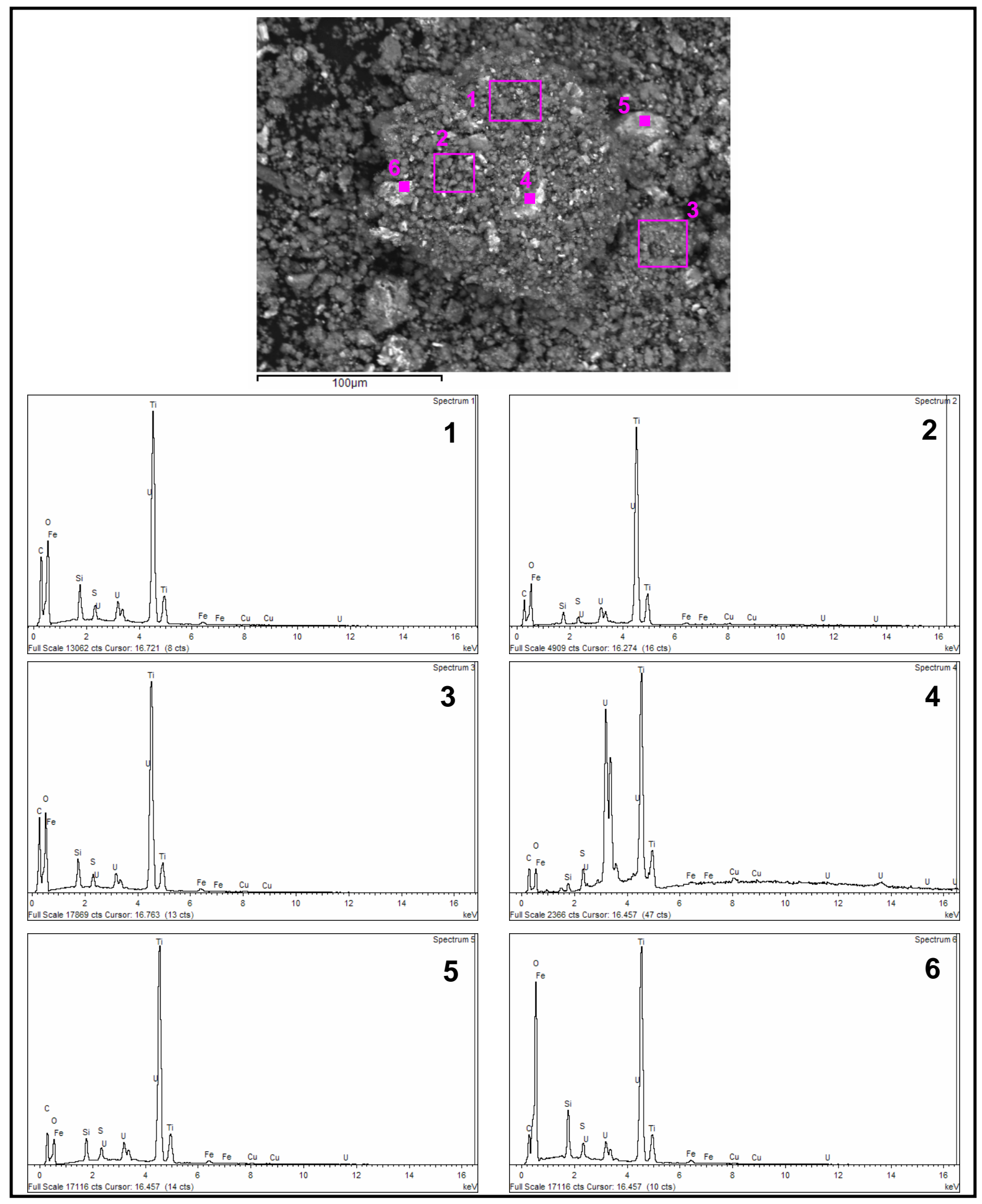

Figure B.1. EDS Spectra for Areas in Particle Aggregates of Metal Storage Solution Precipitate 


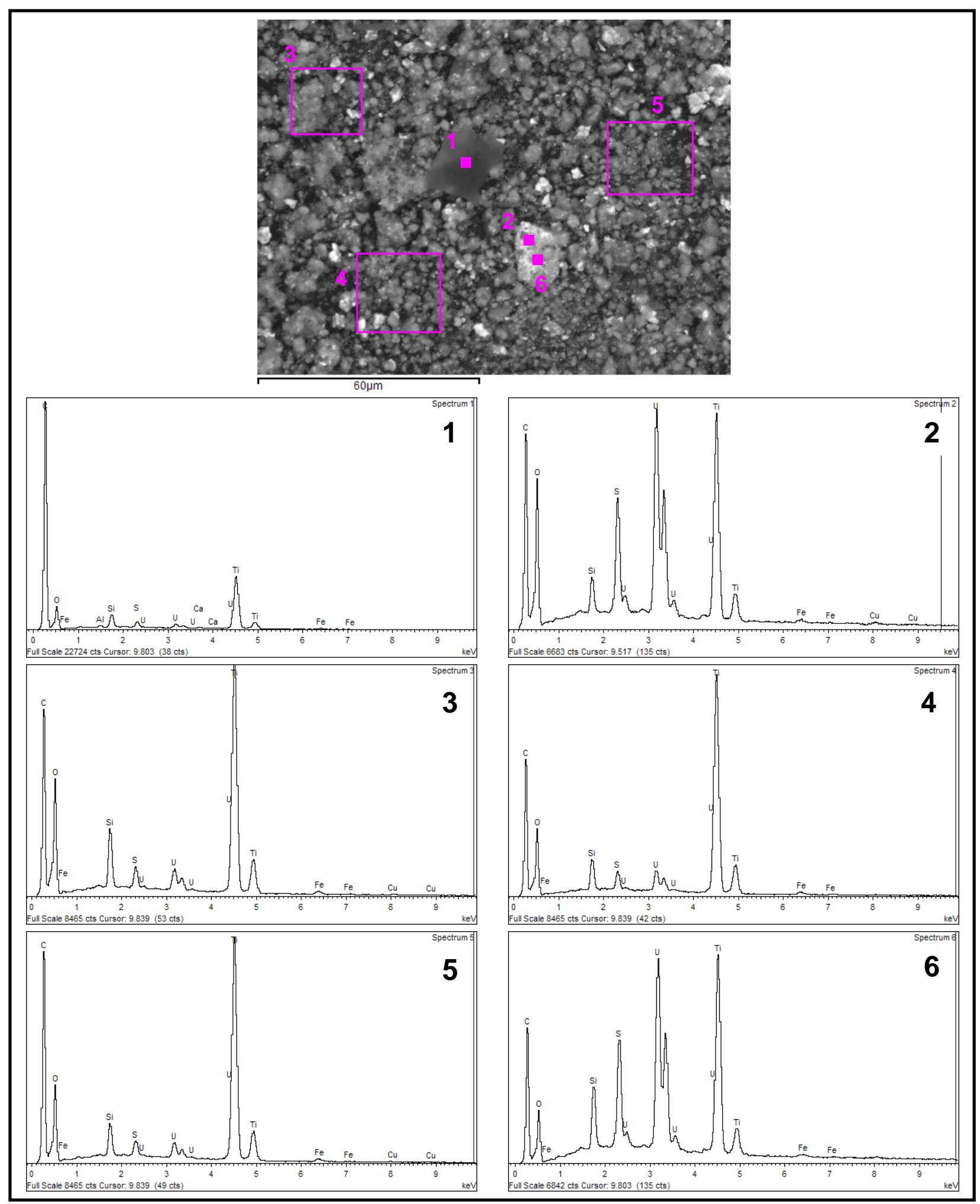

Figure B.2. EDS Spectra for Areas in Particle Aggregates of Metal Storage Solution Precipitate 

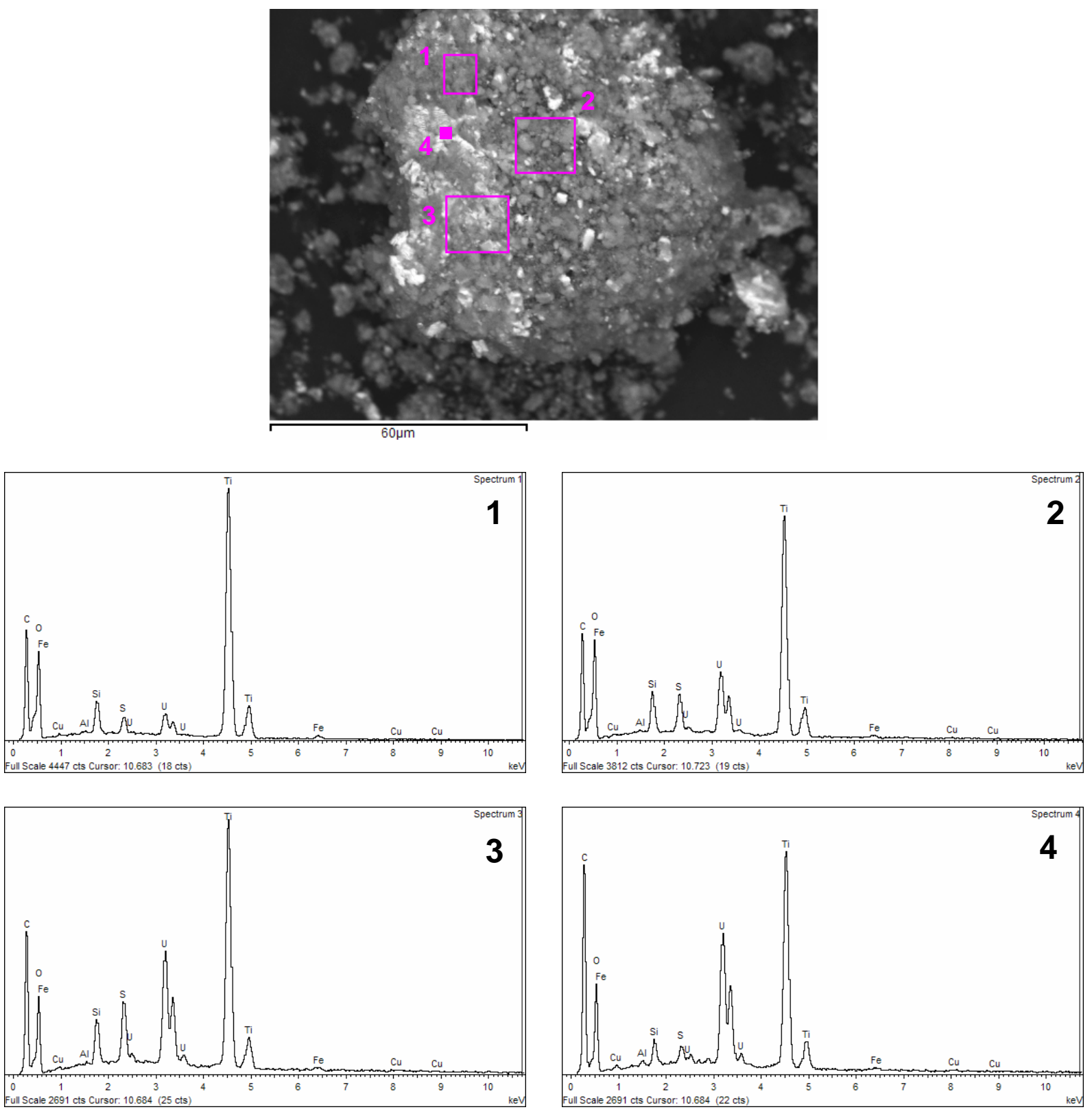

Figure B.3. EDS Spectra for Areas in Particle Aggregates of Metal Storage Solution Precipitate 


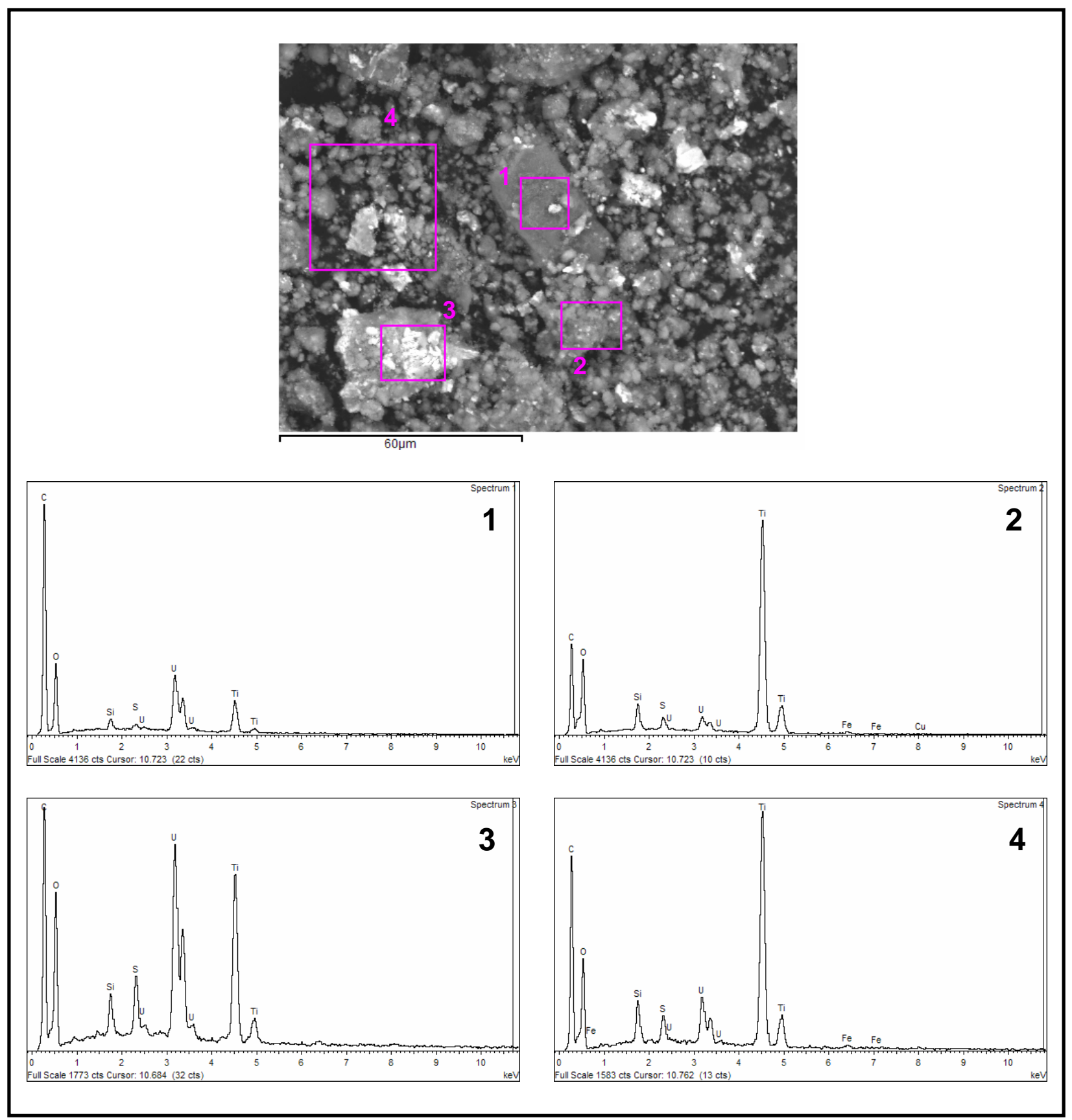

Figure B.4. EDS Spectra for Areas in Particle Aggregates of Metal Storage Solution Precipitate 



\section{Appendix C}

Additional SEM-EDS Spectra for Precipitates Formed during Neutralization of Metal Waste Solution 



\section{Appendix C - Additional SEM-EDS Spectra for Precipitates Formed during Neutralization of Metal Waste Solution}

Appendix $\mathrm{C}$ contains additional scanning electron microscopy images and energy dispersive spectroscopic measurements of the total elemental composition of discrete spots on grains of the precipitates in the neutralized metal waste solution that were imaged by SEM. The precipitates in the neutralized metal waste solution were sluiced along with the neutralized metal waste supernate to singleshell tanks where they likely settled and became known as sludge. 


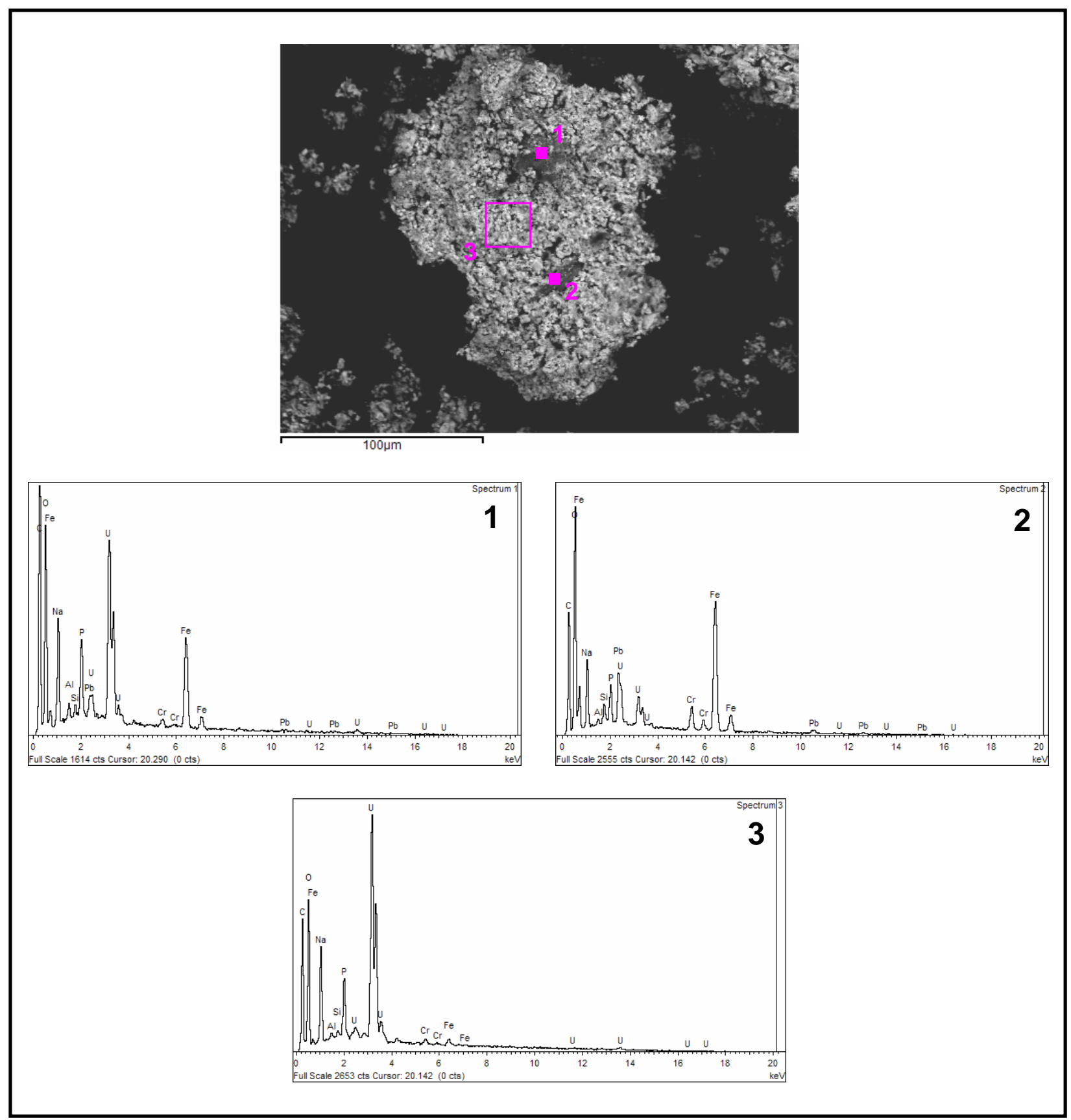

Figure C.1. EDS Spectra for Areas in Particle Aggregates of $\mathrm{KOH}-\mathrm{Na} 2 \mathrm{CO} 3$ Neutralized Metal Waste Precipitate 


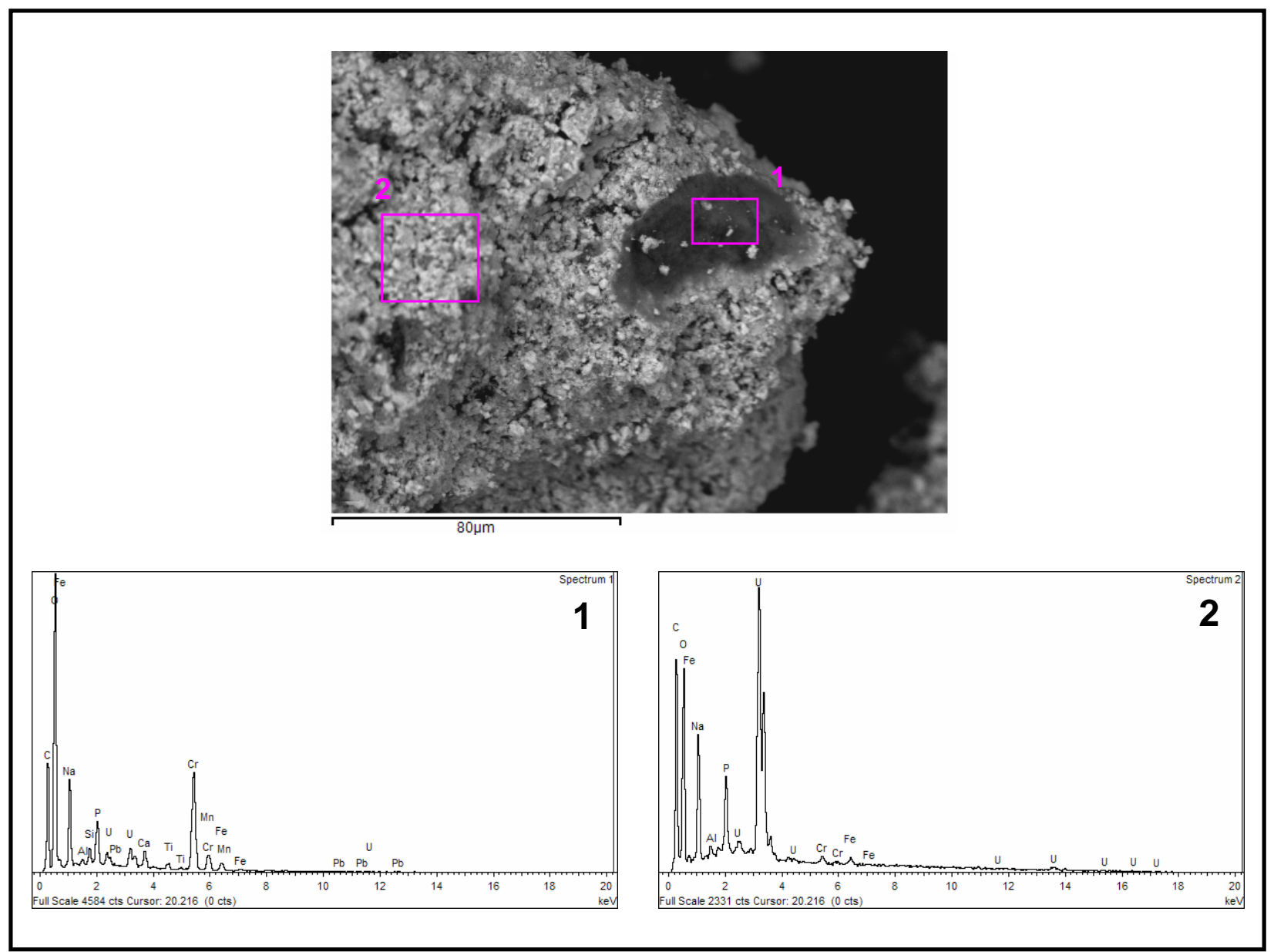

Figure C.2. EDS Spectra for Areas in Particle Aggregates of $\mathrm{KOH}-\mathrm{Na} 2 \mathrm{CO} 3$ Neutralized Metal Waste Precipitate 


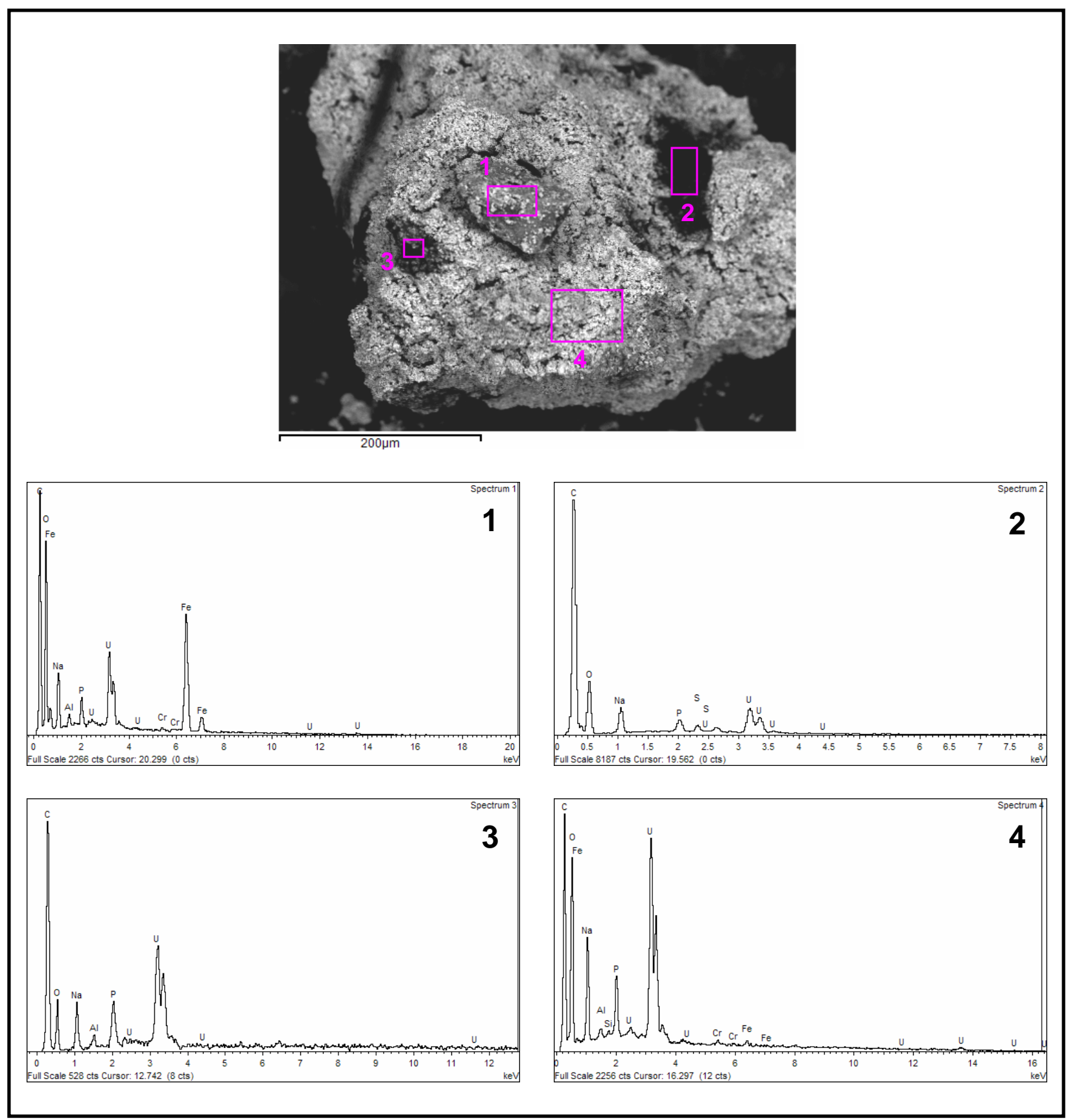

Figure C.3. EDS Spectra for Areas in Particle Aggregates of KOH-Na2CO3 Neutralized Metal Waste Precipitate 


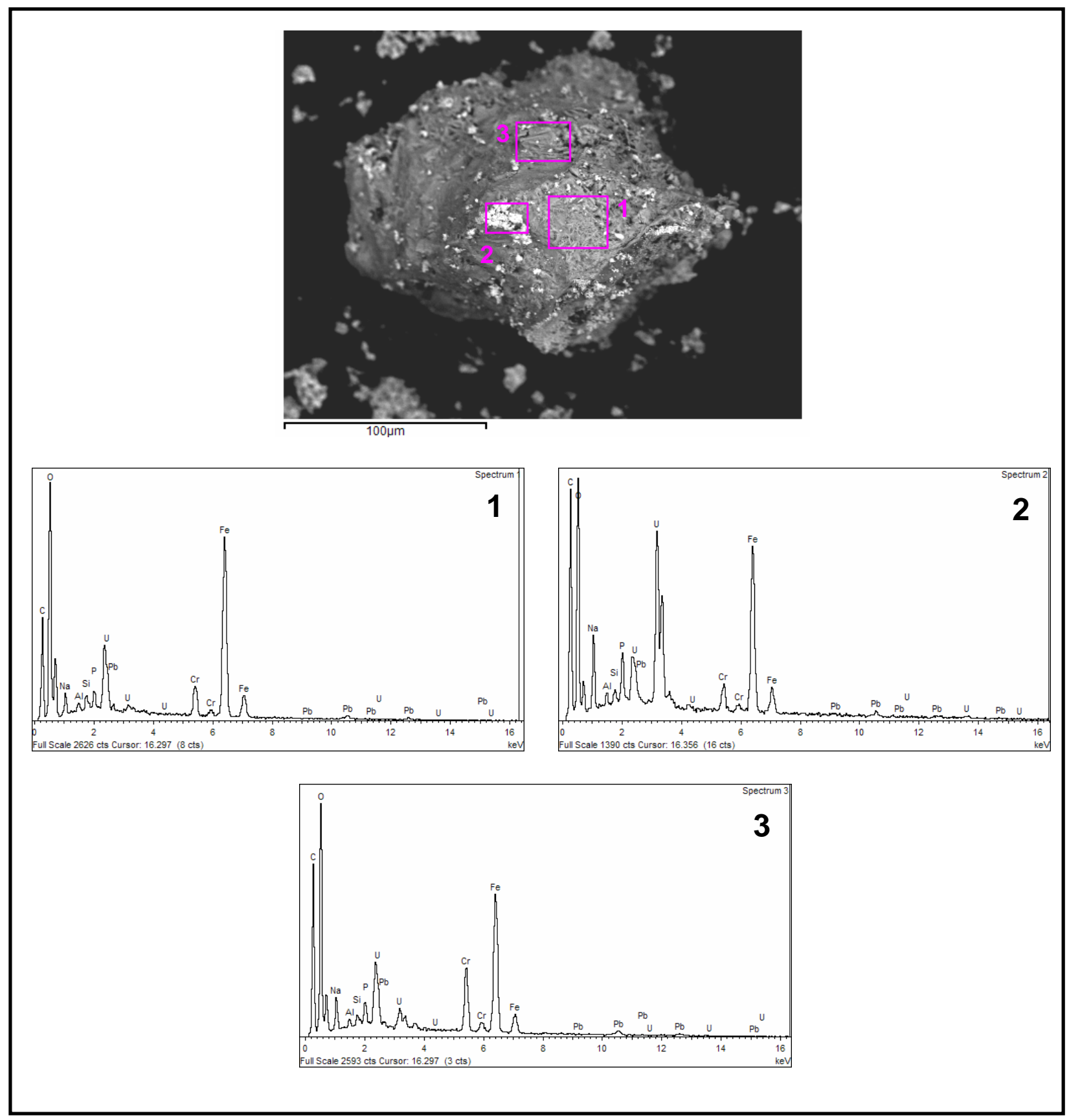

Figure C.4. EDS Spectra for Areas in Particle Aggregates of $\mathrm{KOH}-\mathrm{Na} 2 \mathrm{CO} 3$ Neutralized Metal Waste Precipitate 


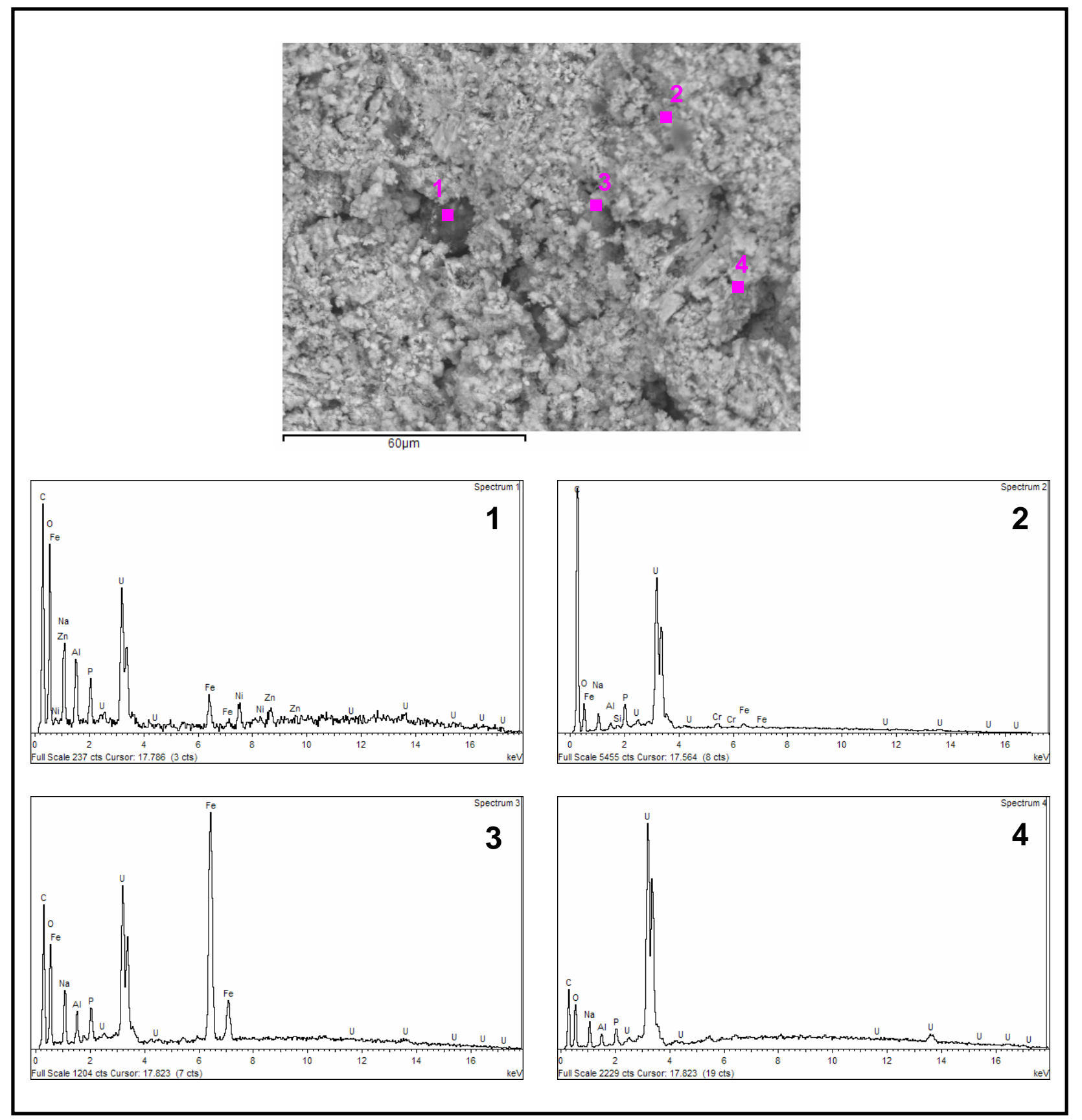

Figure C.5. EDS Spectra for Areas in Particle Aggregates of KOH-Na2CO3 Neutralized Metal Waste Precipitate 


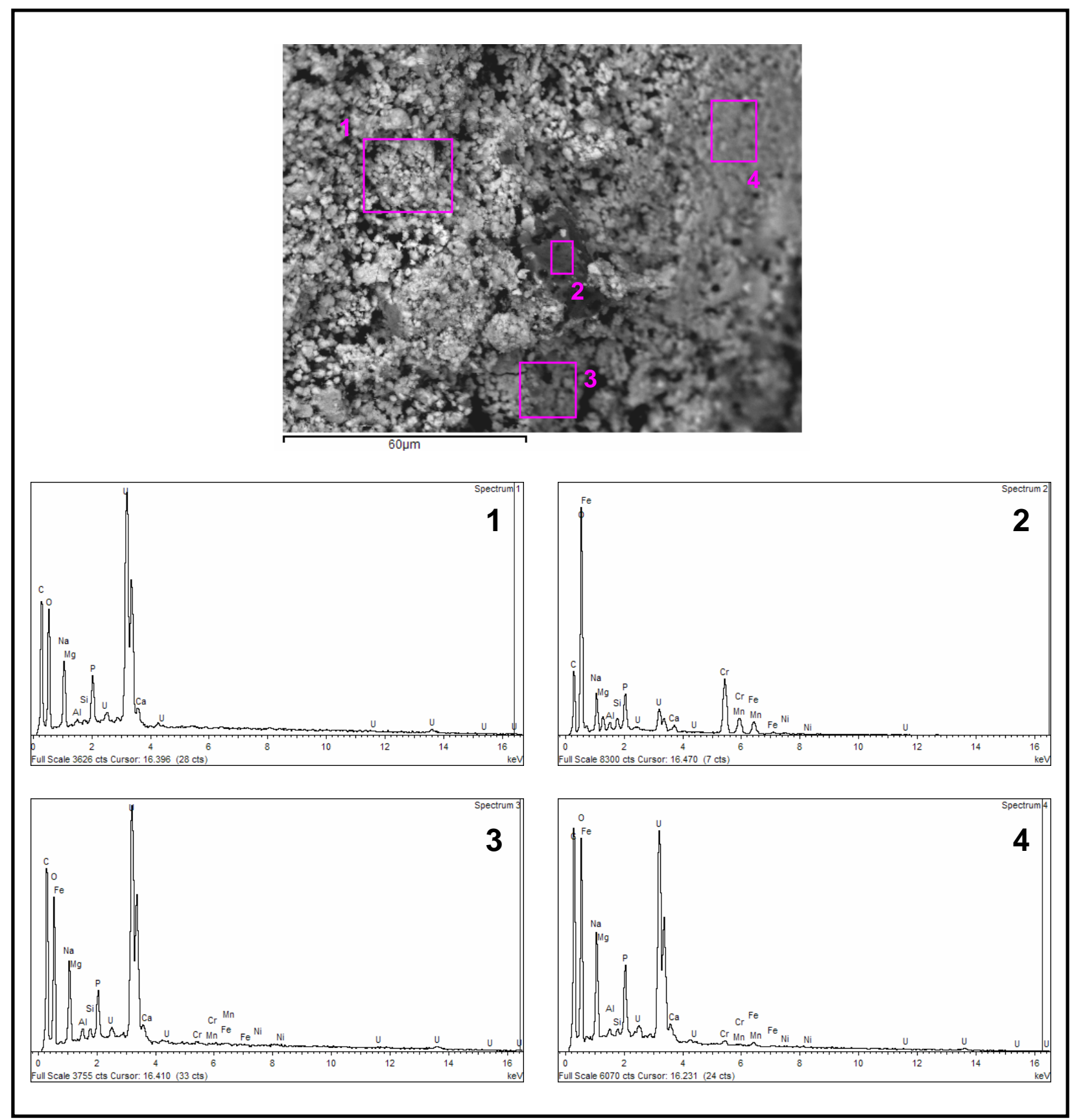

Figure C.6. EDS Spectra for Areas in a Particle Aggregate of $\mathrm{NaOH}-\mathrm{Na} 2 \mathrm{CO} 3$ neutralized Metal Waste Precipitate 


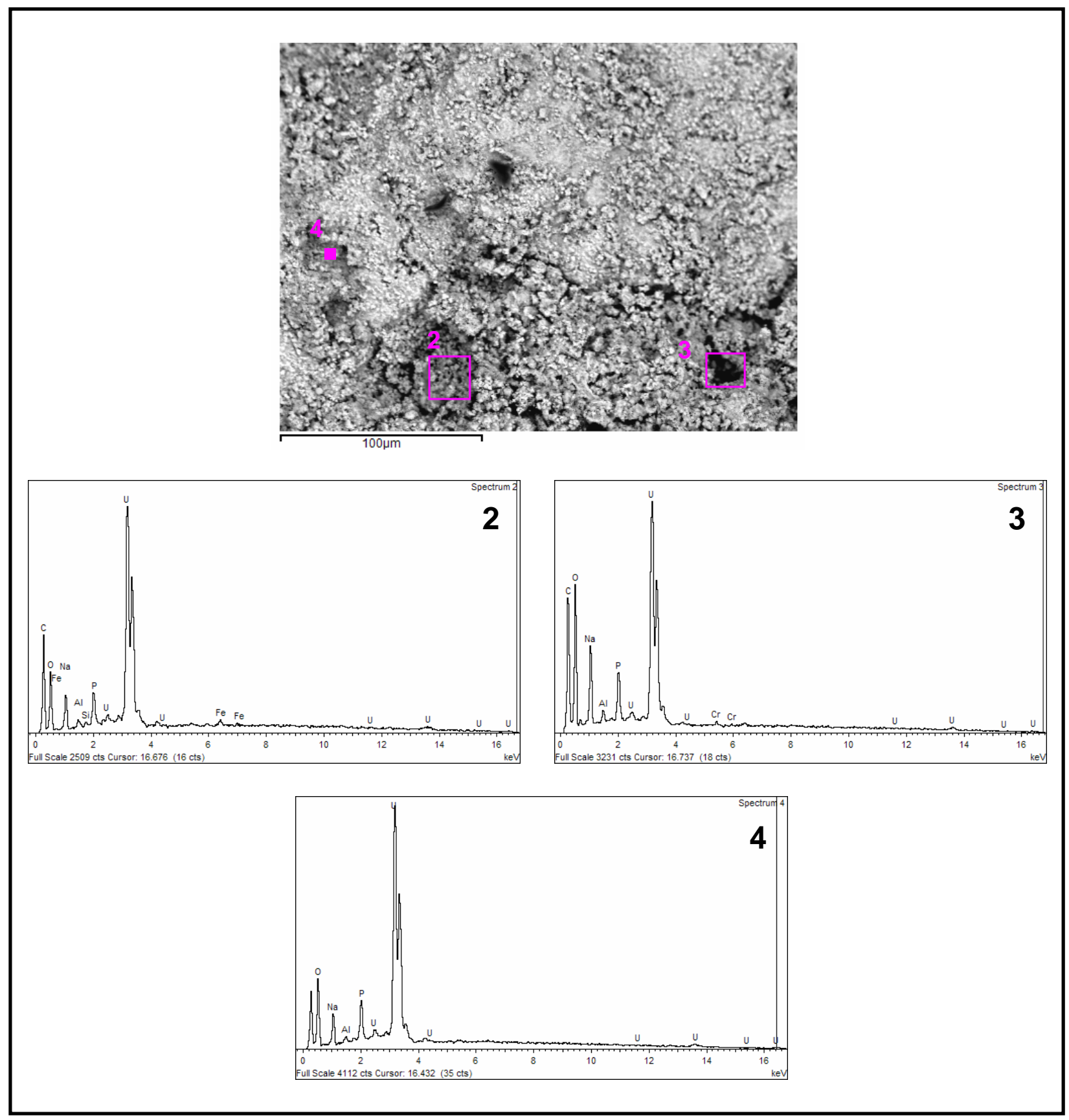

Figure C.7. EDS Spectra for Areas in Particle Aggregate of $\mathrm{NaOH}-\mathrm{Na} 2 \mathrm{CO} 3$ Neutralized Metal Waste Precipitate. Analysis of EDS spectrum for area \#1 (not shown) indicated that it was a small fragment of $\mathrm{C}$ that had dropped on the sample during carbon coating of the SEM mount. 


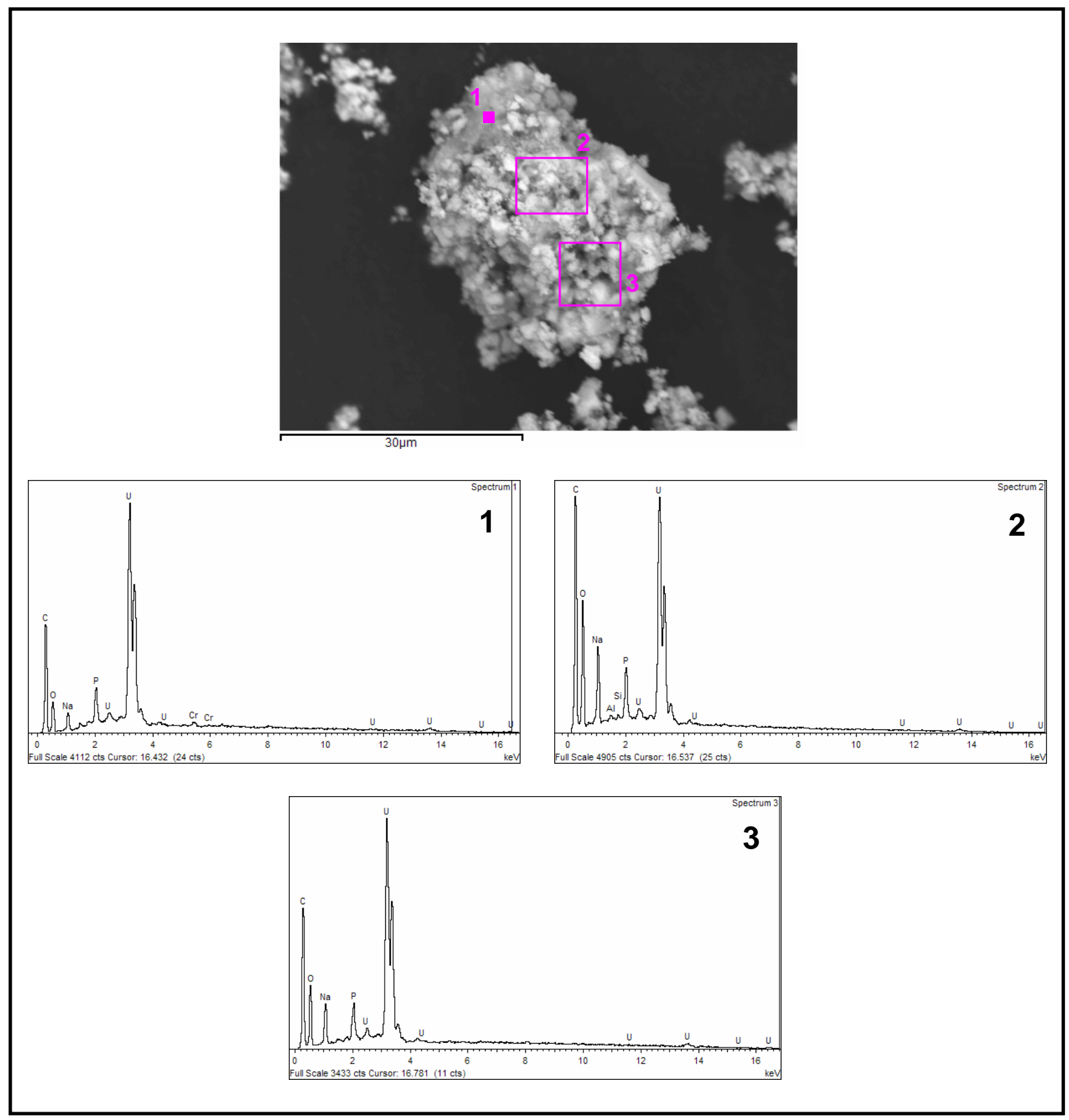

Figure C.8. EDS Spectra for Areas in Particle Aggregates of $\mathrm{NaOH}-\mathrm{Na} 2 \mathrm{CO} 3$ Neutralized Metal Waste Precipitate 

Appendix D

Specification Data Sheet for UNH Purity 



\section{Appendix D - Specification Data Sheet for UNH Purity}

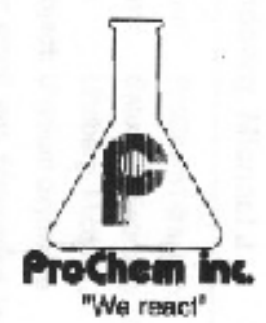

\section{CERTIFICATE OF ANALYSIS}

COMPANY:

P.O.N:

DATE: $1 / 22 / 02$

PRODUCT: URANYL NITRATE, ACS

LOT: 01162

QUANTITY:

ASSAY: $U \mathrm{O}_{2}\left(\mathrm{NO}_{3}\right)_{2} \cdot 6 \mathrm{H}_{2} \mathrm{O}$

$99.7 \%$

Iron (Fe)

$5 \mathrm{ppm}$

Heavy metals (as Pb)

Substances reducing permanganate

$5 \mathrm{ppm}$

Insoluble matter

Chioride $\{\mathrm{C}$ )

Sulfata $\left(\mathrm{SO}_{4}\right)$

$<0.03 \%$

$<0.005 \%$

$0.002 \%$

Alkalies and Alkaline Earths

$0.001 \%$

(as Sulfates)

$0.06 \%$

Aposarance and odor: Birght yellow cyatals

$*$ LSA $* .078 G$ Gq

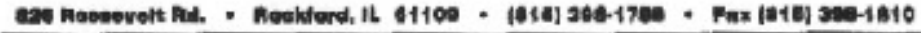

Hilgh Purity inorganiles ' Plosparch Blochemicals " Custon Bynthesis

D. 1 



\section{Distribution}

No. of

\section{Copies}

\section{OFFSITE}

Steve Airhart

Freestone Environmental Services

1933 Jadwin Ave.

Suite 135

Richland, WA 99352

Dr. Harry Babad

2540 Cordoba Court

Richland, WA 99352-1609

Pat Brady

Geochemistry Department, 6118

Sandia National Laboratories

P.O. Box 5800

Albuquerque, New Mexico 87185-0750

Charles R. Bryan

Sandia National Laboratories

4100 National Parks Highway

Carlsbad, N.M. 88220

Susan Carroll

Lawrence Livermore National Laboratory

Mail Stop L-219

Livermore, CA 94550

John N. Christensen

Center for Isotope Geochemistry

Lawrence Berkeley National Laboratory

1 Cyclotron Road Bldg, Mail Stop 70A4418

Berkeley, CA 94720-8179
No. of

Copies

Jon Chorover

Associate Professor - Environmental

Chemistry

Department of Soil, Water and

Environmental Science

Shantz 429, Building \#38

University of Arizona

Tucson, AZ 85721-0038

Dave G. Coles

Coles Environmental Consulting

750 South Rosemont Rd

West Linn, OR 97068

Mark Conrad

Department of Earth and Planetary Sciences

University of California Berkeley

Berkeley, CA 94720

Dwayne Crumpler

Columbia Energy \& Environmental Services

1806 Terminal Road

Richland, WA 99352

Dr. James A. Davis

U. S. Geological Survey

MS-465

345 Middlefield Rd.

Menlo Park, CA 94025

Donald J. DePaolo

Geology \& Geophysics Dept., MC4767

University of California

Berkeley, CA 94720-4767 
PNNL-14120

No. of

Copies

Dirk A. Dunning

Oregon Office of Energy

625 Mariona St. N. E.

Salem, OR 97301-3742

Mark Ewanic

MSE Technology Applications, Inc.

200 Technology Way

Butte, MT 59701

Markus Flury

Department of Crop and Soil Sciences

Washington State University

Pullman, WA 99164

Jim Harsh

Department of Crop \& Soil Sciences

Washington State University

Johnson Hall - Room 249

Pullman WA 99164-6420

Dr. Cliff Johnston

Soil Chemistry and Mineralogy

1150 Lily Hall

Purdue University

West Lafayette, IN 47907-1150

Dr. Daniel I. Kaplan

Westinghouse Savannah River Company

Bldg. 774-43A, Rm 215

Aiken, SC 29808

Dr. Peter C. Lichtner

Los Alamos Natl. Lab

P.O. Box 1663

Los Alamos, NM 87545

Kevin A. Lindsey

Kennedy/Jenks Consultants, Inc.

1020 N. Center Parkway, Suite F

Kennewick, WA 99336
No. of

Copies

Patrick Longmire

Los Alamos National Laboratory

Mail Stop J534

P.O. Box 1663

Los Alamos, NM 87545

Kate Maher

The Center for Isotope Geochemistry

$301 \mathrm{McC}$ Cone Hall

University of California, Berkeley

Berkeley, CA 94702-4746

John M. Matuszek

82 McGuffey Lane

Delmar, NY 12054

Melanie A. Mayes

Environmental Sciences Division

Oak Ridge National Laboratory

P.O. Box 2008

Oak Ridge, TN 37831-6038

Mitzi Miller

EQM Inc

1777 Terminal Dr.

Richland, WA 99352

Dr. Kathryn L. Nagy

Department of Earth and Environmental Sciences

University of Illinois at Chicago (MC-186)

845 West Taylor Street

Chicago, IL 60607-7059

Heino Nitsche

Director, Center for Advanced

Environmental and Nuclear Studies

Lawrence Berkeley National Laboratory

1 Cyclotron Road

MS 70A-1150

Berkeley, CA 94720 
PNNL-14120

No. of

Copies

Phil Reed

U.S. Nuclear Regulatory Commission

Office of Nuclear Regulatory Research

Two White Flint North Building

11545 Rockville Pike

Mail Stop: T9-F39

Rockville, MD 20852-2738

Richard J. Reeder

Dept. of Geosciences

State University of New York at Stony

Brook

Stony Brook, NY 11794-2100

Phil Rogers

13 Mountain Oak

Littleton, CO 80127

Stan Sobyczk

Nez Perce Tribal Consultant

P. O. Box 365

Lapwai, ID 83832

Doug Sherwood

Rivers Edge Environmental

1616 Riverside Drive

West Richland, WA 99353

David K. Shuh

Lawrence Berkeley National Lab

1 Cyclotron Road

Mail Stop 70A-1150

Berkeley, CA 94720

Robert W. Smith, Ph.D.

Professor of Subsurface Science

Adjunct Professor of Geological Sciences

University of Idaho at Idaho Falls

1776 Science Center Drive

Idaho Falls, ID 83402
No. of

Copies

Carl I. Steefel

Earth Sciences Division

Lawrence Berkeley National Laboratory

1 Cyclotron Road, Mail Stop 90R1116

Berkeley, CA 94720

Dr. Samuel J. Traina, Director

Sierra Nevada Research Institute

University of California, Merced

P.O. Box 2039

Merced, CA 95344

Dr. T. T. Chuck Vandergraaf

P. O. Box 857

Pinawa, Manitoba ROE 1LO

Canada

Dr. Jiamin Wan

Lawrence Berkeley National Laboratory

1 Cyclotron Rd. MS 70-0127A

Berkeley, CA 94720

Mr. Ronald G. Wilhelm

Office of Radiation and Indoor Air

401 M Street, S.W.,

Mail Code 6603J

Washington, D.C. 20460

W. Alexander Williams

US Department of Energy

Office of Environmental Restoration

EM-33

19901 Germantown Road

Germantown, MD 20874-1290 
No. of

Copies

\section{ONSITE}

3 DOE Office of River Protection

P. E. LaMont

H6-60

R. W. Lober

H6-60

S. A. Wiegman

8 DOE Richland Operations Office

B. L. Foley

J. P. Hanson

R. D. Hildebrand

K. A. Kapsi

J. G. Morse

K. M. Thompson

DOE Public Reading Room (2)

1 Bechtel Hanford, Inc.

A5-13

A6-38

A5-13

A6-38

A6-38

$\mathrm{H} 2-53$
No. of

Copies

2 Duratek Federal Services, Inc., Northwest Operations

M. G. Gardner

H1-11

K. D. Reynolds

H1-11

\section{Environmental Protection Agency}

Nick Ceto

B1-46

D. A. Faulk

B1-46

Rod Lobos

R2-58

\section{Fluor Federal Services}

R. Khaleel

E6-17

R. J. Puigh

E6-17

20 CH2M HILL Hanford Group, Inc.
R. B. Calmus
S7-75
M. P. Connelly
H6-03
J.G. Field
H6-03
B. A. Higley
R2-58
M Jaraysis
H6-03
M. E. Johnson
H6-19
A. J. Knepp
H6-60
J. G. Kristofski
H6-03
F. M. Mann (5)
H6-03
W. J. McMahon
H6-03
D. A. Myers
H6-03
D. L. Parker
H6-03
G. Parsons
T6-04
D. E. Place
R2-58
D. J. Watson
H6-03
J. A. Voogd
H6-03 
No. of

Copies

14 Fluor Hanford, Inc.

M. W. Benecke

E6-35

J. V. Borghese

E6-35

L. R. Fitch

T. W. Fogwell

B. H. Ford

T. E. Jones (5)

V. J. Rohay

A. F. Shattuck

L. C. Swanson

M. E. Todd-Robertson

G. S. Thomas (2)

M. I. Wood
E6-35

E6-35

E6-35

E6-35

E6-35

E6-35

E6-35

E6-35

E6-35

H8-44

\section{Pacific Northwest National Laboratory}

L.M. Baagesen

B.N. Bjornstad

T.M. Brouns

C. F. Brown (6)

R. W. Bryce

K. J. Cantrell

W.J. Deutsch

P. E. Dresel

M. J. Fayer

A. R. Felmy

V.L. Freedman

M. D. Freshley

J.S. Fruchter

G.W. Gee

D. G. Horton

J. P. Icenhour

C. T. Kincaid

K. M. Krupka (3)

G. V. Last

M. J. Lindberg

K6-28

K6-81

No. of

Copies

R. Mackley

K6-96

W. J. Martin

K6-81

S. V. Mattigod K6-81

B. P. McGrail K6-81

P. D. Meyer

BPO

C. J. Murray

K6-81

S. M. Narbutovskih K6-96

R. D. Orr

K6-81

E. M. Pierce K6-81

Nik Qafoku K3-61

S. P. Reidel K6-81

R. J. Serne (20) P7-22

H. T. Schaef K6-81

M. B. Triplett K6-52

W. Um

$\mathrm{P} 7-22$

M. Valenta

$\mathrm{P} 7-22$

A.L. Ward K9-33

B. A. Williams K6-81

S. B. Yabusaki K9-36

J. M. Zachara K8-96

F. Zhang K9-33

Hanford Technical Library (2) P8-55

P7-22

E6-35

K6-81

K6-81

K6-96

K9-33

K8-96

K9-36

K9-33

K6-96

K9-33

K6-81

K6-81

E6-35

K6-81

K6-81

$\mathrm{P} 7-22$

\section{S.M. Stoller}

R. G. McCain

B2-62

6 Washington State Department of Ecology

J. A. Caggiano

$\mathrm{H} 0-57$

S. Dahl-Crumpler

$\mathrm{H} 0-57$

J. V. Hedges

$\mathrm{H} 0-57$

Jeff Lyon

$\mathrm{H} 0-57$

Beth Rochette H0-57

J. Yokel

H0-57 
